\title{
ChINESE WOMEN AND THE CYBERSPACE
}

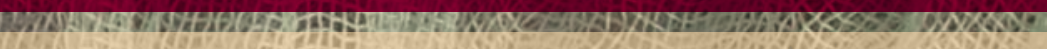

Edited by

Khun Eng Kuah-Pearce 
Chinese Women and the Cyberspace 
(ICAS) Publications Series

\section{General Editor}

Paul van der Velde

\section{Editorial Board}

Jennifer Holdaway (Social Science Research Council)

Christopher A. Reed (Ohio State Faculty)

Anand A. Yang (Director of the Henry M. Jackson School of International Studies and Chair of International Studies at the University of Washington)

Guobin Yang (Barnard College, Columbia University)

Wim Boot (Leiden University)

The ICAS Publications Series consists of Monographs, Edited Volumes and Proceedings of ICAS. The Series takes a multidisciplinary approach to issues of interregional and multilateral importance for Asia in a global context. The Series aims to stimulate dialogue amongst scholars and civil society groups at the local, regional and international levels.

The International Convention of Asia Scholars (ICAS) was founded in 1997. Its main goals are to transcend the boundaries between disciplines, between nations studied, and between the geographic origins of the Asia scholars involved. ICAS has grown into the largest biennial Asia studies event outside the US covering all subjects of Asia studies. So far five editions of ICAS have been held respectively in Leiden (1998), Berlin (200I), Singapore (2003), Shanghai (2005) and Kuala Lumpur (2007). In 200I the ICAS secretariat was founded which guarantees the continuity of the ICAS process. In 2004 the ICAS Book Prize (IBP) was established in order to create by way of a global competition both an international focus for publications on Asia while at the same time increasing their visibility worldwide. Also in 2005 the ICAS Publications Series was established.

For more information: www.icassecretariat.org 


\section{Chinese Women and the Cyberspace}

Edited by

Khun Eng Kuah-Pearce

AMSTERDAM UNIVERSITY PRESS 
ICAS Publications Series

\section{Edited Volumes 2}

Cover design: Maedium, Utrecht

Layout: The DocWorkers, Almere

ISBN 9789053567517

NUR 74I / 745

(c) ICAS / Amsterdam University Press, 2008

All rights reserved. Without limiting the rights under copyright reserved above, no part of this book may be reproduced, stored in or introduced into a retrieval system, or transmitted, in any form or by any means (electronic, mechanical, photocopying, recording or otherwise) without the written permission of both the copyright owner and the author of the book. 


\section{Table of Contents}

$\begin{array}{ll}\text { Acknowledgements } & 7\end{array}$

List of Tables 9

I Introduction

$\begin{array}{ll}\text { KUAH-PEARCE Khun Eng } & 11\end{array}$

PART I WORK, LEISURE, POLITICS AND IDENTITY

2 Internet as Social Capital and Social Network KUAH-PEARCE Khun Eng 25

3 Agency and ICT among Singaporean-Chinese Women JOHNSON Helen 47

4 Can the Internet Help? How Immigrant Women from China Get Jobs

GREVE Arent \& SALAFF Janet

5 Cyberactivism in the Women's Movement LIU Ting

6 Cyber Self-centres?

HO Kiu-chor, TANG Wesley Siu-hang \& HO Petula Sik-ying 117

$7 \quad$ Embeddedness and Virtual Community

GAO Chong

8 Electronic Park Benches

CAPLAN Victoria

PART II LOVE, SEX AND MARRIAGE

9 Sapphic Shadows

SIM Amy 
Io Sex \& Life Politics Formed Through the Internet PEI Yuxin \& HO Sik Ying

II On Sale in Express Package LEUNG Maggi W.H.

I2 Boundary-Crossing through Cyberspace LIU Lihui \& LIU Hong

Contributors

271

Index 


\section{Acknowledgements}

From the conception of an idea, through the germinating process, the gestation period and, finally, culminating in its fruition is a long path that scholars who have trod through will know - that along the way, there are many who have worked to enable us to reach the fruition stage.

The idea of working on a research topic on 'Chinese women and their network capital: the use and abuse of the cyber-network' took off when I was awarded a research grant by the University of Hong Kong. As the research came to fruition, I began to explore the possible idea of organizing an international conference to bring together scholars who are interested in working in this area to share their views and to bring together an edited book on this topic. This has resulted in an international symposium in 2004 on the theme: 'Log on: Chinese women and the cyber-networks' that I organized under the Centre for Anthropological Research at the University of Hong Kong. This international symposium brought together scholars from different parts of the world who presented various issues of Chinese women and their experiences with the cyberspace. The final session of the symposium was a workshop where the conference participants discussed key ideas that emerged in the course of the two-day symposium and we were able to concretize the ideas that would be put into the edited book. Subsequently, I invited some of the conference participants to write for this edited book.

I would like to take this opportunity to express my sincere gratitude to the University of Hong Kong for a research grant that enabled me to conduct the research on 'Chinese women and their network capital: the use and abuse of the cyber-network' which allowed for the seed to be planted at the initial stage. I am also grateful to my former dean, Professor James Tang, who kindly provided a conference grant to enable us to organize the international symposium. I am extremely indebted to my graduate students, especially Gao Chong, Huang Yedan and the administrative colleagues at the Department for helping with all aspects of the conference. I am delighted to acknowledge the contributions by the conference participants for their enthusiasm and ideas and especially so to those who have contributed to this edited volume. 
I am especially indebted to Huang Yedan, my present research assistant who painstakingly helped to edit the stylistic contents of all chapters. I would also like to mention a special acknowledgement to Dr. Paul van der Velde, Series Editor ICAS/AUP Series and IIAS/AUP Series for accepting our manuscript for publication and his editorial team for turning the manuscript into this wonderful book.

Finally, I take this opportunity to thank my family members for their support in my academic work, which makes it such a pleasure to continue to intellectualize and write.

K-PKE

April 2008 


\section{List of Tables}

Table 2.I Education Level of the Interviewee in Hong Kong

Table 2.2 Education Level of the Interviewee in Shanghai

Table 2.3 How Long Has the Interviewee Used the Internet? Hong Kong

Table 2.4 How Long Has the Interviewee Used the Internet? Shanghai

Table 4.I Highest Degree in China by Gender

Table 4.2 Fields of Study by Gender

Table 4.3 Current Job by Gender

Table 4.4 Factors Predicting Wage Levels

Table $4.5 \quad$ Predicting Job Levels

Table 5.I Overall Use of the Internet in Hong Kong, Beijing and Shaanxi in 2003

Table 5.2 The establishment of Women Organising and Their Websites

Table 5.3 Major donors of women organising and their websites in June 2004

Table 8.I Advertising Rates of Baby-Kingdom.com (2004)

Table 8.2 List of Sub-communities on Baby-Kingdom.com

Table io.I Profiles of Interviewees 



\title{
1 Introduction
}

\section{Locating Chinese Women in the Cyberspace}

\author{
KUAH-PEARCE Khun Eng
}

\section{$1 \quad$ Introduction}

In the information galaxy, the cyberspace and the Internet have become an indispensable part of our daily routine. Those who have been touched by this technology have found it irresistible to refrain from using it, even if they are physically on the move. It is no wonder that with the advent of the wireless, tapping into cyberspace and surfing the Internet has intensified among all groups of people.

In present day, the cyberspace and the Internet have become enmeshed into our daily routine and social experiences, so much so that they are not only confined to our working life but increasingly they have penetrated into our social and personal spheres. Likewise, they are no longer viewed as a masculine space and tool as women have not only embraced but also used the cyberspace to negotiate and reframe themselves within existing social structure.

Women in general and Chinese women in particular have also become formidable players in this virtual galaxy. Increasingly, they are both the producers and consumers of the cyberspace and the Internet. Through their involvement in the production of technology, as well as in the development of software and creation of all types of Web 2.0 generations cyber-platforms for all to consume, women in increasing numbers nowadays work to produce the hardware that lubricate the running of the cyberspace. At the same time, they are one of the greatest consumers - engaging in ferreting knowledge from the cyberspace as well as engaging in interactivity communication.

The primary objective of this edited volume is to explore what Internet and the cyberspace mean to the Chinese women and how they use the cyberspace for their own agenda from a socio-anthropological perspective. In this aspect, cyberspace serves as a kind of social capital and enables these women to forge cyber-social networks and communities to facilitate their activities and needs. Furthermore, cyberspace can be turned into a repressive instrument that intrudes into women's private lives and oppresses them by unscrupulous players. From the various 
groups of Chinese women studied, either empirically, from online survey, online interactivity and communication with the netizens, or simply Web-surfing, the use and the abuse of the Internet and cyberspace can be categorized into the following. First, it provides an alternative channel for information gathering and an agency to complete mundane tasks that they had to do manually before the digital age, such as bill payments. Second, it serves as a platform for self-expression when they find that they are unable to share their emotions and feelings with their family members and friends. Third, it serves as a repressive platform to reinforce oppression and patriarchal dominance. Fourth, it serves as a form of social capital to allow for cyber-communication and the formation of cyber-networks and cyber-communities for social, economic and political purposes.

\section{Chinese Women Negotiating the Cyberspace}

Today, the routine use of the cyberspace has resulted in women accounting for half of its use in big cities throughout the world. Given this widespread use, it becomes imperative for us to understand more concretely how and why women use them and what impacts the cyberspace has on these women.

\subsection{Cyberspace as an Alternative Channel and an Agency}

Earlier studies on this subject have expounded two prominent views: one that argues for the cyberspace and Internet to be regarded as an agency where women would benefit from it. Such technology empowers women and provides a virtual space to communicate and articulate their own needs and desires as well as to explicate the feminist ideology and actions using this new found technology. The other perspective is that such technology could lead to abuse and women, in fact, would suffer socially and emotionally from the use, thereby entrenching them further into the existing social structure and reinforcing patriarchy (Adam \& Green I998: 83-97).

One key area of our study is to examine how women make use of the cyberspace for information, work, employment, shopping, love, sex and marriage. As an information agency, the Internet and the Worldwide Web arm women with knowledge, thereby enabling information transfer. In this study, we found that women used the cyberspace to facilitate and ease their daily chores, such as bill-paying, or for searching for information on education, employment or marriage purposes. They also use it for the purpose of organizing political activities and online shopping. Here, we concur with the argument that the use of the cy- 
berspace has enabled women to further their personal interests, either for social or economic gains. We also argued that there is a flipside to this usefulness as some women became victims of their so-called 'success'. This is particularly so in the transnational marriage scene and in the online shopping scene where they could be cheated.

\subsection{Cyberspace as a Platform for Self-Expression}

At the same time, cyberspace is also used as a conduit to conduct online communication and cyberactivity, hence enabling self-expression as well as the formation of cyber-relationship and cyber-communities. Suffice to say here, a limited number of online relationships have been translated into offline relationships. This is not only true of middleclass professional women but also of working class and marginalized women such as migrant, ethnic and lesbian women. In cyber-communication, Kitchin argues that one could preserve one's anonymity and real life identity as long as one hides one's physical appearance and disability and continues to wear a mask or a different persona (Kitchin I998: 80).

In our studies, we found that a group of women has set up their own websites and write Web-based diaries in which they express their own emotions and feelings as well as their views on inter-personal relationships, love, sex and others. Under the cloak of anonymity, they communicate with the netizens yet hide their websites and Web-based diaries from their family members and close friends for fear that their family members would disapprove or worry about their cyberspace forage as well as be ridiculed by friends.

In this sense, the cyberspace provides the women with a space to freely indulge in all sorts of activities and behaviour, including anarchistic behaviour. It is thus seen as a liberating experience for the women (Fletcher I999: 350). In so doing, the cyberspace not only encourages but celebrates the development of multiple identities where real life provides only one of the many windows for expressing oneself and social experiences (Klein I999: I98). At the same time, it also allows the different personas to fantasize, dissociate and split off from each other when the occasion calls for it. At other times, all personas merge together as one (Klein I999: I99). Thus, individual identity and the personas are generally flexible and short lived in the cyberspace (Kitchin I998: 80). At the same time, it is seen as precise empowerment since the individual is able to change identity and personas depending on the online environment (Kitchin I998: 80). Kitchin, citing Lacan, argues that the self is no longer a permanent structure of the mind or fixed within some genetic code, rather 'self is thought of as a discourse where identity is constructed through multiple experiences' 
(Kitchin I998: 8I). Here, 'identity is fragmented, decentred and fluid, changing with time and situations, and indeed different for different occasions' (Kitchin I998: 8I). Other studies have argued that the cyberspace allows for the growth of a variety of virtual communities that are 'free of the constraints of place and based upon new modes of interaction and new forms of social relationships' which is free of geographical space and time zones (Kitchin I998: 86).

While studies of how the cyberspace has provided the users with an imaginative space to self-express the various personas and identities, few have studied the intersection between the cyberspace and real space and our studies, in a small way, attempt to fill in this missing gap. It is also important to note that further studies are needed to explore the intersection of the cyberspace with the real space and the tensions and problems that arise out of this intersection.

\subsection{Cyberspace as a Repressive Platform}

Another area of study relates to how cyberspace is being constructed and whether online social spaces constitute a replica of real-life social space in terms of power relations between the various players in the cyberspace. In our studies, women sex workers, lesbians and those who are involved in transnational marriages have found that while the cyberspace provides opportunities for them to get to know their clients and potential marriage partners, it also eventually turns into an oppressive space in which they continue to function under the clutches of the pimps or are controlled by their husbands once they meet in real-life. Thus, while it is possible for the various players to remain anonymous in the cyberspace, once they have established real-life contact, then repression and oppression of these women might occur as the women in the transnational marriage have testified to. In addition, repressive surveillance, through the webcam installed by the pimps in the case of the sex workers, has led to the further debasement of these women. In all these cases, micro-power politics in the cyberspace often mirror and reinforced offline gender relations and the patriarchal social structure.

\subsection{Cyberspace as a Social Capital to Facilitate Cyber-Communication and the Formation of Social Networks}

A fourth area of study looks at cyberspace as a form of social capital that facilitates cyber-communication and the formation of social networks. The possession of social capital is seen as a significant factor in successfully adapting to host societies among migrant populations, in businesses and social environments which tap into different sets of social relationships (Coleman I988; Lin 200I; Portes I998, 2000). Along 
the same line of argument, this study explores and argues that knowledge of the information technology and cyberspace serves as important social capital and netizens with cyber-knowledge are able to use it to their advantage - be it for the consumption of knowledge or to create online relationships or cyber-networks and cyber-communities.

With the cyber-community, it is often argued that online sociability tends to be confined to small groups of users of a younger age group (Castells 200I). In our studies, we also found that there is a predominance of young women using this technology for establishing cyberrelationships and cyber-networks. In exploring the formation of cyberrelationships and cyber-networks, the question on the sustainability of cyber-relationships needs to be addressed. The durability of these networks is highly dependent on the interests shared by the netizens and the assumed personas that the netizens portrayed online which shift according to their interests.

In our studies, we found that cyber-networks and cyber-communities are formed for specific needs such as Chinese women's desire to understand and obtain beauty knowledge and beauty products and pregnant women needing information on pregnancy needs, food avoidance and consumption, gynaecological advice, care of newborns and others. Likewise, new migrants who have moved to an overseas location need information regarding employment and women who are involved in organizing political activities also forage into the cyberspace to reach out to would-be participants. Under such circumstances, what we are witnessing is the formation of cyber-relationships and cyber-networks that cater to specific needs of these groups of women.

Many of these cyber-networks do not require subscriptions to engage in cyber-activity and communication with the netizens. However, there are specific websites that require women to subscribe as members before they are allowed to participate in the activities in order to screen out the undesirables. However, in some, moral sanction becomes a method to ensure that Chinese women who participate in the cyber-activity observe the unstated rules. For example, in our case of shopping online, moral sanction in the form of praise and criticism of the 'middlewomen' who purchase beauty products on behalf of other women serve to keep the participants in check and prevent abuse.

Depending on the nature of the cyber-community, only a few netizens might transform the cyber-relationship into a real-life relationship. In our studies, those women who use the cyberspace to search for marriage and/or sexual partners eventually come into contact with their potential partners after establishing an online relationship. Likewise, mothers-to-be might seek to establish real-life social contacts for further support with those living in their neighbourhood. However, 
apart from the selected few, most of these online relationships remain in the cyberspace.

\section{Organization of This Book}

This volume, while not exhaustive, attempts to interrogate different issues and interests of Chinese women who use the cyberspace for a variety of reasons. As such, each chapter deals with a specific issue that the women regard as significant in the current socio-economic and political environment and how they explore the cyber-highway for their needs. Another aspect of this volume is its multi-disciplinary and multi-methodological approaches. Several chapters use anthropological and sociological approaches including interviews and questionnaire surveys while others surf the Internet for information and do content analyses. These various approaches provide a rich corpus of data for an informed analysis of how the cyberspace serves as an important platform and how Chinese women tap into them for their own needs.

This book is divided into two sections. The first section deals with work, leisure, politics and identity; the second discusses love, sex and marriage. Chapter One provides an overview and locates the Chinese women within the cyberspace by proposing that the cyberspace can be seen as the following: I) Cyberspace as an alternative channel and an agency; 2) Cyberspace as a platform for self-expression; 3) Cyberspace as a repressive platform; and 4) Cyberspace as a social capital to facilitate cyber-communication and the formation of social networks. As such, the cyberspace as a gendered feminist space is both liberating as well as oppressive.

Chapter Two examines the Internet as a form of social and cultural capital through a comparative study of Hong Kong and Shanghai women. This study shows that women in these two cities regard the Internet as an important tool for both the foraging of information as well as communication purposes, culminating with the formation of cyber-networks. However, it also argues that only few netizens transformed their relationship into a real-life social relationship and with a small measure of success.

Chapter Three explores how women workers in Singapore use the Internet at work and argues that the Internet is considered as an important agency that has become a routine aspect of their job requirement. However, these women avoid using the computer within their home as they prioritize their work along with other family needs such as child caring and domestic chores. This chapter argues that despite the availability of the Internet and information and communication technology to the Singapore women, such technologies do not necessa- 
rily change the social values and outlook of these women, some of whom continued to be bound within the traditional expectations of a patriarchal society.

Chapter Four explores how immigrant Chinese women in Canada make use of the Internet for their work searches and in overcoming, to the extent in which the Internet allows, various types of barriers and discrimination that are associated with the conventional form of face to face job search and interviews. By comparing two types of websites an ethnic Chinese-based job website and a mainstream job website, this study shows that the two websites yield different results for the job-seekers. Those who went for the ethnic Chinese-based website tended to land with non-professional jobs that were below their professional qualification and received wages below the national average. On the other hand, those who landed jobs from the mainstream job website fared better in terms of the types of jobs and salary.

Chapter Five examines the rise of cyber-activism within China and Hong Kong and seeks to understand how these women use the websites to further their goals of gender equality and to protect women's interests by using the awareness/advocacy and organization/mobilization framework. It argues that the ability of these feminist websites to engage cyber-activism is highly dependent on the funding support of various larger non-government organizations (NGOs) to fund the running of these websites. If funding is available, then the feminist groups could carry out their work and expand through the cyberspace. If not, the feminist website might be forced to close or scale down their website activities. It further argues that because the websites rely on outside and often foreign funding, these feminist websites have come under pressure to organize their online activities according to the agenda set by more powerful NGOs which detract them from their original goals.

Chapter Six explores the development of personal websites and online diaries by young Chinese women in Hong Kong. It argues that the personal websites provide these young women with a cyber-platform to express their emotions, behaviour and attitudes towards a plethora of issues in an open manner, given the anonymity of the Internet, when they feel that it is impossible to express or discuss such emotions and behaviour with their family members or close friends. As such, they do not reveal their online diaries and websites to their family members or close friends.

Chapter Seven and Eight look at how women created cyber-networks through the Internet. Chapter Seven looks at Chinese women and their online shopping behaviour and the formation of a virtual network of shared shopping interests. It explores the use of moral sanctions by the women in their chatroom to ensure that all the netizens who parti- 
cipate in the shopping activities observe an acceptable level of behaviour. Through praise and criticism, these women in the virtual shopping community find support for their actions.

Likewise, Chapter Eight examines an exclusive group of women pregnant women and new mothers - and the formation of an online community through the study of a Chinese language parenting site called the Baby Kingdom website. This chapter explores the roles and the types of conversations on the website that revolve around motherhood and child-bearing. Through the study of this website, we come to know how this group of women differentiate among themselves as they progress from their status as pregnant women to becoming mothers and how they use this space as an important gendered space for their self-expression. The chapter also argues that although these women interact in the cyberspace, there is no attempt by these women to alter their real-life identity.

Chapters Nine to Twelve focus on how sexuality and marriages are played out on the Internet. Chapter Nine positions the development of the lesbian cyber-networks in Hong Kong within a broad historical framework and the civil society. It argues that the financial independence of these women allows them to establish women's groups that are otherwise frowned upon. As such, there are parallels between the sworn sisterhood that existed in South China in the nineteenth century and the modern lesbians in Hong Kong society, yet they are perceived differently. While the sworn sisterhood was perceived in a more genteel manner, modern-day lesbians are met with hostility and disapproval as they are more willing to express openly their sexuality which threatens the social and familial order of the society. Because of the continued non-acceptance of their sexual status, some continue to hide their sexuality from their family members and friends. Thus, the cyberspace with the various lesbian websites serve to provide this group of women with a sexual space to articulate their sexuality, express their emotions and form social relationships among themselves.

Chapter Ten uses Doring's sexual empowerment and Gidden's concept of life politics to explore online and offline dating experiences of women in Shanghai and the acceptability and traumas that are attached to such experiences. It argues that as a result of the cyber-love fever, some Shanghai women began to explore and negotiate the cyberspace to find romantic love. Among these women are those who are unhappy with their marriage as well as those who use it as a way out of poverty. The chapter argues that the use of the cyberspace as a platform for engaging in cybersex and romance by these women could be seen as gender empowerment on one hand and lifestyle politics on the other hand. 
Chapter Eleven examines how Chinese (Asian) females in the developing countries are paraded and put on sale as commodities in the cyberspace. By trolling through the various websites, this chapter argues that the proliferation of sex websites has exacerbated this problem of not only worshipping the Chinese (Asian) female body as an exotic commodity, but also continues to allow for the domination and exploitation of the sexualized body by ruthless operators in the sex-related industry. It also argues that as the cyberspace continues to be relatively unregulated, exploitation of the female body is inevitable. Hence, there is a need for stronger vigilance and surveillance of the cyberspace through technological, regulatory and ethical means in order to protect these women from exploitation.

Finally, Chapter Twelve examines how the Internet has become a platform for Chinese women in search of their romanticized and ideal marriages across transnational boundaries. This study explores different groups of women who are engaged in transnational marriages and argues that a majority of them who use the Internet tend to be better educated. It further debunks the stereotype argument that these women married primarily for economic reasons. While some did, others married transnationally for political and other social reasons. For some women involved in transnational marriages via cyberspace romance, they experienced spousal abuse and unhappy marriages in real life. In addition, the study also argues that as a gendered space, the cyberspace could be viewed as a liberating space for some.

\section{$4 \quad$ Towards a Feminized Digital Future}

The routine use of the Internet by a vast majority of women in general, including Chinese women, has led to the creation of a new virtual spatial platform for these women to engage in cyber-activity and form cyber-networks and cyber-communities. To what extent can one see this feminized cyberspace as liberation of women's thoughts and ideology in contradistinction to a conventional patriarchal system? As our study has shown, the picture is a complex one. For some, the cyberspace is viewed as a welcome space to exercise their emotions, thoughts and actions. For others, such form of 'liberation' brings along with it oppression and moral debasement. Yet, for many, they simply attempt to explore the cyberspace and make the best use of it for their own personal aggrandizement and personal gain. As an initial platform of contact, the cyberspace has enabled these women to manoeuvre and explore their emotions, thoughts and actions under the regime of anonymity, hence hiding their real and social identity behind a cyber-veneer (Adam \& Green I998). 
Beyond the personal, the cyberspace is also used prominently for organizing feminist movements and activities at socio-political level. It has permitted the flow of ideas and the spread of feminist activities among feminist non-governmental organizations within a country and on a global basis (Hall, cited in Adam \& Green I998). In this way, the Internet and the cyberspace, when used strategically, provides an alternative platform to further the goals of women beyond the conventional social system (Klein I999). This flow of ideas often cuts across ethnic boundaries and transnational spaces, thereby facilitating different ethnic women groups to join forces and form a globalized cyber-network to further higher causes.

While it is liberating to know that the cyberspace as a gendered platform has facilitated women's actions, other scholars have argued that the Internet, which is essentially masculine in orientation, did not serve to liberate women. On the contrary, it trapped them into the existing patriarchal structure (Lie I995). In our study, the example of the marriage and sex websites as part of the cyberspace platform have attested to the fact that women's bodies continue to be abused by different groups of men who are consumers as well as operators and manipulators of those women under their control. Along with the proliferation of the Internet use and the ease of access, such exploitation has grown in magnitude.

Despite these two opposing views, there are others who see the cyberspace as a neutral space that cuts across gender and enable both men and women to benefit from all the resources that are embedded in the Internet. For them, it is the actors and actresses who are responsible for the actions and behaviour that crisscross along the cyber-galaxy. Thus, the social construction of the cyberspace requires a policy and surveillance in order to ensure that all could benefit from this technology. Thus, it constitutes an important third space but must be mitigated to make it accessible to all groups of all ages.

The cyberspace and its derivatives, together with the rise of telecommunication and digital technology, have resulted in an intricately-wired and connected world. What we are experiencing today is the increased global flows of communication within the cyberspace. At present, the cyber-flow and the social flow tends to glide pass one another as two separate trajectories as individuals assume separate identities. However, when the online meets the offline, the intersection often produces an interesting matrix of social and cyber relationships and communication. In this sense, the embeddedness of the matrix of the various sets of social and cyber relationships begs for a new form of analysis and paradigm in order to fully understand these changing trajectories where the physical meets the cyber and where the social meets the imaginary in our modern globalized socio-cyber world. 


\section{References}

Adam, A. (1998), Artificial knowing: gender and the thinking machine. London: Routledge.

Adams, P. (I995), 'A reconsideration of personal boundaries in space-time', Annals of the Association of American Geographers 85, (2): 267-285.

Adam, A. \& E. Green (I998), 'Gender, agency, location and the information society', in B.D. Loader (ed.), Cyberspace divide: equality, agency and policy in the information society, 83-97. London and New York: Routledge.

Fletcher, B. (I999), 'Cyberfiction: a fictional journey into cyberspace (or how I became a cyberfeminist)', in S. Hawthorne \& R. Klein (eds.), Cyberfeminism: connectivity, critique and creativity, 338-35I. Melbourne: Spinifex.

Haraway, D. (I99I), 'A cyborg manifesto: science, technology and socialist-feminism in the late twentieth century', in D. Haraway, Simians, cyborgs and women: the reinvention of nature, I49-I82. London: Free Association Books.

Hawthorne, S. (I999), 'Cyborgs, virtual bodies and organic bodies: theoretical feminist responses', in S. Hawthorne \& R. Klein (eds.), Cyberfeminism: connectivity, critique and creativity, 2I3-249. Melbourne: Spinifex.

Herring, S. (I996), 'Posting in a different voice: gender and ethics in CMC', in C. Ess (ed.), Philosophical perspectives on computer-mediated communication, II5-I46. Albany N.Y.: Statue University of New York Press.

Kitchin, R. (1998), Cyberspace: the world in the wires. Sussex: John Wiley and Sons.

Klein, R. (I999), 'The politics of cyberfeminism: if I'm a cyborg rather than a goddess will patriarchy go away', in S. Hawthorne \& R. Klein (eds.), Cyberfeminism: connectivity, critique and creativity, I85-2I2. Melbourne: Spinifex.

Lie, M. (I995), 'Technology and masculinity: the case of the computer', European Journal of Women's Studies, 32 (3): 379-394.

Wellman, B. \& C. Haythornthwaite (2002), The Internet in everyday life. Malden, MA; Oxford, UK: Blackwell Pub.

Women and computing. http://archive.cpsr.net/program/gender/. [Retrieved 25 October 2005]

Yorgey, A. (200I), 'Bridging the gender gap: statistics of male and female British Internet users'. http://findarticles.com/p/articles/mi_hb3450/is_200IoI/ai_n8218I50?cm_ven=YPI [Retrieved 25 October 2005] 



\section{PART I}

WORK, LEISURE, POLITICS AND IDENTITY 



\title{
2 Internet as Social Capital and Social Network
}

\author{
Cyberactivity of Hong Kong and Shanghai Women'
}

\author{
KUAH-PEARCE Khun Eng
}

\section{Introduction}

This is the age of globalization and digitalization, and we seem unable to escape from the pervasive influence of the two processes. Irrespective of whether we are at home, in the subway, on the bus, in shopping malls, schools or offices, our lives have become interconnected with the digital equipment that has brought us so close to one another. We do not seem to be able to divorce ourselves from such aids anymore, and if we did not possess any one of them, we surely would feel very lost, as we have become highly dependent on them for communication and interaction. The digital age has now made us slaves of the digital inventions that are supposed to aid us.

One of the greatest creations of the digital age has been the Internet, which allows us to reach one another with messages almost instantaneously and relatively cheaply. Chatrooms allow for simultaneous interaction between two or more individuals, and personal blogs carry personal information to the rest of the world. For the public, the Worldwide Web has been loaded with every conceivable kind of information, and information overload is available at a click, allowing us to download not only the personal but also the commercial, the academic, the political, etc. Now, as we move further into the $2 \mathrm{I}^{\text {st }}$ century, the digital revolution is contributing massively to the creation of a variety of new life styles that are coming into being. This is especially so with the advent of Web 2.0 where interaction among the netizens has become the norm rather than exception. With the creation of interactive websites and Web-based communities, the Web has become a platform for instant, simultaneous dialogic communication and interaction on a bilateral or group basis, expressing immediate views of various types of issues that cut across geographical and temporal space.

As the world marvels about the advantages and usefulness of this technology, there is also the flip side to this innovation. Internet abuses have now occurred at a more rapid rate than before. We hear of cyberaddiction, cyber-crime and of how the Internet is used to foster and re- 
inforce hatred, violent behaviour, religious radicalism, sexual crimes, etc. In addition, the Internet has also become a space for radical action such as a gathering of people that influence one another in the matter of committing mass suicide to conducting illegal activities.

Through the lenses of two groups of women from Hong Kong and Shanghai respectively, this chapter will explore how women use the Internet as a form of social capital and social network and negotiate cyberspace for their own needs and demands and reposition themselves in local and global society. In so doing, they have correspondingly enlarged the cyberspace and converted it into their social space.

\section{Scope and Methodology}

This study uses quantitative research methods that enabled us to compare women in Shanghai and Hong Kong in their use of the Internet. The sample size was 300: a standardized questionnaire was distributed to Ioo women in Shanghai and 200 in Hong Kong. The survey was conducted from November 2003 to May 2004. The original target was for a sample size of Ioo for each city. In Hong Kong, however, the enthusiastic response from participants has enabled us to double the sample size. Stratified sampling was used to ensure that a distribution of women from different age groups answered the questionnaire. Informants were chosen from among university students, office workers and housewives.

\section{Internet as Socio-cyber Capital}

Bourdieu (I986), Coleman (I988), Lin (200I), Portes (I998, 2000) and others have expounded extensively on the importance of social and cultural capital and the possession of such capitals that enable individuals to become successful in various socio-economic and political environments. Social and cultural capitals, together with the possession of social networks, also help individuals to adapt themselves to a new environment. In exploring how the Hong Kong and Shanghaiese women use the Internet, it is possible to argue that they have transformed this new technology into important cyber-capital not only to perform various tasks but also for networking purposes.

The operation of the cyber-capital comes in various forms along with various types of users. The simplest of which is the ability to get connected and to use the Internet for obtaining information. There are those who are able to make use of the discussion boards to communicate, air their views and tap others' views on different issues. There are 
also others who create and write blogs on themselves or other issues for public consumption, as well as to elicit views from the netizens. With the advent of the second generation of Web-based communities and hosted services platforms, commonly called Web 2.0, simultaneous and instant, communication among the netizens has become possible. These various groups of netizens with varying degree of technological understanding of the cyber-technology and cyber-interests can be said to possess a form of cyber-capital that place them in enviable position vis-à-vis those who do not have. They are able to muster cyberfriendship and create cyber-networks for themselves. By positioning themselves within the cyberspace, they are able to establish new forms of communication to honk their cyber-social skills and enlarge their cyber-networks. In this way, the possession of cyber-capital enables the netizens to create strategies to deal with a variety of issues - ranging from information gathering to establishing networks and communities.

As the Internet has become an indispensable daily tool, those in possession of this cyber capital, in varying degrees, will be able to compete with the have-nots. In recent years, the ratio of male to female Internet users has narrowed considerably. In the U.S., according to Nielsen Net Ratings, 51.7 per cent of Internet users are women. Likewise, in the U.K., there are more women AOL users than men (http://archive.cpsr. net/program/gender, retrieved 25 October 2005). According to the U.K. Internet Monitor survey from Forrester Research, 46 per cent of U.K. Internet surfers are women (http://findarticles.com/p/articles/ mi_hb3450/is_200IOI/ ai_n8218150?cm_ven=YPI, retrieved 25 October 2005). In the Asian countries and cities, female Internet users have gone up to over 40 per cent. In South Korea, women Internet users are around 45 per cent of online population. In Hong Kong, it is 44 per cent whereas in Singapore, it is $4^{2}$ per cent and in Taiwan, it is $4 \mathrm{I}$ per cent (http://archive.cpsr.net/program/gender, retrieved 25 October 2005). Despite this increase in the use of the Internet by women in Asia, use and access of the digital technology is unevenly distributed across the world and within each country. Arguably, this form of technology works to the advantage of the young and the middle class women. Thus the reach of cyber-capital continues to be confined within the middle class women.

In some Asian countries such as Singapore and Hong Kong, there have been attempts to popularize and bring cyber-technology to all, including those at the lower social stratum. This is in response to the belief that the digital age is here to stay and that digital technology will become the overruling apparatus in modern living. In such countries, governments have allocated and spent a large sum of money to bring cyber-technology to the reach of their population. In such situations, 
schools and students become the targets for a cyber-revolution. Likewise, community centres and public places are installed with computers to allow the general public access to this technology. Increasingly, the computer will become an indispensable household item. Among these governments, the belief is that the possession of cyber-capital is not only advantageous but also essential for modern development and to compete with the rest of the world on a global scale. In short, in a post-industrial world, advancement and modernity are closely twined with the cyber-world.

One of the key arguments is that the Internet has become an important gadget for the young, trendy and educated. This argument is also reflected in our survey of both cities where over 80 per cent of respondents were aged betweens I8 and 35. Among those who are computer literate in Hong Kong, 40 per cent have a secondary and/or post-secondary education; 37.5 per cent have a college, tertiary and/or postgraduate education. In Shanghai, 40.5 per cent have a secondary and/or post secondary education, and 58.5 per cent have a tertiary and/or postgraduate education.

Of the Hong Kong users, ig per cent stated that they have used the Internet for I-3 years, 26 per cent for 3-5 years, and 24 per cent 5-8 years. In Shanghai, the beginning of Internet use was much more recent than in Hong Kong: 47 per cent of the informants indicated that they had only started using the Internet I-3 years previously, with 39 per cent having used it for 3-5 years.

In terms of accessibility and ownership of a computer, our research results showed that among our Shanghai respondents, 84 per cent own a computer and 75 per cent in Hong Kong own one. These are very high rates of ownership compared to those of other developed countries in the world, reflecting and reinforcing the class divide in terms of accessibility to this new form of technology. It is thus not surprising that this is correlated to their daily usage where among the Shanghai respondents, about 48 per cent surf the Internet on a daily basis and 28 per cent surf it two to three times a week. Likewise, in

Table 2.1 Education Level of the Interviewee in Hong Kong

\begin{tabular}{rrrrrr}
\hline & & Frequency & Percent & Valid Percent & Cumulative Percent \\
\hline & & 43 & 21.5 & 21.5 & 21.5 \\
& & & & \\
& & & & \\
\multirow{4}{*}{ Valid } & Secondary school & 1 & .5 & .5 & 22.0 \\
& High school & 36 & 18.0 & 18.0 & 40.0 \\
& 45 & 22.5 & 22.5 & 62.5 \\
& College & 39 & 19.5 & 19.5 & 82.0 \\
Total & University & 30 & 15.0 & 15.0 & 97.0 \\
& Master or above & 6 & 3.0 & 3.0 & 100.0
\end{tabular}


Table 2.2 Education Level of the Interviewee in Shanghai

\begin{tabular}{lrrrrc}
\hline & & Frequency & Percent & Valid Percent & Cumulative Percent \\
\hline & high school & 15 & 15.2 & 15.3 & 15.3 \\
Valid & College & 25 & 25.3 & 25.5 & 40.8 \\
& University & 54 & 54.5 & 55.1 & 95.9 \\
& Master or above & 4 & 4.0 & 4.1 & 100.0 \\
Missing & Total & 98 & 99.0 & 100.0 & \\
Total & & 1 & 1.0 & & \\
\hline
\end{tabular}

Table 2.3 How Long Has the Interviewee Used the Internet? - Hong Kong

\begin{tabular}{|c|c|c|c|c|c|}
\hline & & Frequency & Percent & Valid Percent & Cumulative Percent \\
\hline & & 43 & 21.5 & 21.6 & 21.6 \\
\hline & Less than 1 year & 6 & 3.0 & 3.0 & 24.6 \\
\hline & 1 to 3 years & 38 & 19.0 & 19.1 & 43.7 \\
\hline & 3 to 5 years & 52 & 26.0 & 26.1 & 69.8 \\
\hline \multirow[t]{5}{*}{ Valid } & 5 to 8 years & 48 & 24.0 & 24.1 & 94.0 \\
\hline & 8 to 10 years & 8 & 4.0 & 4.0 & 98.0 \\
\hline & More than 10 years & 2 & 1.0 & 1.0 & 99.0 \\
\hline & Others & 2 & 1.0 & 1.0 & 100.0 \\
\hline & Total & 199 & 99.5 & 100.0 & \\
\hline Missing & 999 & 1 & .5 & & \\
\hline Total & & 200 & 100.0 & & \\
\hline
\end{tabular}

Table 2.4 How Long Has the Interviewee Used the Internet? - Shanghai

\begin{tabular}{lrrrrc}
\hline & & Frequency & Percent & Valid Percent & Cumulative Percent \\
\hline & less than 1 year & 6 & 6.1 & 6.1 & 6.1 \\
& 1 to 3 years & 46 & 46.5 & 46.9 & 53.1 \\
Valid & 3 to 5 years & 38 & 38.4 & 38.8 & 91.8 \\
& 5 to 8 years & 5 & 5.1 & 5.1 & 96.9 \\
& 8 to 10 years & 3 & 3.0 & 3.1 & 100.0 \\
Missing & Total & 98 & 99.0 & 100.0 & \\
Total & 999 & 1 & 1.0 & & \\
\hline
\end{tabular}

Hong Kong, 49 per cent go online daily and I7 per cent do so two to three times a week.

In our survey, in rating the overall usefulness of the Internet, 35 per cent of Hong Kong women rated it as being very useful and another 32 per cent rated it as useful. Only 3 per cent rated it as not useful at all. Likewise, 37 per cent of Shanghai women rated it as very useful and 34 per cent rated it as useful. 2 per cent rated it as not useful at all. As for dependence on the Internet, 2I per cent of Hong Kong women relied 
heavily (80-Ioo per cent) on it for all sorts of information and another 37 per cent relied moderately (50-80 per cent) on the Internet. In Shanghai, 27 per cent of women relied heavily (80-Ioo per cent) on the Internet, with another 39 per cent relying moderately (50-80 per cent) on it for all sorts of information and activities. This explains why, in Hong Kong, 65 per cent of the women informants considered the Internet an important alternative source of communication as well as a resource tool for information; while in Shanghai, 93 per cent of the women considered the Internet as a tool and an alternative source of communication.

The informants surf the Internet for a variety of reasons. In our survey, we found that, among the Hong Kong informants, surfing the Internet for news is one of the most important tasks. 33 per cent ranked reading news from the Internet as their first and second most important reason for surfing. In Shanghai, 63 per cent of my informants use the Internet to surf for news. In Hong Kong, a second important reason for surfing the Internet is to get information regarding education 42 per cent ranked this to be an important reason for going online, while in Shanghai, only 22 per cent go online to get information on education. Students generally surf the Internet for information regarding various issues when they worked on school projects. Others surf the Net to get information regarding schooling abroad. This is especially so among the Mainland Chinese women who desire to go abroad for their studies. The Internet becomes a ready avenue for all types of information pertaining to studies in various countries. In Shanghai, 36 per cent looked to the Internet for information on beauty and health, contrasting sharply with 8.5 per cent relying on the Internet for this kind of information in Hong Kong. In Hong Kong, about 25 per cent use the Internet to search for jobs, but only ro per cent do this in Shanghai. I4 per cent of Hong Kong and about Io per cent of Shanghai women informants use the Internet as a means to find friends and potential marriage partners.

From this set of statistics, it is possible for us to conclude several trends. First, both women in Hong Kong and Shanghai are increasingly using the Internet. They do so in a variety of ways. They use it to gather the latest news and current affairs; and this is in line with the global trend of young people going online to read news instead of relying on newspapers. Several factors account for this trend. First, going online provides one with the most updated news. Second, women can more conveniently surf news from a variety of e-newspapers instead of confining themselves to one or two printed newspapers; and this includes access to e-newspapers from different countries. In this sense, unlike the print media, which tend to be localized and parochial, access to e-news opens up the world to netizens. Third, the Internet saves cost 
and time, particularly concerning the purchase of foreign newspapers - which, in any case, often arrive by courier, and with outdated news. And fourth, quite obviously and quite importantly, for Shanghai users the Internet provides a convenient, and sometimes an exclusive, means of getting news not censored, managed, packaged and coloured by the State. As such, the Internet allows the users to become politically aware of not only events that are outside China, but more significantly of what is happening within China. Such knowledge can galvanize these Chinese into social or political actions when the occasion demands it.

A second use of the Internet is to search for information regarding education. Increasingly, among secondary and tertiary students, the Internet is an important resource base for searching for all kinds of information. Given the fact that many schools and universities require students to work on projects, search engines such as Google and Yahoo have become extremely important for providing students with easy access to information. Within universities, students are increasingly citing websites from which they have downloaded information and ideas. Among the informants, the Internet is also significant in providing information pertaining to overseas studies. Among the Chinese in Hong Kong and Shanghai, an overseas education is a coveted one and the ability to travel overseas to study would increase the amount of social capital that the individual possessed, which would eventually be translated into better jobs, a higher salary and eventually a better lifestyle choice.

A third use is to gather knowledge on beauty and health. The very significant difference between Internet use among respondents in Shanghai and Hong Kong in this regard could be the result of the following factors. First, in Hong Kong, information on health and beauty is readily available and accessible in various forms. Glossy printed women's magazines are top choices for many socialites, office and executive women who power-dress to work. Such glossy magazines provide information on the latest trends in fashion and cosmetics. Also, they provided information on what constitutes beauty and how one can attain it. Besides, the proliferation of beauty parlours, hair salons, and slimming and body contouring centres, as well as plastic surgery clinics in Hong Kong has allowed women great access to attaining their desired body shape and facial look - not only the wealthy, but also for working class women. This brisk trade is directly the result of marketing, which influences the perception on what constitutes acceptable beauty in Hong Kong society. Women feel more confident when they have an acceptable appearance. Research has also found that a 'beautiful' face is more likely to get a job or promotion or salary increase in a work environment that continues to be male-dominated. 
Likewise, with the rise of the new economy on the Mainland and opportunities in white-collar job sectors, Mainland women too are beginning to revisit what constitutes beauty. In both Hong Kong and the Mainland, 'beauty' is regarded as important social capital that will bring not only employment opportunities but also good marriage prospects. Women in both areas thus go to great lengths to achieve desirable images. Apart from makeup and slimming, plastic surgery has become very popular, especially so among the Mainlanders. In 2004, the first man-made beauty contest organized in Mainland China attracted a sizeable number of participants who had undergone plastic surgery to become more beautiful. However, despite the opening of the Mainland economy and media, there continue to be restraints on publicity for such fashion aids.

Foreign cosmetic products have remained excessively expensive on the Mainland but are the products most coveted by Mainland women. So the dearth of information has led Mainland Chinese women to click onto the Internet for information and advice on beauty and health, and the Internet has become an avenue for discussion and exchange of ideas pertaining to beauty, health, plastic surgery and the like. Thus, when there is insufficient or incorrect type of information on the latest trends in fashion and beauty on the Mainland, the Internet becomes a ready source for all to tap into. Many considered the Internet as providing a more reliable source of information than the largely state-controlled newspapers. Also, increasingly, online shopping for the coveted foreign goods has become a trend where purchases from foreign-based and internationally recognized websites can provide guarantee of authentic products. This is especially so on the Mainland Chinese market which is flooded with large quantities of counterfeit and substandard quality products.

Another reason for the high use of the Internet by women Internet users in China has much to do with the fact that among the female Chinese youth, there is a growing sense that foreign ideas about things like beauty, fashion and glamour are superior to the local ideas. They look to Hong Kong, Paris, New York, London and Rome - and seek to emulate the beauty concepts of these cities. Among Mainland Chinese women, despite increases in wealth and the increasing gap between the wealthy and the working class women, there is an emerging mentality among all to increase their cultural and social capital through a 'traditional' mean - that is, refocusing their attention on their beauty and sexual attractiveness.

It is thus possible to argue that women have recognized the possession of cyber-capital and negotiated it for various purposes. At the pragmatic level, the possession of such skills facilitates one's entry into the white-collar work sector and allows for promotion within the occupa- 
tional hierarchy. The work environment now sees cyber-capital as a necessity and not an added asset. At the social and political level, it allowed for the enlargement of cyber social communication beyond the existing social networks. While the young might find it exciting to embrace this new technology, middle age and older women often find the acquisition of digital skill a major challenge, to which many are unable to muster it well. As such, the Internet remains a formidable challenge to these women.

\section{Cyber-networks and Cyber-communities}

A second key area is that Chinese women used the Internet for interactive communication and to build up social networks and create cybercommunities. As with all other forms of socialization and communication, there arises a virtual community or cyber-network among the cyberspace users. Castells (Castells 200I: II8) argues that the Internetbased socialibility is confined only to a small group of users, primarily to teenagers where they are at the age of constructing and experimenting with their various sets of identities. While it is a fact that the young people are at ease with this form of information technology, other age groups, the older ones as well as other social groups such as women and ethnic minorities are also now using the Internet to further their instrumental as well as social goals. The Internet tends to reinforce social and interactive communication among friends. This is especially so in modern society where global migration results in movements of people and the need for them to be connected to their family, friends, political and business bodies. At the same time, it also brings together women with common political agendas and allows them an alternative voice in a conventional setting (Thompson, Gomez \& Toro 2005).

However, the question remains as to the extent to which cyberfriends and netizens are able to form cyber-networks to cater for their social and individualized needs and the durability of these cyber-networks. It has been widely argued that friends formed over the cyberspace necessarily remain in the cyberspace for a variety of reasons, but mostly because the topic for interactions tend to be topical in nature and the netizens' interests shift along with new interests and topics for discussion. At the same time, netizens might adopt one or more personas and this again shifts along with their changing interests. As such, netizens often shift from one site to another in search of their new interests and hence, new cyber-friends. This euphemistic cyber-relationship serves as a constraint to the establishment of permanent social relationship but yet as a liberating force to allow for short-term but more varied types of cyber-interaction. Does such kind of social interaction 
suits the modern needs of the individuals? Are we witnessing the demise of the old fashioned style of social relationship that emphasized on quality and durability? Instead, are we witnessing the emergence of a short intense kind of relationship where instant gratification is the modus operandi between two or more people and among them, various sets of cyber-relationship?

Apart from cyber-networks that are of a social nature, other networks are more instrumental and pragmatic for specific objectives. While there is social interactivity among the netizens, often the primary focus is not on the establishment of a set of social relationships. Rather, the type of cyber-relationship is based primarily on the needs for specific information or interaction arising out of common goals and common social experiences. For example, women who tap into health and beauty websites are interested in information on these two issues and those who interact within these websites often communicate and exchange information on topical issues of this nature. Thus, the cyberbonds created among the netizens who patronized websites of this nature are necessarily focused and parochial bonds.

Women cyber-networks can thus be open and fluid as well as closed and focused. They could also be open and focused. Apart from personalized cyber-networks, the boundary of these cyber-networks remains relatively open and fluid. Often access is via open portal or in other cases, through a subscription. Subscription offers the members a sense of exclusivity but there is no guarantee that the netizens will interact with the right type of women, although there is assumption that this will be the case as subscribers will have common interests. Increasingly as the portals rely on advertising revenue, subscription has become less fashionable although it continues to be important for those that aim at a specific group of netizens. In general, it is not uncommon for Chinese women to have several sets of cyber-networks, each catering to a specific need.

These different types of cyber-network structures come about because of the different needs of these women. Such needs are very much influenced by the class and education status of these women consumers as well as their understanding and expectations of the roles of the Internet for their use. In general, women who use the Internet tend to be middle class with secondary education. In many cases, access to the hardware is also an important consideration to their use. Those with a personal computer at home use the Internet more frequently and establish more sets of cyber-networks than those without. Those with access to cyber-cafes are more likely to have some forms of cyber-networks than those without.

Cyber-networks can be ranked according to the participation rate of the members found within a website portal. It ranges from passive to 
responsive and to highly interactive according to the level of participation by these women. Passive interaction involves women tapping into the website for information. Responsive ones are those where women are engaged in interactive communication. Highly interactive are those that chat regularly on the issues posed on the Web and go beyond just merely responding to questions on the website. In this sense, Lee (2006) argues, when he refers to the production of the hardware components by male participants, that women tend to be the end-users and consumers rather than the producers of this dominant technological knowledge.

In a highly interactive cyber-environment, often there is a group of women who communicate their views, ideas, advice, information, etc. onto the discussion board. Much of the interaction stops at the cyber-level. Only a small group will attempt to transform cyber-communication into real life face to face type of communication. As such, it is possible to argue that arising from the new development in cyberspace is the development of various types of cyber-networks and cyber social bonds among the women netizens. Chinese women might have several sets of cyber-networks and cyber social bonds. Out of these sets of cybernetworks and cyber social bonds, a selected few might translate them into real social networks and social bonds with face to face interaction. When such a transformation takes place, the cyber-networks merge with the social networks and netizens become social friends.

However, as the situation appears today, to go beyond the cyberspace and transform the different sets of cyber-networks and cyber social bonds into personal social networks and friends requires the netizens to overcome the psychological barrier of 'coming out' of the cyberspace into the real social face. This is not especially easy as many netizens have assumed various personas and 'coming out' of this might create tensions when expectations became unfulfilled. Furthermore, the assumption of various cyber-personas presupposes that the 'real' self prefers to take a backstage in order to allow its alter ego to function in an expressive and uninhibited manner. In this sense, the anonymity of the cyberspace is imperative for interactivity communication and the creation of alternative sets of networks that might otherwise be impossible in a real social environment. Such networks therefore could only find audience within the cyberspace. Any attempt to transform these network structures would necessary create problems for the 'real' self of the netizens as the two selves might contradict each other in real and cyberspace. In short, what we see is the gliding of the two sets of selves passing each other in which each performs different roles, although sometimes complementary and supplementary ones, to each other. In most cases, each self looks after a different set of needs and demands. 
It is possible to postulate here that such bonds are unlikely to easily transcend beyond the boundary of the cyberspace on a mass scale. Although at the individualized level, low level of flow might reach into the personal life of selected individual netizens who work to transform the cyber-bond into tangible social bond.

In our survey, we are also interested to know of the existence of cyber-communities among these informants, including the networks that have been established within the cyber-communities. 73 per cent of Hong Kong informants have a chatroom account, while 77 per cent of Shanghai informants have one. In Hong Kong, about half of the informants are members of cyber-communities and chat online on a regular basis; while in Shanghai only I5.5 per cent are members of cyber-communities. This difference can be attributed to the fact that in Hong Kong, information technology has been in use for a longer period of time and which has been popularized since the I980s and ubiquitous since the I99os. An added point could be that Shanghai women adopted a more conservative and non-trusting attitude towards strangers. One point to be noted here is that despite the ubiquitous nature of the Internet and the ease to the numerous websites, time and locality continue to govern the nature of communication and the formation of cyber-communities. While transnational cyber-linkages and communities are common within Mainland China, it is most common for Mainland Chinese women to tap into several common China-based websites such as Sina.com rather than those from outside of China. This could be attributed to the ease of access of these websites, but also to the fact that some of the foreign-based websites are blocked by the State and Mainland Chinese have no access to them.

Perhaps more importantly, Mainland authorities impose close surveillance of the Internet and sometimes interfere with chatroom communication and the flow of information through cyberspace. It is not uncommon for chatrooms to be closed or websites blocked when the authorities regard them as dangerous or undesirable for the social, moral or political good of the wider community.

Another reason for the difference in the rate of usage may be the emergence of a cyber-culture among Hong Kong women in particular and Hong Kong people in general. To a large extent, the ability to use the computer and the Internet and to have chatroom communities is a sign of sophistication in tandem with modern trends and fashion. In short, it is the way Hong Kong women express their modernity.

In regards to the variety of issues chatted online, it was found that Hong Kong women chat on a range of topics fairly regularly and evenly, with an average (over 45 per cent) of chatting on news and current affairs, job searching, beauty and health, and education; while 56 per cent chat on friendship and marriage and only 38 per cent on to- 
pics related to sex. In contrast, Shanghai women seem reluctant to chat online. Over 70 per cent failed to answer questions of a personal nature, in particular questions pertaining to sex and related issues. Around I5 per cent of those who did answer chatted on topics ranging from current affairs to friendship and marriage. Only 3.6 per cent mentioned that they chatted on 'adult' issues such as premarital sex, sexual relationship with the opposite sex and their sexuality and sexual preferences.

To analyze, it seems that Hong Kong women are more comfortable using the Internet as a communicative device, since they chat much more freely than their Shanghai counterparts. It also reflected on their more general liberal views, confident attitude and their 'cosmopolitan' outlook as compared to the Shanghai women. The more open attitude of Hong Kong women is reflected in their willingness to share views on personal matters with others. In contrast, Shanghai women are more conservative and shy away from questions that are of a personal nature. This could be attributed to several reasons. One could be that they are generally less comfortable in expressing their views. Second, it could also be attributed to the 'fear culture' where state institutions regularly collect information that can be used against people. It would be naïve to say that institutions are not capable of Internet spying on the Mainland and fear of persecution could restrain their expressions of ideas while communicating online.

Online chatting has become an important part of the cyber-self. In Hong Kong, 33.5 per cent chatted on a daily basis and another 19.5 per cent chatted once every 2-3 days. In Shanghai, 22.5 per cent chatted on a daily basis and another 22 per cent chatted 3-4 times a week. The remainder chatted occasionally, some once every few days and others once a week. The popularity of online chatting is also reflected in the length of time to which the netizens chatted. In Hong Kong, 32 per cent chatted less than one hour each session, 29 per cent chatted I-2 hours each session and 8.6 per cent chatted for more than 3 hours each session. Among them, 28.6 per cent are under I7; 34.5 per cent are I8-25; and I0.8 per cent are from 26-35 years old. In Shanghai, 27.4 per cent chatted less than one hour per session, 42 per cent for I2 hours each session, and 6.3 per cent chatted for over 3 hours. 63 per cent of those who chatted were I8-25 years old; 24 per cent were 26-35. 20 per cent chatted less than one hour, 20 per cent for I-2 hours and 5 per cent chatted over 3 hours.

Comparing the online chatting patterns of Hong Kong and Shanghai women, we found a higher proportion of Shanghai women chatted online for much longer than Hong Kong women. This could be attributed to two factors. First, Hong Kong women have other means of communication, especially with readily available mobile phones. It is estimated 
that over 80 per cent of Hong Kong people own mobile phones, making Hong Kong the highest in terms of mobile phone ownership. The fact that the cost for talking on mobile phones has gone down tremendously in recent years as a result of competition also means that they have become very affordable for working class and young people. Communication by mobile phone costs only several cents per minute, making it attractive for users. Besides, Hong Kong people are used to answering quickly and immediately to calls. Of course, in recent days, as Shanghai has become more affluent and its citizens become wealthier, mobile phone has also become an important item for communication. It will be interesting to compare their online behaviour in the years to come. These two factors make them favour mobile phones over the Internet as a major means of communication. Mobile phone communication can be seen everywhere and anywhere - from the café to the bus and the subway, from private to public places - one can see men and women talking aloud in earnest and oblivious of their surroundings. Internet, despite the almost instant response, is still slower than a mobile phone, and is less mobile although the introduction of wireless Internet services through mobile phone such as the Blackberry has made substantial inroads in recent years. However, the Internet continues to be important for long distance communication, especially with friends and family members residing overseas in Hong Kong and on the Mainland.

\section{From Virtual Space to Social Reality}

In Hong Kong, 63 per cent of respondents indicated that they have online friends. Of these netfriends, 35 per cent are male and 65 per cent are female. In Shanghai, however, 63.6 per cent are male. The higher percentage of male online friends indicates that young Chinese women are more willing to use a less personal form of communication when communicating with people of the other sex. In some ways, this resembles the 'blind marriage' of earlier Chinese society, when the marriage was arranged and the couple often did not meet prior to the wedding. In a twist, this form of modern technology has now become a new form of matchmaking agency - a mediator - where young men and women can meet in an anonymous and amorous fashion prior to meeting in real life. Cyber-meeting and cyber-romance have increased rapidly in recent years and the Internet has become an increasingly important avenue for men and women to meet, chat, socialize and get to know one another online before meeting in real life. While many simply meet, chat and socialize online, there is a growing number of women who engage in more explicit romantic and sexual activities online, 
such as cyber-sex. Indeed, some Mainland Chinese argued that cybersex is preferable to real sex with physical contact for men and women who are unmarried. One key argument is that cyber-sex is 'clean and disease-free' and they favour cyber-sex over pre-marital sex.

In Mainland China, the Internet is also regarded as a liberating space for women where they can express their sexuality. It is used by a small number of women to post their personal sexual odysseys. One example is $\mathrm{Mu} \mathrm{Zi} \mathrm{Mei}$, who kept an online diary and told of her sexual experiences with countless men in a conservative socialist Chinese society. Her online diary was read by several million Chinese men and women until it was shut down by the Chinese authorities. The Mainland Chinese authorities regarded her sexual behaviour as unacceptable and as a form of moral decadence. Mu Zi Mei subsequently produced a book based on her online diary which was also banned by the authorities but continued to be sold widely by underground bookshops. After her, there was another female university professor who wrote about her sexual encounters and was also dismissed by the university that employed her. Since then, such online diaries have been popularized and Shanghai women have started writing them, although including less lurid sexual stories. Chinese women are thus able to use the Internet as a social and sexual space to express their sexuality in a public forum - something that has been denied to them in more conventional forms.

Of the 63 per cent who have online friends in Hong Kong and Shanghai, I5.5 per cent considered their cyber-friends to be close friends, while another 30 per cent considered them as friends. However, in Hong Kong, only 6 per cent considered them close friends, and 16.5 per cent as friends. When it comes to meeting face to face with cyber-friends, only I6.5 per cent of Hong Kong women have done so, while 26 per cent of Shanghai women have. In Hong Kong, II.5 per cent met their cyber-friends because they wanted to meet new friends - only I.5 per cent considered meeting them as potential marriage partners, 3 per cent met out of curiosity to see how their cyberfriends looked and behaved in reality. In Shanghai, however, 9 per cent met out of curiosity, I3 per cent because they were new friends and I per cent for potential marriage consideration. Although the Internet is now regarded as a new and important space for meeting potential marriage partners, this research shows that women in Hong Kong and Shanghai continue to look and use it with caution. This study is in tandem with a recent study which has shown that a group of Chinese women used the Internet as a tool for searching out potential marriage partners, and do so with some success (Noble 2003).

Among the Shanghai women who chatted online and had met their cyber-friends in person, there was a range of responses. Some said, gi- 
ven the fact that they and their cyber-friends had already chatted online for a period of time, that when they met up they did not feel like strangers and could easily strike up a conversation and a relationship. Others wrote that the online and offline personas of their cyber-friends differed substantially, so much so that some of them did not feel comfortable meeting and communicating with the real person. One commented that 'What I feel is simply very disappointing since, in the world of the Internet, people could use language to whitewash themselves. In this sense what I obtained at first sight was just a fictitious image built up with words, together with my further embellishment. What I found out in the end was nothing but cruel reality'. On the other hand, another expressed that:

'... with some of my cyber-friends, we could develop an even better relationship in real life contact than simply in the cyberspace - I felt like we had already known each other the first time we met. For example, we had dinner and chatted together, and they also lent me a hand when I had problems in computer operation. But for some other cyber-friends I met, I find that they behaved in real life differently from the way they usually appear to be online. In this sense, I think people chatting in cyberspace are quite diverse, and the cyber-world can sometimes hide the true nature of the netizens from us.'

Some of the women who chatted online usually chatted with friends in the social circle that they knew in real life. One said that 90 per cent of them are from her real life friends. These are the women who feel that they want to be able to control their cyber-communication and who want to 'play safe'. Some of them mentioned that, given the fact that the Internet is faceless, it is not possible to know the netizens that one is communicating with, so it becomes preferable to cyber-communicate with those they already know in real life. They have also been strongly influenced by the negative news of rape cases, where women and young girls were raped by the netfriends upon meeting them.

As Lacan and others such as Levine (I982) and Morris (1994) have pointed out, with the existence of different selves within an individual, it is not surprising that individuals would adopt different online and offline personas. Whether the online persona aims to reflect the hidden self or the real self, Hong Kong and Shanghai women have attested to the divergent personalities of their online friends when they met them offline. However, although expectations resulting from online interactivity communication might not often tally with the reality one meets offline, such meetings can still result in long-term relationships. One woman wrote that: 
'The two cyber-friends I met offline were not only ugly in appearance, but were also very different from the way they usually behave during online chatting. However, it is also through online chatting that I have come across a person who later became my boyfriend. And because we treasured our relationship then, we exchanged our photos in the chatroom before we really met offline'.

In Hong Kong, the women who had ICQ accounts and chatted online found online relationships more satisfactory, as they provided them with a sense of communicating with a 'mysterious person'. However, such 'mysterious status' disappeared once they met in real life. One said that it is 'not so satisfying. Usually the online person would lose his or her sense of mystery for me once we met in person'. Others, too, referred to the gap between the online and offline personas. Another respondent wrote that, when she met the person in real life, it was 'not bad, but somewhat different from what I had imagined. Cyber-friends usually have different characteristics from what she or he presents during online chatting'.

Some reported that, while it is fun to chat online, they were wary of online cyber-friends. One put it: 'I never meet those cyber-friends that I don't know beforehand'. So some of these women would only meet with friends with whom they had prior friendships in real life. To expand their online network of friends, some women indicated that they made net friends who were, in fact, friends of their friends. In this case, there was less worry about the characters of these net friends, and it also became easier to meet in person, as they were not meeting strangers for the first time. One responded that 'usually they are my friends' friends. They probably understand my character in advance, so they will be satisfied to meet a person that they seemed already know or understand'.

The Internet is also an important avenue for many women to reconnect with lost or past friends. Some said that they had reconnected with their primary or secondary classmates that they had not seen for a long time. The Internet makes this easier and less awkward to do. These women felt it harder to pick up a phone and call someone whom they had not seen for a long time. One reason for this could be the relatively anonymous identity of the Internet. Because one is not facing the other person, appearances, behaviour, speech and other visible actions become less significance. In some way, the Internet has become an important outlet for expressions, particularly for those with introverted characters. Cloaked in an anonymous identity, individuals are able to imagine, fantasize and even come out of their introverted nat- 
ures and engage in communication. In some ways, this can be psychologically liberating.

Those who had chatted their way to eventually landing a boyfriend looked at the Internet in this way. One respondent, Ling, said that, after online communication and after seeing a photo of the guy that she had chatted with, she met him. She said, 'He looks shorter than in the picture. But anyway, he's nice and we are close friends now'. Another respondent, Ching, said, 'I felt quite satisfied with him. He is a friendly and kind person'. Yet another said that expectations were usually high prior to meeting the net friend in person, especially if he is of the opposite sex. Thus when the reality falls short of expectations, the friendship dies almost instantaneously. A third respondent, Ming, said, 'The relationship with two of my net friends died right after we met each other because the expectation was completely different'. In recent years, in order to avoid the embarrassment of either rejecting or being rejected by their net friends, it has become a fairly common practice for net friends to send and view photographs so as to formulate visual images of each other. If they do not like the look of the person, they might reject a meeting in real life, but if the net friend looks reasonably good, they will make an appointment to meet. This is particularly the case when a woman considers meeting an online male friend.

Among Hong Kong and Shanghai women, looks and appearance continue to be important criteria for measuring friends, both male and female - but this is especially the case among women looking for male net friends. Whether they intend to develop an intimate relationship or not, they feel that an acceptable level of looks is especially important. Why is this so? Such an attitude can be attributed to several factors. First, among these two groups of Chinese women, there is a strong attachment to what they consider to be 'beautiful', so that their friends have to be of 'reasonable looks' and character. This is related to the notion of personal ego, where the inability to have friends of such calibre is a personal failure. This is so for those who have been unable to forge relationships with people in their social circles or within the community at large.

A second reason is related to 'face' as, within their social circles, there is an expected level of what constitutes an acceptable appearance. Those who had net friends that did not match the expected level of appearance would lose face among their peers and would be teased. It is not uncommon for women to gossip with one another about their net friends and compare notes on their attitudes, behaviour and looks. So, having good-looking net friends in a way raised a woman's self-confidence and her status among her friends. This is especially so concerning male net friends. It is also fairly common among these women who circulate their net friends among their circle of women friends. 
In comparing the attitudes of Hong Kong and Shanghai women towards net friends, it is important to note that both groups of women found that the chatroom can be a dangerous place, and that they are conscious of the dangers lurking behind the use of chatrooms to communicate with strangers online. They take precautions to ensure that they are safe when communicating in cyberspace. However, Hong Kong women tend to be more adventurous than their Shanghai counterparts, with some saying that the 'mysterious identity' of the net friends provides them with a greater sense of adventure and excitement. Both groups of women tend to communicate more frequently with online male friends but with varying degrees of control over their cyber-communication, with Shanghai women tending to be more cautious.

To sum up: both Hong Kong and Shanghai women claim that the Internet provides an important virtual space in which to expand their friendship circles, but both also feel that online friendships are less certain than offline ones; and that the Internet is also a good avenue for negotiating sexuality.

\section{Conclusion: Beyond the Virtual Space}

Women's access and ability to use technology such as the Internet is significant in determining how they set agendas and reposition themselves in the $2 \mathrm{I}^{\text {st }}$ Century. We are witnessing a greater percentage of women users going online for various purposes - from simple tasks such as searching for information and knowledge to self-expression and the creation of cyber-communities - as they attempt to negotiate between the patriarchy and a newly created feminized cyber-structure. By embracing the Internet and the cyberspace, these women have accumulated significant socio-cultural capital and are creating a feminized virtual space for their use. However, it remains to be seen whether they will be able to institutionalize the cyber-structure and use it to restructure the social and gender relationships that have been embedded within our existing social structure. Will women be able to use their individual set of socio-cultural capital and transform it into collective sociocultural capital to usurp the existing social structure and recreate different sets of social relationships that are more gender friendly and egalitarian? Until then, their set of socio-cultural capital remains personalized enabling them to express and negotiate their identities and needs in their daily routine life. 


\section{Note}

I. An earlier version of this paper was presented at the Second International Conference on 'Chinese Women and Their Cybernetwork', organized by the Centre for Anthropological Research, University of Hong Kong, 20-2I October 2004. The author wishes to acknowledge the University of Hong Kong for a CRCG research grant that helped to fund this research. The author also wishes to thank her research assistants Huang Yedan, Jason Yip and Selina Wan for assisting in this research.

\section{References}

Adam, A. \& E. Green (I998), 'Gender, agency, location and the information society', in B.D. Loader (ed.), Cyberspace divide: equality, agency and policy in the information society, 83-97. London and New York: Routledge.

Adam, A. (I998), Artificial knowing: gender and the thinking machine. London: Routledge.

Adams, P. (I995), 'A reconsideration of personal boundaries in space-time', Annals of the Association of American Geographers 85 (2): 267-285.

Bourdieu, P. (I986), 'The forms of capital', in J.R. Richardson (ed.), Handbook of theory and research for the Sociology of education, 243. New York: Greenwood Press.

Castells, M. (200I), The Internet galaxy: reflections on the Internet, business, and society. Oxford: Oxford University Press.

Coleman, J.S. (I988), 'Social capital in the creation of human capital', American Journal of Sociology 94 (Supplement): 95-I20.

Constable, N. (2003), Romance on a global stage: pen pals, virtual ethnography, and "mail order" marriages. Berkeley: University of California Press.

Damm, J. \& S. Thomas (eds.) (2006), Chinese cyberspaces: technological changes and political effects. London and New York: Routledge.

Fletcher, B. (I999), 'Cyberfiction: a fictional journey into cyberspace (or How I became a cyberfeminist)', in S. Hawthorne \& R. Klein (eds.), Cyberfeminism: connectivity, critique and creativity, 338-35I. Melbourne: Spinifex.

Haraway, D. (I99I), 'A cyborg manifesto: science, technology and socialist-feminism in the late twentieth century', in D. Haraway, Simians, cyborgs and women: the reinvention of nature, I49-I82. London: Free Association Books.

Hawthorne, S. \& R. Klein (eds.) (I999), Cyberfeminism: connectivity, critique and creativity. Melbourne: Spinifex.

Hawthorne, S. (I999), 'Cyborgs, virtual bodies and organic bodies: theoretical feminist responses' in S. Hawthorne \& R. Klein (eds.), Cyberfeminism: Connectivity, critique and creativity, 213-249. Melbourne: Spinifex.

Herring, S. (1996), 'Posting in a different voice: gender and ethics in CMC' in C. Ess (ed.), Philosophical perspectives on computer-mediated communication, II5-I46. Albany N.Y.: Statue University of New York Press.

Kitchin, R. (1998), Cyberspace: the world in the wires. Sussex: John Wiley and Sons.

Klein, R. (I999), 'The politics of cyberfeminism: if I'm a cyborg rather than a goddess will patriarchy go away', in S. Hawthorne \& R. Klein (eds.), Cyberfeminism: connectivity, critique and creativity, I85-212. Melbourne: Spinifex.

Kuah-Pearce, K.E. (ed.) (2004), Chinese women and their social and network capitals. Singapore: Marshall Cavendish International.

Lee, M. (2006), 'What's missing in feminist research in new information and communication technologies', Feminist Media Studies 6 (2):I9I-210. 
LeVine, R.A. (1982), Culture, behavior, and personality: an introduction to the comparative study of psychosocial adaptation, $2^{\text {nd }}$ ed. New York: Aldine Publ. Co.

Lie, M. (1995), 'Technology and masculinity: the case of the computer', European Journal of Women's Studies 32 (3): 379-394.

Lin, N. (200I), Social capital. Cambridge: Cambridge University Press.

Loader, B.D. (ed.) (1998), Cyberspace divide: equality, agency and policy in the information society. London and New York: Routledge.

Morris, B. (1994), Anthropology of the self: the individual in cultural perspective. London and Boulder: Pluto Press.

Mu, Z.M. (2003), Ashes of love (Yiqingshu). Nanchang City: $2 \mathrm{I}^{\text {st }}$ Century Publisher.

Porter, D. (ed.) (1997), Internet culture. London: Routledge.

Portes, A. (1998), 'Social capital: its origins and applications in modern sociology', Annual Review of Sociology 24: I-24.

- (2000), 'The two meanings of social capital', Sociological Forum I5 (March): I-I2.

Rheingold, H. (1993), The virtual community: homestading on the electronic frontier. Reading: Addison-Wesley Publishing Company.

Tepper, M. (1997), 'Usenet communities and the cultural politics of information', in D. Porter (ed.), Internet culture, 39-54. London: Routledge.

Thiel, S. (2004), 'Shifting identities, creating new paradigms: analyzing the narratives of women online journalists', Feminist Media Studies 4 (I): 2I-36.

Thompson, M.E., K.A.Gómez \& M.S. Toro (2005), 'Internet audience perceptions of Feminist International Radio Endeavour (FIRE)', Feminist Media Studies, 5(2): 215-236.

Turner, V. (1967), The ritual process. Ithaca: Cornell University Press.

Wellman, B. \& C. Haythornthwaite (2002), The Internet in everyday life. Malden, MA; Oxford, UK: Blackwell Pub.

Wilbur, S.P. (1997), 'An archaeology of cyberspaces: virtuality, community, identity' in D. Porter (ed.), Internet culture, 5-22. London: Routledge.

Women and computing. http://archive.cpsr.net/program/gender/. [Retrieved 25 October 2005]

Yorgey, A. (200I), 'Bridging the gender gap: statistics of male and female British Internet users'. http://findarticles.com/p/articles/mi_hb3450/is_200IOI/ai_n8218150?cm_ven=YPI [Retrieved 25 October 2005] 



\title{
3 Agency and ICT among Singaporean-Chinese Women
}

\author{
JOHNSON Helen
}

\section{Introduction}

While enthusiasm for the social and economic potential of information and communication technologies (ICT) in the many countries that constitute 'Asia' is high, it has not led to access for a substantial number of people (Ang 200I; Castells 200I; Johnson 2003; Lee \& Khatri 2003). Access to ICT in Asia is often limited to private individuals from the higher income bracket working in universities, government, financial institutions, and businesses. Some scholars, in recent works, have commented on the relationship between 'development' and ICT as well as the perception that ICT automatically empowers women $(\mathrm{Ng}$ $\&$ Mitter 2005; Ong \& Collier 2005; Reddy 2007). There is also growing evidence of de-skilling, commodification of creativity, and co-implication into established labour relations amongst knowledge workers in information societies (Day 2007; McLaughlin \& Johnson 2007; Sullivan 2007).

However, Singapore provides a contrast to many Asian countries due to the diffusion of ICT access throughout its society, which is seen as resulting from strong infrastructure, education, political and commercial leadership of its centrally planned society, and the pragmatic-idealist ideology of many of its Singaporean-Chinese citizens. In the I990s the government launched programmes for the majority of its citizens to train office workers, to make computers available to those who did not have them in their home, and to provide computers at community clubs and via school-based programs (Gan 1997: 147; Johnson 2003). No programmes were targeted exclusively at women, men, or at minority groups. Rather, via budget allowances of SGD 600 million per year, they were designed to be available for all who wished to participate (Gan I997).

Singapore is seen in the region as providing a particularly constructive model of the ways that ICT can be integrated into a large community to create an information society. But when gender is used as an analytical prism can mere access to ICT actively challenge and change women's status and socioeconomic opportunities? And what opportunities are open to women to actively create social change via access to 
ICT? A case study of Singaporean-Chinese female employees' engagement with ICT via online resources in their workplace and at home, and how they assessed the benefits and dilemmas of ICT in their professional and personal lives, is presented here to explore these questions. The focus on female employees in one commercial enterprise is not to argue that 'Singaporean-Chinese women' should be considered a homogenous group but to investigate the interrelationship between ICT and Singaporean-Chinese women's practices. While Singaporean women do not necessarily self-identify as 'Chinese', and Singapore has a multicultural population, it is nonetheless numerically and politically dominated by people who recognize familial ancestry from 'mainland China'; hence, my informants are termed 'Singaporean-Chinese'.

Data from the case study suggested that the two key modes of engagement with ICT were word processing to create documents and reports, and access to the Internet to send electronic mail (email), pay bills, and to surf to gather information. The Internet in particular has gained considerable magnitude as a communicative and adaptive means of sharing and disseminating information (Castells 2004, 2007; Castells \& Cardoso 2006) via which many subject-specific networks of individuals and organizations, rallying around shared expertise and ideals, have grown. Hari Srinivas has argued that, due to the design and technology upon which computer networks function, they 'are fundamentally different from the current mass media of television, radio, newspapers and magazines. Computer networks encourage the active participation of individuals rather than the passive non-participation induced by television' (2004: I). Examples of the first generation of computer-mediated communications that have changed people's sociality are email, the World Wide Web, bulletin boards, and search engines. In the next generation, encompassing webcams, blogs and Youtube, people target their activities to avoid the excess information the Internet can provide; rather than 'surfing' for information their engagement is specific and structured (Ward in Silverstone 2005).

Past analyzes of gendered access to ICT in the United States (US) (MacKinnon I995; Miller I995; Wolf I998) have stirred debate in Asian nation-states about whether the Internet perpetuates regressive social structures or enables progressive female agency, have detailed the time and financial constraints that hinder women's access to ICT, and have argued that providing access to ICT is fundamental for women. Other studies have noted that because technological literacy has been defined generally as not being a part of women's daily competencies, vital questions need to be asked about whether ICT is yet another tool of masculinized social, economic and political power (Ghosh 2004; Hirose 1997; Joshi 1997; Lumby 1997). Post-2005 work has problematized women's access to and engagement with ICT (Barak in 
O’Toole et al 2007; Mazarella 2005; McKercher \& Mosco 2007), contending that 'ICTs in and of themselves will not necessarily transform gender relations, nor automatically empower women, as much also depends on the socio-cultural and political context in which they are being introduced' (Ng \& Mitter 2005: I5). In Singapore, despite the government's vigorous programme to place ICT in the hands of all citizens in the I990s, Su-Lin Gan (I997) asserts that the gender-marking of ICT as a male domain has been transferred to the Internet via gender-coded societal conditions. Hence, cultural ideologies and social attitudes about women's roles and capabilities also need to change in order for women to receive the full range of benefits accompanying ICT development.

\section{Singapore and ICT}

There are powerful local and regional discourses about Singapore's strength as a key component of the global knowledge-economy and as an example to which other nations in the region should aspire (Shamsul 2004: pers. comm.). With a population of 4,I08,000 and 2,247,000 Internet users, Singapore is a densely 'wired' Asian nationstate. Despite early strategies to censor ICT, with the support of Singaporeans (Ang \& Nadarajan I995), Open Net Initiative in 2007 proposes:

'Singapore's Internet content regulation depends primarily on access controls (such as requiring political sites to register for a license) and legal pressures (such as defamation lawsuits and the threat of imprisonment) to prevent people from posting objectionable content rather than technological methods to block it. Compared to other countries that implement mandatory filtering regimes that ONI has studied closely, Singapore's technical filtering system is one of the most limited.'

(http://www.opennetinitiative.net/studies/ singapore, retrieved 2I November 2007)

The number of websites in the country's .sg domain has risen from 900 in 1996 to more than I7,000. More than 40.8 per cent of adult Singaporeans are Internet users (NTU Singapore Internet Project Adult Survey 200I), and Internet use among women in Singapore has risen from a baseline of 46 per cent (http://unification.women.or.kr/ ehome/singapore.html, retrieved 2I November 2007). Singaporean women are generally at ease with the notion and practice of living, working, and playing in a highly technological society, and government poli- 
cies link to education strategies through the Ministry of Education and local community groups to ensure that technology remains a vital element of modernizing processes (Johnson 2003: 6I, 2007). Nonetheless, according to a South East Asia Regional Computer Confederation (SEARCC) survey, the rate of ICT specialization by gender is unbalanced, with men at 8 I.6 per cent and women at I8.4 per cent (www. scs.org.sg, retrieved 9 August 2004).

Women comprise almost 50 per cent of Singapore's population, were given suffrage at the same time as men, and are supported by Article Twelve of the Constitution which addresses equality of the sexes, wherein 'all persons are equal before the law and entitled to the equal protection of the law'. The Singaporean Government also endorsed the ASEAN Declaration on the Advancement of Women in I988, the Seven-Point Plan of Action in the Ottawa Declaration on Women and Structural Adjustment in I990, and the II-point Jakarta Declaration on Women in Development in I994. The Employment Act, Industrial Relations Act, and Trade Unions Act also accord equal employment rights to women and men. Indeed, the Singaporean Civil Service is one of the island-nation's largest employers of women at 5I per cent, while 20 per cent of the Civil Service's super scale officers are female.

Despite these positive steps towards gender equality, for which Singapore should be applauded, early studies of women's use of ICT noted that although women believed they enjoyed as much access to ICT as men, women did not agree they had access to equal training. Their perception was supported by the Asian Media and Information Communication Centre, which showed that 'although enrolment of female students had increased at most mass communication programmes, very few women had broken through to the ranks of senior management in media organizations' (Gan I997: I53). Gan contended that this occurs because the messages conveyed via ICT hardware and its use was not changing social values and attitudes about women (I997: I54-I55). As a consequence, she called for government initiatives that assisted in the democratization of women, provided greater educational opportunities, flexible working hours and sponsored day-care, and supported the benefits of telecommuting (Gan I997: 155), none of which have occurred. As a consequence, despite official claims that a cyberutopia exists in Singapore, specific issues arise in relation to women's place within it.

Notwithstanding the creation of an enabling infrastructure for its citizenry and educational policies that place Singapore at the forefront of ICT development and practice in Asia, Singapore's official culture has been judged as 'masculine'. The government is seen to reinforce patriarchal modes of thinking and practices, the official and dominant ideology is perceived to give primacy to economic productivity, and the patriarchal ideological bias honours cultural values of masculinity such 
as power, conflict, success, respect, and self-reliance. Although feminist values compete with the dominant patriarchal ideology and implicitly challenge its prevalence, in their struggle for equality women's groups are perceived as occasionally acting in ways that support the dominant ideology. For example, the mass media have established an image of the aggressive feminist but most women's groups have not tried to reclaim the ideals, image, and range of feminisms now open to women in modernizing societies. Also, specific government programmes designed to benefit women are often justified more broadly as contributing to economic growth, thereby muting the concept of women's specific and different needs and the ensuing political requirement to address them. In these ways feminist culture in Singapore challenges yet accommodates the dominant ideology via a strategy that Berlinda Nadarajan terms 'pragmatic feminism' (I997: I69).

\section{Conceptual Approach}

Social structures, institutions, and values such as norms, customs, rights, and laws link with economic institutions such as markets to shape relationships between 'women' and 'men', to form their socially expected roles, and to influence the resources to which women and men have access, what activities they can or cannot undertake, how they may participate in broader society and the economy, and their perceived status. Hence, social scientists have examined the ways that ICT may change modes of thinking as well as social practices. Annette Wong (2000), for example, shows how new ICT changes not only material reality but also the ways people think about reality, arguing that cyberspace not only connotes the possibility of transcending one's body but also provides a utopian space for transcendence to a higher state of being. Rohani Razak (I997) explores changes to modes of thinking via the creation of an index to Malay women's social consciousness, ascertaining how media technologies act to reinforce women's concepts of identity. Jayant Joshi (2004) examines the difficulties of ensuring that a range of people participate in digitally empowered development in India, and Rajora Rajesh (2002) concentrates on issues of access when considering the potential for social disadvantage that is exacerbated by ICT development. In the US, Susan Walsh (2005) explores how the Internet site, Blue Jeans Online, provides young girls with opportunities to negotiate, resist and/or reject dominant meanings relating to gender roles in societies, and Lynn Clark notes that teenage girls with access to message technology 'experience themselves as active agents in control of their environments and of their relationships with those who are important to them' (2005: 2I8). 
A focus on women and ICT has produced research that has assessed changes to women's status and their socioeconomic opportunities via the participation of women in computer science as a profession (Klawe \& Leveson I995; Spender I995), issues of access analyzed through the prisms of race, class and gender (Balka i996; Consalvo \& Paasonen 2002; Ebo 1998; Light I995; Taylor, Kramarae \& Ebben I993), the diversity of social interactions and their potential for the constitution of multiple identities (Cherny \& Weise I996; Consalvo \& Paasonen 2002; Kendall 2000; Winter \& Huff I996), the gendering of information systems (Adam 2005; Balka I997), issues of sexual harassment and online pornography (Cebulko 2007; MacKinnon I995; Miller I995; O'Toole et al 2007; Waskul 2004), and feminist historical analyses that have illuminated a range of concepts and actions missing from mainstream social studies of ICT (Cockburn \& Ormrod I993). Leslie Shade notes that a focus on women can pinpoint the relevant social actors and the gendered assumptions in the design, diffusion, and consumption stages of an ICT's life cycle (2002: 6) and highlights various women's active use of ICT for social change, support networks, and 'as a means of self-expression' (2002: 10).

Allucquère Stone (I995) and Sherry Turkle's (I995) work has focused on women's engagement with the Internet to consider how women experiment with identity, arguing they have a wider latitude to explore traditional or multiple identities than in 'traditional spaces'. Their approach suggests that the Internet can be understood 'as transformative spatiality where gender categories become reconfigured' (Consalvo $\&$ Paasonen 2002: 2). Conversely, technologically neutral or determinist positions that do not critically assess the social structures and cultures framing ICT have been critiqued for not analyzing differences between women and the particular sociocultural histories of women's daily practices. Mia Consalvo and Susanna Paasonen's edited collection (2002) is vital to questioning whether the Internet facilitates masculinized social, economic and political power. Alecia Wolf has highlighted how time and financial constraints for women in the US may hinder their ability to access the net outside working hours due to the double burden of women's domestic tasks and, if single mothers, the financial hurdles of hardware, software, and ongoing telecommunications charges (I998: 22). And Dorer (2002) has argued that because concepts of access are anchored in notions that men and women may become empowered in and through cyberspace, access is fundamental. Yet the gender marking of ICT as a male domain has been seen to have 'unconditionally transferred to the Internet' (Dorer 2002: 63) via gender-coded social conditions that 'gender' ICT and create gendered employment options that produce gender-differentiated 'access to the Internet' (Dorer 2002: 68). Recent literature suggests that detailed, con- 
text-specific analyses of women as 'empowered knowledge workers' in information societies are required (McKercher \& Mosco 2007). As a consequence, it is necessary to question whether access to ICT is sufficient for women to actively challenge and change their status and socioeconomic opportunities, and to enable women to create social change, in Singapore.

\section{The Research}

The case study was created from field work with a commercial organization in Singapore. The research examined what work practices involving ICT were required by the employing company; the ways female Singaporean-Chinese employees engaged with ICT for work and nonwork related issues in the workplace, and for work and non-work related issues at home; and whether and, if so, how they perceived their work status to have benefited by knowledge about and engagement with ICT.

A qualitative research methodology was employed using multiple methods such as in-depth interviews, informal conversations, short questionnaires, and 'quick ethnography' (Denzin \& Lincoln 2000; Handwerker 200I) in order to access as many informants in the time available for the research and to build a complex portrayal within the case study format. I conducted ten in-depth interviews using openended questions while five informal conversations eventuated from short-term friendly relationships that developed during the research and were conducted during coffee breaks, observing Chinese New Year celebrations, and enjoying lunch outside the work environment. The short questionnaires were designed for informants who wished to add further information, were not available to be interviewed during my field trip, or preferred not to take part in the discussions but wished to contribute unobtrusively in their own time. Of 35 distributed, eleven were returned.

The research was conducted with the Singaporean branch of an international public relations company. Although the company was originally a Singaporean company established by an Australian male, it had been purchased three years earlier by a transnational corporation. The company worked to retain a local identity however. It was located in a group of renovated shop-houses in Chinatown, retained much of the original façade, employed many Singaporean-Chinese staff, and engaged vigorously in the practices that were part of the Chinese New Year festivities being conducted at that time. Indeed, one day's interviews were delayed for three hours as we waited for the dragon that 
was bringing good luck to complete its dance outside the building and to wind its way through the numerous conjoined shop-houses.

All 26 informants were Singaporean-Chinese women and had access to ICT at their workplace and all, besides two, had access to ICT at home. The informants were predominantly aged between 20 and 35 . Of the 26 informants, five were paraprofessional in that they were skilled administrative assistants; 2I were educated to the tertiary level.

At work all the informants accessed ICT for word processing purposes to compile documents, reports and letters. While half the informants accessed the Internet up to fifteen times per day, one informant noted she accessed the Internet 'all the time' in short necessary bursts to access sites for information, images and statistics around which a marketing campaign could be built, but only spent approximately fifteen minutes per day on the Internet. The balance of the informants accessed the Internet less than ten times per day, but spent significantly longer in the Internet, researching up to two hours at a time. All tasks performed in the workplace were for the purpose of marketing research, and obtaining and retrieving information.

Personal access to the Internet also reflected the task orientation of the workplace. Informants surfed for consumer product promotions, travel information, to pay bills, to check account statements, to research information for personal use such as holiday destinations and hotels (often referred to as 'just surfing'), to check emails, to redeem purchases, and to obtain cinema and theatre tickets, and medical and pharmaceutical information. When, during interviews, I pressed for further details about what information they were researching, my informants told me it was issue specific, depending on what they needed to know at any particular moment. No informants told me in person, or via the questionnaire, that they had altered their gendered identity online during their work duties in order to achieve a more efficient outcome by self-presenting as male, nor had they altered their gendered identity online while accessing the Internet at home. This is significant as many US studies have investigated the way informants access the Internet to explore the cybersocial behaviours expected of a different gender, and/or to explore a different mode of sexual expression online to that usually presented in the informant's daily life (Campbell 2004; Millar I998; O’Riordan \& Phillips 2007).

Preference was a significant factor in accessing ICT, and particularly the Internet, at home. For example, four informants stated they preferred their husband or sons to access ICT at home to pay bills and obtain general information in a time efficient manner. Many informants articulated their capacity for active human agency, stating they preferred alternative tasks to 'working on the computer'. Three stated they were 'too tired' to access ICT and wished to embark on other tasks; as 
one informant averred, 'I do not arrive home until after $7 \mathrm{pm}$. We are all tired. It is easier for me to prepare dinner while my husband spends time on the computer. Also, I have not seen my children all day, and I want to spend some time playing with them'.

When asked whether my informants perceived their work status to have benefited from their access to ICT and particularly to the Internet, they were evenly split in their responses. Of the questionnaires four responded 'No', of the in-depth interviews four responded 'No', and in the informal conversations two responded 'No'. They perceived the Internet to be merely another information retrieval tool that was incorporated into their daily tasks. One informant in the questionnaire responded 'Not applicable' to the question.

The six informants who responded 'Yes' on the questionnaires wrote that their work status had benefited from access to ICT because they were learning about new things during their research, it was faster to obtain data on the Internet than to check it manually in a book, the Internet was an excellent tool for increasing knowledge and a great source of information, the Internet enabled a person to obtain up-todate data very quickly, and it allowed speedier access and promoted the accumulation of knowledge. The interviews portrayed how my informants were pragmatic in their perceptions of and access to ICT. They told me how access to ICT knowledge and hardware in their office space enabled them to upgrade their skills, which they perceived as beneficial for themselves and for the clients who enabled them to remain employed in a highly competitive commercial market. They did not access ICT to produce broader social and political change, nor did they network with other women. Primarily they accessed ICT for easily concluding domestic, personal and professional tasks, and as an extension of their professional capabilities. While my informants did not tell me that non-use of ICT was a deliberate 'choice' to resist the ways that new technology could encroach upon their personal space and time, they described their preference for activities they considered to be more important and enjoyable because they were conducted away from a computer screen and keyboard. For example, while younger informants engaged in many of the same activities as those described by Sharon Mazzarella for US teenagers (2005: I), those who lived in an apartment with their parents told me they preferred to watch television, attend the cinema, or go shopping - pastimes outside the work environment involving face-to-face social activities. Older women with children described how they preferred to prepare dinner if they did not have a maid, to play with their children if a maid was taking care of the domestic tasks, or to talk on the telephone with other family members such as parents and siblings, rather than 'sit in front of the computer'. 
Overall, the informants stated that the wealth of information that is easily accessible is the greatest benefit of access to ICT at work; ICT was perceived primarily as framing an information retrieval tool. While informants chose the Internet as a key mode to access information they were aware of its problems, judging that data are difficult to verify, that paradoxically the Internet's linking capabilities enable viruses to be fast-tracked through personal computers, that the Internet creates a dependence in the user as an 'effortless' source of information, and that it can be an intrusion into their personal space and time.

\section{What Insights Can Be Gained from the Data?}

The data provided insights into some Singaporean-Chinese women's access to ICT and specifically their engagement with the Internet. Despite the problematization of received ideas about the empowering nature of ICT, this group of Singaporean-Chinese women demonstrated that they are primarily pragmatic in their access to ICT. In contrast to US studies my informants did not suffer problems of access to ICT either at work or at home. Neither did they disclose that when engaging with the Internet they had made any changes to their gendered identity in order to achieve goals at work or home, to explore traditional or multiple identities, or to place their sexuality in play in the physically non-threatening arena of cyberspace. The Singaporean-Chinese women in this case study contrast with US studies in which informants face difficulties accessing ICT and, when they so do, (many work to transform their identity on the Internet.?) My informants' statements suggest they did not perceive the Internet to be an arena of 'transformative spatiality', as Stone's (I995) and Turkle's (I995) work proposes.

The case study did, however, generate three important issues. The first links to whether and how access to ICT and engagement with the Internet may challenge and change Singaporean-Chinese women's status and socioeconomic opportunities. Certainly there were limitations on online creativity generated by the women's predominantly paraprofessional status and the focused practicality of their tasks on the Internet at work. But my informants generally did not perceive access to ICT and engagement with the Internet to radically alter their status in the workplace. All informants focused on their workplace responsibilities and interwove personal use of ICT into their daily tasks. Although supervision was not overt they were aware that tasks needed to be completed by deadlines and those working in a direct relationship with a manager had to account for their time. However, although information-seeking is the most popular online activity for Singaporean users 
of the Internet generally, at 5.8 hours per week, with email second at 4.6 hours per week, and the majority of users content not to make any online transactions at home (http://www.ntu.edu.sg/sci/SIP/Summary, retrieved 2I November 2007), the in-depth interviews also suggested that women should not necessarily be categorized as 'victims' if they preferred not to access ICT in their home environment. Many informants preferred not to 'work on the computer' and strategically positioned themselves to gain the benefits of leaving computer tasks to their husband. The statement 'sometimes he'll pay my credit card charges' was followed by good-natured laughter, and supports Wazir Karim's contention that in Southeast Asia women use 'strategic bases for establishing human relations' and operationalize their culture in constructive, productive, complementary and nonconfrontational forms (I995: 20). The case study suggests that sociocultural factors such as active human agency, and the women's stated preference not to engage with ICT but to engage in more pleasurable social interactions, are crucial to women's ways of thinking about ICT and may be seen as unarticulated ways to resist ICT's encroachment into their personal space and time available outside working hours.

The second issue that arises is a potential critique of the pragmatism of this group of Singaporean-Chinese women in their lack of actively creating social change via their access to ICT. Consalvo \& Paasonen (2002), Dorer (2002), and Ng \& Mitter (2005) have argued that ICT can perpetuate regressive social structures and maintain gendered social conditions. The study suggests that my older, married informants exhibited a complex array of perceptions of gendered relations in their preferred activities in their homes. While older, married women are recognized as being less likely to use the Internet (http://www.nut.edu. sg/sci/SIP/Summary, retrieved 2I November 2007) my informants' articulation of 'preference' and their strategic thinking in relation to which family member would 'work on the computer' at home suggested they were optimizing their domestic relations in ways that enabled them to juggle fulltime work, childcare and domestic duties (albeit some with the assistance of a domestic worker).

Nonetheless, it can be argued that a gendered division of labour is operating in the home and women are shouldering the multiple responsibilities of paid work and unpaid domestic tasks. As Nadarajan proposes, the demands of unlimited access to ICT and long days at work exact a high cost from Singaporean women, who despite having made strides in education and earning power, 'still shoulder the bulk of the task of taking care of the home and raising children' (Yim \& Ang I997: I74). Despite the passing of the Women's Charter (Amendment) Bill 1996, which sought to give greater consideration to women's nonfinancial contribution to the family, Singapore has not fully ad- 
dressed the workload issues of working mothers (Nadarajan I997: I74). The informants' responses linked with the NTU survey, which states two of the most frequent reasons given for not using the Internet were 'no time' and 'no interest' (http://www.ntu.edu.sg/sci/SIP/ Summary, retrieved 2I November 2007). My informants' 'preference' not to access ICT in their home following a busy day's work may well be an act of human agency in terms of ensuring that the burden of labour at work and in the home is shared, and that their preferences are acknowledged. Equally, it must be recognized that their 'preferences' fall within socially appropriate ideals of 'women's work' in the patriarchal ideologies that shape Singaporean society. While pragmatism and agency are operating in my informants' decisions about access to ICT, it can be argued that their access is not producing major positive structural changes to women's overall status and socioeconomic opportunities in Singaporean society, nor are women actively creating social change.

It is noteworthy that none of my informants stated they accessed ICT and engaged with the Internet to network for political purposes. This disparity in relation to research from the US suggests that the third issue generated by the case study is my informants' preference to access ICT as a tool to achieve workplace goals and to complete domestic tasks rather than as a tool to network for political change in the centrally planned and well-monitored society of Singapore. There is a strong argument internationally that women should be more involved in the development of ICT and the Internet in particular, not only for themselves, but also to mould a promising medium with gender sensitivity. It is suggested that partnerships need to be developed to constitute a justly gendered Internet, where women have access to the wealth of information which resides on the Internet in the form of news, research, information exchange, debate, communication and the intellectual growth and stimulation which interaction with new technology brings. However, my Singaporean-Chinese informants accessed ICT only for its benefits as a practical tool, and engaged with it as one of an array of activities. Their passive resistance manifested in their preference not to use ICT in their personal space and during their non-working time, and to engage in activities away from the computer. As Singaporean-Chinese people recognize themselves as pragmatic and will opt for lesser political freedom in order to maintain high social and economic stability, my informants situated themselves within the broader social constraints of patriarchal Singaporean society, an approach that is reflected in the pragmatic feminist political strategies of Singapore. 


\section{Women and the Future of Cyberculture}

Globally, women's access to ICT is increasing as more women are engaging with online electronic tools such as email, instant messaging, mailing lists, the Web, blogs, and YouTube and are encouraging other women to so do. ICT is an evolving medium and it has proven its ability to educate and raise awareness on a global scale (Shade 2002). Women are building and sharing online resources that are women-focused, while others repackage online information for those without access. New ICT facilitates increased opportunities to obtain abstract information and to network socially (Clark 2005). But women have both negative and positive experiences of ICT at work and at home (Srinivas 2004), not only because much product design and content is dominated by and for men but also, as this study shows, women work and live within patriarchal social constraints.

The case study suggests that when gender is used as an analytical prism access to ICT is insufficient to actively challenge and change women's status and socioeconomic opportunities beyond providing a speedier process of information retrieval, and that opportunities for women to actively create broader social change via access to ICT are limited. Some of my informants perceived that access to ICT enhanced their work capabilities. However, because many occupied supervised paraprofessional positions and older informants with families juggled the double burden of paid work and unpaid domestic labour, the case study also suggests that women's engagement with ICT's potential is shaped by broader sociocultural constraints.

Yet, as Ng and Mitter argue, if women 'do not engage with the information society in its formative years, women's voices will not be heard in the future [and] women's active involvement is essential to ensure that a plurality and diversity of views are accepted in the information society [to promote] gender equity' (2005: I0). Singapore shows how a key to overcoming the barriers, shortcomings and misconceptions of women's participation in ICT development resides in the comprehensive education of women, the promotion of equal access for young women to scientific and technological arenas, the provision of opportunities for increased technological training, and the strengthening of decision-making in women's roles. But governments must also legislate to enable equal access and opportunity for all via their policies and programmes and more broadly in the private sector and the larger civil society so that social attitudes, cultural ideologies, and gender stereotypes can be changed. By partnering local communities with progressive feminist women's groups, strategic and practical engagement with ICT can be encouraged, a gender-sensitive development of online information content can be facilitated, relevant information and online content 
can be produced, managed and delivered appropriately, and further lobbying and advocacy for a change in attitudes and approaches to women can also occur.

Additionally, Srinivas (2004) recommends the development of a series of 'gender information systems' that address the issues of gender imbalances and serve as a gender database for women's groups, providing specific information on women's groups, statistics, gender policies, programmes, projects and plans. Such a network, he proposes, could provide tools in the form of practical ideas, guides, strategies, courses and methodologies; success stories in the form of case studies, comparisons, inspiring ideas, and best practices; articles in the form of theoretical and practical analyses of the issues of interest; and resources in the form of organizational and operational information on current policies, programmes, projects and other initiatives.

While the research in Singapore adds empirical detail about Singaporean-Chinese women's social practices to broader theoretical debates about gender and access to ICT, it also provides a springboard for future investigations into the ways that social interactions with ICT are shaped by gendered and crosscultural difference. For women's capacity to make choices about how they manage their time, how they access and engage with ICT, and ICT's importance in their lives relative to other ways of being must also be recognized. Balancing the opportunities offered by ICT with the time, energy, and knowledge required to engage with it is important, particularly when discussing how and why women may best work with new ICT. We may then see Singapore as a gender-sensitive model to be emulated, while adjusted with cultural sensitivity to the needs of women in the Asian region.

\section{References}

Adam, A. (2005), Gender, ethics and information technology. New York: Palgrave Macmillan.

Ang, I. (200I), 'Desperately guarding borders: media globalization, "cultural imperialism", and the rise of "Asia", in S.C. Yao (ed.), House of glass: culture, modernity, and the state of Southeast Asia, 27-45. Singapore: Institute of Southeast Asian Studies.

Ang, P. \& B. Nadarajan (I995), 'Censorship and the Internet: a Singapore perspective'. http://www.isoc.org/HMP/PAPER/I32. [Retrieved 2I November 2007]

Asia Pacific Women's Information Network Center (2007), http://unification.women.or.kr/ ehome/singapore.html [Retrieved 2I November 2007]

Balka, E. (I996), 'Women and computer networking in six countries', The Journal of International Communication, July: 66-84.

- (I997), 'Participatory design in women's organizations: the social world of organizations structure and the gendered nature of expertise', Gender, Work and Organizations, 4: 99II5. 
Barak, A. (2007) 'Sexual harassment on the Internet' in L. O’Toole, J. Schiffman, \& M. Kiter Edwards (eds.), Gender violence: interdisciplinary perspectives, I8I-I94. New York: New York University Press.

Campbell, J. (2004), Getting it on online: cyberspace, gay male sexuality, and embodied identity. New York: Harrington Park Press.

Castells, M. (2007), Mobile communication and society: a global perspective: a project of the Annenberg research network on international communication. Cambridge, Massachusetts: Cambridge University Press.

- (ed.) (2004), The network society: a crosscultural perspective. Cheltenham, England: Edward Elgar.

— \& G. Cardoso (eds.) (2006), The network society: from knowledge to policy. Washington, DC: Center for Transatlantic Relations, Paul H. Nitze School of Advanced International Studies, Johns Hopkins University.

Cebulko, S. (2007), The impact of Internet pornography on married women: a psychodynamic perspective. Youngstown, New York: Cambria Press.

Cherny, L. \& E. Weise (I996), Wired women: gender and new realities in cyberspace. Seattle, WA; Seal Press.

Clark, L. (2005), 'The constant contact generation: exploring teen friendship networks online' in S. Mazarella (ed.), Girl wide Web: girls, the Internet, and the negotiation of identity, 203-222. New York: Peter Lang.

Cockburn, C. \& R. Furst-Dilic (eds.) (I994), Bringing technology home: gender and technology in a changing Europe. Buckingham, England; Philadelphia: Open University Press.

— \& S. Ormrod (I993), Gender and technology in the making. London: Sage.

Consalvo, M. \& S. Paasonen (eds.) (2002) 'Introduction: on the Internet, women matter' in Women a everyday uses of the Internet: agency and identity, I-IO. New York: Peter Lang.

Day, W. (2007), 'Commodification of creativity: reskilling computer animation labor in Taiwan' in C. McKercher \& V. Mosco (eds.), Knowledge workers in the information society, 85ıоo. Lanham, Rowman \& Littlefield Publishers, Inc.

Denzin, N. \& Y. Lincoln (eds.) (2000), Handbook of qualitative research. Thousand Oaks, California: Sage Publications.

Dorer, J. (2002), 'Internet and the construction of gender: female professionals and the process of doing gender' in M. Consalvo \& S. Paasonen (eds.), Women and everyday uses of the Internet: agency and identity, 62-89. New York: Peter Lang.

Ebo, B. (ed.) (I998), Cyberghetto or cybertopia?: race, class, and gender on the Internet. Westport Connecticut, London: Praeger.

Gan, S. (I997), 'Singapore: empowerment or impediment?’ in I. Joshi (ed.), Asian women in the information age: new communication technology, democracy and women, 143-168. Singapore: Asian Media Information and Communication Centre.

Ghosh, J. (2004), 'Globalization and economic empowerment of women: emerging issues in Asia', at the Beijing Platform for Action, UN-ESCAP, 7-Io September 2004.

Handwerker, W. (200I), Quick ethnography. Walnut Creek, CA: AltaMira Press.

Hirose, Y. (I997), 'Japan: equalizing opportunities', in I. Joshi (ed.), Asian women in the information age: New communication technology, democracy and women, 87-96. Singapore: Asian Media Information and Communication Centre.

Johnson, H. (2003), 'Gender, technology, and the potential for social marginalization: Kuala Lumpur and Singapore', Asian Journal of Women's Studies, 9 (I): 60-79.

Joshi, J. (2004), 'People's participation in digitally empowered development: challenges and initiatives', at the Second Biennial Conference of the Indian Association for Asian and Pacific Studies, January 2004 .

Karim, W. (ed.) (I995), 'Male' and 'female' in developing Southeast Asia. Oxford, Washington DC: Berg Publishers. 
Kendall, L. (2000), ' “OH NO! I'M A NERD!”: hegemonic masculinity in an online forum' in Gender and Society, I4: 256-274.

Klawe, M. \& N. Leveson (I995), 'Women in computing: where are we now?', Communications of the ACM, 38: 29-35.

Lee, I. \& Y. Khatri (2003), Information technology and productivity growth in Asia. International Monetary Fund Working Paper, WP03/15.

Light, J. (I995), 'The digital landscape: new space for women?', Gender, Place and Culture, 2: I33-I46.

Lumby, C. (1997), Bad girls: the media, sex and feminism in the '9os. Sydney: Allen \& Unwin.

MacKinnon, C. (1995), 'Vindication and resistance: a response to the Carnegie Mellon study of pornography in cyberspace', The Georgetown Law Journal, 83 (June): I959-1967.

Mazarella, S. (ed.) (2005), Girl wide Web: girls, the Internet, and the negotiation of identity. New York: Peter Lang.

McKercher, C. \& V. Mosco (eds.) (2007), Knowledge workers in the information society. Lanham, Rowman \& Littlefield Publishers, Inc.

McLaughlin, L. \& H. Johnson. (2007), 'Women and knowledge work in the Asia-pacific: complicating technological empowerment' in C. McKercher \& V. Mosco (eds.), Knowledge workers in the information society, 249-268. Lanham, Rowman \& Littlefield Publishers, Inc.

Millar, M. (I998), Cracking the gender code: who rules the wired world. Toronto: Second Story Press.

Miller, L. (I995), 'Women and children first: gender and the settling of the electronic frontier' in J. Brook \& I. Boal (eds.), Resisting the virtual life: the culture and politics of information, 49-57. San Francisco: City Lights.

Nadarajan, B. (1997), 'Singapore: pragmatic feminists?', in I. Joshi (ed.), Asian women in the Information Age: new communication technology, democracy and women, I69-178. Singapore: Asian Media Information and Communication Centre.

Nayang Technological University (2007), http://www.ntu.edu.sg/sci/SIP/Summary [Retrieved 2I November 2007]

Ng, C. \& S. Mitter (eds.) (2005), Gender and the digital economy: perspectives from the developing world. New Delhi, Thousand Oaks, London: Sage Publications.

Ong, A. \& S. Collier (eds.) (2005), Global assemblages: technology, politics and ethics as anthropological problems. Malden, Massachusetts: Blackwell Publishing.

Open Net Initiative (2005) Internet filtering in Singapore in 2004-2005: a country study. http:// www.opennetinitiative.net/studies/singapore [Retrieved 2I November 2007]

O’Riordan, K. \& D. Phillips (eds.) (2007), Queer online: media technology a sexuality. New York: Peter Lang.

O’Toole, L. \& J. Schiffman, \& M. Kiter Edwards (eds.) (2007), Gender violence: interdisciplinary perspectives. New York: New York University Press.

Rajesh, R. (2002), Bridging the digital divide: gyandoot the model for community networks. New Delhi: Tata McGraw Hill.

Razak, R. (1997), 'Malaysia: reinforcing women's social consciousness and identity', in I. Joshi (ed.), Asian women in the information age: New communication technology, democracy and women, I23-128. Singapore: Asian Media Information and Communication Centre.

Reddy, C. (2007), 'Plant tissue culture industry and women's participation: "nimble fingers" or docile labor?', Gender, Technology and Development, II: I79-198.

Shade, L. (2002), Gender and community in the social construction of the Internet. New York: Peter Lang.

Shamsul, A.B. (2004), Personal communication at the Monash Asia Institute RUCTA Conference, Mumbai, India, February 2004.

South East Asia Regional Computer Confederation. www.scs.org.sg [Retrieved 9 August 2004] 
Spender, D. (1995), Nattering on the net: women, power and cyberspace. Melbourne: Spinifex Press.

Srinivas, H. (2004), 'Internet and online networking' in Online Technology and Networking Some Gender Perspectives. http://www.gdrc.org/gender/ait-paper.html [Retrieved I3 January 2008]

Stone, A. (1995), The war of desire and technology at the close of the mechanical age. Cambridge: MIT Press.

Sullivan, J. (2007), 'Marketing creative labor: Hollywood "making of' documentary features"' in C. McKercher \& V. Mosco (eds.), Knowledge workers in the information society, 69-84. Lanham, Rowman \& Littlefield Publishers, Inc.

Taylor, J. \& C. Kramarae, \& M. Ebben (eds) (I993), Women, information technology, and scholarship. Champagne-Urbana: Centre for Advanced Study, University of Illinois.

Turkle, S. (1995), Life on the screen: identity in the age of the Internet. New York: Simon and Schuster.

Walsh, S. (2005), 'Gender, power, and social interaction: how Blue Jeans Online constructs adolescent girlhood' in S. Mazarella (ed.). Girl wide Web: girls, the Internet, and the negotiation of identity, 69-84. New York: Peter Lang.

Ward, K. (2005), 'Internet consumption in Ireland - towards a "connected" domestic life' in R. Silverstone (ed.), Media, technology and everyday life in Europe: from information to communication, I07-I24. London: Ashgate Publishing.

Waskul, D. (ed.) (2004), Net.seXXX: readings on sex, pornography, and the Internet. New York: Peter Lang.

Winter, D. \& C. Huff (1996), 'Adapting the Internet: comments from a women-only electronic forum', The American Sociologist, 27 (I): 30-54.

Wolf, A. (1998), 'Exposing the great equalizer: demythologising Internet equity' in B. Ebo (ed.), Cyberghetto or cybertopia?: race, class, and gender on the Internet, I5-32. Westport Connecticut, London: Praeger.

Wong, A. (2000), 'Cyberself: identity, language and stylization on the Internet' in D. Gibbs \& K. Krause (eds.), Cyberlines: languages and cultures of the Internet. Albert Park, Victoria: James Nicholas Publishers Pty Ltd.

Yim, S. \& S. Ang (1997), 'Income trends: the gender income gap', Singapore Statistics Newsletter, I9: 3 . 



\title{
4 Can the Internet Help? How Immigrant Women from China Get Jobs
}

\author{
A Survey on PRC Immigrants' Employment Status in \\ Canada ${ }^{1}$
}

\author{
GREVE Arent Q SALAFF Janet
}

\section{Introduction}

This chapter studies how the Internet can ease access to skilled jobs for Chinese women immigrants in Canada and where it fails. Labour markets develop mechanisms that segment the working populace into those who are seen as more and less worthy of the good jobs. Gender and the attribution of who are indigenous or intruders are key divisions between contenders for prime positions. In North America, entrenched divisions between women and men, immigrants and locals, are accompanied by definitions of who possess the required characteristics for job holders. With the pay, prestige, and culture of jobs differing, good jobs are contested by means of definitions of who is worthy. Institutional theory conjectures that these rationales are socially constructed, shared beliefs that are not questioned. Newcomers on the block, especially women immigrants, fail to get good jobs because they fit poorly into the institutional environment. They do not have the power to cross the boundaries into the desirable jobs.

A number of writers posit how the Internet can break through the institutional allocation of gender roles and work roles. Post modernist theory claims that through the need for new information, the knowledge society flattens traditional hierarchies and rigid subjectivities underlying gendered and racialized jobs and restructures the institutional order (Bell I973; Castells I996; Webster 2005). Some writers posit that the Internet builds networks and can create new forms of useful contacts, or social capital. They contend that most immigrants lack information about the new country and they do not have much social capital. Caidi and Allard (2005) maintain that access to the Internet can help them build social networks. However, there are indications that the Internet does not change the old order (Gamba \& Kleiner 200I) and most of the so-called networking websites build their connections 
on existing social relations so that immigrants will face the same problems on the Internet that they face in real life. Most networks form around similar others (Ibarra I992; McPherson et al. 200I). We argue that the Internet affects social structures indirectly by enabling job seekers to apply in ways that minimize control of gatekeepers. Gatekeepers to jobs are part of the gendered and racialized segmented labour force, and we posit that the Internet can help reduce the gate keeping effects through randomness in screening from large numbers of applicants.

This topic has immense practical relevance. Canada and other advanced nations court skilled immigrants that come from the leading industrial sectors in large cities of rapidly developing nations, hoping to further their careers in their highly specialized fields. As a settler country which values immigrants as a key contributor to its demographic and economic well-being, Canada accepts and absorbs large numbers through a liberal naturalization policy and a relatively open political system. Citizenship and Immigration Canada applies a point system to assess skilled worker immigration applications. An applicant needs 70 points, which can be earned by education, language fluency, job experience, and having Canadian kin. In practice, they usually have a university degree and some professional job experience. Over 80 per cent of Mainland China immigrants applying since I999, enter in the Economic Class, consisting of skilled workers and investment classes (Li 2004). (http://www.cic.gc.ca/English/skilled/) Immigration is the key in expanding Canada's workforce and investment capital. In 200I, eighteen per cent of the Canadian population was foreign born (Citizenship and Immigration Canada 2003) and the proportion has since grown. The 2006 Census from Statistics Canada set the percentage of foreign born to I9.8. Yet Canada has not eased immigrant access to the labour market for those with international education. Educated women and men from the People's Republic of China (PRC) count among the largest waves of new immigrants to Canada. With their credentials and their experiences unrecognized, newcomers face great difficulties in acquiring well-paying professional jobs at the same level as before they emigrated (Bauder 2003; Li 2000, 200I; Pendakur \& Pendakur I998; Reitz 200I; Salaff \& Greve 2006). Despite their past record as China's elite, their employment record in Canada is dismal. Given these constraints, ways to give new immigrants the same chance to get jobs as locals are sought after.

We turn to our theoretical framework on the links between hiring and the Internet, and describe the methods of our study. We then look at the results of our study by providing a statistical analysis of a Webbased survey of 303 recent PRC immigrants to Toronto, complemented with interviews from a sub-sample of 28 survey respondents. 


\subsection{The Institutionalization of Labour Markets}

Labour markets are highly institutionalized with unquestioned, taken for granted rules. Newcomers need to learn and confront these rules in order to land jobs. Two key institutional components of the system for hiring professional and skilled labour greatly affect women immigrants from China. First are the rules that require local certification and practice for qualified candidates to be deemed appropriate for the job. Immigrants selected on the point system are trained within their profession in their country of origin. When their credentials are not accepted, immigrants have difficulties getting jobs within their professions (Li 200I). Second is the gendered stratification system which differs in each country. Hence, their training in work roles considered female in China may be ill suited to Canadian work roles. Given these encumbrances, job search methods cannot solve institutional discrimination against immigrant professional women. They can, however, ease immigrant women's way through these institutions. Below we suggest how the Internet offers advantages in getting around institutional discrimination.

\subsubsection{Professions and Certification}

In Canada specialized professions in each province have assumed control over whom to hire. The professions guard entrance to jobs, set numbers and selection mechanisms with government compliance. Credentials become an institutionalized sorting mechanism (Collins I979). These rules presuppose Canadian training, which hampers the job search and requires retraining of new immigrants (Leung 2000; Mwarigha 2002). Although the Canadian government restructured the immigration system to encourage international talent, it has not restructured the institutionalized system based on professional control over hiring workers. The outcome largely excludes those with a foreign education, regardless of gender.

Institutional theory views schools as instruments that enable allocation of labour. Schools produce occupational distinctions that indicate social categories (Meyer I977). Credentials confer status as much as skills, and the content of the education becomes less important than status conferral. Consequently, people view education and training as instruments to get jobs, not as skills to do the job (Fevre et al. I999). Credentialism sees investment in education as a way of obtaining higher paid jobs and positions not because of higher productivity, but as a result of the higher educated people's control over access to these positions (Collins I979). Job matching becomes a signal processing activity. To employers, credentials are signals to pick job applicants. Job seekers manipulate signals to get attention from people who hire (Spence 
I973). Signals that conform to institutionalized jobs make matching relatively simple.

An institutional structure has several social categories that actors perceive in similar ways. Employers interpret signals within coarse categories, as gender, ethnicity, social background, educational credentials and experience. They are less able to distinguish variations within each attribute (Tilly I998). Weiss (I995) claims that educational credentials give employers a host of correlated signals that they look for when hiring people. These signals are not only related to professions but also attached to the institutions that educated them and their social background. There are also behavioural expectations connected to people with higher education. Education socializes people into work roles that also correlates with social expectations. Indeed, from the perspective of the immigrants who must re-credential in order to qualify for consideration, the function of the credential is entirely in legitimization.

The credential is a manifestation of the overall appearance or social construction of the ideal candidate. Rarely are professional applicants required to demonstrate their actual skills for these positions. Instead, certain indications, appearances, symbols in a resume, are taken to be evidence that a person can do the job. Put more generally, the candidate gives off signals, and the employer chooses the candidate from those giving off the proper signals. Those without information about or ability to give off the right signals are presumed unworthy of consideration.

\subsubsection{Signaling and Screening}

The norms of the Canadian labour market resemble a set of rules that guide allocation of jobs. Employers need ways to assess whether candidates for jobs have the appropriate skills. Because they cannot easily distinguish people's actual skills, employers fall back on a range of conventions to discern the ability to do the work and other qualities (Bills 2003; Weiss I995). They rely on the signals given off and interpreted, of which education is a priority. An institutionalized labour market has a predefined set of beliefs of the suitable jobs for people with various types of education. When newcomers do not give off familiar signals about their education and training in other lands, employers suspect that their schooling is not good enough. Next, employers also rely on signals about the social background of job applicants, even more than on signals about appropriate education and experience (Rosenbaum et al. I990). These include other background data, such as class, culture or immigrant status (Bourdieu I983). As a result, these conventions serve as cultural means to distinguish between Canadian and immigrant job seekers (Bauder 2005). Employers rarely question the institutional frame of reference and its well established screening methods 
they use to interpret signals. Usually they interpret signals through the prism of their own ethnic and social groups, finding immigrants unsuitable (Henry \& Ginzberg I985). Immigrants are likely to send signals that have negative values. Their accented English and lack of readily recognizable academic accreditation and work experience signal their outsider status to employers, who cast them as unable to hold responsible positions because they signal a lack of the proper cultural background (Bauder 2005; Pendakur \& Pendakur i998; Tomlinson \& Egan 2002).

\subsubsection{The Gender Stratification System}

These social categories also include beliefs about suitable jobs for women. Labour markets are stratified by gender and social class. In each country, the gender stratification system distinguishes jobs for women and men in historically constructed ways. Where Chinese and Canadian gender role stratification vary, immigrant women face problems presenting themselves as qualified for jobs.

In China, from the I950s through the I980s, following the Soviet model, there was an overriding pressure on all out production which focused on the production of heavy industrial goods, and drew women into the industrial labour force. The state's promotion of women's rights reduced gender gaps in job mobility (Cao \& Hu 2007). Women's public presence challenged gendered conceptualizations of workplace, technological competence, and proletarian identity (Chen 2003). Gender stratification differed by specific fields. State policies encouraged women to engage in traditionally male professions like tractor driving or engineering. Highly valued, many women and men certified. Medicine was seen as less productive, and less money was put into its development. Less valued, females dominated its rank and file.

In contrast, educated North American women mainly fill jobs that are human relations or people oriented. They also may focus on clerical and paper work and manipulate symbols (Baron \& Newman I990; Bielby \& Baron I986; McKeen \& Bu 2005). Whereas Canadian women are seen suited for humanistic and people-oriented jobs, especially in the human relations field, this is not the case for Chinese immigrant women with the same degrees. Employers view immigrants as unsuitable for the people-oriented jobs of managers because they are unfamiliar with Canadian culture. Sophisticated machines also give prestige in North America, but they are male controlled. Engineers and the specialist physicians are mainly indigenous males (McKeen \& Bu 2005). The gender definition of the supporting tiers of technicians depends on the occupation. Machinist industries are male-dominated, both women and men enter chemical and computer technician jobs, while medical support technicians are mainly female or immigrant labourers 
(Salaff \& Greve 2003). Consequently, many immigrant women send signals that are inappropriate for the jobs they seek, regardless of having qualifications. They need to find ways to override these signals to get a hearing.

\section{Ways of Searching for Jobs}

The job seeker needs to locate a job that uses her education. She can recast neither the power of the professions to control entry nor the gender stratification system that channels women and men to different positions, stereotyping what immigrants can do. Confronted with institutionalized gatekeeping, she must minimize the control over access to positions or the gatekeepers' power to mischaracterize her. Her only area of control she has is finding an approach that presents her in the best light. To begin with, she needs to learn about available jobs, in itself not easy. Next, she needs to apply in ways that avoids being disregarded because she gives off the wrong signals: being foreign and being female. The use of the Internet makes a difference.

The Canadian institutional system encourages immigrants to integrate in the political sphere (Bloemraad 2005), but in the job area support is decentralized and undeveloped. There is no uniform, national Canadian job registry. When they search for a job, new immigrants turn to decentralized and fragmented organizations. Their job search becomes random. There is state recognition that finding work requires a learning process in many ways. Yet, there is little economic support to re-qualify. Learning language skills is up to them. They take English as Second Language (ESL) courses, upgrade their education, attend job hunting and resume writing workshops where also some employers post job vacancies. These sources of job information are low cost but not backed by economic incentives and not integrated overall. In this decentralized setting, the Web could widen circles of information for job seekers, employers or agents, past the narrow circles of those they know.

People take paths to find a job, which reveal key institutional features of labour markets. Paths refer to the institutionalized, common and appropriate ways to learn about the existence of a position and to announce to employers one's availability and suitability to fill a vacancy. Paths differ by the occupation, sector, level and location, whether within a country or internationally. They differ in China and Canada, and consequently how people get jobs is structured in a different manner. They also differ by the stage in a person's life.

The two main paths to jobs in Canada are social capital and the Internet, each of which conveys diverse information about the job see- 
kers. Each path sends different signals that employers consider relevant to employment. Additionally, there are employment agents, job fairs, newspaper ads, and walk-ins, which we will not dwell on in this chapter.

Paths convey information, or signals, about job candidates. We distinguish sparse signals and rich signals. Sparse signals give basic information to evaluate candidates, which for skilled workers are credentials, type of education and job experience. Rich signals give additional information on the background of the applicants, such as social class, identity, ethnicity, and gender. These signals do not provide clear unambiguous information about whether or not the person can do the job. Nevertheless, employers use them to determine whether or not the person is likely to fit in. Immigrants' signals that do not conform to institutional expectations deter their employment. In the following section we describe how signals enter these paths to jobs, and the problems signals create for these new immigrants in using social capital, and how the Internet operate on sparse signals and large numbers.

\subsection{Social Capital}

Social capital refers to people's direct and indirect contacts and the social networks that help them reach their goals. Here, it refers to the contacts that help people get a job (Granovetter I974; Lin 200I). Of all the job paths, social capital carries the richest information about the job searcher. It includes signals about the person's attachments to organizations, knowledge of particular others, and cultural milieu (Bourdieu I986). It also indirectly provides information about the social fields to which they belong. Their association with others lends credibility to a person's consideration for a job. However, the status of contacts tends to determine the level of jobs they can mediate. Immigrants' contacts rarely reach into the mainstream professional job market.

In the context of the immigrants' job search, most important for job attainment are their contacts and reputation that reach into the realm where they seek a job (Lai et al. I998; Podolny \& Baron I997). Contacts mediate about 40 per cent of all jobs (Hadass 2004; Hagtvet 2005). Through their selected networks people make available information of job openings that are not widely known (Granovetter I974). Some act informally as brokers to connect job seekers to jobs (Bian I997; Cheung \& Gui 2006). Antcliffe, Saundry and Stuart (2007) learned that for professionals open and closed networks serve different functions. Open networks with weak ties are more effective in providing jobs, whereas closed networks cater to professional needs. 
Immigrant women lack social networks to attain jobs. For one reason, social capital's reach is gender specific. Whereas women's networks help them in their family work, men's social networks more effectively link them to work spheres. Many find that immigrant women do not have the same number or reach of social networks as men (Stoloff et al. I999; Wellman I992). For another reason, the specialized jobs which female professionals vie for are reputation based. They involve manipulating symbols and human relations and presuppose trust. To hear about vacancies, one's networks must reach directly into firms, and people's contacts need to be willing to share insider news about vacant jobs. Well-placed contacts are more able to transfer information about good jobs than poorly placed people. Their suggestions about the candidate are taken more seriously (Fernandez \& FernandezMateo 2006). The value of social capital is therefore contingent. People's connections can only help them get a job in the sectors in which their networks are embedded. Social networks are not better than their reach, and most immigrants' social networks at most reach into the ethnic enclave.

Social capital has been praised as the solution to immigrants' job problems. Some maintain that immigrants do better by using their social capital to get positions in the ethnic enclave (Portes \& Jensen I989). Being able to call attention to their cultural attributes may hinder the immigrant's job integration, but these attributes call attention to her belonging to those who want to fill cultural needs of their immigrant groups. Others may want to promote their immigrant group's well being. Nevertheless, most professionally trained PRC immigrants desire mainstream jobs, and for these, their ethnic based social capital is inefficient (Salaff \& Greve 2006).

Lack of social capital that bridges the social fields of their profession is a main problem in immigrants' getting jobs. It is particularly problematic for this latest wave of the Chinese Diaspora. Their lack of useful contacts to suitable professional jobs flows from their distinct cultural history. Whereas, since the I96os, Hong Kong and Taiwan supplied middle class immigrants to Canada, due to the cold war, PRC immigration was largely dormant. But immigration intake soon changed dramatically. By I996, Canada had opened its door to those Chinese who could meet its strictures as economic immigrants. At the same time China allowed them to exit, and it's growing middle class motored a diasporic wave (Zweig \& Chen I995). The people that answered our survey are part of that flood. Due to the broken waves of immigrants from China, they arrived as individuals, having heard of immigration by word of mouth, the Web, or from private immigration agencies. They had few established friends in Canada. 
To get good jobs through social capital, they need contacts with good positions themselves (Lin 200I). Knowing no one to give them leads to good jobs, some contacted others they heard about, but they were not well placed either. Nor did PRC immigrants enjoy the accomplishments of earlier Diasporas from Hong Kong and Taiwan, who did not share their language or culture. In an earlier study we found that a few had worked in joint venture firms or other organizations that recommend them to their brother organizations in Canada. However, most arrived without contacts into good positions (Salaff \& Greve 2006).

Using social capital to get jobs not only involves rich signals, it is also a game with low numbers. The number of contacts that can bridge social systems and mediate jobs is limited, and often depends on few people doing similar work (Burt 1997). Thus, for positions with many people doing similar work, social capital is less efficient in providing advantages, and hiring may be done through other paths. These immigrant women are unlikely to have these valuable contacts. It is more likely that their contacts can provide lower level jobs in the ethnic enclave.

\subsubsection{Online Chinese language forums}

Communities without social capital can build community networks, systems that electronically connect individuals who also occupy common geographic space (Virnoche \& Marx 2000; Virnoche 2000). We investigated whether online Chinese language forums are a solution to the job searchers' lack of social capital. Since new immigrants arrive without knowing many others, those who do have good jobs should be able to pass on insider information about other jobs in their firms to Chinese like themselves. We found Chinese forums are effective community network builders. However, providing leads to good jobs does not follow.

In I999, Chinese immigrants started many online voluntary associations and webpages to provide social capital to the Putonghua speaking Chinese community, which was floundering without resources and leadership. These associations use the Internet to help newcomers reach these previously unconnected people. The popular Internet forums devoted to the settlement of their compatriots in Canada have open access, appeal to PRC Chinese, and have high readership. They act as a reputation system, a system of communications with trust. These Chinese websites aimed to unify the Mainland Chinese into a community, enabling people to find each other, to find services as well as broader social service agencies that they may need to contact. They also aimed at providing job information.

For example, Chinese immigrants built 'Xing Yi Wang' (http://www. $\mathrm{IS}_{4}$ U.net), one of the first Chinese websites in Canada. Former compu- 
ter scientists administrated the website, their modest income coming from ads placed on the site. The forum contains a career centre, a number of other forums and chat rooms, with news, discussions on renting an apartment, selling second hand goods, finding services, such as day care, a piano teacher, English study, and entertainment, among other topics important to Chinese women. There are surveys on various issues affecting new immigrants and useful to lobbyists when arguing for changes in Canadian labour force regulations.

We monitored this website from 28 March 2003 to 6 October 2003 and found this website posted few good jobs. Of the Io2 job postings, the bulk was aimed at low skilled Chinese immigrants. They were also gendered. These postings would not help skilled immigrants break into the Canadian professional world. Of the IO2 postings, about 30 per cent (28) were for professional or teaching positions, whereas the rest were labour, sales and office jobs, all below the level of skilled immigrants. About 25 per cent of the posts, especially those targeting new immigrants and international students, appeared fraudulent. Further, this website directed Chinese immigrant labour towards the ethnic market. The few non-enclave jobs are mainly IT jobs and direct marketing. This website reflects the stereotypes of immigrant Chinese labour.

Readers also post resumes on the Chinese webpages, and a glance at these showed that women seek jobs below their educational level. During this period 48 people ( 22 female, 26 males) posted resumes. They were well educated, yet applied well below their skill level. Female applicants sought a job as cashier, receptionist, secretary or other low level positions, regardless of holding a higher degree. For instance, a woman with a Master's degree in Japanese sought a position of kitchen help. In contrast, male applicants with a Bachelor's degree or higher sought technical jobs in their related fields, only slightly below their educational level. Only males with the lowest education, high school diplomas, applied for the positions of waiter and kitchen help.

\subsection{The Internet and Jobs}

The ability to reach out more widely to new circles by using online access to job postings broadens their possibilities. The Internet has been extolled as value free, based on sophisticated technology available to all, connectivity through search engines, not personal relationships, and text based neutrality. Access to the Internet gives immigrants a chance at breaking into the wider labour market through broadening job information, thereby widening job searches, and reducing signals that convey discriminating attributes. The Internet's unique characteristic is its ability to link widely. The Web can widen circles of information about available jobs and candidates. Through Internet postings, people learn 
about vacancies beyond what their personal friends can tell them. Both employers and job seekers get more information online.

In recent years, the Internet has become a key channel for firms to post positions, job seekers to post resumes, and agents to make matches (Morrison et al. 2000). Vacancies are advertised on corporate pages, with links to job opportunities. Over 90 per cent of large US firms have websites dedicated to recruitment information, the most visited sections of their websites (Cappelli 200I; Peters 200I). In addition, agents advertise, newspapers post job wanted sections, and, most crucial, numerous webpages are dedicated job search sites. Large numbers of jobs are posted on two websites in particular: www.workopolis.com and www.monster.com. Job seekers also can post their own resumes. A large-scale survey in I5 European Union countries found that searching for jobs was the third most popular use of the Internet (Neuville 200I). A study of ten years of hiring in a large multinational firm similarly traced a great increase in Internet use, replacing the use of agents. In 2002, the firm hired almost 2I per cent of its employees through online applications, largely replacing the use of agents. Nevertheless, personal contacts accounted for 60 per cent of all hires, still the most important source (Hadass 2004).

The Internet is efficient. 'A single process of rationalization - which involves not only accumulating and standardizing information but also resorting to automated procedures for sorting data with [parameter driven] search engines - underlies the many technical arrangements made possible thanks to computers' (Neuville 200I: 349). Technical jobs, which are easily accompanied by job descriptions that list education and speciality, are the most advertised posts. Job seekers can assess whether or not they are capable of doing the job before applying. Posted jobs are directed to everyone who qualifies. For instance, when IT workers were in high demand, a wide range of firms sought suitable employees online. Clearly, many Asian immigrants with their technical backgrounds are suited to apply for positions posted online.

Nevertheless, there are limitations, beginning with the range of jobs that are posted. Although employers in a competitive job market generally want to spread their reach, in Canada firms are not required by law to list openings online. By convention, some professions advertise widely, but many others rely on their social contacts. In contrast, in Sweden and Norway, public and private sector firms and institutions are required by law to list all openings, making the Internet a source that contains information of most job vacancies. ${ }^{2}$ In this regard, many query the Internet's cultural disinterest, noting social divisions in access, and the non-humanist bias of technology (Chen \& Wellman 2005; Kennedy et al. 2003). Humanist jobs are less likely to be posted than technical positions, for example. 
Since the Internet reflects the society of which it is a part, the society's social inequalities are embedded within it (Sassen 2002). Entry to this technology is conditional on home Internet access (Green \& Adam I998; Kuhn \& Skuterud 2004). Multiple family demands on women in the home reduce the time they have to surf the net for self improvement, including job advancement (Kennedy et al. 2003). Nevertheless, even with the constraints governing the amount of job information online in Canada, since women can log in as well as men, Internet posting gives them greater knowledge of available jobs. Studies of the US labour market in 2000 and 2002 find no gender difference in using the Web for finding jobs (Kennedy et al. 2003).

Internet users are somewhat distinct. First, the young and well educated search for jobs on the net to the largest extent (Anderson 2004). Internet users are also likely to rely on ads and other information sources, and less likely to use personal ties (Kuhn \& Skuterud 2004). They may not have personal ties, or feel encumbered by them. This factor points to the Web as a good channel for immigrants, because they lack the social networks that the locals have.

There are other social downsides to the Web search. Using the Web does, or did before it became widespread, imply a certain ability. However, the unemployed who use the Internet do not find jobs faster than those searching for jobs in other traditional ways. In fact, it was the opposite. Those who have jobs but surf to find a better position tend to find a better job than do the unemployed that search for jobs online (Eriksson \& Lagerström 2004). By holding a job, the surfers show the employer that they are particularly worthy. The unemployed cannot show this. This is problematic for unemployed new immigrants who have nowhere to start.

A further source of discrimination enters into the hiring process. The labour market is structured around common understandings of who can do what jobs. Gender is such an understanding. There is a gendered labour market, and women and men have access to different jobs. There are several steps from access to information about jobs available, to applying, being shortlisted, interviewed, getting hired, to keeping a job. While the net has a special use for screening and shortlisting interviews, getting the first contact with an employer through the Internet does not guarantee a job. At the time of the hiring, networking and face to face contacts allow employers' prejudices to enter into their decisions (Neuville 200I). Women may be still disadvantaged. Finally, Internet applications do not always get the fastest results. The Internet appears superior in getting a job compared to a newspaper ad or cold calling, but less efficient than using one's social capital (Feldman \& Klaas 2002). In sum, the Internet is not free from social factors at all. It has its own cluster of social factors. 
The Internet uses sparse signaling, another feature that eases immigrant women's access to good positions. Job seekers can place their $\mathrm{CVs}$ on job search websites. The design and information on the CV is part of the signaling from the job searcher. The problem is giving information that can be captured by screening processes, whether these are processed automatically or by humans. Given the large number of available positions and the large number of job seekers submitting their applications, firms have to batch process and use coarse categories. For both the firm and the job seekers, this introduces randomness in hiring. Randomness has always been part of hiring since it is well documented that firms do not adequately assess qualifications of applicants (Rosenbaum 1986), nor do they get better assessment after observing job performance (Greve 1992; March \& March 1978). The numbers game, large number of vacancies and job applications, renders a low probability of getting a job. However, the Internet makes it easy to submit numerous applications, which enhances the chances of getting a good job. This process reduces the effect of negative signals that immigrants send, and increases the probability of getting a better job than using paths with richer signals. Discrimination because of nationality, gender or immigrant status can be more easily bypassed online.

Further, the Internet can hide many personal characteristics, reducing stereotyping and prejudice. Online job applicants can shape their resumes to look like everyone else's and more easily be granted an interview. An accent is invisible. In Canada where it is illegal for employers to choose workers based on personal traits, job seekers can post resumes that conceal gender, age, and even parts of their job histories and education (Schleef 1996). In this manner, online postings may get around employers' prejudices that immigrants, women, the handicapped, those on welfare, or older workers cannot do the job.

If limited, or socially controlled information is the major problem for female immigrants, the advent of the Internet may revolutionize the job search. By making information neutral the probability of getting a job may become the same as for other groups. If Chinese women are able to manipulate their symbolic image, then gender and other personal characteristics that push them into stereotyped jobs, should be less salient.

\section{Our Study}

To learn about newcomers' experiences in the job search, we conducted an online survey announced on the two most popular and longest standing Chinese language websites, based on number of visits per 
month (one of them reached Io million visits, or clicks, a month!), directed towards the PRC community, These were http://www.ChinaSmile.net and http://www.IS4U.net. The Web masters recommended the survey and made a link to the questionnaire on our University webpage. The 27 brief questions in Chinese on their job search experiences in Canada, personal background, and Internet habits took fifteen minutes to complete. The survey was accessible from 28 July 2004 to io August 2004, on Salaff's homepage.

303 Chinese immigrants voluntarily responded. All newcomers with relatively similar backgrounds and human capital, had worked in skilled professional or semi-professional fields in China and entered Canada in the independent application category skilled workers. They responded because they knew that new PRC immigrants like themselves have trouble getting good jobs. Some had already found satisfactory positions. By answering our survey, they could inform their compatriots that it was possible to break into a good profession in Canada, and encourage perseverance. In contrast, most had bad job search experiences, and used our survey to express themselves and learn from others.

Nearly half of the sample gave their follow up contact information on the survey form, from which we drew ten per cent for semi-structured interviews. We talked with 28 interviewees for an hour on their personal experiences in the job search in China and Canada to learn how the labour market works. These respondents were slightly older and had somewhat lower job achievements than our larger sample, and more were women. We did not interview employers, and drew on the job seekers' accounts for employers' expectations of suitability for the job. The quotes in the text come from the qualitative sample, identified by survey case number, pseudonyms, education in China, and university major. We analyzed the survey responses statistically (with SAS-JMP), and coded their interviews with qualitative data analysis software (QSR N-Vivo 2 and Tinderbox, Eastgate.com).

\subsection{The Respondents and Their Jobs}

Admitted as skilled workers, our survey respondents are well educated. Two-thirds have Bachelors degrees and 28 per cent received post graduate degrees in China (see Table 4.I).

In China they mainly studied technical fields: 83 per cent majored in engineering and sciences, including medicine. However, education was gendered, and women dominated those fields that were humanities based. This hampered their job search in Canada, where they were seen as not being Canadian enough for well paid humanist and cultural jobs. Nevertheless, many women had technical and scientific 
Table 4.1 Highest Degree in China by Gender

\begin{tabular}{lllllc}
\hline Row \% & College & Bachelor & Master & Ph.D & Number \\
\hline Female & 9.52 & 70.24 & 19.05 & 1.19 & 84 \\
Male & 4.11 & 65.30 & 27.85 & 2.74 & 219 \\
Total & 5.61 & 66.67 & 25.41 & 2.31 & 303 \\
\hline
\end{tabular}

Table 4.2 Fields of Study by Gender

\begin{tabular}{lllllllll}
\hline Row \% & Engineer & Science & Humanities & Medicine & Business & Education & Other & Number \\
\hline Female & 30.95 & 17.86 & 14.29 & 7.14 & 22.62 & 5.95 & 1.19 & 84 \\
Male & 69.86 & 21.92 & 2.28 & 1.37 & 3.65 & 0.46 & 0.46 & 219 \\
Total & 59.08 & 20.79 & 5.61 & 2.97 & 8.91 & 1.98 & 0.66 & 303 \\
\hline
\end{tabular}

training: those who studied engineering, science, and medicine are: women, 56 per cent; men, 93 per cent (see Table 4.2). The technically trained do better in the Canadian job market.

In China, these women and men had risen to the top of their fields. 82 per cent had been professionals and middle and higher managers in their last job in China. There were not many differences in the professional standing of women and men. Although fewer women than men had been high and middle managers, as many women as men, 58 per cent, had held professional positions.

Our main criteria for assessing how well they do are levels of unemployment, job status and wages. In Canada, however, they had fallen in status. Starting with unemployment: 24 per cent of the entire sample was not working. Of the 76 per cent working, the three biggest occupational groupings are: professionals 34 per cent (IO2 people), labourers fifteen per cent, and technicians eight per cent. The proportion is inconsistent with studies that find that PRC skilled immigrants to Canada rarely achieve professional level occupation (Salaff \& Greve 2003). Possibly it results from the voluntary nature of our survey: those most proud to have obtained higher positions were most likely to fill out the survey form. As well, this proportion may have resulted from self classification. This proportion of professionals is similar to another study by Wang and Lo (2005) in which respondents self reported their occupations. From our interviews we learned that many computer technicians and other white collar service positions considered their lower level supervisor job as professional, whereas we would refer to them as semi-professionals.

Getting re-established in Canada places them in a new institutional framework and is not accomplished in one stroke. Re-certification is a beginning. By the time we met them, they had realized that their PRC credentials were unrecognized in Canada. Knowing that they needed 
recognized credentials to get better jobs in Canada, 25 per cent received some education abroad. Women were more likely to study abroad: women 30 per cent, men 22 per cent. Of these, seven women and ten men got Master degrees and two men received a Ph.D. abroad. Men were gearing for technical jobs, while women were resigned to nontechnical positions. Whereas the courses of the men that studied abroad were concentrated mostly in technical fields: engineering (47 per cent) and computer science ( 25 per cent), women clustered in business (29 per cent), engineering (2I per cent), and accounting (I8 per cent). Since their skills needed to be recast to fit Canadian definitions of human capital, overall, this re-certification has not yet made a great difference in unemployment, job levels, or pay. As a result of having to recast themselves into the Canadian mode, length of stay makes it easier to gain better jobs. The longer they resided, the better things got: the less likely they were to be unemployed and the higher their job status and earnings. In particular, those that have professional jobs have resided longer (see Table 4.4 and 4.5 ).

Women have been slower to establish themselves in Canada, falling behind men in finding work, job levels and pay. Unemployment is highest among women: 3I per cent compared to the men's rate of 2I per cent. The fields they studied further affect the likelihood of unemployment for all our respondents. For both women and men, there is above average unemployment for those trained in science, medicine and humanities. Medicine and humanities, the fields where women predominate, especially suffer unemployment. Women trained in engineering are doing better than those with other backgrounds, nevertheless even here, far more former female engineers are unemployed than their male counterparts.

Fewer working women than men reported having professional status jobs (see Table 4.3). The thirteen women who refer to themselves as professionals are most numerous in engineering (7). Hence, their dominance in engineering and science give the men an edge over the women. Whereas overall, most of the professionals in this sample are engineers and scientists (86 per cent), more men are professionals in engineering and science fields: males 95 per cent; females 47 per cent.

Table 4.3 Current Job by Gender

\begin{tabular}{lrlrllllrrr}
\hline Row \% & Labour & Manager & $\begin{array}{r}\text { Office } \\
\end{array}$ & & $\begin{array}{l}\text { Profes- } \\
\text { sional }\end{array}$ & $\begin{array}{l}\text { Self- } \\
\text { Employed }\end{array}$ & \multicolumn{2}{l}{$\begin{array}{l}\text { Skilled } \\
\text { Labour }\end{array}$} & \multicolumn{3}{c}{ Technician } & \multicolumn{2}{c}{$\begin{array}{l}\text { Un- } \\
\text { employed }\end{array}$} \\
\hline Female & 8.33 & 4.76 & 11.90 & 22.62 & 7.14 & 3.57 & 10.71 & 30.95 & 84 \\
Male & 16.89 & 5.48 & 1.37 & 37.90 & 1.83 & 7.76 & 7.31 & 21.46 & 219 \\
Total & 14.52 & 5.28 & 4.29 & 33.66 & 3.30 & 6.60 & 8.25 & 24.09 & 303 \\
\hline
\end{tabular}


The next largest group (four women) reports business as their field, and there are two women professionals in the science and medicine categories.

The average wage in Canada is CAD 20 an hour, and the minimum wage is around CAD 8 an hour. Based on these averages, we refer to good jobs as those earning CAD 25 and more an hour and bad jobs as those earning less than CAD Io an hour. There are sharp gender differences in the earnings of women and men as well, see Table 4.4. Few women earn good wages, and more women than men earn bad wages. Of the 230 respondents with jobs, two-thirds earn less than CAD 25 an hour and more of these low earners are women: 88 per cent of the women and 56 per cent of the men earn less than CAD 25 an hour. The distribution of the salaries of the 58 women shows that only seven (I2 per cent) receive more than CAD 25, 28 (48 per cent) are in the CAD I5-24 range, eleven (i9 per cent) get CAD IO-I4, and twelve (2I per cent) get less than CAD IO, compared to ten per cent of the men. Jobs with the highest prestige have the highest wages. Professionals account for 75 per cent of those with the highest wages. Professionals that make CAD 25 or more an hour are comprised of: women 26 per cent, men 69 per cent. Yet not all professionals do that well. Over one-third that classified themselves as currently working as professionals simultaneously reported dismal earnings below their educational level and authority: 39 per cent of professionals earn less than CAD 25 an hour. More of these are women. Similarly, the lowest earning fields are those dominated by women. For instance, those educated in the humanities are not only more likely to be unemployed, they also earn the least. Both women and men earn less than their education warrants, but women do worse regardless of their education, professional field or position. Women get significantly less pay for their work even when holding everything else constant: holding same jobs, having same education, and marital status (see Table 4.4).

Table 4.4 is a regression that explores the features that influence the salary levels of the respondents. This is an ordinary least squares regression model with effect screening emphasis. We use orthogonally coded independent variables to avoid regression errors due to correlations among predictors and parameter estimates (Sall et al. 2004). The last three columns are the most informative, and we look at the magnitude of the parameters and their significance levels. The higher the value of the parameter, the more influence on pay levels, either in a positive or negative direction. Detailed statistical output is available from the authors. The parameters of the column labeled orthogonally coded are scale invariant and can be compared directly to each other. They are also true estimates since all variables are transformed to be independent. Five main social factors help respondents get higher earnings, and five 
Table 4.4 Factors Predicting Wage Levels

\begin{tabular}{|c|c|c|c|c|c|}
\hline Term & Original & $t$ Ratio & $\begin{array}{l}\text { Orthog } \\
\text { Coded }\end{array}$ & $\begin{array}{l}\text { Orthog } t \\
\text { Test }\end{array}$ & Prob $>|t|$ \\
\hline Intercept & 13.49 & 7.72 & 20.37 & 56.72 & $<.001$ \\
\hline Gender $[\mathrm{F}]$ & -1.28 & -2.49 & -1.78 & -4.96 & $<.001$ \\
\hline Length of stay in Canada & 0.82 & 3.39 & 3.14 & 8.74 & $<.001$ \\
\hline Marriage Status[Divorced] & -2.16 & -1.51 & 0.89 & 2.48 & 0.014 \\
\hline Marriage Status[Married] & 2.07 & 2.41 & 1.78 & 4.95 & $<.001$ \\
\hline Highest degree[Bachelor] & 0.69 & 0.83 & 0.08 & 0.22 & 0.826 \\
\hline Highest degree[College] & -2.79 & -1.93 & -1.03 & -2.88 & 0.004 \\
\hline Highest degree[Master] & 0.09 & 0.10 & 0.93 & 2.58 & 0.010 \\
\hline Profession[Engineer] & 1.80 & 1.83 & 0.69 & 1.93 & 0.055 \\
\hline Profession[Science] & 1.29 & 1.11 & 1.03 & 2.87 & 0.005 \\
\hline Profession[Humanities] & -0.95 & -0.52 & -1.24 & -3.45 & 0.001 \\
\hline Profession[Medicine] & -2.16 & -1.03 & -0.26 & -0.74 & 0.461 \\
\hline Profession[Business] & 1.84 & 1.37 & 0.26 & 0.71 & 0.478 \\
\hline Profession[Education] & -0.34 & -0.15 & -0.33 & -0.92 & 0.357 \\
\hline Job[HighManager] & 7.90 & 2.26 & 0.58 & 1.60 & 0.110 \\
\hline Job[Labour] & -8.57 & -8.00 & -3.41 & -9.48 & $<.001$ \\
\hline Job[LowManager] & -1.82 & -0.86 & -0.25 & -0.70 & 0.485 \\
\hline Job[MidManager] & 3.00 & 1.59 & 0.34 & 0.94 & 0.348 \\
\hline Job[Office] & -2.67 & -1.61 & -0.63 & -1.75 & 0.082 \\
\hline Job[Professional] & 4.37 & 5.13 & 2.12 & 5.89 & $<.001$ \\
\hline Job[SelfEmployed] & -0.25 & -0.14 & -0.07 & -0.20 & 0.844 \\
\hline Job[SkilledLabour] & -2.32 & -1.74 & -0.74 & -2.06 & 0.041 \\
\hline Source of job [Internet] & 0.58 & 1.04 & 0.46 & 1.29 & 0.199 \\
\hline Source of job [Social capital] & 0.00 & 0.01 & 0.00 & 0.01 & 0.994 \\
\hline R Square & 0.60 & F Ratio: & 13.47 & $\mathrm{n}=230$ & $<0.001$ \\
\hline
\end{tabular}

are likely to give them lower earnings. The longer our respondents have stayed in Canada, the higher the salary level. Over time, immigrants are able to improve their earnings. Getting a professional job also gives higher earnings, and those who studied sciences get an additional push in income. People who are married also earn more than non-married, and the divorced earn less than all others. Education splits our respondents according to degree, those with a Master degree do better than the average, and those having only a College diploma do worse, the rest are average. The remaining factors pull salary levels down. Those in the $\mathrm{Hu}-$ manities earn less than in other fields. Manual labor is the most poorly paid job, skilled labor is also paid below average. Next, women get significantly less pay for their work even when holding everything else constant. Women are less paid than men when holding same jobs, having same education, and marital status. Getting the job through the Internet or other sources does not affect wage levels. 


\subsection{How They Get Their Jobs}

\subsubsection{Social Capital}

Almost 30 per cent got their current job through social networks. But since the few people they knew were not well placed, two-thirds of the cases using this path got positions with low job status and pay. Women did worse than men using social capital, only nineteen per cent got higher level jobs through social capital compared to 42 per cent of the men. Respondents understood that getting jobs through networks generally got them bad jobs because their networks consisted of people like themselves.

Ms. Huang (\#ıо, college diploma, chemical engineering) is an example of the tenuous indirect social ties most relied on. She got a job as a technician (CAD I3.50 per hour).

'When we came here, one of my husband's sister's classmate's classmate in the U.S.A helped us find a house. Then one of my husband's middle school teacher's friends helped us get a job. He called me and told me that his sister knew a person who had a job. He urged me to go there as soon as possible.'

Because they were not linked to well-placed people, even those that got jobs through Canadians mainly got low paid low status jobs. For instance, Pan (\#200, civil engineer and architect in China) told us:

'I went to work at George Brown College while I was a student there. The school's secretary saw me in the hall reading, and asked me if I wanted to work in the office part time (CAD 8 per hour.) It was very comfortable there. I can get around 800 per month, we really needed this money. I felt a lot of pressure after I came to Canada and found myself in a weak position.'

A sole woman had good transnational social networks, and she is the only woman who has regained a position that matches her high level job in China. Ms. Yang (\#30 MSc Mechanical Engineering) got a good job through well placed contacts. Yang's parents, both engineers, had pushed her into their field, but she did not enjoy engineering. After graduation in I990, she got a job advertised in the paper as a technical manager for a Japanese joint venture cement company. She spent six months in the Tokyo headquarters learning Japanese and getting onthe-job training, then returned as field supervisor. Since there was little chance of being promoted in a male-dominated, heavy industrial company, after her contract expired, she took a marketing position in Exxon Mobil's new Chinese branch. After immigrating to Canada, the VP of 
Honda Beijing, an Exxon client, sent ahead a reference that landed her a position as a parts analyst at Honda, Canada. Her Japanese language skills and experience were highly valued and she was made manager. Yang's experience in Canada is fairly unique in our sample because she landed a good job through her past business connections. Her company's client has branches in North America and welcomed her expertise gained from two countries.

In contrast to the others, Ms. Yang is doing well because her network spans the same professional and organizational fields across both countries. Yang's ability to get a job flows directly from her transnational social capital. Her networks cross borders and thus are effective in getting jobs in Canada. Her exceptional case shows that if the immigrants' contacts and reputation reach into the realm where they seek a job, they have a much better chance to get a good professional position.

\subsubsection{The Internet}

The Internet is the most popular job seeking path. These respondents are both good at using the Web and they have little choice. The kind of jobs they seek were those most likely to be posted online. Knowing no one in Canada made them depend heavily on the Internet for their job searches. Nearly all ( 92 per cent of the sample) have tried to apply for a job online. Only slightly fewer women (86 per cent) than men (95 per cent) applied through this means. Landing jobs is harder than applying: 30 per cent of the entire sample found their current jobs through the Internet, slightly fewer women than men. ${ }^{3}$

The Internet provides our respondents with higher level jobs than any other information channel (see Table 4.5). However, webpages cannot completely remove institutional blockages to getting jobs. These start with the gendered family/educational system. A large proportion of posted jobs are technical in nature, but fewer women are qualified for technical jobs. On the other hand, those that do have such background can apply. Since there is gender discrimination, they would face the widespread doubt that women can do work of a technical nature. By using initials, they can obscure their gender. The next step is getting shortlisted. At this point, they would face discrimination that men also face, notably, the ignorance and exclusion of those with international education and careers.

Table 4.5 shows that five variables can significantly predict the respondents' attained job level. The table displays an ordinal logistic regression model. The dependent variable "Job levels," is ranked at four levels. I) The highest level is higher level managers and professionals. 2) Lower and middle level managers and self-employed. 3) Technicians and office workers are the next level up. 4) The lowest levels include 
Table 4.5 Predicting Job Levels

\begin{tabular}{lccc}
\hline Variables & Coefficient & Std. error & Significance level \\
\hline Intercept (1) & -1.91 & 0.49 & $<0.001$ \\
Intercept (2) & -1.41 & 0.48 & 0.003 \\
Intercept (3) & -0.53 & 0.47 & 0.264 \\
Gender (Male) & 0.26 & 0.17 & 0.14 \\
Length of stay in Canada & 0.45 & 0.09 & $<0.001$ \\
College exam & -1.13 & 0.53 & 0.035 \\
Bachelor degree & -0.04 & 0.30 & 0.887 \\
Master degree & 0.67 & 0.32 & 0.035 \\
Profession (refers to education): Engineer & 0.28 & 0.34 & 0.377 \\
Profession: Science & 0.44 & 0.40 & 0.269 \\
Profession: Humanities & -1.44 & 0.62 & 0.021 \\
Profession: Medicine & 0.04 & 0.73 & 0.957 \\
Profession: Business & 0.01 & 0.46 & 0.978 \\
Profession: Education & -0.07 & 0.77 & 0.929 \\
Source of job: Internet & 0.63 & 0.20 & 0.002 \\
Source of job: Social capital & -0.19 & 0.20 & 0.340 \\
Model -Log-likelihood & 27.75 & & $<0.001$ \\
N = 230 & & &
\end{tabular}

unskilled and skilled labour. There are no differences between men and women once controlled for the other independent variables. Three factors predict higher job levels: I) The longer they stay in Canada, the higher level jobs immigrants get. 2) Using the Internet as a source of the jobs, followed by 3) having a Master degree gives higher level jobs compared to other degrees. To the contrary, two variables predict lower job levels: I) Having only a college exam (diploma), but not a Bachelor degree, and 2) being in the professional field of Humanities; this category consists mostly of women. These get lower level jobs. The Internet gives our respondents higher level jobs, but they are not necessarily higher paid (see Table 4.4 above).

We refer to the use of online Chinese webpages to get jobs as a form of Internet use because the applicant does not mobilize those in her social networks. However, use of these pages sends out strong signals. Employers and agents that browse Chinese webpages are familiar with the needs and qualities of the applicants. Hence, they easily get good workers for low pay. Yu (I84) got her first job through a Chinese website and earned a little above the minimum wage. Certainly, the agent contacting her through these sites knew that as a new immigrant, she must be desperate. She had a Masters degree and in China was a manager in an IT company. The following is an account of Yu's first Canadian job found on 5I.ca, a Chinese website for a Chinese company dealing with Chinese customers: 
'It was a Chinese company, not too big. I was a customer representative. The company sells products, and we answer the customers' questions regarding the products. The salary is CAD I500 per month, and I have to work from Monday to Friday from 9:00 am to 6:00 pm. The customers are Chinese. This is my first job, if I didn't take it; somebody would.'

Did the Internet make a difference in job levels? There is good and bad news. The Internet is important in accessing the better jobs. 59 per cent of all jobs that the respondents got through the Internet are professional level jobs. Among the female respondents using the Internet, 50 per cent got these high level jobs, compared to 62 per cent of the men.

\subsubsection{Pay and Paths to Job}

There are benefits from applying online, but it bifurcates into either the highest salary bracket or the lowest, with just a few in the middle levels. Of the few women with higher salaries, many got their jobs through the Internet. Four of the seven highest paid got their jobs through the Internet. At the same time, women also do poorly on the net. Five of twelve in the lowest pay bracket, below CAD Io got their jobs through the Internet. Further, many women remained unemployed, even though they also tried to use the Internet to get jobs. In fact, desperate, they tried the Internet even more than the employed.

What are their earnings when they found work through other channels? The next largest category of job source for both women and men are social networks. Women that heard about jobs through friends did not get the best paying jobs. They got middle paying jobs (CAD I5-24 an hour). However, fewer women that got jobs through social networks fell to the low end jobs.

Jobs found on the Internet were higher level jobs, more professional, more science and engineering than those coming from other sources, but the pay level was not uniformly higher. The sources did not guarantee job level, nor did job level assure good income. Even some of those women and men with higher job status earn low pay (see Table 4.5). Nor can the Internet overcome the strong gender discrimination in society, although online access lessens its impact. Using the Internet as a source of the jobs improves their job level, getting the job through the Internet does not improve wage levels.

Using the Web enables the women to broaden their circles and gather information to start a new career in Canada. The Web gave them an entry to the Canadian industrial world. It was not the final job but the beginning. Ms. Hao (\#I84) with an MA in Engineering was an IT Manager in China. She was a devoted Web browser. She earns CAD I2 per 
hour without benefits or Employment Insurance (which is illegal) in a position as an office assistant, in a real estate agency in Toronto.

'The only way I find jobs is the Internet because I cannot think of other ways than this, jobbank.com or monster.com. I sent my resume to them, and they called me for the interview. The manager is from India, and he has been here for more than twenty years. My job is to help them with some business and design the webpage for them. They don't have too many cases, which means I don't spent too much time on receiving phone calls. Most of the time, I design the webpage for them. My boss has many webpages because he is very interested in such things. He buys them, and I put those pages on our network system. If there are any updates that need to be done, I'll do it. He definitely doesn't know how to design the webpages, but he can work out some business deals online. He spent a lot of money on the webpages because he believes he can earn money. Anyway, I just do what he told me to do.'

Ms. Mao (\#20I) was a physician in China, who had been recognized by being awarded a World Health Organization fellowship to Australia. Faced with the need to re-certify in Canada, she used the Internet to gather information on the exams needed, study programmes, and refresher courses.

'I found my first job by myself from an official website of Canada, Job Bank. I also got some information about tests, programs, and preparations of the test online.'

She found online discussions invaluable to get information on circumventing institutional restrictions:

'Everybody is talking about the doctor's license tests online. We talk about how to prepare for the tests, if there changes in the quotas of people, and also which book is better for preparation for the tests, etc. When people are talking very happily, I ask their phone numbers and give them mine. All of them are in Toronto.'

She passed the screening exam but did not pass the next exam which qualified the top 50 physicians with international education for residency. She gave up the goal of re-certifying for medicine and went to college, first in a registered nursing programme and then transferred to an ultrasound programme at a local institute. 
'I got to know this institute because I met a person, also a doctor from China doing radiation therapy there, who gave me its website. I went to the website and found the ultrasound technology course.

'When I just came here, I was out of circles. Therefore I needed to discover friends on the same direction. I go online mainly because doctors cannot be primary applicants, and we all came here as applicants' spouses. There are only a few people talking about medicine online, because it is not the mainstream. But now more people are taking about nursing. Nursing is really popular now. Many doctors begin to learn nursing, including myself.

'After I get the diploma I'll take an American ultrasound license test, because Canada doesn't have it here and uses America's. It tests some foundational stuff, for example, chemistry. It's difficult for us. Mainly because of English concepts and the special terms. Ultrasound is clinical, it's easier for us. The classes are difficult, equal to college in Canada, but it's like the high school in China. We feel that the foundational stuff is more difficult for us. But the salary will not be high. It cannot be compared with doctor. I heard it's about forty-fifty thousand dollars per year.

'I think I have found my future direction. I have discussed with my husband that I can just do the ultrasound for my whole life. Women are more suitable for being clinical assistants, because clinicians need a lot of energy. Even if I get the doctor's license, it's labourious to be a resident physician. Also, I hope to give birth to a second child as soon as possible. Look at me. I am going to be thirty-six after I graduate from the ultrasound technology. So I am so eager to have another child.

'The feeling of isolation from the outside world was really terrible when I just came here. The efforts in the past were wasted; it's liked a blank paper, and no one approves you for anything.'

\section{Summary and Conclusion}

Skilled immigrants from China, practised at accessing the Internet, locate jobs online to overcome their narrow social circles in Toronto. Our study of Chinese Internet forums and an online survey of $303 \mathrm{immi}$ grants found that they are good at locating publicly available information about jobs. Their search widens access to job information, but cannot overcome prejudices and institutionally circumscribed regulations. These institutional structures especially hurt women's job search. 
There is both enclave and mainstream online job information. Those that try the forums set up for Mainland Chinese Internet readers invariably get offered jobs stereotyped to Chinese, poorly paid, without career opportunities. Many exploit the new immigrants' lack of information of the job market. They lure them into the least desirable slots in the labour market.

In contrast, the mainstream Internet webpages provide greater opportunities for women and men to break into professional jobs. Unlike the Chinese Internet pages, the mainstream Internet does not appear to introduce new forms of discrimination. Many women that use the Internet do relatively better than the rest. Nevertheless, the Internet is not a panacea. Not all of these online job seekers are earning high wages. Moreover, women get lower pay than men. Institutional issues enter. They can apply online and can learn about jobs outside their narrow circles, but they cannot get jobs that are not offered them. Job applications may not end up as job offers.

The Internet can help skilled professionals by exposing new immigrants to a larger number of available jobs in the mainstream economy outside of the ethnic enclave. As long as social institutions create inequality, the Internet cannot break all the structural barriers to Chinese immigrant women's search for good jobs.

The way the Internet systematically gives our respondents better jobs, indicates that signaling and random hiring work to overcome some of the systematic social and institutional discriminations in Canada. A nonrandom process works against immigrants. Introducing randomness works like a job lottery, the more tickets you put in, the better the chance of getting a hit. People are able to improve their positions over time. This indicates that they learn to send acceptable signals that give them a better chance at a job interview.

\section{Notes}

I. We acknowledge gratefully the support of this research by The Social Sciences and Humanities Council of Canada. The Web masters of is4u.net, chinasmile.net and beifang.ca, gave us considerable assistance. Gary Zhang helped with the analysis of is4u.net postings. Tao Rua Hua designed the online survey and Xiaorong Chen did valuable interviewing work. Tracey Kennedy gave helpful bibliographical references and Kikaku Miyata passed on her experience on building a Web-based survey. Thanks to Peter Li for helpful comments. An earlier version of this paper was delivered at International Symposium: Log On: Chinese women and the Cyber Networks, Hong Kong University, October 20-2I, 2004, sponsored by the Centre of Anthropological Research and Department of Sociology, Hong Kong University.

2. The Norwegian webpages are at https://www.nav.no/sbl/stillingssok/enkelt.do and Swedish at http://www.amv.se (The English pages differ from the Norwegian and Swedish text; they are focused on foreigners applying for jobs in the two countries). 
3. In reality, the proportion of those that used the Web to get jobs is even higher than we note here. Our questionnaire detailed the source of finding a current job, but failed to clearly distinguish the medium used. For example, many of these recorded found their jobs through agents (I7 per cent), newspapers (9 per cent), or sent resumes (II per cent). But some of these did so online, and did not say so. We had to count them by the source rather than medium.

\section{References}

Anderson, B. (2004), 'Everyday research in the knowledge society: who uses ICTs to find job and health information', Chimera Working Paper.

Antcliff, V., R. Saundry \& M. Stuart (2007), 'Networks and social capital in the UK television industry: the weakness of weak ties', Human Relations 60 (2): 37I-393.

Baron, J.N. \& A.E. Newman (I990), 'For what it's worth: organizations, occupations, and the value of work done by women and nonwhites', American Sociological Review 55 (2): I55-I75.

Bauder, H. (2003), 'Brain abuse" or the devaluation of immigrant labor in Canada', Antipode 35: 699-717.

- (2005), 'Habitus, rules of the labor market and employment strategies of immigrants in Vancouver, Canada', Social a Cultural Geography 6 (I): 8I-97.

Bell, D. (1973), The coming of post-industrial society: a venture in social forecasting. Harmondsworth: Penguin, Peregrin Books.

Bian, Y.J. (1997), 'Bringing strong ties back in: indirect ties, network bridges, and job searches in China', American Sociological Review 62: 266-285.

Bielby, W.T. \& J.N. Baron (1986), 'Men and women at work: sex segregation and statistical discrimination', American Journal of Sociology 9I (4): 759-799.

Bills, D.B. (2003), 'Credentials, signals, and screens: explaining the relationship between schooling and job assignment', Review of Educational Research 73 (4): 44I-469.

Bloemraad, I. (2005), 'The limits of de tocqueville: how government facilitates organisational capacity in newcomer communities', Journal of Ethnic and Migration Studies 3I (5): 865887 .

Bourdieu, P. (1983), 'Economic capital, cultural capital, social capital (Ökonomisches Kapital, kulturelles Kapital, soziales Kapital)', Soziale Welt, Sonderheft 2: I83-I98.

- (I986), 'The forms of capital', in Richardson, J.G. (ed.), Handbook of theory and research for the sociology of education, 24I-258. Westport, CT: Greenwood Press.

Burt, R.S. (1997), 'The contingent value of social capital', Administrative Science Quarterly 42 (2): $339-365$.

Caidi, N. \& D. Allard (2005), 'Information and/for social inclusion', Library and Information Science Research (in press).

Cao, Y. \& C.Y. Hu (2007), 'Gender and job mobility in postsocialist China: a longitudinal study of job changes in six coastal cities', Social Forces 85 (4): 1535-I560.

Cappelli, P. (200I), 'Making the most of online recruiting', Harvard Business Review 79 (2): I39-I46.

Castells, M. (1996), The Rise of the network society, the Information Age: economy, society and culture. Oxford, UK: Blackwell Publishers Inc.

Chen, T.M. (2003), 'Female icons, feminist iconography? Socialist rhetoric and women's agency in I950s China', Gender and History I5 (2): 268-295.

Chen, W. \& B. Wellman (2005), 'Minding the cyber-gap: the Internet and social inequality', in M. Romero \& E. Margolis (eds.), The Blackwell companion to social inequality, 523-545. Malden, MA: Blackwell.

Cheung, C.K. \& Y. Gui (2006), 'Job referral in China: the advantages of strong ties', Human Relations 59 (6): 847-872. 
Citizenship and Immigration Canada (2003), Facts and figures: immigration overview 2002: permanent and temporary residents. Ottawa: Citizenship and Immigration Canada, Strategic, Policy, Planning and Research.

Collins, R. (I979), The credential society. New York, NY: Academic Press.

Eriksson, S. \& J. Lagerström (2004), 'Competition between employed and unemployed job applicants: Swedish evidence’, IFAU - Institute for Labour Market Policy Evaluation, Working paper 2004-2.

Feldman, D.C. \& B.S. Klaas (2002), 'Internet job hunting: a field study of applicant experiences with online recruiting', Human Resource Management 4I (2): I75-I92.

Fernandez, R.M. \& I. Fernandez-Mateo (2006), 'Networks, race, and hiring', American Sociological Review 7I (I): 42-7I.

Fevre, R., G. Rees, \& S. Gorard (I999), 'Some sociological alternatives to human capital theory and their implications for research on post-compulsory education and training', Journal of Education and Work I2: II7-I4O.

Gamba, M. \& B.H. Kleiner (200I), 'The old boys' network today', International Journal of Sociology and Social Policy 2I (8-IO): IOI-IO7.

Granovetter, M. (I974), Getting a job: a study of contacts and careers. Cambridge, MA: Harvard University Press.

Green, E. \& A. Adam (I998), 'Online leisure: gender, and ICTs in the home', Information, Communication \& Society I (3): 29I-3I2.

Greve, A. (I992), Turnover and career mobility. Bergen: Alma Mater.

Hadass, Y.S. (2004), 'The effect of Internet recruiting on the matching of workers and employers', Working paper, Harvard University.

Hagtvet, H. (2005), Undersøkelse om rekruttering av arbeidskraft. Oslo: Aetat.

Henry, F. \& E. Ginzberg (1985), Who gets the work? A test of racial discrimination in employment. Toronto: The Urban Alliance on Race Relations and the Social Planning Council of Metropolitan Toronto.

Ibarra, H. (I992), 'Homophily and differential returns: sex differences in network structure and access in an advertising firm', Administrative Science Quarterly 37 (3): 422-447.

Kennedy, T., B. Wellman, \& K. Klement (2003), 'Gendering the digital divide', IT \& Society I (5): I49-I72.

Kuhn, P. \& M. Skuterud (2004), 'Job search methods: Internet versus traditional', Monthly Labor Review I23 (Iо): 3-II.

Lai, G., N. Lin, \& S.Y. Leung (1998), 'Network resources, contact resources, and status attainment', Social Networks 20 (2): I59-I78.

Leung, H.H. (2000), 'Settlement services for Chinese Canadians in Toronto: the challenges toward an integrated planning', Chinese Canadian National Council, Toronto Chapter, Toronto. http://www.spcottawa.on.ca/CBRNO_website/DIV_abstract_Settlement_Services_Chinese_2000.htm [Retrieved Io January 2008]

Li, P.S. (2000), 'Earning disparities between immigrants and native-born Canadians', La Revue Canadienne de Sociologie et d'Anthropologie/The Canadian Review of Sociology and Anthropology 37: 289-3II.

- (200I), 'The market worth of immigrants' educational credentials', Canadian Public Policy XXVII (I): 23-38.

- (2004), 'Deconstructing Canada's discourse of immigrant integration', PCERII Working Paper Series Working Paper No. WPo4-03.

Lin, N. (200I), Social capital: a theory of social structure and action. Cambridge, UK: Cambridge University Press.

March, J.C. \& J.G. March (I978), 'Performance sampling in social matches', Administrative Science Quarterley 23 (3): 434-453. 
McKeen, C.A. \& N. Bu (2005), 'Gender roles: an examination of the hopes and expectations of the next generation of managers in Canada and China', Sex Roles: A Journal of Research $57(7-8): 533-546$.

McPherson, J.M., L. Smith-Lovin, \& J.M. Cook (200I), 'Birds of a feather: homophily in social networks', Annual Review of Sociology 27: 107-I20.

Meyer, J.W. (I977), 'The effects of education as an institution', American Journal of Sociology 83: 55-77.

Morrison, J.B., P. Pirolli, \& S.K. Card (2000), 'A taxonomic analysis of what world wide Web activities significantly impact people's decisions and actions', Xerox Palo Alto Research Center, Tech. Report UIR-R-2000-I7, Palo Alto, CA. http://citeseer.ist.psu.edu/morrisonootaxonomic.html [Retrieved 2I February 2005]

Mwarigha, M.S. (2002), 'Towards a framework for local responsibility taking action to end the current limbo in immigrant settlement - Toronto', Maytree Foundation (January).

Neuville, J.P. (200I), 'Les bons "tuyaux" du marche de l'emploi: Internet peut-il faire de "l'economie de la qualite" un marche? (Good "tips" in the labor market: can the Internet make an "economy of quality" a market?)', Sociologie du Travail 43 (3): 349-368.

Pendakur, K. \& R. Pendakur (I998), 'The colour of money: earnings differentials among ethnic groups in Canada', Canadian Journal of Economics 3I (3): 518-548.

Peters, K. (200I), 'Five keys to effective e-cruiting', Ivey Business Journal 65 (3): 8-Io.

Podolny, J.M. \& J.N. Baron (I997), 'Relationships and resources: social networks and mobility in the workplace', American Sociological Review 62 (5): 673-693.

Portes, A. \& L. Jensen (1989), 'The enclave and the entrants: patterns of ethnic enterprise in Miami before and after Mariel', American Sociological Review 54: 929-949.

Reitz, J.G. (200I), 'Immigrant skill utilization in the Canadian labor market: implications of human capital research', Journal of International Migration and Integration 2 (3): 347-378.

Rosenbaum, J.E. (I986), 'Institutional career structures and the social construction of ability', in J.G. Richardson (ed.), Handbook of theory and research for the sociology of education, I39-I7I. New York: Greenwood.

— (I990), T. Kariya, R. Settersten, \& T. Maier, 'Market and network theories of the transition from high school to work: their application to industrialized societies', Annual Review of Sociology I6: 263-299.

Salaff, J.W. \& A. Greve (2003), 'Gendered structural barriers to job attainment for skilled Chinese emigrants in Canada', International Journal of Population Geography 9: 443-456.

- (2006), 'Why do skilled women and men emigrating from China to Canada get bad jobs?', in E. Tastsoglou \& A. Dobrowolsky (eds.), Women, migration and citizenship: making local, national, and transnational connections, 85-105. Aldershot, UK and Burlington, VT: Ashgate Publishing Company.

Sall, J., L. Creihton, \& A. Lehman (2004), JMP start statistics: a guide to statistics and data analysis using JMP and JMP-IN software. SAS Institute: Curt Hinrichs (3rd ed).

Sassen, S. (2002), 'Towards a sociology of information technology', Current Sociology/La Sociologie Contemporaine 50 (3): 365-388.

Schleef, D.J. (1996), 'Lawyers on-line: professional identity and boundary maintenance in cyberspace', Research in Community Sociology 6: 193-214.

Spence, M. (1973), 'Job market signaling', The Quarterly Journal of Economics 87 (3): 355-374.

Stoloff, J.A., J.L. Glanville, \& E. Bienenstock (I999), 'Women's participation in the labor force: the role of social networks', Social Networks 2I: 9I-Io8.

Tilly, C. (1998), 'How categories work', in C. Tilly (ed.), Durable inequality, 74-II6. Berkeley: University of California Press.

Tomlinson, F. \& S. Egan (2002), 'From marginalization to (dis)empowerment: organizing training and employment services for refugees', Human Relations 55 (8): I0I9-1043. 
Virnoche, M.E. (2000), 'Communications equity and information technology: a study of a community network and the experiences of the groups that it served', Dissertation Abstracts International, A: The Humanities and Social Sciences, 6o, I2, 46r4-A.

- \& G.T. Marx (2000), 'Only connect. E. M. Forster in an age of electronic communication: Computer-mediated association and community networks', Sociological Inquiry 67 (I): 85IO०.

Wang, S. \& L. Lo (2005), 'Chinese immigrants in Canada: their changing composition and economic performance', International Migration 43 (3): 35-72.

Webster, F. (2005), 'Making sense of the information age: Sociology and cultural studies', Information, Communication Q Society 8 (4): 439-458.

Weiss, A. (I995), 'Human capital vs. signaling explanations of wages', Journal of Economic Perspectives 9 (4): I33-I54.

Wellman, B. (I992), 'Men in networks: private communities, domestic friendships', in P. Nardi (ed.), Men's friendships, 74-II4. Newbury Park, CA: Sage Publications.

Zweig, D. \& C.G. Chen (1995), China's brain drain to the U.S.: views of overseas Chinese students and scholars in the 1990s. Berkeley, Calif.: Institute of East Asian Studies. 



\title{
5 Cyberactivism in the Women's Movement
}

\author{
A Comparison of Feminist Practices by Women Organizing \\ in Mainland China and Hong Kong
}

\author{
LIU Ting
}

In response to the presence of activism on the Internet, social-movement theorists have coined the concept 'cyberactivism' to describe social movements which demand cultural and social change, such as the feminist ones, and can take shape in the virtual world (McCaughey \& Ayers 2003; Naples 1998; Rheingold 1994). After comparing collective identity among online and offline feminist activists, one of these theorists, Ayers (Ayers 2003: I6I-I62) especially calls into question 'the nature of what comprises a social-movement group in cyberspace' and 'how, if at all, social movement(s) work online'. This chapter explores the issue of cyberactivism in the complex cultural context of contemporary China. Specifically, it examines Chinese cyber feminist activism as it responds to and functions within different underlying political and economic conditions.

There have been a number of discussions of Chinese netizens' involvement with political issues in the global media (Kabul Press 2004; AP 2004). In addition, there has been some interest from academics about state-led feminist-activism in cyberspace (McLaren 2003). However, almost no research has been carried out comparing women's political activities in cyberspace in mainland China with those of Hong Kong. This chapter examines how the growth of feminist net presence reflects the nature and shape of political activism in the women's movements of contemporary China by exploring the emergence of feminist activities in cyberspace across websites maintained by nine feminist websites in China and two in Hong Kong. These feminist websites were all established with the explicit goals of furthering gender equality and/or protecting women's interests. They were selected from a list of active women's groups which updated their websites frequently when the research was conducted. In addition to surfing online to compare the contents of different Web spaces, a respondent interview process 
has been carried out on a face-to-face manner during my visits to Beijing, Tianjing, Xian, Wuhan, Guangzhou, Shanghai and Hong Kong. Views were sought from a total of eighteen people, mainly from selected mainland websites, on their online practices. While the majority of the websites are from China, the two chosen from Hong Kong are still useful for showing the similarities and difference in women cyberactivism in these two regions. These offline interviews unveil the changes in the process of digitalization of women's groups over times which are not available from the information available on their websites.

In the first section, I apply feminist-activism theories to analyse the role of women's concern groups in feminist movements in the Chinese context. The second section summarizes the new trend in the women's movement towards digitalization. I cite some examples in the third section to show the extent to which Information Communication Technology (ICT) creates opportunities for increasing the diversity of women's activism and feminism. Finally, I examine the strategies that feminist activists employ in using the Internet.

Following the lead of Jaschok and Milwertz, this chapter uses the term 'organizing' in place of 'organization' (including 'non-governmental organization' or 'non-profit organization') (Jaschok et al. 200I: 6; Milwertz 2002: I). In doing so, the debate over 'structural features of organization' in China's party-state system can be avoided (Jaschok et al. 200I: 6). Also, the use of this term enables this study to focus primarily on the process of organizing itself and the shifting and dynamic character of women organizing activities that aim to create social change' (Jaschok et al. 200I: 6-7). Many researchers suggest that women enter the political sphere through the practice of organizing, as this process shapes participants' awareness of dominant gender relations and gender politics in society (Chatty \& Rabo I997; Naples I998; Basu I995). This process of organizing, including the activism to which it leads, is centring on the action of a social movement (Eyerman \& Jamison I99I; Eyerman \& Jamison I998). Organizing here is defined as 'a method by which citizens, diverse groups and organizations, including corporations, attempt to create what they envision to be the good society' (Christensen-Ruffman I995: 374). Through the cultural and social process of organizing, new thoughts and practices related to gender and political participation and a collective identity develop in a women's movement (Milwertz 2002: II). 


\section{Women's Movements and Women Organizing}

Studies of women organizing around the world recognize that women's concern groups with an activist element enable feminism to participate directly in effecting social change. Largely based on women's life-world experience, feminism takes diverse shapes. On the one hand, it refers to 'the theory of the political, economic, and social equality of the sexes' (Lai et al. I997: 269). On the other, feminism can be defined as women's groups 'organized for change, whose agendas AND/OR actions challenge women's subordinate [or disadvantaged] status' in society in general and in their own community (Gluck I998: 34). Hence, with feminist theories running interactively, 'consciousness-raising groups' are one of the most typical activities of modern feminism (Dahlerup I986). Identified as 'expressions of feminism' (Milwertz 2002: 9), activism is the core component for understanding women's movements.

The women's movement in Hong Kong has long resembled that of the feminist movement in the West (Tang et al. 2000: 20I). Especially in the I980s, many educated women initiated women's groups 'to raise women's awareness and to promote the fight for rights of women', and then spread 'the idea and action to women at the grassroots level' (Lai et al. I997: 30I). Despite great improvements in various social fields, the persistence of gender discrimination at work and gender disparity in wages suggest that 'Hong Kong women continue to occupy a disadvantaged position in society' (Tang et al. 2000: 204). Currently over 200 women's groups are working with specific focuses in Hong Kong.

Since the I990s, women organizing in mainland China have largely duplicated the approaches of the I980s Hong Kong women's groups. China researchers have identified the formation of a phase of the mainland Chinese women's movement specific to the years since the I990 - it is a period that has featured the proliferation in activities of popular women's organizations (Wesoky 2002; Milwertz 2002: 5; Liu I99I; Hsiung et al. 200I). Milwertz (2002: 6) writes that women in this period of an incipient independent women's movement have established groups, organizations and networks, and organized activities on their own initiatives. Activists have found office places and meeting space, sought funding, and strengthened organizational construction. They have also managed development projects, established social services to support women in vulnerable situations, and made their voices heard in the media and through policy recommendations (Milwertz 2002; Hsiung et al. 200I). All of these 'form the basis for challenging dominant discourses on women and gender issues' (Milwertz 2002: 5).

Before this development, for a long time 'there was a top-down women's movement in China, initiated by the Party-led All China Women's Federation (ACWF). It was sarcastically dubbed a 'move women 
movement' instead of a "women's movement” (Feng 2000: I). 'Feminism' has not been commonly used to describe women's movements in mainland China until recently (Lin 1997). Many theorists have explored the complex process of Chinese acquiring the concept feminism since the movement toward 'self consciousness' and 'self awareness' emerged in the I980s. Some, like Li Xiaojiang, argue that 'feminism' carried a negative connotation, since it was viewed as a Western bourgeois concept contradicting the discourse of Marxist class-centred liberation (Li I999: 268). Others, such as Ding Xiaoqi, recognize that women designated as feminists are commonly labelled 'mannish women' or 'freaks of nature' in Chinese society (Ding I99I: III). Moreover, the state did not support feminism, and consequently women refused to have their names linked to the tag 'feminist' (Liu 2002; Lin I997; He 2004).

The rejection of the Western conception of feminism has gradually declined since the introduction and translation of works of Western feminism in the mid-I980 as part of 'the trend in westernization' (He 2003). However, the efforts to indigenize feminist theories and practice based on China's reality continue unabated. Feminism has been commonly translated as nüxing zhuyi to emphasize gender difference. The old Chinese term nüxing zhuyi, mainly in circulation before the I990s, which implied aggressive demands for 'women's political rights reminiscent of the earlier women's suffrage movements in China and in the West' was almost abandoned in the I990s' women's movement (Liu 2002: I5I). After a carefully maintained distance to the public enquiry to nüquan (women's rights), the Web has revealed a possible revival of the demand for women's rights from some groups. In 2005, the relatively radical Sex/Gender Education Forum specifically added a new column on their website entitled funü weiquan (protection of women's rights). In 2006, a small group of young people reorganized their cyberspace as nüquan Zhongguo (women's rights in China) based on several women's forums on university networks run by them previously. A founder emphasized their preference for nüquan in my interview with her:

'It was too sensitive to mention "rights" after the Liberation and the Cultural Revolution; however, many women's rights do get suppressed, for example, women's rights to explore and express their sexaultiy.... Lack of enquiry to rights has led to lack of actions.... The academic kind of approach can make social progress in gender issues, but it is not direct enough in action-taking'. (Feminism China) 
Although the adequacy of the appropriation of Western feminism to understanding the Chinese women's movement is still called into question, it is clear that 'more and more researchers started borrowing feminist theory resources' in an attempt to explain women's situation in China, a country in great transformation. Scholars around the world simultaneously began acknowledging 'diversity in women's activism and feminism' in Western and non-Western countries (Milwertz 2002: 9). For example, Milwertz argues that 'organizing by women in Beijing qualifies as social movement activism' because 'nondisruptive modes of action' applied in the movement are 'active in the Chinese political context' (Milwertz 2002: 4-5), although such organizing may not fully match the boundaries given by Dehlerup (I986) for a strict definition of social movement. ${ }^{\mathrm{I}}$

Regardless of these new developments, there have always been concerns over how to link en masse with the current women's movement. For example, $\mathrm{Pu}$ (2004) questions the low degree of women's autonomy at grassroots' level, while 'more often women appear to be organized and helped' in the mainland media. In Hong Kong's case, researchers and activists have suggested that the tradition of women's 'groups with a strong grass-root basis' should be continued (Tang et al. 2000: 202-203). Women organizing have historically incorporated communication technologies such as newspaper, radio, TV, and film into efforts to connect with and mobilize a broader society to be concerned with women's interests and issues. More and more citizens all around China adopt online communication, but the interactive Internet technology is hardly new to women organizing. A wave of digitalization of women organizing has been in progress since the start of the $2 \mathrm{I}^{\text {st }}$ century.

\section{Women Organizing Digitalization}

Before moving on to women organizing cyber practice, I will provide a summary of the use of the Internet respectively in Hong Kong, Beijing, and Shaanxi Province where most of my fieldwork was conducted. Hong Kong has been among the most developed areas in the world in terms of digitalization. In 2003 around 67 per cent of the population were Internet users (see Table 5.I below). The number of Internet users is also growing rapidly in mainland China, especially in big cities such as Beijing where the number of Internet users in Beijing is expected to equal that of Hong Kong very soon. However, the use of the Internet on the mainland as a whole is still under-developed, especially in more remote areas like Shaanxi Province, where they comprise less than 6 per cent of the provincial population. The geographical 'digital divide' 
cannot be ignored. Accordingly, my investigation of websites recognizes this problem as central to the exploration of women's involvement in ICTs in China.

Table 5.1 Overall use of the Internet in Hong Kong, Beijing and Shaanxi in 2003

\begin{tabular}{lllllll}
\hline Prov. & Population & Users & $\begin{array}{l}\text { Publishing } \\
\text { Date }\end{array}$ & $\begin{array}{l}\text { Percentage } \\
\text { of Population }\end{array}$ & Sample Age & Source \\
\hline HK & $6.8 \mathrm{M}$ & $4.6 \mathrm{M}$ & Feb-04 & $67.50 \%$ & 10 and above & Nielsen/NetRatings \\
BJ & $14.2 \mathrm{M}$ & $3.98 \mathrm{M}$ & Feb-04 & $28 \%$ & Above 6 & CNNIC \\
SX & $36.4 \mathrm{M}$ & $1.97 \mathrm{M}$ & Feb-04 & $5.40 \%$ & Above 6 & CNNIC \\
\hline
\end{tabular}

Despite the overall 'digital divide' among women living in different regions, establishing websites has become more common for women's groups all over the world. Cyber-women organizing in mainland China were no slower than their counterparts in Hong Kong to commence the new wave of digitalization. The establishment dates of all websites selected in this study indicate that digitalization of women organizing happened nearly simultaneously (see Table 5.2 below). Regardless of the region, Chinese women adopted the new webpage technology at almost the same time. However, with the growth in numbers of cyberwomen organizing and the increase of Internet users, a greater diversity of approaches in cyber-feminism and activism emerged.

Table 5.2 The establishment of women organising and their websites

\begin{tabular}{llll}
\hline Province & Name & Organisation & Website \\
\hline Hong Kong & AAF & 1984 & 2000 \\
& Nüxing Wang & 1984 & 2003 \\
\multirow{3}{*}{ Beijing } & Gutsy Women & 1997 & 2002 \\
& Maple & 1988 & 2004 \\
& Genderwatchina & 1996 & 2003 \\
& Woman-legalaid & 1992 & 2002 \\
& Stop DV & 2000 & 2003 \\
& Rural Women & 1993 & 2003 \\
Shaanxi & GAD & 1999 & 2000 \\
& West Women & 1986 & 2002 \\
\hline
\end{tabular}

Chinese women organizing have been working to establish their websites with help from global donors (see Table 5.3 below). The Ford Foundation and Oxfam Hong Kong have played determining and guiding roles in this process of digitalization in mainland China, as they fund seven Chinese women's groups. At least five of these groups acknowledge direct funding of the establishment of the websites. Typical of this sentiment is the Rural Women site that explicitly declares its 
website's objectives to be ‘to propagate the organization's concept, activities and previous work', 'to let more charities understand the organization's advantages, needs, achievements, work scales and plans through the website, and to seek more cooperation opportunities and funding'. The history of West Women indicates the significant influence of foreign donors on women's organizing digitalization in recent China. The original organization of West Women was formed in I986 as an association of women's studies under the local branch of the All China Women's Federation (ACWF). Its liberal activities organized by young scholars were harshly criticized by the Communist Party and stopped for several years after the I989 democracy movement. In I995, Beijing held the Fourth World Conference on Women and this has enabled women activists to more openly rejoin trends from around the world. With this background, the Ford Foundation offered to sponsor training projects on women's legal rights and interests. However, none of the ACWF's local branches were permitted to apply for the fund because of the sensitive background of the Foundation, which revived hibernating West Women. The founder of West Women recalled that 'using the name of the Association the project application was approved eventually. After that, I started to realize that there was a very big space for women NGOs to develop'. In 2002, West Women started to look for sponsors to set up a website after they realized that their major role would not be to replace the role of the government through running projects to serve women's needs, but to advocate certain ideas in to influence government and society. As Hong Kong Oxfam turned down their application, the Ford Foundation eventually gave them a green light.

Clearly, international or exogenous donors' support is a major impetus for women organizing to move into cyberspace. Responding to the availability of little local resource for women to construct their cul-

Table 5.3 Major donors of women organising and their websites in June 2004

\begin{tabular}{|c|c|c|c|c|}
\hline \multirow{2}{*}{$\frac{\text { Website }}{\mathrm{AAF}}$} & \multicolumn{4}{|c|}{ Donor } \\
\hline & HK/ global & & & \\
\hline \multirow[t]{3}{*}{ Nüxing Wang } & Astraea & & & \\
\hline & Lesbian Action & & & \\
\hline & Foundation & & & \\
\hline Gutsy Women & Self-helped & & & \\
\hline Maple & Ford Foundation & & Starr Foundation & Individual (global) \\
\hline Genderwatchina & & Oxfam HK & & \\
\hline Woman-legalaid & Ford Foundation & & Spangenber & \\
\hline Stop DV & Ford Foundation & Oxfam NL & Sida Sweden & Uni OSLO \\
\hline Rural Women & Ford Foundation & Oxfam HK & others (China) & others (global) \\
\hline GAD & & Oxfam HK & Individual (China) & \\
\hline West Women & Ford Foundation & Oxfam HK & Asia Foundation & others (global) \\
\hline
\end{tabular}


tural space, almost all women organizing in mainland China seek funding globally to overcome their common problem of scarce financial resources. An interviewee said:

'[Running a website] needs money. If it runs well, most probably it is commercialized. Since men occupy more social resources, it is mostly them who can offer part of the Web as a cultural space to attract people. For women, the resources they can occupy are not only very little but also mostly foreign'. (Sex/Gender Education Forum)

Another factor behind the great demand for foreign funding is the increasing requirement from women NGOs to improve their work efficiency. A leader of one group said:

'If I could hire professionals to manage the website, I would use them wisely. But if I use volunteers, it would be very hard to require them to finish something within a certain period.... Also, if they were professionals, whether they agreed with my opinions or not, they would have to finish their work, which would make a big difference in work efficiency'. (Sex/Gender Education Forum)

As a result of foreign sponsorship, many new projects have been made possible. For example, to help female village leaders solve everyday problems, Rural Women established 'a supporting network for female village leaders'. With the help of the foreign donors, the group also set up a sub-Web in their website for hundreds of trainees who attended their project which aimed to improve women village leaders' capability in political participation. Six women leaders so far have been given a computer each for the convenience of keeping continuous communication after returning to their working villages.

Donor interest in these websites may have a deeper significance than merely supporting a certain project run by women's groups. For example, the concept of domestic violence was not introduced to China until the mid i99os. The establishment of the website Stop DV (DV for Domestic Violence) exemplifies the efforts of international donors challenging the idea that violence in the home is inconsequential. In some cases, donors can directly influence the agenda of some women's groups. Women Legal Aid established three task forces in 2004 focusing on women's labour rights, domestic violence, and women's property rights based on sponsor's requirements. Besides their initiatives, a new website WomenWatch-China was established accordingly as a result of the project to monitor the situation of the protection of women's 
interests and rights in China. An interviewee explained how they worked out their agenda with donors:

'Sponsors would not interrupt our work directly. But every year when we apply for funding, we negotiate with them about our agenda for the following year. We provide our plan for the following year or several years for their approval in order to get the money' (Women Legal Aid).

As Milwertz (2002) explains, western interest in funding Chinese women organizing has distinct political agendas. Their increasing interest in these women's groups is largely based on the hope of developing civil society in China and transforming China towards a democratic society (Milwertz 2002: 2). Western media have long viewed the Internet as a mechanism by which the public sphere penetrates the party-state's totalising control of information (Liu 2003: 13). Supporting websites can be seen as promoting the emerging civil society in a country where sectors of the mainstream media still resist the influence of Western bodies. Marginalized feminist groups thus have been encouraged to establish their own websites so that they can potentially voice concerns different from those of official or mainstream ideologies.

Apart from directly funding new projects, introducing new concepts, and influencing group agendas, donors can bring changes in the ways of working and thinking among women's groups. While talking about a foreign sponsored project they have been running, an interviewee said: 'This is foreign sponsorship, which ensures a unique way of managing. For example, [we have to] make clear our use of every penny we get from them' (Women Legal Aid). Another interviewee discussed the change in thinking associated with the foreign funded activities:

'The concept of NGO refers to the civil society they talked about. In my understanding it means the democratic way of thinking. If we were still within the official system, it would be meaningless to start up everything top-down again. Now, through our network of membership and volunteers, we are not only learning the new concepts and ways of managing, but also accumulating our perceptual knowledge of running a NGO'. (West Women)

In the case of Hong Kong, the connection between donors and the websites of women organizing is also evident. Nüxing wang, Women's Network was established by the Association for the Advancement of Feminism (AAF) and has been run by a women's sub-group of the AAF. The AAF initiated this special website for creating a space where 
issues like women's sexuality can be discussed in way different from mainstream stereotypes. The website has a section called nü tongzhi (literally meaning 'women comrade', but 'lesbian' in current usage) to address queer issues, especially queer sexuality which is regarded as one of the dimensions of sexuality the group want to talk about. The AAF then sought funding from the Astraea Lesbian Action Foundation in the United States for the construction of the website. Therefore, the foundation of nüxing wang is a result of common ground these two organizations share on lesbian issues in the Hong Kong region. Sometimes, lack of funding from agencies can result in increasing inactivity of women's websites. Gutsy Women, whose trademark was its independence taking control of its own agendas, had to minimize its action and its consultancy and information dissemination because it failed to get funding. A member of the group expressed her disappointment in an interview with me in 2005 . She said:

'The original idea was that after one year self-funded staff condition, we can get funding to show how effective we can be. But it was sad and disappointing to say even though we've had, I would say, very very good impact, these issues about women's slimming trend, women's sexuality, [and] women against violence, are still quite marginalized. We just failed to get funding'. (Gutsy Women)

\section{$4 \quad$ Cyberactivism and Women Organizing}

It is difficult to find widely accepted boundaries of cyberactivism largely because activism takes many forms in cyberspace. Activists and scholars have long debated the legitimacy of cyberactivism (McCaughey \& Ayers 2003). Vegh (2003: 7I-72) neatly defines cyberactivism as 'a politically motivated movement relying on the Internet', but admits that activists can take different strategies and be either 'Internet-enhanced' or 'Internet-based'. The types of online activism are further classified into three general categories: awareness/advocacy, organization/mobilization, and action/reaction. In the following discussion, I apply Vegh's classification system to examine women organizing cyber activities in Beijing, Shaanxi and Hong Kong.

\subsection{Awareness/advocacy}

The primary process of distributing and accessing information has important implications for cyberactivism. As Vegh (2003: 72) points out, 'public awareness is achieved by accessing information that is relevant 
to the cause'. For website hosts and users, 'access to alternate forms of information and, most important, the power to reach others with your own alternatives to the official views of event, are, by their nature, political phenomena' (Rheingold I994). Generally, different women organizing with certain concerns manage various online awareness campaigns to raise public consciousness of women issues.

The most common method used in online advocacy is to provide users with educational information and resources, on the websites, that favour the cause. News updates in text and photos, Internet-transmitted laser-projected messaging, internal mailing lists, and online collection of publication information are the basic patterns of this type of cyberactivism. In Hong Kong, nüxing wang also has a Web radio program which discusses sex issues and targets teenagers; Gutsy Women provides an online video program.

There are several reasons that women's groups in mainland China are slower in using technological tools to enrich their Web performance. In an interview with a leader of a women's group in mainland China, technological difficulty was considered one of the major obstacles 'since video files are too big to be watched online clearly and comfortably' (Sex/Gender Education Forum). According to the same conversation, keeping the distribution of videos that the group shoots merely in a person-to-person way among academics is a result of 'concerns about Web users' responses [to these programs] without any professional guidance while watching'.

With fewer technological obstacles and fewer concerns, women organizing in Hong Kong have used a wider variety of online technological tools to distribute their ideas and match their tasks in cyberspace than their counterparts on the mainland. However, they have also encountered various difficulties. Taking the Gutsy Women's video program as an example, it was initiated by another group called the Self-help Centre which organized some small groups without funding, office space or infrastructure to take on different times to have a video broadcasts online. Later they found that the number of people who went online to see the videos were few and the broadcasting was stopped. The low quality of the program is one of the reasons for attracting small audience. A group member reviews one of the visual programs they produced:

'We just want different guests, different people to talk [about topics we raised]. Once we invited a friend who also felt strongly about the anti-slimming campaign. She is a big woman and she, of course, suffered a lot from discrimination. We just carried on that discussion in front of the video camera. We were sitting on the sofa and it is quite boring to see three people just 
talk. And we don't have other techniques because it is just technically infeasible for us to go so complicated'. (Gutsy Women)

A further area of divergence between Hong Kong-based websites and their counterparts on the mainland is in the ideas and knowledge that they seek to convey. The main difference is in the area of politics of sexuality and sexual orientation. Nüxing wang in Hong Kong provides sections for marginalized groups such as sex workers, gays and lesbians, and teenagers. Similarly, Gutsy Women advocates women's rights to their sexual freedom. In contrast, there is little such information in the websites of mainland women organizing except Sex/Gender Education Forum in which organized activities opposing discrimination against homosexuals in China were recorded. Different from the conservative attitude held by most women's groups, sexuality might have been the most liberal topic in the Chinese cyberspace. This has forced the state to run campaign after campaign attempting to put the virtual world under its control. The most radical move has been the efforts made by Li Yinhe, a famous sexologist, to legalize sex-same marriage in China, which often makes her personal blog a controversial forum for heated debates.

The separation of feminists and lesbians on the mainland women organizing emerged probably for the following reasons.

First, the discussion of feminism in mainland China focuses on macrosocietal problems that have been officially recognized as sites for intervention by the central party/government. These include problems of marriage and family (including domestic violence), poverty, political participation, and education.

Second, Chinese feminism is currently at a stage of prioritising its own specific goals, and this renders it insensitive to seeking simultaneous improvements for other marginalized groups. As one of the interviewees explains, 'the space party/government has left to us at this stage is big enough for us to work on... we can hardly meet the needs even now' (Rural Women). Mainland feminist groups do not make the connection between their own marginalized status and other marginalized groups. Nor do they connect their own goals of seeking social justice and equal rights with those of other groups. Mainland Chinese feminists have not yet enunciated an understanding of this broader political aspect of the feminist movement. Instead, they struggle alone and often treat other marginalized groups with the same hierarchical mentality found in traditional patriarchal social orders. Within this ideology, lesbians are somehow regarded as having different, lesser rights than other women and less legitimate claims to equality and social justice. 
Third, the party/government has never regarded social inequalities based on sexuality as fundamental or significant problems. Also, mainstream Chinese culture is largely intolerant of non-mainstream sexual orientation (Liu 2003). Widespread awkwardness and embarrassment about sexuality and non-mainstream sexual orientations has consolidated the separation between the mainstream feminist movement and lesbian political movement on the mainland China.

Both Hong Kong and mainland China's women's groups have influenced public debate through their activism - their websites have been major vehicles for espousing their views and promoting them to society at large. For example, on 8 October 2002, the Apple Daily and the Oriental Daily reported on their frontpages the story of a sex worker who had been robbed and held hostage. To accompany the story, both papers published a large picture of the woman - unclothed and still in the clutches of her attacker - as well as her address. The AAF issued a statement condemning the two newspapers, saying that by printing the picture and the address of the victim, they reinforced society's discrimination and denigration of sex workers' bodies. The AAF also lodged a complaint with the Hong Kong Journalists' Association and the Hong Kong Press Council. The Hong Kong Press Council replied at the end of October 2002 that they had issued a statement declaring that the two newspapers had violated the professional guidelines. They also reported that this particular incident would be used in future education campaigns for professionals.

On the Mainland, a women's group worked with other media outlets to achieve its goal of challenging the acceptability of invoking the traditional marriage practice of men keeping 'second wives'. At New Year 2003, a real estate company posted an advert in Beijing asking 'Do you have a second house? (niyou di'ertao fang ma?)'. However, the wording was manipulated to appear as 'Do you have a second wife? (niyou erfang ma?)'. Women Watch China issued criticism jointly with the ACWF's newspaper China Women's News to protest against the company's invocation of traditional norms that discriminated against women. On I3 January, the company was forced to remove all its posters from its Beijing branches as a result of media pressure. The Beijing ACWF and the Capital Women Journalists Association also issued a statement urging the government to take legislative action against the misrepresentation and under-representation of women in media. Details of the protest can be found in both the Women Watch China website and the China Women's News online edition.

Another form of online advocacy is the formation of networks for information-distribution. Stop DV offers a section called 'Journalists' Toolkit' to provide media workers with advice on how to report issues relating to domestic violence, as well as on ethical matters. Journalists 
can also access collections of previous reports published by famous journalists and pictures of the group's activities for downloading, and subscribe to mailing lists to receive automatic email notice of upcoming events. The site invites comment from users to enable Stop DV to serve journalists better in promoting knowledge about domestic violence. The aim of this type of online advocacy is fairly straightforward: to encourage media involvement in the group's work and to have their voices heard by the public at large through mainstream media reportage.

Vegh classifies three types of online lobbying: the first is 'aimed at one's own government's legislative body'; the second, at 'coalitions formed around a particular issue'; and the third 'targets the government of oppressive regimes' (Vegh 2003: 74). Lobbying is a standard form of advocacy in most Western democracies, and can be found among the offline activities of Hong Kong women organizing. But no direct involvement of online lobbying methods have been observed in the Hong Kong websites selected in this research.

Lobbying practices are relatively new to mainland China. For instance, a leader of a women's group claims on the website that, as a civil group, it is impossible for them to influence legislation directly. Current lobbying conducted by women organizing in mainland China still concentrates on effecting legal change offline, and the Internet is mainly used to promote awareness of the groups' achievements and their offline efforts to seek changes in the law. For instance, a member of Women Legal Aid said:

'We have submitted our amendment to the draft law of the People's Republic of China on the protection of rights and interests of women which can be found in our website. The ACWF, the semi-official organization having its own funding resources just like Labour Union, also has its amendment to the draft law. We handed in our proposal through a certain channel. It was completed from our perspectives and did not consult others. It would be pointless if different versions were largely identical but just with minor differences'. (Women Legal Aid)

Websites of women's groups in mainland China are often used as places wherein offline lobbying practices can be recorded. However, several examples have shown that views spreading via the Internet do have certain influence on governments' legislative bodies. A famous instance is Sun Zhigang's case. Sun, a young graphic designer from Wuhan, was arrested as a vagrant on the streets of Guangzhou and beaten to death for not carrying ID (China Daily 2003). He is perceived as a victim of the previous chaotic management of the mobile population. 
After his death, the old holding system to force urban vagrants and beggars back to their rural or regional hometown was abolished in China, due to the strong protests from the public (Amnesty International 2003). Voices from Web users were certainly part of these protests and were crucial in forming public opinions over this issue. Not many people, though, know that a women's group, the Sex/Gender Education Forum, contributed one of the earliest voices to Sun's case sent out to the Web. The difficulty of breaking into mainstream media and the efficiency of distributing alternative opinions in the Web partly resulted in the establishment of the website of this women's group located at the Sun Yat-sen University, Guangzhou. This group then started to use the Web for furthering civil participation concerning gender issues in the region, on their own initiative. One instance is the Sex/Gender Education Forums Alliance with other women's groups such as Stop DV to advocate public awareness and legal reform in cases of domestic violence through advancing Huang Jing's case online. This advocacy has caused some judicial modification and will be discussed later in this chapter.

The above instances indicate that successful online advocacy usually combines different forms of activism in both real and virtual worlds. Moreover, in most websites of women organizing, online advocacy campaigns seem to be largely an expansion and a narration of their offline actions.

\subsection{Organization/mobilization}

The first way to use the Internet for mobilization is to distribute emails or post messages on websites to call for offline actions - for example, attendance at a demonstration or rally (Vegh 2003: 74). Very few such calls for public assembly have been found in mainland websites selected for this research, though a similar form of mobilization may exist in the use of group mailing lists. For example, the Gender Watch China utilizes a mailing list to encourage members to write on women issues in the media. Some of women's group members admit that they are conservative in mobilising their users to conduct radical actions for the 'survival' of the websites and host groups. It is a strategic decision, which many of the groups make so as not to pay too high a price for advocating their causes.

However, in some online forums and websites focused on the advancement of feminism and maintained by young netizens in mainland China, messages such as those calling for attendance at feminism training sessions run by formal women's groups can be found. This has largely been a matter of one-way communication between women's groups and these young forum participants. An interviewee who is a 
moderator of a forum said: 'They [women's groups] don't care what we have been doing... I think I have been trying to squeeze myself into [them], but it is a small circle and very difficult to enter for us' (Feminism China). For members of women's groups, another side of the story exists. An interviewee from a women's group explains why they seldom respond to their Web visitors: 'We have too much to do already... We just don't have more energy to take care of our website visitors' (Sex/ Gender Education Forum).

Now young people have started to initiate their own actions via their websites, although they may not have any financial support from international funding groups as the more formal women's groups do. For example, on 16 January 2005, the Feminism China (Nüquan Zhongguo), a website claiming to be 'the largest website providing feminist resources' in China, which was established by a small group of self-organized young graduates living in different cities, started to recruit players to perform the Vagina Monologues (now given the title Brave Flowers in Chinese) in Beijing. This call is a real challenge - a previous attempt to perform this play in public by another women's group, Stop DV, was prohibited in Beijing around 2003.

Similarly, websites of Hong Kong women's groups have been spaces for Hong Kong citizens to practice a kind of cyberactivism by posting messages calling for actions in the real world. The response of women's groups to the protest against the interpretation of the Basic Law by the Standing Committee of the National People's Congress (NPC) on II April 2004 stands as an example. The AAF, as a regular practice, published a review of its involvement in and position on the rally on the day the action was taken. A member said: 'I think we haven't launched anything in large scale after the Internet became so important, not for women's issues. But for the I July March, we have by mobilising people to attend'. On Gutsy Women, no call was sent out from the website's host group, but on its message board user, 'Barber' posted a message entitled 'Will you join the protest against the interpretation of the Basic Law' in the early morning one day before the action, giving details of the meeting place and time, and called for university students to attend. ${ }^{2}$ User 'Red-eyed' responded, 'I will go, too' that night, and shortly after his/her reply another user, 'Uphold', posted a message to 'Support NPC's interpretation'.

The second method of organization/mobilization is to "call for an action that normally happens offline, but can be more efficiently done online' (Vegh 2003: 74). The outcrop of this type of cyberactivism is present in both mainland China and Hong Kong. However, while organization/mobilization now often involves both offline and online actions, it is hard to evaluate their effectiveness respectively. For example, Gutsy Women - a young, small and self-supporting women's concern 
group in Hong Kong - provides a good example in its mobilization of users to take part in an online petition aiming to remove sexual harassment against women in public transportation. Nüxing wang, hosted by the AAF which struggled for the same cause in the r980s, also joined the email petition, supporting the action by including details in its 'Activity Information' section and by making a link to Gutsy Women website. Nonetheless, Gutsy Women admit that they cannot say that the current achievement of this campaign is mainly because of the online petition. The group conducted a survey on sexual harassment in public transportation in Hong Kong and found that the problem was serious. Consequently, they held a press conference to release their survey results and got a cover page in the Apple Daily, one of the biggest newspapers in Hong Kong. Afterwards, they started an online petition asking citizens to join. But even before they passed the petition through to the government, they had already received the response that the posters would be put on. In July 2004, bus route No. 9 became the first public transport route to post a pink poster in its vehicles that reminded female passengers not to keep quiet if sexually harassed on buses. Interestingly, this achievement triggered a debate on the message board of Gutsy Women because some male users felt discriminated against by the specific mention of 'female passengers' on the poster. They said male passengers might face similar problems but they might not feel being encouraged and supported if they complained. Overall, the success of this case indicates that the cyberspace has provided opportunities for small women's groups to mobilize public opinion while mainstream media still plays a major role in publicising their campaigns.

In the case of mainland China, similar online action has been taken in seeking solutions to specific women's issues. An example is a campaign West Women organized to fight against domestic violence. A woman, a long term member of its domestic violence victim group, was seeking a divorce after years of suffering but was murdered by her husband. The husband was prepared to jump off a building after the killing but was rescued. On the following day, local media releases in the local mainstream media reported this case with a strong bias indicating that the husband committed the crime because the victim had long been discriminating him for he was a laid-off worker. A member recalled,

'We organized a series of activities in which her friends and family members could speak for her... We posted all the information and opened a forum for further discussion on this case... Many people noticed that our views were very different from official media... After several cases like this, we found that the 
website was very useful... We are now making it a kind of medium in our hands... in which we are actively voicing our opinions'. (West Women)

Another example is the involvement of women's groups in the ongoing online petition demanding a complete police investigation into the death of Huang Jing. Stop DV set up a special section on the investigation of the death of female teacher Huang Jing, who was found dead and naked at her school dormitory in Hunan Province on 24 February 2003. Huang was suspected of having died as a result of date rape. Police failed to investigate a stalker suspected of involvement and subsequently faced allegations of trying to cover the truth. Huang Jing's case drew public attention to date rape and domestic violence generally, as well as to issues of social justice and the competence of the forensic appraisal system. In the special section on Huang Jing's case, users could find detailed reports on legal medical checkups given by different forensic appraisal bodies; Huang Jing's online memorial; netizens' comments and articles; special sections in other websites such as the Sex/ Gender Education Forum; and, significantly, an online petition link to the NPC, the High Court, the Police and the Judiciary. The first set of more than two thousand netizens signed the online petition in 2003 . The initiators affirmed that the action was to continue until the case was solved. Users have further called for a fund to be established to help support Huang's family.

Strong public pressure resulted in the authories to suppressing protest voices. But some people from women's groups insisted in speaking out online when mainstream media became relatively silent in this matter. Many scholars were called upon to sign their names for support of a fair investigation of Huang's case in memorial activities organized by women's groups. Consequently, the proposed resolution No. I342 was formed in a meeting of the Standing Committee of the NPC which pushed for a national judicial change. The case was reopened for judicial inquiry once again in 2004. As a direct result, on I October 2005, qualified agents started to play a major role in forensic appraisal system - a judicial reform replacing the previous system whereby examinations for legal purpose were controlled by different mechanisms such as the court and the judicial administration, often leading to contradictions and doubts (Du 2005).

The third method of organization and mobilization in cyberspace is 'action/reaction' - that is, to 'call for an online action that can only possibly be carried out online' (Vegh 2003: 75). This is considered, by Vegh, to fall into the last category of cyberactivism, 'hacktivism', which refers to online attacks committed by 'hackers' (Vegh 2003: 75). There is no evidence of women's groups organizing this type of cyberactivism 
in either Hong Kong or mainland China. However, there have been examples of users attacking the women organizing websites. Often, uninvited advertisements and baleful posting on message boards are a source of annoyance to women's groups. More seriously, users' attacks can highly damage the women organizing cyberspace. In an interview, a member described the unpleasant experience they had in shutting down their message board which used to be fairly active:

'You know how the Internet is organized. You don't need to review your true identity. People just put nonsense, even foul language, [and] very disgusting comments both towards our work and towards each other's comments. That was really a very damage-making stage... There was a discussion, but I cannot really remember what it is about because it is really not a rational discussion at all. It became a forum for finding fault in each other's lines. There was a particular person who thought he had a lot of logic and this women's group had no logic. He attacked us as having double standards, discriminated against men, and menhating. He was attacking us and we of course were engaged into some kind of argument for some time. At some point, he started to flood our message board with disgusting comments, with foul language. You see the message board has a whole page of such comments. That is when we think we want to shut it down'. (Gutsy Women)

\section{Conclusions}

In this chapter, I have examined the uses of different types of cyberactivism by women organizing in pursuing their goals in mainland China and Hong Kong. The forms of cyberactivism women organize apply differently from group to group. The effectiveness of these forms of online action also needs to be justified from case to case. This study indicates that women's groups in Hong Kong have taken more advantage of the technologies and techniques provided by the Internet to distribute their information. They also have a more relaxed political environment and less concern about their survival while conducting online action. Women's groups in Hong Kong occasionally progress to the second step of organizing and mobilising their websites' users to take online or offline action on their own initiative. Women organizing in mainland China are primarily still concentrating on the very first step of online activism: seeking and distributing basic information and advocating public awareness. However, some of these women's groups 
and the younger generations who have just joined the cause have started to call for users' participation in their campaigns.

Despite these differences, these strategies of all ten women's groups discussed in this chapter are essentially Internet-enhanced rather than Internet-based. As Vegh (2003: 72) points out, 'In the former case, the Internet is only used to enhance the traditional advocacy techniques, for example, as an additional communication channel, by raising awareness beyond the scope possible before the Internet, or by coordinating action more efficiently'. Such a move into cyberspace benefits the feminist movement by linking online action and offline action. However, if overused, this risks changing the websites into electronic notepads for women organizing. One effective way to overcome this problem is to attract more users to participate in websites' discursive communities and inspire them to take actions for women's causes. Logging onto the Web provides diverse possibilities for women organizing to practice cyberactivism. But this is not merely a technological matter. Broader public involvement and stronger cooperation among diverse groups plays a more determining role in enhancing the power of civil society over women-related issues.

\section{Notes}

I. According to Dehlerup, a social movement is 'a conscious, collective activity to promote social change, with some degree of organization and with the commitment and active participation of members or activists as its main resource'. Three characteristics are further added to this definition: I) 'a combination of spontaneity and organization'; 2) 'direct actions and disruptive tactics'; and 3) 'an entity of activities by organizations, groups and followers who share a commitment to a common cause'.

2. The names of interviewees in this chapter have been changed to protect the identities of those whose postings or messages are cited.

\section{Related Websites}

AAF (www.aaf.org.hk)

GAD in China (www.chinagad.org)

Gender Watch China (www.genderwatchina.org)

Gutsy Women (www.gutsywomen.org.hk)

Maple (www.maple.org.cn)

Nüxing Wang (www.nuxingwang.org.hk)

Rural Women (www.nongjianv.org)

Stop DV (www.stopdv.org.cn)

West Women (www.westwomen.org)

Woman Legal Aid (www.woman-legalaid.org.cn)

Sex/Gender Education Forum (genders.zsu.edu.cn)

Feminism China (www.feminism.cn) 


\section{References}

Amnesty International (2003), 'Migrant worker dies in custody'. web.amnesty.org/web/wire. nsf/print/July2003China [Retrieved I2 August 2004]

AP (2004), 'China's "netizens" log on to parliament', Taipei Times. Taipei, I4 May 2004.

Ayers, M.D. (2003), 'Comparing collective identity in online and offline feminist activists', in M. Mccaughey \& M.D. Ayers (eds.), Cyberactivism: online activism in theory and practice, I45-I64. New York \& London: Routledge.

Basu, A. (I995), 'Introduction', in A. Basu \& C.E. Mcgrory (eds.), The challenge of local feminisms: women's movements in global perspective, I-24. Boulder: Westview Press.

Chatty, D. \& A. Rabo (eds.) (I997), Organizing women: formal and informal women's groups in the Middle East. Oxford \& New York: Berg.

China Daily (2003), 'Sun Zhigang's brutal killers sentenced', China Daily. Beijing, Io June 2003 .

Christensen-Ruffman, L. (I995), 'Women's conceptions of the political: three Canadian women's organizations', in M.M. Feree \& P.Y. Martin (eds.), Feminist organizations: harvest of the new women's movement, 372-396. Philadelphia: Temple University Press.

Dahlerup, D. (I986), 'Is the new women's movement dead? Decline or change of the Danish movement', in D. Dahlerup (ed.), The new women's movement: feminism and political power in Europe and the USA. London: Sage Publications.

Ding, X. (I99I), 'Feminism in China', Asian Studies Review I5: III-II3.

$\mathrm{Du}, \mathrm{W}$. (2005), 'New regulations launched formally on I October: a new forensic appraisal system towards unity (Xingui shiyue yiri zhengshi shishi: sifajianding guanli zouxiang tongyi', People's Daily. Beijing, 28 September 2005.

Eyerman, R. \& A. Jamison (I99I), Social movements: a cognitive approach. Oxford: Polity Press.

Eyerman, R. \& A. Jamison (1998), Music and social movements. Cambridge: Cambridge University Press.

Feng, Y. (2000), 'Claim rights: beyond the slogan and provisions'. www.philantrophy.org [Retrieved I2 August 2004]

Gluck, S.B. (I998), 'Whose feminism, whose history? Reflections on excavating the history of (the) US women's movement', in N.A. Naples (ed.), Community activism and feminist politics: organizing across race, class, and gender, 3I-56. New York \& London: Routledge.

He, G. (2003), 'Three resources for contemporary women's literary critics (Dangdai nüxing wenxue piping de sanzhong ziyuan)', Xinhua Digest (Xinhua wenzhai) 3.

Hsiung, P.C., M. Jaschok, C. Milwertz \& B. Chan (eds.) (200I), Chinese women organizing: cadres, feminists, Muslims, queers. Oxford \& New York: Berg.

Jaschok, M., C. Milwertz \& P.C. Hsiung (200I), 'Introduction', in P.C. Hsiung, M. Jaschok, C. Milwertz \& B. Chan (eds.), Chinese women organizing: cadres, feminists, Muslims, queers, 3-24. Oxford \& New York: Berg.

Kabul Press (2004), 'Huang Qi Awarded 2004 Cyberfreedom Prize', Kabul Press, 24 June 2004 .

Lai, B.L.L., K.C. Au \& F.M. Cheung (I997), 'Women's concern groups in Hong Kong', in F. M. Cheung (ed.), Engendering Hong Kong society: a gender perspective of women's status, 267306. Hong Kong: The Chinese University Press.

Li, X. (I999), 'With what discourse do we reflect on Chinese women? Thoughts on transnational feminism in China', in M.M.H. Yang (ed.), Spaces Of their own: women's public sphere in transnational China, 26I-277. Minneapolis \& London: University Of Minnesota Press.

Lin, C. (1997), 'Finding a language: feminism and women's movements in contemporary China', in J.W. Scott, C. Kaplan \& D. Keates (eds.), Transitions, environments, translations: feminism in international politics, II-20. New York \& London: Routledge. 
Liu, B. (2003), 'Refuse? integration? cooperation? Discussing the relationship between feminism and lesbianism in China (Jüchi? rentong? xieshou? Tantao zhongguo nüxingzhuyi yu nütongxinglian de guanxi)', Friend Correspondence (Pengyou tongxin ). www.powow. com/friend/tantaonu.htm [Retrieved 22 June 2005]

Liu, L.H. (2002), 'Invention and intervention: the making of a female tradition in modern Chinese literature', in S. Brownell \& J.N. Wasserstrom (eds.), Chinese femininities/Chinese masculinities: a reader, I49-I74. Berkeley, Los Angeles \& London: University Of California Press.

Liu, T. (2003), 'Speaking out on online forums: the emerging public spheres in China', M.A. dissertation. School Of Arts, Media \& Culture, Griffith University.

Mccaughey, M. \& M.D. Ayers (eds.) (2003), Cyberactivism: online activism in theory and practice. New York \& London: Routledge.

- (2003), 'Introduction', in M. Mccaughey \& M. D. Ayers (eds.), Cyberactivism: online activism in theory and practice, I-24. New York \& London: Routledge.

Mclaren, A. (2003), 'Targeting Chinese women: constructing a female cyberspace', paper presented at the Women, information and communication technology in India and China Forum, the University of South Australia, 5-7 November 2003.

Milwertz, C. (2002), Beijing women organizing for change: a new wave of the Chinese women's movement. Copenhagen: NIAS Press.

Naples, N.A. (ed.) (1998), Community activism and feminist politics. New York \& London: Routledge.

- (I998), 'Women's community activism', in N.A. Naples (ed.), Community activism and feminist politics, 327-350. New York \& London: Routledge.

$\mathrm{Pu}$, Y. (2004), 'The definition of women's movement in the new period (Xinshiqi funü yundongde jieding)'. www.pku.edu.cn/academic/wsc/dongtai/16/jieding.doc [Retrieved ro January 2006]

Rheingold, H. (1994), The virtual community: homesteading on the electronic frontier. New York: Harperperennial.

Tang, C.S.K., W.W.T. Au, Y.P. Chung \& H.Y. Ngo (2000), 'Breaking the patriarchal paradigm: Chinese women in Hong Kong', in L. Edwards \& M. Roces (eds.), Women in Asia: tradition, modernity and globalization, I88-207. St. Leonards: Allen \& Unwin.

Vegh, S. (2003), 'Classifying forms of online activism: the case of cyberprotests against the world bank', in M. Mccaughey \& M.D. Ayers (eds.), Cyberactivism: online activism in theory and practice, 7I-96. New York \& London: Routledge.

Wesoky, S. (2002), Chinese feminism faces globalization. New York \& London: Routledge. 


\title{
6 Cyber Self-centres?
}

\section{Young Hong Kong women and their personal websites ${ }^{1}$}

\author{
HO Kiu-chor, TANG Wesley Siu-hang a HO Petula Sik-ying
}

\section{Introduction}

Every once in a while we are reminded of the ever-increasing popularity of the Internet and the addiction of the young to it. ${ }^{2}$ The Asian Internet growth rate is found to be very high (Mitra \& Schwartz 200I). The rapid growth of the Internet is increasingly international, with young people being the early adopters in most countries (Skinner, Biscope \& Poland 2003). Witnessed in our own lives, for many of us, the first thing to do in the morning is to check our mailboxes - the virtual ones. In addition to the use of e-mail and instant messengers, constructing and maintaining personal websites has become one of the most popular online activities. ${ }^{3}$

In an online survey conducted by a non-government youth service organization, Breakthrough (2005) suggests that 75.5 per cent of respondents from the age of to to 29 have been writing online diaries. ${ }^{4}$ According to Miller and Arnold (200I), the real space of cyberspace is (perhaps) on the bodily, non-virtual side of the screen, and the webpage presence can be a means by which people can increasingly find ways (in their own voices) to tell their stories. We observe that, by regularly updating their websites, young webmasters establish and maintain a virtual connection with other webmasters, thereby expanding their personal networks and social spaces.

One of the popular assumptions about cyberspace is that it allows individual users to express and actualize themselves. The survey conducted by Breakthrough also supports this idea and suggests that most young people writing online diaries aim at expressing their own emotions and points of view. ${ }^{5}$ But when we take a close look at the survey, it is quite surprising to find that the research method painstakingly generalizes the respondents without paying much attention to their gender difference. In the following sections, we will show that gender implication is often overlooked by researchers who analyze the sociocultural influences of emerging digital media (e.g. online diary and personal website). 
Our investigation must not only involve issues of self, but also gender. As Youngs (2002) notes, 'Technology is not a neutral realm [...] in broad terms, there are historically entrenched differences between men's and women's socially constructed relationships to the broad realm of technology and the innovation associated with it' (http://www. bci.org/abw/papers/pap/int.htm, retrieved I2 October 2004). In effect, many researchers are keen to explore the gender differences in various cyberspace activities. While it is significant to explore how the cyberspace activities contribute to women's understanding of the world, there are only limited studies which concern their selfhood in cyberspace.

In this chapter, we will examine how young women in Hong Kong use cyberspace as a site to construct their identity as women in relation to their significant others, focusing on both their self-representations in cyberspace and in real-life settings. Contrary to the long-established belief in 'female technophobia' (Van Zoonen 2002), the case of young women in Hong Kong shows that women could possibly be 'technoguerrillas' who actively participate in cyberspace by hosting their personal websites. How they try to construct their identities and present the different aspects of themselves in their personal websites are perhaps a form of resistance for these young women (Foucault I983; Garey I999; Ho 200I, 2007; Ho \& Tsang 2005). We will explore the kinds of images they use to represent themselves on their personal websites and how these images reflect their needs, concerns and desires. We will also examine how these women make use of cyberspace to expand their social circles, leading to the merging of the real and the virtual space (Aker, I996; Mitra \& Schwartz, 200I). As Foucault (I986) argues, 'we live inside a set of relations that delineates sites' (Foucault I986: 23), the merging relationship between the real and virtual spaces can create new sites and spaces where participants can try and exercise their own intrinsic power.

\section{Producing Self in Cyberspace}

Some scholars have indicated their interest in the relationship between personal homepages and their authors' self-identities. For instance, Alexander's (2002) research attempted to explore how queer identities are constructed and represented on US Web servers. In the field of educational research, Robbins (200I: 8) examines how the use of the Internet makes possible 'the search for identity, the exploration of social relationships, and the quest for personal competence and accomplishment' for adolescent girls in the United States. The basic and common understanding under Alexander's and Robbins' studies is 
that, a homepage is a medium for communicating one's ideas and that the production of a homepage is a self-motivated, intentional and deliberate practice to present oneself to the public. The authors conclude that analyzing self-representation on the Web is a significant scholarly undertaking which helps us understand better 'how [individuals] represent themselves and are represented on the Web, and what such representations might mean for our understanding of ourselves, our cultures, and our futures, both locally and globally' (Alexander 2002: 85). Our study shares Bell's (200I) view that 'as a self-conscious articulation of self-identity ... homepages make a useful starting-point for opening up the question of identity in cyberculture' (Bell 200I: II8). Similarly, scholars like Cheung (2000), who are convinced that 'homepage selfpresentation is a wholly voluntary affair', assert that these homepage authors 'can choose which aspects of their multiple and contradictory selves they wish to present' (Cheung 2000: 45). Under the premise of self-presentation, Cheung applied Goffman's concept of symbolic interactionism (dramaturgical account of presentation of self) to understand the homepage creators. In the virtually constructed text, the multiple sets of 'sign vehicles' manipulated by the homepage authors, Cheung argues, constitute 'a much more polished and elaborate delivery of impression management compared to face-to-face interaction' (Cheung 2000: 45).

We are, however, cautious about the tendency of these scholars to perceive personal homepages as a virtual sphere where the authors have 'total control over the production of the site (within the structural confines of the medium)', equating it with 'total control over the production of the self' (Bell 200I: II8). We doubt if the production of the self in cyberspace is carried out by an isolated existence which provides an individual with total autonomy and 'free will' to create whatever content or forms of self-presentation he or she wants. Challenging the popular conception that one has complete control of self-presentation in virtual sphere, we argue that the authors of homepage or personal websites are also subject to the different kinds of social and cultural constraints of their 'real life' situations. It is important that we re-conceptualize cyberspace self-representation and problematize the dichotomy between 'virtual' and 'real'.

Cheung (2000) suggests that personal homepages emancipate their authors, who no longer need to feel embarrassed, rejected or ashamed when they are presenting themselves to other people. For Cheung, the homepage also liberates those who want to present the 'hidden' - perhaps also 'forbidden' - aspects of their personalities to the public. Cheung argues that a personal homepage is a very powerful medium for ordinary people to present the selves that may not otherwise be displayed in "real life"' (Cheung 2000: 48); but we are more conservative 
than Cheung regarding the emancipatory function of personal websites for their authors. This is not because we deny the impact of cyber selfrepresentation of identities but because we are forced to re-think the issues in relation to the narratives of the young women we have interviewed and the way they make sense of their own experiences. What are the meanings of personal websites to their authors? Do they see them as self-representation projects? If personal websites are the intersecting points of their authors' complex, multiple and contradictory identities, can we, by simply regarding the 'hidden' aspects of self, explain how the process of emancipation takes place?

\section{Cyberfeminist Perspective on Women's Online Activities}

Attempting to introduce a gender perspective into the discussion of cyberspace and self-representation, cyberfeminists hope that by shaping and putting the new information and communication technologies to work from women's points of view, we would have a different way to organize tomorrow's societies' (Arizpe I999: xiii). In other words, cyberspace could be a 'possible way out' for women to resist existing patriarchal social structure. Arizpe calls for an awakening of women's consciousness and hopes that '... women should be active agents in ensuring that the satyr-like potential of information technologies is directed towards enhancing human well-being rather than strengthening existing power monopolies... the meanings of tomorrow must be created today and women, especially young women, now have greater freedom of spirit and of experience to be creative' (Arizpe I999: xiv-xvi). The idea of emancipating women via information technology is also shared by other cyberfeminists like Brayton (I997), who states that 'cyberspace offers women the platform and environment for putting forward their own versions of reality, the body and identity; a place where gender becomes fluid and the body becomes embodied' (http://www.unb.ca/ web/PAR-L/win/cyberfem.htm, retrieved 4 May 2003). Influentially, it is becoming an increasingly popular view that cyberspace could help shape and re-create one's gender identity anew.

Apparently, these cyberfeminists are expecting women, particularly the young ones who possess the technical competence to take action in cyberspace, to work towards the goal of the 'breakdown and disintegration of contemporary gender boundaries' (Brayton I997, http://www. unb.ca/web/PAR-L/win/cyberfem.htm, retrieved 4 May 2003). Other cyberfeminists experimenting with the use of electronic art projects are often fascinated to find how, unlike men 'who more typically participate online to avoid face to face personal communication' (Kaplan \& Farrell I994: II), these young women are able to 'supplement and en- 
hance their communications with others' (Kaplan \& Farrell I994: II). We keep seeing how the projected images of cyberspace, for these cyberfeminists, are optimistic possibilities to empower women 'over there - online'. Yet we are skeptical about the underlying, fundamental assumption that cyberspace is an isolated virtuality or a totally new dimension of living which sharply contrasts with reality. According to this view, the reality which has been structured and entrenched by gender ideologies could be transformed by young women's actions in cyberspace. Such arguments are problematic for a number of reasons. First, they fail to delineate the 'nature' of cyberspace in relation to its sociological and cultural structures. More importantly, they have not provided us with a way to listen to the voices of the young women involved and to understand their lives in the new era of information society.

Lately, there have been studies investigating the proposition that women can make use of cyberspace to speak for themselves. For example, Gajjala attempts to see if a South Asian woman could 'produce her own counter-sentences to narratives regarding her identity - thus finding a "space" to speak from email discussion groups' (Gajjala 2004: I9). These studies mainly focus on the narratives of women within a social organization - in particular, within well-organized women's groups. To explore the possibility of the empowerment of women in cyberspace, we are inspired by the cyberfeminists viewpoints but we want to go further to investigate how individual young women can make use of their personal websites as practices of self, or self-representation projects, to deal with the difficulties they encounter in their everyday lives.

\section{Re-conceptualizing VL and RL}

Kember argues that 'the challenge for cyberfeminism - which, like other aspects of feminism [...] - is to recognize the plurality of positions which simultaneously undermine and strengthen not just its own case but that of its supposed adversary [...]. Resistance and opposition are only rhetorics in the face of an enemy which is neither unified nor static' (Kember 2003: viii-ix). We agree with Kember that in our effort to explore the use of cyberspace for resistance or as a tool of empowerment, we must go beyond the conceptualization of homogeneous discourse. The great source of conflict and control does not rest in a unified category. Similar to Kember, we seek to work against the binary opposition of 'virtual life' (VL) and 'real life' (RL) that underlies the problems of many of the works and theories in the area. Dichotomizing VL and RL has trapped us in an imagined cyberspace in which individual Web users, be they presenting themselves via websites or play- 
ing online games or bidding e-bay products, are only practicing 'the virtual' and have little negotiation or interaction with 'the real' life. Such an imagined cyberspace fails to recognize how the space online is inextricably intertwined with the space of everyday life. We can no longer distinguish virtuality from reality by drawing a clear-cut boundary between the two. We are not even content with the argument that cyberspace has intruded into people's real lives, given the rapid development of information technology and its common application in everyday life practice. If we are to be historically and culturally specific in the discussion of certain Hong Kong young women's self-representations in cyberspace, we find it almost impossible to talk about the differences between VL and RL as if they were two separate spheres of life (Mitra \& Schwartz 200I).

The existing literature related to cyberspace and women's identity has provided us with a basis on which we have been able to set the main focus of this study. We are aware of how we should attend to these young women's talk about their lives in terms of a mixture of 'on-screen' and 'off-screen' self if we are to come up with a more contextualized analysis. By focusing on the engagement and dialogue between the on-screen selves and off-screen selves of the subjects, we hope that this study will throw light on the relationship between personal websites and their authors' self-identities, and particularly on the meanings of these websites to the identities of women, and on whether there are any possibilities for liberation or empowerment. Practical experiences of Hong Kong young women in creating personal websites will be studied with a view to exploring the dynamics between gender and cyberculture.

\section{Young Cyber Women}

Data collection for this study was conducted by the first and second authors of the chapter from four young women webmasters who called themselves 'Toppy', 'Caprice', 'Sim' and 'Dimzi' on their respective personal homepages. The four interviewees were selected by the researchers via their own informal and virtual networks of personal websites. Two of the authors play dual roles as webmasters of their own personal websites and as researchers of young women's websites. We have thus made use of our own experiences as participants in cyberspace to help understand these young women's lives. The second author's sharing of his observations of these women's websites with the participants in this study serves to provide them with added stimulation for discussion. In a way, this study documents the experience of an informal socio-cyber network of 6 persons, whose ages ranged from 22 to 27 . Hav- 
ing hosted their personal websites for between one and a half years and five years, they are proficient in Web-design, although their occupations bear no direct relationship to information technology. The interviewees include full-time university students, a flight attendant, a free-lance music teacher and a scriptwriter of a local TV station.

First, we will present an overview of how meanings of the concept of 'self' are textually conveyed on the informants' personal homepages. We will examine the contents and styles of narratives on these self-published websites in order to analyze the construction of self-identities of their authors and the ways they represent themselves in the virtual space. Subsequently, by conducting in-depth interviews, we will seek to understand how these website authors have made sense of their own presentations and the personal meanings these websites have for them.

It is important to note that we first encountered the interviewees via each other's websites a year before this research began, when we began reading and responding to one another's Web writings. Subsequently, after several 'off-line', face-to-face gatherings, we became friends. The virtual connection between researchers and interviewees has thus facilitated conducting interviews in an atmosphere of mutual understanding. We are also interested in the roles these websites play in the social lives of their authors, particularly in how they have affected their relationships with us, their significant others, as well as those they have met via the net.

As we aimed at contextualizing their cyberspace experiences, particularly the interactions and negotiations between their cyberspace and social activities in a 'real life' complex, a set of questions listed in our interview guide was raised in both written and oral formats. Some key questions include: Why did you start building your personal website? How often do you update your website? What is your favorite section of your website? What is the subject matter that you like to write about in your website? What do you think you are like in the eyes of your Web-readers? Do your family and friends know that you have your own personal website? In what ways have they participated in the production of your website? What are their views on your website?

\section{Virtual Community and Personal Websites of Local Young Women}

In order to create a dialogue between life on-screen and life off-screen, we analyzed the personal websites before interviewing their creators. These four cyberspace authors were selected not only because we personally encountered them via their published websites but also because we found them as part of a virtual community that is developing and 
struggling between cyber-liberty and socio-cultural pressures - a point that we shall discuss later at length.

These website authors are all locally-born young people who are relatively well-educated, with tertiary education, and are in their twenties. They are not, at first glance, related to gender issues. However, gender does play an important role in the production of personal websites. The second author of this study, for instance, has been hosting his personal website for more than two years, but most of his male friends do not share his interest in website hosting. ${ }^{6}$ He found that, in general, the personal websites of local young men are more thematically organized than those of young women. Their contents are varied, ranging from film reviews, music reviews, book reviews and social and political commentaries to cultural critiques.

We observe that a great number of young women's websites appear on different hyperlink webpages - yet what has drawn our attention to them is the frequent updates of their layouts and contents. We are impressed by the frequent, usually daily, updates of these websites, which show how strongly self-motivated these young women are in the production of their self-images, as they add new elements on their websites which enable a constant renewal and re-creation of their self images. Another characteristic of this virtual network is the interconnection of hyperlinks: when we check out the hyperlinks of their websites, we are often directed to the personal websites of other authors, but as we continue to explore the hyperlinks further we very soon run into the websites of the same four authors again. This strange network can be considered as a union of 'interest groups' which form personal relationships in cyberspace (Rheingold I993), although the structure is neither formal nor institutionalized. Our interviewees suggest that the friends they have encountered via their websites often share similar interests in films and books and have similar attitudes and world-views. These young women treasure the friendships they have developed from 'on-screen' to 'off-screen' so much so that they consider being able to develop intimate friendships which can bring significant changes to their lives, the greatest reward for investing their time and energy in their webpages. In recalling the gathering at which these young women first met their 'Web-friends', the interviewees expressed much excitement and joy. 'It's like heading into a new world', said Dimzi, one of our interviewees, who felt her life circle had suddenly expanded because she could hang out with her 'Web-friends' at coffee shops and talk to them in a way she could never do with her own 'real' friends. ${ }^{7}$ It is also interesting to note that their new socio-virtual network has been formed primarily among young women more or less the same age, with the addition of only one or two male members. As an informal union the existence of which the members are not fully aware, this un- 
classified network has become a minor league of young women, nurturing a sense of 'sisterhood.' The young women closely attend to each other's lives via their respective websites, and are very ready to provide immediate support and encouragement when necessary. 'Toppy', another interviewee, said that such spiritual and emotional support became more readily available after the development of their 'off-screen' friendship. Both 'Dimzi' and 'Toppy' felt that, once they had grown from 'Web-friends' to become 'real' friends, their topics for sharing began to shift more to daily routines like shopping and dining - the kind of topics they tend to share with their own 'real' friends. The new 'offscreen' activities that netfriends share are, according to our interviewees, 'shallower' than the messages they have written on their websites' guestbooks. Having said that, they do think these friends generally know them better because of their 'on-screen' and 'off-screen' meetings, and they are confident that they can develop their friendships 'off-screen'. They are convinced that their Web writings are truthful, and those who frequented their websites prior to their meeting in person tended to have a good understanding of their personalities.

\section{Cyber Self-centres?}

All four personal websites we have studied were built and developed very competently. Unlike some template-based Open Diaries (e.g. the online journal and weblog service provided by www.diaryland.com and www.blogger.com), these personal websites all have individualized designs. ${ }^{8}$ Although their layouts might sometimes be simple and their navigation designs not too skillful, their contents are always rich. Apart from literary texts such as diary entries, poems and other forms of creative writing, multi-media elements like photographs and music are usually organized rather systematically. They usually feature interactive devices like message board and hyperlinks to other personal websites.

While these websites all vary in details, they do share some general characteristics. Autobiographical introductions, for example, are a very common feature on these websites and provide useful background information about their authors. The personal information offered, however, consists of manipulated facts that require readers to make use of their imagination and ability to make associations, as the authors often seek to project their images by appropriating those from popular culture and mass consumption such as bestsellers, movies, music styles, places and food, thus shedding light on the cultural capital that they possess.

One of the popular ways of doing a biography is to list 'Ioo things about me'. ${ }^{9}$ Although the format is standardized, the contents are var- 
ied. Ranging from personal particulars like name, nickname, birthday, horoscope and schools attended to refined expressions like '[I have] the ability to swallow seven pills all at once', they testify to the authors' freedom to present the multi-faceted aspects of their self-images in cyberspace.

Another ubiquitous feature is the online diary section. In the interviews, we spent a great deal of time discussing why they like their diary entries, and it is clear that they attach great importance to personal sharing. From elusive explanations like 'to share one's feelings', we notice their narratives, both on the web and in the interviews, seem to suggest that, apparently, the means and the channels for expressing and sharing personal feelings with others are missing in their real lives, and they badly need a new venue for such expressions. Furthermore, for these young women, active participation in the construction of personal websites is less about quantity than quality. When asked what they would like to achieve through their writings on their websites, one of our interviewees, 'Dimzi', answered in a solid tone: 'To write about myself'. Other interviewees gave similar answers, such as 'to express my feelings towards life' and 'to express my personal feelings'. Indeed, we found that the theme of the online diary entries of these young women is extensively centred on the issue of 'self' - a phenomenon less common on the websites we have seen of young men in Hong Kong. Our interviews with these authors seem to confirm our initial observation that these young women have attempted, rather consciously, to express their innermost feelings in their very own cyberspaces and that this element of emotional expression is most crucial in their self-representation projects.

When we went on to ask what kinds of feelings they liked to express, all of them, quite surprisingly, said that their diary entries allowed them to record and express less about the 'ups' than the 'downs' of their daily lives. 'Dimzi' says that she thinks she writes better when she is frustrated. 'Toppy' even emphasizes that she tends to put her depressions over 'there, online' when she is heartbroken. Perhaps this preoccupation with sorrowful feelings is not surprising, considering how one of the interviewees, 'Caprice', posted on her website a huge number of drawings in the style of some Taiwan's 'illustrated stories', a popular cultural form which combines both literary text and drawings to express emotional and sentimental feelings, especially sadness (see Figure 6.I below). ${ }^{\text {Io }}$ We asked these women what they thought they were like in the eyes of their Web-readers. Their replies were, once again, related to sorrow and sadness. They were conscious that the images they project online are of 'an unhappy person', 'a sad girl' and 'an emotional girl'. 
'Actually I feel very embarrassed', said another interviewee, 'Toppy', who disclosed her personal website to her former classmates and friends.

"When they discovered my "mellow" writings "over there online", they were shocked, because I always come across as such a cheerful and easy-going person to them. Maybe such a great contrast will make them wonder if I am schizophrenic!'

The trouble caused by her online diary entries is in fact two-sided. While her sorrow makes her a psycho-freak to her former classmates, her ability to express her feelings through literary writings also earned her the cynical nickname of 'the-talented-writer-girl' ${ }^{\text {'I }}$ among her colleagues who accidentally come across the address of her personal website from the information column of her instant messenger (ICQ). This story suggests that, in the context of the social encounters these young women have with other people, they feel that they have been assigned a role with a happy face - that they should always be cheerful and put on a happy face, even if it is an empty happiness and they are hurting inside. The interaction between Toppy and her colleagues can be viewed as a conflict between two different sets of expectations and practices from two agents. On the one hand, her colleagues expect that Toppy, as a 'normal' girl at their age, would reiterate in the cyberspace the 'usual' practice of a young and cheerful young women, just like the 'Toppy' they get to know in the workplace. On the other hand, Toppy's revelations of her deep thoughts and sorrowful feelings in front of an 'anonymous' audience have surprised and almost completely contradicted her colleagues' typical understanding of the girls at Toppy's age. Although our research has not unearthed a coherent set of gender norms regulating young women in Hong Kong, we seem to detect some traces of a 'performative discourse' which constantly disciplines how they should perform and behave in front of different parties.

\section{Tension between Life On-screen and Life Off-screen}

'My boyfriend doesn't seem to appreciate my website... It is absurd that he used to love reading my stuff "over there" before we began our relationship. He told me that he had spent three days "studying" all my online writings when he first came across my website. Then he had a crush on me and wanted to date me. But after we developed a stable relationship, he resented my dedication to write on Web. He says that I am revealing "too 
much" of my personal feelings to strange Web-visitors. He thinks it is "potentially dangerous"'.

Apparently, Caprice's boyfriend does not want her to expose herself to people who might exploit her openness. Neither Caprice nor we could assert any unspoken intention from her boyfriend's literal proposition. Did the resentment emerge out of jealousy? What did the boyfriend mean by 'potential danger'? Did he feel threatened by some unknown male readers of her website? We could not tell. All we know is that, in a firm tone of voice and with serious facial expressions which are so contradictory to her usual manner of politeness and deference, Caprice told us she would not give up her website: 'We have quarreled over this matter for several times already. Finally I told him that he should simply avoid reading my stuff if he feels uncomfortable.' Thus, she uses her personal website as a tactic to draw boundaries to resist a kind of domination: the expectation for her to be a good girl who has to rely on the protection of the people she loves for the security of her identity, be it physical, psychological or social. Except for Dimzi who is not currently engaged in any intimate relationship, all the interviewees have experienced conflicts with, and in fact received explicit objections from, their boyfriends over their 'rights' to write truthfully on their own personal websites. Toppy was accused by her boyfriend of sharing her sadness with 'strangers' but not with him. Perhaps he felt quite uneasy that some 'strangers' become intimate with Toppy through the sharing of these negative feelings that are 'usually' not disclosed unless to people who are really close. In the quarrel, she found herself 'speechless' and decided that the next time, if she were to start a new relationship, she would simply keep her website out of sight and out of reach of her boyfriend.

Different to the operation of the 'performative discourse' of cheerful young women in workplace, men-women relationship involve more dynamic and penetrating sites, crowding up virtually all the spaces between the couple. Over the course of the relationship, these young women have to fulfill their boyfriends' unspoken expectation of a weak dependant who seeks protection solely from her boyfriend. This regulation only surfaced when one of the less safeguarded sites, their personal websites, is trespassed by a third party Web surfer. All the reactions of the boyfriends, including the verbal resentments, the quarrels and the suggestion of the risk disclosing their feelings, are performing as 'soft commands' on the young women. If these commands were not followed, they would probably repeat the commands, perhaps in a stronger tone. For these young women, their personal websites constitute a partially 'autonomous' space in which they can express 
their 'truthful' feelings towards life, but this freedom is often challenged and can never be taken for granted.

Besides men-women relationship, the interviewees also feel that their personal websites can be potential sources of conflict with their families. All four interviewees say that they have 'good' relationships with their families. Toppy, for instance, told us that she would roll over to her parents' bed and have a chat with them before she goes to sleep. They all believe that, as 'good daughters', they should not make their parents worry - in fact, they all try very hard to make their parents not worry about them. Their complicated representations and depressing feelings expressed by these young women on their personal websites, however, seem to violate and subvert the ideal image of trouble-free daughters. Dimzi said, 'It's like being seen naked by them...Usually I would write my stuff in the midnight, after they go to bed, because I don't want my parents to know that I am not happy'. Toppy was once caught by her father when she was updating her website. Her father read her words out loud but Toppy lied that the passage was written by someone else. She then realized that she did not want her parents to know she was hosting a personal website, even though her parents were not computer literate. Dimzi's father also expressed a negative view when he saw her daughter reading One Hundred Years of Solitude $\mathrm{I}^{\mathrm{I2}}$ because of the sad title of the book. Both Dimzi and Toppy informed their siblings of their websites but they had a tacit understanding that their websites must not be disclosed to their parents. When being asked whether they will one day take off the 'mask' and reveal their websites to their parents, Toppy did not answer directly. If she had to, she said, she would see to it that she could explain in great detail why she had to build her personal website, in order to avoid shocking her parents. The first author of this chapter also has difficulty in revealing her website to her parents. She knows that if her parents ever found out about her website, they would call her 'weird' and 'too radical'. More importantly, she wants to preserve a sphere of her own in which she can express her vulnerable emotions. When she sees her parents, she insists on presenting herself as their toughest and smartest daughter, for she knows that they are so proud of her. For these young women, their websites should remain their best-kept secret from their parents.

Being a 'trouble-free', sweet daughter like Toppy and Dimzi is another facet of the 'performative discourse' of ideal young women in Hong Kong. As daughters, the conflict between these young women and their parents is both momentary and permanent. This life-long identity is and will be carried by these young women, but unlike the penetrating sites of men-women relationship, they are obligated to perform the 'trouble-free' daughter role only in the sites where family ac- 
tivities take place. The momentary absence of their parents, as in Dimzi's case that she thinks she has to update her website in the midnight, would immediately break loose this 'voluntary' duty, and as they are stepping into independent adulthood, they have more flexibility to arrange their engagement in family activities.

Through analyzing the different situations where their personal websites would shock and predictably upset their relations, three facets of the 'performative discourse' of ideal young women in Hong Kong are observed. Social encounters, family and men-women relationships are the major sources of institutional constraints that these young women have to deal with in developing their self-identities. From one site to another, the obligations are exhaustively imposed. As a result, they all prefer to keep their websites not only separated but also blocked from their loved ones, especially from their parents and boyfriends. This attempt and determination to conceal could be read as the reaction on the part of the interviewees to the domination and control that the people they love try to impose on their daily lives. Their roles as girlfriends and daughters, apparently, have deprived them of a greater sense of control over themselves, which perhaps explains why they wanted to create their personal websites in the first place. Only in their self-created cyber spheres can they experience precious moments of true freedom and release their innermost feelings.

\section{Conclusion: The 'Realities' of Cyber-selves}

From our interviews, we notice that the liberating effect of cyberspace promised by some feminists must not be assumed. Cyberspace does provide a highly-accessible medium for computer literate young women. Their 'on-screen' self-expressions can be perceived as a constant reflection and recognition of their ways of living, of their ideas and desires. The construction of a personal website is a self-motivated project, not entirely different from the act of taking care of oneself, in which each could possibly actualize her ethical subjectivity as a young woman (Foucault I988); the sense of freeing oneself from the normal gender constraints is evident. But, at the same time, these moments of freedom foreground precisely the limits of such freedom: such resistance is by and large set by the 'real' society they are living in and the kind of gender socialization that they have been subject to. The social and communal support they have received from their self-representation projects in cyberspace (on-screen) is not particularly helpful to these young women in the way they deal with various kinds of performative constraints in their real life settings (off-screen). On the contrary, these personal websites often contribute to the conflicts between the web- 
masters and their boyfriends. Their projects of the self, these women feel, should also be hidden from the sight of their parents because the complicated feelings they express online often contradict their presentations of themselves as good daughters. The closer we look into how each woman deals with her multiple roles as 'daughter' and 'girlfriend', the more vividly we see how these young women have to face conflicts between their socially assigned roles and the 'personas' they put merely online. Cyberspace is a site of contestation between their own selves and their significant others. More so than often, their actions over cyberspace further complicate the unbalanced power relations between these young women and their significant others in various 'real life' situations. We cannot always assume that cyberspace gives women all the unfulfilled freedom they need in real life.

There will always be tension between one's on-screen and off-screen identities. As we have discussed above, the obstacles to these women's pursuit of freedom often springs from their intimate relationships, especially from their boyfriends and parents, and theses obstacles do not and will not disappear with the constructions of their personal websites. The courage to face these obstacles has to be sought in any micro-political situation where individuals strive for their sense of autonomy by directly addressing their grievances and concerns to their role partners (Ho \& Tsang in press; Ho et. al. in press). Without the social conditions for freedom of speech and expression in their real life settings, these self-construction projects in cyberspace do not offer any sustainable resolution, since the crux of the problem lies in their relationships with their loved ones. The constraints are imposed often in the name of love. For better or for worse, on-screen activities like theirs could yield positive impact on their construction of self, but what causes pain off-screen can not be solved simply by on-screen action.

\section{Afterword}

The interviews were conducted in September of 2004. Nine months later, one of our interviewees Caprice posted an announcement of her wedding on her website's index page. She created a little 'feature' on a pop-up window for her Web-readers. By clicking on the link 'Go to my wedding', we see a few pictures of Caprice, the bride-to-be, in a white wedding gown. In the final page, she gave a statement confiding her feelings about getting married at the age of just twenty-three. 'Let us believe, with innocence, in love and marriage, which are actually simple and beautiful', she concluded.

Ten days before her wedding, Caprice kept writing on her website to talk about her thoughts and emotions, her hesitation to discuss her 
early marriage with her friends, the troubles she faced during the preparation of wedding, and her anticipations towards marriage. As a reader of Caprice's website, by seeing her wedding announcement, we suddenly realized that we were witnessing her entry into a new stage of life since she was 20 years old. Sooner or later, we also realized, our respondents would move from girlhood to womanhood, perhaps even motherhood. What would happen in the brave new world? Would they keep writing on their personal websites? What kinds of conflicts would emerge from the new sites created by marriage? What kinds of struggle will they go through as they age? Would they be able to acquire more autonomy with their experience of creating and re-creating themselves in the cyberspace in their changing situations? It would be interesting to explore further into the changing relationship of these "techno-guerrillas" as they go through their life course.

\section{Notes}

I. This paper was first presented at the Second International Symposium on 'Chinese Women and Their Cybernetwork' in October 2004 when the Web2.0 phenomenon (which can be generally understood as blogging and other online activities which involve the sharing of user-generated contents and the collaborations among cyber citizens) was still very much underdeveloped in Hong Kong.

When compared with bloggers who make use of advanced Internet technologies to interact with the world, the webmasters we interviewed experienced a different form of interactivity: there was no effective and organized means to 'trackback' someone's writings, give publicly accessible comments, subscribe a personal website via RSS, and share and vote for an interesting post in any digital broadcasting platform with only a few clicks.

Yet before the term Web2.o was publicized, these authors might be engaging in 'blogging' practices already - particularly in the sense that they were using the Internet as a platform to share thoughts, views or feelings with a known or unknown audience, and have developed a form of social and cultural exchange that is now widely acknowledged and celebrated as one of the key contributions of the Web2.o phenomenon.

While we do not wish to generalize the diversities and specificities of different forms of negotiations about selfhood in various cyber activities, our paper offers empirical examples of how these young women in Hong Kong appropriate their basic level of technological literacy and realize the potential to express and negotiate their self-images online when Internet technologies were less advanced and available in 2004 .

2. A study by the Commission on Youth (2002), which involved the surveying of I,2I8 Hong Kong parents and I,7I3 of their children aged 9 to 24 , revealed that the young in Hong Kong are better acquainted with computers than their parents. New arrivals in the city from China had even less experience than Hong Kong parents. Details of the study can be viewed at http://www.info.gov.hk/coy/eng/report/it.htm.

3. Personal websites are different from online diaries. Though they are both platforms in cyberspace that allow the writers to upload and share text, image and other content materials, users of online diaries would face more constraints while webmasters of personal websites would have to solve more technical problems. We will further elaborate the differences between the two in the following sections. 
4. The survey, conducted in Chinese, was publicly reported by Breakthrough Ltd., a nonprofit-making youth organization based on Christian faith, in April 2005. The results were generated by online questionnaire posted on local websites and newsgroups. A total number of 1064 questionnaires were submitted, achieving a response rate of 51.0 per cent. Among the completed questionnaires, the majority of the respondents are students (80.9 per cent), and 62.5 per cent of the respondents are female. http://www.breakthrough.org.hk/ir/Research/29_onlinediary/onlinediary.htm [Retrieved 25 June 2005]

5. According to the survey conducted by Breakthrough (2005), most respondents think that the most important function provided by online diary is the opportunity for self-expression and emotional release. 77.9 per cent of the respondents declare that online diary enables them to unleash their feelings, ideas and opinions and 50.4 per cent of respondents think that it is a space of expression. At the same time, 77.7 per cent of the respondents make use of this cyber 'platform' to freely express their feelings, and 6I.5 per cent of the respondents claim that the medium drives them to share their feelings with other people. 49.9 per cent of the respondents even suggest that online diary give them courage to say something that they do not dare to. The study also shows that 67 per cent of the respondents learn more about their thoughts and feelings.

6. Instead of building their own websites, some young men in Hong Kong simply upload the photos they have taken to online photo albums like 'Yahoo! Photos' < http://photos. yahoo.com> and share them with their friends. Although this observation is not confirmed by any quantitative research at the moment, as far as we are concerned, the relatively 'practical' use of the Internet by these young men is quite common.

7. Instead of hanging out at coffee shops, 'Dimzi' and her 'real' friends usually go to karaoke boxes and have meals at popular dining places like Korean barbecue restaurants.

8. Weblog and other online diary services provide their subscribers some standardized templates on which the users can input their contents conveniently. At the cost of convenience, only a certain degree of modification of the layout is allowed.

9. 100 Things About $\mathrm{Me}$ is a popular Internet project which begs its participants to come up with a list of roo things about themselves and put their lists on their own websites. For more information, see: http://www.mizdos.com/roothings.htm [Retrieved is February 2005]

Io. One of the Taiwan-styled 'illustrated stories' artists who is very well-received in Hong Kong is Jimmyspa. For more information about his works, see: http://www.jimmyspa. com [Retrieved I9 February 2005]

II. During the interview conducted in Hong Kong Cantonese, Toppy used the Chinese Term Cai Nu. This is originally a positive recognition of a woman's talent but in the context suggested by Toppy its meaning was ironic.

I2. Gabriel Garcia Marquez, One Hundred Years of Solitude. 'Dimzi' was reading the Chinese translation of the book.

\section{References}

Acker, S.R. (1996), 'Space, collaboration and the credible city: academic work in the virtual university', Journal of Computer Mediated Communication I (I). http://www.ascusc.org/ jcmc/volı/issuer/acker/ACKTEXT.HTM.

Alexander, J. (2002), 'Homo-pages and queer sites: studying the construction and representation of queer identities on the World Wide Web', International Journal of Sexuality and Gender Studies 7 (2-3): 85-106.

Arizpe, L. (I999), 'Freedom to create: women's agenda for cyberspace', in W. Harcourt (ed.), Women@Internet: creating new culture in cyberspace, xii-xiii. London: Zed Books.

Bell, D. (200I), An introduction to cyber culture. London: Routledge. 
Brayton, J. (1997), 'Cyberfeminism as new theory', Women's relationships with the web: gender and technology research resources. http://www.unb.ca/web/PAR-L/win/cyberfem.htm

Breakthrough (Breakthrough Ltd., Hong Kong) (2005), 'Research on online diary and youth' (in Chinese). http://www.breakthrough.org.hk/ir/Research/29_onlinediary/onlinediary. htm.

Cheung, C. (2000), 'A home on the Web: presentations of self on personal hompages', in D. Gauntlett (ed.) Web.studies: rewriting media studies for the Digital Age, 43-51. London: Arnold.

Commission on Youth (2002), 'Study on the influence of information technology on youth', Research reports and surveys, commission on youth, Hong Kong SAR Government. http://www. info.gov.hk/coy/eng/report/it.htm

De Certeau, M. (1984), The practice of everyday life. Los Angeles: University of California Press.

Foucault M. (1983), 'The subject and power' in H.L. Dreyfus \& P. Rabinow (eds.) Beyond structuralism and hermeneutics, 208-228. Chicago: Chicago University Press.

- (I986), 'Of other spaces', Diacritics I6 (I): 22-27.

- (I988), 'Technologies of the self', in L. Martin, H. Gutman \& P. Hutton (eds.) Technologies of the self: a seminar with Michel Foucault, I6-49. London: Tavistock.

Gajjala, R. (2004), Cyber selves: feminist ethnographies of South Asian women. Walnut Creek: AltaMira Press.

Garey, A.L. (1999), Weaving work and motherhood. Philadelphia: Temple University Press.

Ho, P.S.Y. (200I), 'Breaking down or breaking through: An alternative way to understand depression among women in Hong Kong', The Journal of Ethnic and Cultural Diversity in Social Work, iо (3): 89-106.

- (2007), 'Desperate Housewives - the case of Si-nai in Hong Kong', Affilia 22 (3): 255-270.

— \& Tsang, A. K. T. (2000), 'The things girls' shouldn't see: relocating the penis in sex education in Hong Kong', Sex Education 2 (I): 6I-73.

— \& Tsang, A. K. T. (2005), 'Beyond the vagina-clitoris debate: From naming the sex organ to the reclaiming of the body', Women's Studies International Forum 28: 523-534.

- (in press), 'Eternal mothers or flexible housewives: Middle-aged Chinese married women in Hong Kong', Sex Roles: A Journal of Sex Research.

Kember, S. (2003), Cyberfeminism and artificial life. London \& New York: Routledge.

Miller, H. \& J. Arnold (200I), 'Self in Web home pages: gender, identity and power in cyberspace', in G. Riva \& C. Galimberti (eds.), Towards cyberpsychology: mind, cognitions and society in the Internet Age, 73-94. Amsterdam: IOS Press,.

Mitra, A. \& R.L. Schwartz (200I), 'From cyber space to cybernetic space: rethinking the relationship between real and virtual spaces', Journal of Computer-Mediated Communication, 7 (I). http://www.blackwell-synergy.com.eproxy2.lib.hku.hk/doi/full/Io.IIII/j.ro83-6Ior. 200I.tboor34.x

Robbins, J.I. (200I), Making connections: adolescent girls' use of the Internet [online] PhD thesis, Virginia Polytechnic Institute and State University. http://scholar.google.com/

Rheingold, H. (I993), 'A slice of life in my virtual community', in L.M. Harasim (ed.) Global networks: computers and international communication, 57-82. Massachusetts: MIT Press.

Skinner, H., S. Biscope \& B. Poland (2003), 'Quality of Internet access: barrier behind Internet use statistics', Soc Sci Med 57 (5): 875-880.

Van Zoonen, L. (2002), 'Gendering the Internet: claim, controversies and cultures', European Journal of Communication I7 (I): 5-23.

Youngs, G. (2002), 'Empowering women in the Internet Age', Presentation at Association of Baha'i Women UK Gender Studies Forum, University of Leicester. http://www.bci.org/abw/ papers/pap/int.htm 


\title{
7 Embeddedness and Virtual Community
}

\author{
Chinese Women and Online Shopping
}

\author{
GAO Chong
}

\section{Introduction}

The rise of the Internet and cyberspace puts great effect on human life because the new communication technology restructures and reproduces human life (Escobar I994) and fosters virtual community (Baym I995; Fox \& Roberts I999; Jones I995), which is different from that of the social world of physical contact. However, it is important to point out that cyberspace is not actually isolated from the physical world (Ward I999: 2I; Wellman I997: 448), as 'Virtual communities involve a combination of physical and virtual interaction, social imagination and identity' (Shumar \& Renninger 2002: I-2). As the node of the intersection and interaction is usually the actor who constructs social networks in both virtual and real space, his/her actions may carry across the boundary of the two spaces. The dialectical relationship between human action and social networks may be the key to understanding Internet society.

The classical studies of relations between action and social network usually choose economic action as the research object and propose the concept of embeddedness (Beckert 2003; Granovetter 1985, 1992). The traditional concept of embeddedness was generated by disputes on whether or not economic action in industrial society is economically rationalized and separated from interpersonal networks and other personal attributes. Polanyi pioneered the study of embeddedness and argued that 'man's economy, as a rule, is submerged in his social relationships' (Polanyi 1957/I944: 46). Economic rationality continues to be challenged as some scholars believe that it is partial and inadequate to understand economic behaviour in an isolated domain dominated by the hypothesis of economic man (Billig 2000; Salisbury I973). 'It has long been the majority view among sociologists, anthropologists, political scientists, and historians that such behaviour was heavily embedded in social relations in premarket societies but became much more autonomous with modernization' (Granovetter 1985/1992: 53). Modernization theory also claims that the rationalization of market ex- 
change should isolate economic action from personal relations and human emotion. But some studies that followed showed that social relations and social network still operate in modern economy (Davern I997).

As both economic action and social network operate in the real world, it is not difficult to identify the dynamics of embeddedness. On the other hand, the rise of virtual community leads one to wonder whether or not online economic action is still embedded into social network. Here, social network per se is problematic: which does it refer to? To virtual community, or community in the real world? Or both? This chapter aims to explore whether or not the concept of embededdeness works in the virtual community by examining the case of Chinese women's online shopping action.

As the premise of embeddedness is that social actors mobilize their social networks for economic action, the gender implications of the actors should be considered. From a gender perspective, females may employ different methods and mobilize different social relations when facing the same purposive action as males (Aldrich et al. 1997). Women tend to turn to close kin or proximity friends for help in business - that is, they tend to rely on strong ties (Bian 1997) rather than weak ties (Granovetter 1982). The consideration of the gender dimension should enrich our understanding of embeddedness.

This chapter focuses on online shopping practices among Chinese women and examines how the women negotiate their online social networks and their counterparts in the real world to operate their online business. It will explore how the concept of embeddedness works in such economic action, which operates across both virtual and real space. The empirical data is collected from a website of Chinese women: www.onlylady.com.

Onlylady.com is a comprehensive female website in which there are 30 theme forums about all aspects of female daily life, including: makeup, clothing fashion, affection and love, household design, children, family issues, touring, financial arrangements, health, food, entertainment, career, pets, weddings, computer games, flea markets, English study, essential oils, cartoons, jewelry, fashion sewing, keeping fit, cars and beauty, perfumes and women, fulish $e^{\mathrm{I}}$ and so on. Its slogan is 'fashion, women and living' (时尚 女人 生活). It primarily involves professional females aged 25-35; secondarily, urban females aged I8-25 and 35-42. It is based in Mainland China and is operated by an IT company registered in Shanghai. Through it, some female Chinese netizens $^{2}$ construct online community within which they socialize and exchange ideas on female topics such as makeup, travel, health care, marriage, apparel, child rearing and 'snacks'. This sharing may generate specific demands for certain products (for example, beauty pro- 
ducts) that are not available in some places or are more expensive in some markets than in others. Some capable participants promise to buy these products on behalf of those who desire to get them, charging a low percentage as labor cost. This form of online shopping is usually called daigou (代购) in Chinese. It operates through a specific forum: Fulishe.

\section{Methodology}

When it comes to methodology in the study of cyber community, the first and foremost consideration should be the nature of the research scheme. 'We must apply to the conditions of use of analytical techniques and to ensuring that they fit the question at hand' (Bourdieu \& Wacquant I992: 226). This chapter aims to explore the social process of online shopping and to examine the dynamics of social network mobilization, and ethnographic fieldwork is considered an appropriate method.

Based on the dichotomy of real and virtual space, it is questionable whether the techniques and methods generated and developed in the real world can be applied in the study of virtual community (Christians \& Chen 2004: I9-20; Denzin 2004; Fox \& Roberts 1999; Ward I999). The general viewpoint is that the existing ethnographic techniques should be reconsidered critically. For instance, it must be decided how one may enter and be exposed in online community, how one may conduct participant observation in cyberspace, how one will collect textbased data and so on (LeBesco 2004; Kendall 2004).

For this study, participant observation was conducted by becoming a member and logging on the website frequently. Onlylady is a closed community, open only to those who register as members. As a member, one can read posts (tiezi) and make responses to others, but one has no right to initiate a post in certain specific forums to organize shopping online. I registered as a general member and read and replied to others' posts. As the active participation of a researcher may lead users to 'alter their online behavior' (Fox \& Roberts I999: 65I652), I chose to lurk (LeBesco 2004: 64) to some extent and did not take an active role. Of course, I notified others of my research by posting a thread in the member center of onlylady.com.

As all the communications and arrangements for online shopping take the form of text and are completely documented on the website, enough data can be collected by reading posts on daigou. The initiator writes down all the details concerning the contents of prospective shopping, and those who are interested ask all kinds of questions about products, sending remittances (payment), packaging and so on. All the an- 
swers to questions about daigou can be found in the posts, which convey valuable information on how social network is constructed and mobilized for daigou. The members' center of onlylady.com leaves room for those who engage in daigou to commend good people and good conduct; and to complain, to uncover and even to boycott those who act in an unsatisfactory manner. It is thus easy to find out how the parties interact after daigou, as the whole process of daigou can be seen clearly from the texts online. 'The massive amount of conversational data that have been recorded by the computer' (LeBesco 2004: 69) is the main source of data for this study.

\section{Shopping Online in Mainland China}

Shopping online is a newly-invented mode of buying through Internet technology. It has been developing rapidly in China since the end of the I990s, as the Internet has become increasingly popular and more and more Chinese people have gained IT knowledge and have become able to afford the cost of surfing on the Internet (Qiu Zeqi 2001: 3638). According to the Statistical Report of the Fourteenth Survey on the Development of Internet in China, which was released on 20 July 2004, there were $87,000,000$ netizens in mainland China, among whom 40.7 per cent were female. 7.3 per cent of all netizens took advantage of online shopping service frequently, and 37.8 per cent of all netizens had bought some commodities or services through shopping websites in the previous year, and 24.6 per cent of all netizens affirmed that they would attempt to shop online in the coming year.

There are various modes of online shopping nowadays, which can be classified under three categories. One includes 'shops' online which reproduce the traditional pattern of shops or supermarkets but on the Internet. Such a shop online usually takes the form of a website on which pictures and simple descriptions of some commodities are listed. Potential customers log on and visit the shop, looking through digitalized commodities. Once they find some products they want to buy, they place an order and have them sent to an appointed place. Payment is made online by credit card or by another online bank service, or by cash when the goods are delivered. Although shops online go beyond geographical limitations, the whole buying process is similar to what happens in the real world.

The second category may be called 'collective purchase'. Dispersed potential customers who plan to buy a certain a commodity constitute a collective shopping group on the Internet in order to get the best deals. With the BBS system (bulletin board system) or through an online forum, customers in the same area or neighboring areas exchange 
information on the commodity and where to buy it. Once a date and venue are confirmed, they will go to given shops to bargain with the seller and ask for extra discounts or for the so-called wholesale prices (pifajia), arguing that bulk purchases should be at preferential prices. As soon as each participant gets the desired price and commodity, the shopping group will disappear, and few group members will contact each other again.

Common shopping online at onlylady.com includes both shops online (in 'flea market') and collective purchase online (tuangou), but this study focuses on daigou, which can be considered as the third mode. Unlike shops online and collective purchase, communal purchase online takes place within a preexisted virtual community - that is, it is based on long-term interaction. According to Tongxin, a member of onlylady.com:

'In simple words, daigou means I remit you some money, you buy a commodity for me and then mail it to me; while the premise of daigou is that you can buy what I can not find, or that for which the price is much higher in my locality. I should pay you for your time or labor, according to the percentage we have negotiated.'

But the whole process of daigou shows that it originates from an online community with strong mutual trust. Only those who are respected and trusted can get enough support from other fellow members to carry out a daigou activity successfully. Moreover, the core value of daigou is mutual-aid and mutual-benefit - that is, buyers get desired beauty products at discount, while the initiator gets economic profit, respect and appreciation.

The main cause of the rise of daigou is the imperfect consumption market in China. Take beauty products as an example: some beauty products or some brands of such products are sold only in Hong Kong, Macau or big cities in Mainland China, and it is not easy for women in inland provinces or cities to find them. However, it turns out to be easy for women in developing areas to get information about such products by communicating with others in virtual community. The establishment of numerous women's websites allows Chinese women to exchange information on makeup and stimulates the demand for good quality beauty products at reasonable prices. It is ironic that beauty products are sold at extremely high prices in the hinterland; and so some women prefer to pay io per cent of the commodity's value, plus mailing costs, to join daigou.

In addition, learning about makeup and skin care through online communities stimulates daigou. Under the pressure of socialist ideol- 
ogy, Chinese women did not care about makeup and skin care until the era of reform, as makeup and skin care were regarded as articles of a 'bourgeois lifestyle' before the I980s. With economic development and the modernization of living conditions, makeup has become a fashion among Chinese women, and especially among professional women. Women in big cities and coastal areas are usually one step ahead of those in inland provinces. The rise of the Internet offers a good opportunity for them to learn from each other about makeup. Some pioneers, or those with much knowledge of makeup, may introduce information about makeup to those who know little about it and recommend some new or effective products. Thus the demand for daigou is generated in some female online communities (Wilson \& Peterson 2002), within which there are extensive communications on beauty products, and those with more knowledge or ability concerning them may feel it is their obligation to help 'sisters' (community members) who do not get certain beauty products.

It is not surprising that most participants of daigou are middle class office ladies who have stable income and practical demand for beauty products. Those low class women who fail to access to Internet and do not afford imported beauty products have been excluded from such buying activity.

For some potential buyers, daigou is more attractive than shopping in the streets by themselves. First, it is not easy for everyone to recognize fake or bad quality beauty products of various brands. As the able have rich experience in using them, they can guarantee quality. Second, buyers can communicate with the able about beauty products while buying and using them, and they thus cherish the feeling of being cared for. Third, daigou is the most immediate and convenient way for buyers in some areas to buy and get some products. Onlylady. com carries all daigou activities in its fulishe forum, and, according to a survey conducted by Tongxin, the previously-mentioned member of onlylady.com, I3 out of 28 respondents from onlylady.com stated that fulishe was one of their favorite areas of onlylady.com.

It is not difficult to find that the driving force behind daigou is much complex, including economic consideration, access to makeup skill and knowledge of beauty products, as well as transaction risk. As these demands can not be fulfilled in the real consumption activities, some Chinese women turn to Internet for help. Their counterparts in the Western countries may find it is more convenient to buy beauty products in given shops or counters for specific products in department stores and to get access to related information through fashion journals or catalogs. As such, the opportunity for them to employ Internet in shopping is relatively small. 


\section{Online Social Network in Initiating Daigou}

A few sub-themes exist in fulishe (examples include beauty products, apparel and household goods); this study concerns only the most active one, beauty products, the daigou of which, compared with that of other commodities, is much more active. It seems that more and more Chinese women are full of enthusiasm about beauty products.

The common procedures for daigou include: glancing over information on daigou, choosing what one plans to buy, confirming an order, paying through the post office or bank, and receiving the delivered goods. A person who plans to organize daigou (the initiator) will post a message (tiezi) about the products she will supply (usually including pictures), the prices (converted according to exchange rates offered by the initiator), her own bank account or mailing address, delivery charges, and the deadline of the service. Interested members may then place orders directly or ask questions before doing so. Products at fixed prices are required to be paid for before the initiator buys, while those at negotiable prices will be paid for after they have been bought. The initiator usually does not deliver the goods until she gets remittances from buyers. Once the payment has been settled, the initiator delivers the goods by express delivery or common delivery through the post office. Once the buyer gets the goods, she often informs the initiator about it.

Initiators play a vital role in daigou because they push the whole process, so there are many requirements for those who want to become initiators. First, the management of onlylady.com set a series of regulations for applying for daigou. According to these regulations, anyone who plans to engage in shopping for profit must submit real individual data, contract modes and a scanned copy of her ID card to the management of onlylady.com. He/she is required to pay $50 \mathrm{RMB}$ each month as an information charge in order to be authorized to post information on daigou ${ }^{3}$. In addition, the applicant must fulfill another two requirements: (I) she must have been registered with onlylady.com for at least five months; (2) she must be recommended by ten members who have been registered for more than three months. The requirement on duration is to guarantee that the initiator is a permanent member with 'human feeling' (ganqing) for others and not just an opportunist whose purpose is merely to make money. The recommendation of long-term members thus urges potential initiators to construct good interpersonal relations (guanxi) with others and gain their trust, as the core of daigou is not just to buy some beauty products but also to share the happiness of buying, using and communicating. With the flow of beauty products, each party senses the others' respect, appreciation, trust, kindness and belongingness to 'our own community'. Professional mer- 
chants without their own social networks in the community are not welcome in fulishe because they are not regarded as insiders.

The major feature of online community is that all members are identified by pseudonymous IDs. The actual person behind the ID is usually neglected, as what one contacts in virtual community is the ID. Even the actual person who uses a given ID may change without others knowing it. Therefore, someone may post information about buying an ID with a net age of over six months in the 'flea market' of onlylady. com, and it is supposed that someone may want to register as an initiator of daigou in fulishe. Of course, most potential initiators use their IDs for a long time and maintain contact with others.

Various measures are taken to construct social network in fulishe. The primary one is to communicate with others actively - to read posts and make responses and join all kinds of discussions. The more one exposes oneself in fulishe, the more members may get to know or make friends with one. As there are 30 themes and over roo sub-themes in onlylady.com, hundreds of topics are posted each day. It is not difficult for one to find interesting posts to respond to and to express one's own standpoints and perspectives. Those with common interests and ideas may turn into friends online (wangyou), who in turn will become referees for daigou. Usually, it is not difficult for those who are considerate, nice, and warm-hearted, and who have adequate knowledge on beauty products, to weave their social networks.

Of course, daigou is not an easy job at all. Tongxin's comments on daigou are widely agreed to:

'It is necessary to remind all initiators and potential initiators that daigou is toilsome both physically and psychologically. It is not enough to have only a little interest and time and convenience. Before you decide to do it, you should ask yourself whether or not you are really patient and nice enough to answer all kinds of questions from members who want to join; whether or not you have enough time; and whether or not you are mature enough to face compliments, praise, doubts, and even enmity. If you say no, please do not do it if you are not eligible.'

The most immediate way to organize a social network is to initiate nonprofit daigou - that is, to buy commodities for others free of charge. This is more attractive for those with low incomes and who are unwilling to pay labor charges, remittance charges and mailing charges. During the process of organizing the daigou the buyers can come to understand the initiator through her/his attitude towards them, her knowledge of products and her performance in doing the business. In short, organizing nonprofit daigou allows the initiator to accumulate personal 
credits and social capital - social resources based on membership/social network (Bourdieu 1986/1983; Coleman 1990: 302; Lin 2001: 29).

Once the potential initiator gets enough referees' support, she/he may register as a formal initiator and be authorized to initiate daigou. The referees will be mobilized to send emails to the management of onlylady.com and indicate that they support the given member's becoming an initiator. Some potential initiators may post information in the member's center, publicly looking for support; while others, who have many friends, may just mobilize their friends privately by messages within onlylady.com. Then the potential initiator will send a message to the management of onlylady.com describing the product category, the channel to access the commodity and the brand. The management will reply and require her/him to offer information in detail about the coming daigou and him/herself. After filling in some blanks online and remitting an information charge, the initiator will be allowed to initiate the daigou.

Social network not only plays an important role in applying for daigou, but also dominates the daily operation of daigou. As most members only take part in daigou initiated by their friends or acquaintances at onlylady.com, there is little room for initiators who do not have their own social networks. The closure of social network is important for the generation of trust (Coleman I990: 318-320). The Internet offers an open and free space for netizens to communicate and organize collective activities, but its anonymity makes cheating popular. Those who decide to take part in a given daigou often have to remit the commodity's price to the initiator in advance. In fact, the so-called initiator is nothing but a pseudonymous ID in a virtual community, and it is not difficult for her/him to register under another ID after cheating participants of some money. In order to reduce this risk, potential buyers prefer to exchange with those who are within their social networks. If the buyers believe that the initiator they contact is nice and trustful, they may sing high praises for her/him by post in the member's center. The praise will establish his/her reputation and attract more buyers to join the given initiator's daigou group. Through this snowballing process, one initiator may expand her/his social network in onlylady.com quickly.

The member's center of onlylady.com facilitates the establishment of trust and social network among buyers and initiators. All the members are eligible to communicate everything they care about in the center, so both the bad and the good are exposed to the public. For example, Weian (薇安) was so glad to get a package of AVON products from mylily (the initiator) that she posted (tiezi) the picture of what she bought in order to thank mylily. 
' $\mathrm{MM}^{4}$ (mylily) packed them carefully and each item was sealed with adhesive tape and then wrapped in newspaper before being put into a box. So they keep well. This is praiseworthy! She also sent me some small gifts. Those who have doubts about fulishe can take a look at the attached photo!:)'.

Of course, all the initiators who are praised enjoy these words and promise that they will do better in the future. The praise and appreciation from buyers may be an important impetus for those who hope to become initiators. For them, daigou is not only economic transaction but also a mutual aid pattern.

Trust fuels participation of daigou, and a considerable number of members enjoy the sense of being trusted. Tongxin was told that the goods she ordered had been delivered to her before she paid for them through the bank. 'It is lucky to be trusted by the others and it is fortunate and happy to be trusted by those who do not have face to face contacts. I am appreciated and moved by the beautiful trust I gain.' She even decided to join the particular initiator's shopping group if she needed to buy toiletry. In other words, she turned into a member of the social network constructed by the initiator. This shows how 'trust, in short, is a form of "faith", in which the confidence vested in probable outcomes expresses a commitment to something rather than just a cognitive understanding' (Giddens I990: 27).

The member's center offers valuable information for potential buyers to evaluate initiators. Both praise and criticism of initiators can be found in the center, so it is not difficult for those who plan to join a given daigou to judge. They can post and consult others who have joined the initiator's daigou group about her/his credibility if it is their first time to engage in an exchange. There are two categories of posts of enquiry concerning credibility: one consists of posted on the message board by potential buyers who want to know the record of a given initiator; the other is that of posts from an initiator who has organized daigou for some time and hopes to get comprehensive comments from her/his customers and leaves a personal trust record. For example, Toni posts asking about the credibility of sandoo2 8 before deciding to buy some hair care products from sandoo28. Within two days, seven members who have bought something from sandoo2 8 replied, the general comment being that sandoo 28 is not bad. Another example is shanghainannan (上海囡囡), who asked members to recommend those whose fame and credibility is good. Six members choose dingdingxiaomao (丁丁小猫), although one complained that she is too busy to reply to questions.

There is a call on members to comment on all the initiators they have contacted. Moguixinniang (魔鬼新娘) posted it and got I2O responses. 
All the replies are valuable and helpful for potential clients to evaluate a given initiator's credibility and make their decisions. As the information is transmitted within a certain social network, those initiators who are not embedded in it will face more difficulties in organizing daigou.

The initiators who believe in their own credibility may invite their customers to comment on them. For example, Moonz called on all those who had ever bought goods from her to say something to establish her credibility and she gets 178 responses, the majority of which are supportive:

'I have registered in OL for a long time and initiated daigou many times. I hope to form a trust post for myself so that potential buyers can use your words as reference. Please, those MMs who have conducted business with me, comment on our transaction. All kinds of comments are welcome. Thanks, MMs.'

Complaints about some initiators are also posted in the member's center. For example, moqinghan (漠轻寒) was found to be a cheat because she got a remittance from qiufengsese (秋风瑟瑟) but did not mail her the commodity. Many members got involved in their dispute and called on all community members to drive away such cheats. Baifenbaizhi'er accused wawayou2002 (蛙蛙呦2002), who refused to make compensation for him. He had bought a face wash from wawayou2002, but when it arrived, he found that it had been used. He required wawayou2002 to return his money or send him a new one, but he did not get it and so brought the case to the member's center, to remind others about wawayouzoo2's behavior.

The exposure of cheating cases arouses members of onlylady.com to exclude those who are not rooted in the social network, whose only aim is to conduct business and make money. Some people who operate online shops selling beauty products on www.eachnet.com find it lucrative to start a business on onlylady.com, and also register IDs and try to initiate online shopping. As soon as some members identify certain IDs belonging to these strangers, they call on the others to repel them and drive them away. These businesspeople are labeled as double-dealing merchants (jianshang) because some of them cheat the members. The emergence of jianshang breaks the peace, trust and lovely family atmosphere of the community, so that some members initiate the campaign to uncover their evil-doing and better the 'big family'.

Some initiators often take part in online shopping initiated by others, thus reinforcing the mutual trust among the community members. Xiaomaoqianqian (小猫茜茜) organized collective purchases from Hong Kong several times but has also joined at least twelve shopping programs initiated by others. For example, she bought perfume from 
moonz, beauty products from hkshopping, shampoo from cn_benny and so on. This double identification reveals that such initiators are embedded in the virtual community through their participation in these various daigou.

It is important to point out that daigou in fulishe is just a byproduct of socializing and communicating online in onlylady.com. Most members' main purpose in logging on to this website may not be to buy commodities through it but merely to share information and relax. Based on this sisterhood constructed through online interaction and socializing, some choose to become initiators and serve the other 'sisters'. Naturally, some successful initiators become respected and considered good friends.

\section{Business Embedded into Sisterhood}

Some members of onlylady.com participate in shopping online because they enjoy the sisterhood generated in the virtual community. For instance, Guang (光), one buyer, appreciates meiya (one of well-known shopping initiator in fulishe) for her efforts for benefits of JMs (sisters $)^{5}$ :

'Two weeks ago I order something of South Korea with meiya jiejie (elder sister). The express delivery company promise to send it to me within three days from Weihai to Shanghai. But it takes one week to do it. In the course of waiting, I call the express delivery company again and again, which makes me crazy to some extent. I have to thank meiya jiejie. She is an earnest and responsible jiejie. She does not inquire about my case with express delivery company but also call me and ask the progress. How much profit is my order? I believe it does not cover the charges of long-distance telephone calls. What is more, jiejie always is patient to listen to me and say sorry in her calls. Her attitude makes me believe that she does not consider online shopping as her business but also tries her best to seek for benefits for "sisters". With the expansion of OL (onlylady), fulishe grows with the care and expectation of most "sisters". I hope that fulishe adheres to its original intention in rise of Internet economy and seeks for benefits of 'sisters' actually. I also hope that there will be more initiators who consider interests of "sisters", such as meiya jiejie.'

For both buyer and initiator, the business of daigou is more than business because the sisterhood generated among their interactions makes 
daigou turn to be integration of economic exchange and social exchange.

Some participants insist that making friends with many 'sisters' can offset their deficiency of profits. For example, although yiyi_ny does not make some money from her first daigou business, she believes that it is pleasant to accumulate some experience and get to know many sisters (JM in her words). Before she stopped accepting orders, she left a message to announce her decision:

'As all the commodities have to be brought by my friend and it is impossible to bring too much, I have to stop accepting orders. This is the first time for me to organize daigou. Please, JMs (sisters), forgive me if I do not answer your questions or make responses on time. Although the service charge collected may not cover my friend's expenses (for transportation fares, collecting data online, and answering questions), I am very happy to have got some experience and to know many JM (the logogram of Chinese pinyin Jie Mei).'

Some initiators are accepted and appreciated through their efforts with daigou because they benefit other 'sisters', in two ways: one, that through them some 'sisters' get the beauty products that are not available in their cities; the other, that they do so at reasonable prices, less than the local prices, despite the service and delivery charges. Service charges for daigou products is less than io per cent of the product value - far less than the beauty product import of I8-25 per cent, which added to the huge profits obtained by retailers. In the eyes of daigou participants, business should not be at the expense of friendship - the ideal situation is to help the others and make money from business at the same time.

Extensive communications through daigou foster sisterhood. Due to the uncertainty of online shopping, buyers usually have a lot of questions to ask about beauty products, makeup skills, usage, effectiveness of products and so on. As most initiators are not fulltime merchants, they often have to devote their private time to answering questions and operating daigou. Some buyers sense the great efforts made by a given initiator. 50 comments on meiya, an initiator who conducts exchanges with her frequently, in this way:

'I can not remember how many questions I have asked meiya jiejie (elder sister) as there are too many, at least ıoo. She answers them patiently one by one so she may be the initiator with the best temper and patience I have ever encountered ... she is the most adorable initiator at onlylady.com for me. I have been 
registered in OL (abbreviation of onlylady) for half a year and I am satisfied with fulishe. I will not visit shops in the real world.'

As each participant's personality and temperament is demonstrated through daigou, some of them become good 'sisters'. Moguixinniang admits that she likes shopping in fulishe because she can get to know some good JM (sisters).

Yuhoudehuanghun (雨后的黄昏) sings high praises of moontrip, as she has a lot of questions to ask:

'Finally, I feel impatient myself but she still answers patiently. She informs me about each step, from placing an order and confirming payment to delivering goods. I received goods one day after paying. She even refunded me extra money, as I paid more than the price. But even I did not realize that I had paid too much.'

Hyalite appreciated Zhiman for her perfect packaging service when she bought one bottle of facial cream:

'In addition, ij (Zhiman) only charged me eight yuan for the mail service, but the sum on the package is eight yuan and eight jiao (one tenth of one yuan), not including the price for the package box and the packaging charge. What makes me embarrassed is that she sent me a small gift when I only paid another two yuan. If everyone is served like me, $\mathrm{jj}$ will lose money in her business. I will continue to follow her daigou program in the future.'

Sisterhood and its obligations not only foster daigou but also facilitate its daily operation. Purchase online is shaped by sisterhood and is embedded in online social networks. But this is only one part of the whole story, as some procedures, such as purchasing and delivery of commodities, have to be completed in the real world.

\section{Integration of Social Network in Virtual and Physical Community}

As the nature of daigou is buying on others' behalf, shopping initiators must have the channels to get the goods that are greatly needed by members of the community. Although most steps in daigou (introducing products, communicating with buyers and getting orders, even collecting remittances) are completed in virtual community, the vital part - buying the commodities - must be carried out in the real world. 
That is, the initiators have to approach given marketplaces to buy products according to orders and then send them to the respective buyers. It is not easy for one initiator to do this, so social networks in physical community are usually mobilized.

Some members in the cities of the Pearl River Delta, such as Shenzhen, Zhuhai and Guangzhou, have advantages for acting as initiators, as they or their relatives or friends can go to Hong Kong or Macau easily to buy what others desire. Hkshopping is one of the most welcomed initiators. She stays in Shenzhen and usually goes to Hong Kong twice a week, on Wednesday or so and on the weekend. The goods she promises to buy are delivered to her customers on Friday of the same week or Monday of the following week.

Some initiators do not buy commodities in person but turn to their relatives or friends, who travel to Hong Kong, Macau or other countries frequently for help. Xiaomiaoqianqian of Nanjing conducts her business in this way. One of her friends goes to Hong Kong three times each week, so her business arrangements have to be based on her friend's trips. Yiyi_ny extends her service to New York, USA, because she has friends staying there. As one of her friends was to return to China from New York in August 2004, she posted information promising to buy beauty products in New York and then had them brought to Beijing on 2 August. Although she had promised that it would not be necessary to pay international mailing charges, she had to apologize for not accepting orders for products in bulk, as did not want to owe too many favors to her friend. The scale of her business was thus connected with this friendship. The New York daigou lasted for about one month and more than one hundred pieces of information about it can be found in fulishe.

Even some members studying or staying abroad act as initiators, as they can get the most up-to-date information on makeup and skin care and they have geographical advantages for buying beauty products in the international market. Catherinechang, who is studying in Melbourne, Australia, makes use of her stay there to buy beauty products, health products and apparel in the Australian market. Zuiaimiaomiao (最爱猫猫) is studying in Toronto, Canada. She collects popular beauty products at reasonable price in Canada and promises to buy them on behalf of those who are interested in them. In order to save mailing charges, she puts small products together in big packages, which she sends to Beijing, asking her father to deliver the smaller components to individual buyers. If she is not in Toronto, her boyfriend is mobilized to buy the ordered goods. It is thus obvious that at least two men in her social network in the real world are mobilized in her daigou activity. 
Most initiators mobilize their social networks in both the virtual community and in real space to carry out their daigou practice. The operation of daigou is time-consuming and involves heavy work, so that initiators usually mobilize their close relatives for help. In addition, some initiators have to mobilize their friends to buy ordered commodities. Another important reason for this is the geographical separation of purchase and delivery. Like Zuiaimiaomiao, initiators abroad usually send commodities to Mainland China in big packages to save on delivery charges and ask their families, relatives or friends to repack the items according to orders and send them to the respective buyers. Although daigou appears to be a pattern of online shopping in appearance, this study finds that it bridges initiators' social networks in both virtual community and the physical world.

Some buyers who enjoy the friendly process of daigou not only practice it by themselves but also introduce their friends in the physical world to join and share in it. Mogujiejie (蘑菇姐姐) introduced Dingdingxiaomao to her friends in her company and promised to support Dingdingxiaomao's business because she thought that exchanges with Dingdingxiaomao were a pleasant experience, that Dingdingxiaomao had a nice attitude, delivered quickly and provided fresh products. Jofox gets to know onlylady.com and Xiaoyijiejie (小意姐姐) through one of her colleagues:

'At that time, I had no courage to shop online. But I really appreciated my colleague, who introduced OL (onlylady.com) and Xiaoyijiejie to me. If she hadn't, I would regret it! Since then, I have bought some goods from JJ (Xiaoyi) by myself. This has been successful! So I begin to love OL and trust it absolutely. When I have more money, I will buy more!'

When they sense benefits and sisterhood on onlylady.com, some buyers mobilize their friends to take part in daigou and get more Chinese women involved in online shopping.

Two dimensions can thus be found in the integration of virtual and physical social network in daigou practice. One is that some initiators 'push' daigou from online into the real world; the other is that some buyers 'pull' more and more of their friends in the real world into the online shopping practice.

One study of female entrepreneurship in the real world argues that women can not get enough information, resources and support from their kin-centered social networks (Lynn \& McPherson I993: 233-237), and that this limits them in their entrepreneurial practice. It is obvious that in the Internet age, Chinese women are empowered through organizing their own virtual communities and creating their own economic 
niches. Their strong sense of sisterhood allows valuable information and offers a circle of customers for their daigou business. As the buyers usually pay in advance, it is not necessary for the initiators to collect a big sum of startup capital. Their physical social networks are also mobilized to boost daigou. The emergent onlylady.com offers a good opportunity for some Chinese women to start their own businesses, although the tenets of online daigou practice may not directly be directed towards this.

\section{Concluding Remarks}

Communal shopping online (daigou), as practiced by Chinese women, demonstrates that economic action online remains embedded in social networks, including both online and real-world networks. In order to fulfill the requirements for initiating daigou, one has to construct a social network and create trust in a given virtual community. One study in real space shows that 'women view their business as a cooperative network or relationship rather than a separate economic entity' (Brush I992: 24). Many Chinese women who take part in daigou enjoy the fun of making friends with good 'sisters' and being respected or trusted by others. For them, economic gain is just one part of business, and sisterhood should be cherished and maintained.

On the other hand, online shopping penetrates into the real world with the action of initiators and buyers. Some initiators have to mobilize their social networks in the physical world in order to complete all the procedures of daigou. In fact, daigou includes some physical logistical steps, such as purchase and delivery of products and payment through bank or post office. Chinese women usually turn to their families, relatives or friends for help when they encounter difficulties. In addition, some buyers introduce daigou of onlylady.com to friends in the physical world because they really like the joy of daigou.

In short, economic action online is double embedded - in both virtual community and in social networks in physical world. Although the Internet and virtual community facilitate the initiation of some economic actions, their operation is not isolated from the real world. Usually, some people in the actor's social networks in the physical world are mobilized to solve practical problems. Although social network in virtual space is constructed by netizens who are presented as mere IDs, it still involves human character and feelings - for example, in this study, 'sisterhood'. Thus the boundary between virtual community and the physical world may not be as clear as imagined. Some simple economic actions, such as daigou, link the two parties. 
At the theoretical level, daigou activity implies that embeddedness of economic action is not only an abstract generalization of the relationship between economic behaviour and social structure (Granovetter I992/I985) but also the dynamics of economic action following interpersonal relation principles of given society. The initiators of daigou manipulate various social relations or networks in both the real world and virtual communities, which indicates that what makes sense is not the conception of embeddedness itself but how economic action is carried out and the embeddedness is practiced under different social contexts.

\section{Notes}

I. The website uses the Chinese term 福丽社, which combines the meanings of 福利 (benefits) and 美丽 (beauty) - 'good quality beauty products at reasonable prices' and 'beauty products make beauty'.

2. According to the definition given by the China Internet Network Information Center (CNNIC), netizen refers to those Chinese citizens who use the Internet for at least one hour per week. It is claimed that only profit-oriented daigou initiators pay an information charge and that it is waived for nonprofit daigou.

3. $\mathrm{MM}$ is an Internet term used in China. It originates from the Chinese word Meimei (美 眉) - young and beautiful girl. In onlylady.com, all female members can be called MM.

4. All the members call the others MM (for Mei Mei美眉, 'beautiful girl) or JJ (for jiejie, 姐 姐, 'elder sister'). JM (jiemei, 姐妹, 'sisters') refers to the collectivity of all members of onlylady.com. Through the use of these words, members construct their own belonging and identity with the community.

5. All the names mentioned are the ID addresses registered in onlylady.com. The names in Chinese characters are spelled in pinyin while the English ones are adopted without change.

\section{References}

Aldrich, H.E., A.B. Elam \& P.R. Reese (I997), 'Strong ties, weak ties, and strangers: do women owners differ from men in their use of networking to obtain assistance?', in S. Birley \& I.C. Macmillan (eds.), Entrepreneurship in a global context, I-25. London: Routledge.

Baym, N.K. (I995), 'The emergence of community in computer-mediated communication', in S.G. Jones (ed.), Cybersociety: computer-mediated communication and community, $\mathrm{I}_{3} 8-\mathrm{I}_{3}$. Thousand Oaks, California: SAGE Publications.

Beckert, J. (2003), 'Economic sociology and embeddedness: how shall we conceptualize economic action?’, Journal of Economic Issues 37 (3): 769-787.

Bian, Y.J. (I997), 'Bring strong ties back in: indirect ties, network bridges, and job searches in China', American Sociological Review 62 (3): 366-385.

Billig, M.S. (2000), 'Institutions and culture: neo-Weberian economic anthropology', Journal of Economic Issues 34 (4): 77I-788.

Bourdieu, P. (I986/1983), 'The forms of capital', translated by R. Nice, in G.J. Richardson (ed.), Handbook of theory and research for the sociology of education, 24I-258. New York: Greenwood press. 
Brush, C.G. (I992), 'Research on women business owners: past trends, a new perspective and future directions', Entrepreneurship Theory and Practice (summer): 5-30.

Clifford, C.G. \& S.L.S. Chen (2004), 'Introduction: technological environment and the evolution of social research methods', in M.D. Johns, S.L.S. Chen \& G.J. Hall (eds.), Online social research: methods, issues, and ethics, I5-23. New York: Peter Lang Publishing.

Coleman, J.S. (I990), Foundations of social theory. Cambridge, MA: Harvard University Press.

Davern, M. (I997), 'Social network and economic sociology: a proposed research agenda for a more complete social science', American Journal of Economic and Sociology 56 (3): 287-302.

Denzin, N.K. (2004), 'Prologue: online environments and interpretive social research', in M. D. Johns, S.L.S. Chen \& G.J. Hall (eds.), Online social research: methods, issues, and ethics, II2. New York: Peter Lang Publishing.

Escobar, A. (I994), 'Welcome to cyberia: notes on the anthropology of cyberculture', Current Anthropology 35 (3): 2II-23I.

Fox, N. \& C. Roberts (I999), 'GPs in cyberspace: the sociology of a "virtual community", The Sociological Review 47 (4): 643-67I.

Giddens, A. (I990), The consequences of modernity. Stanford, California: Stanford University Press.

Granovetter, M. (1982), 'The strength of weak ties: a network theory revisited', in P.V. Marsden \& N. Lin (eds.), Social structure and network analysis, I05-I30. California: Sage Publications.

- (1985/1992), 'Economic action and social structure: the problem of embeddedness', in M. Granovetter \& R. Swedberg (eds.), The sociology of economic life, 53-8I. Colorado: Westview Press.

Jones, S.G. (1995), 'Understanding community in the Information Age', in S.G. Jones (ed.), CyberSociety: computer-mediated communication and community, IO-35. Thousand Oaks, California: SAGE Publications.

Kendall, L. (2004), 'Participants and observers in online ethnography: five stories about identity', in M.D. Johns, S.L.S. Chen \& G.J. Hall (eds.), Online social research: methods, issues, and ethics, I25-I4O. New York: Peter Lang Publishing.

LeBesco, K. (2004), 'Managing visibility, intimacy, and focus in online critical ethnography', in M.D. Johns, S.L.S. Chen \& G.J. Hall (eds.), Online social research: methods, issues, and ethics, 63-79. New York: Peter Lang Publishing.

Lin, N. (200I), Social capital: a theory of social structure and action. New York: Cambridge University Press.

Lynn, S.L. \& J.M. McPherson (I993), 'You are who you know: a network approach to gender', in P. England (ed.), Theory on gender/feminism on theory, 223-25I. New York: Walter de Gruyter.

Polanyi, K. (1957/I944), The great transformation: the political and economic origins of our time. Boston: Beacon Press.

Qiu, Z.Q. (200I), 'Zhongguo Shehui de Shuma Quge (Digital division in China's society)', Ershipi Shiji (21 ${ }^{\text {st }}$ Century) 63: 36-42.

Salisbury, R.F. (I973), 'Economic anthropology', Annual Review of Anthropology 2: 85-94.

Shumar, W. \& K.A. Renninger (2002), 'Introduction: on conceptualizing community', in K. A. Renninger \& W. Shumar (eds.), Building virtual communities: learning and changing in cyberspace,I-I7. Cambridge: Cambridge University Press.

Ward, K.J. (1999), 'The cyber-ethnographic (re)construction of two feminist online communities', Sociological Research Online 4 (I) http://www.socresonline.org.uk/socresonline/4/I/ ward.html

Wellman, B. (1997), 'The road to utopia and dystopia on the information highway', Contemporary Sociology $26(4): 445-449$.

Wilson, S.M. \& L.C. Peterson (2002), 'The anthropology of online community', Annual Review of Anthropology 3r: 449-467. 



\title{
8 Electronic Park Benches
}

\author{
Online Mothers in Hong Kong Using the Baby Kingdom
}

\author{
CAPLAN Victoria
}

\section{Introduction}

In studies of the Internet from the early I990s to the turn of the century, there was a concern that users of the Internet (or at least the Usenet) were overwhelmingly white, male, American, and highly educated (Barwell \& Bowles 2000), and that English dominated much of the Net, with the voices of most women marginalized or silenced (Inayatullah \& Milojevic 1999). At the same time there was an ongoing debate about the existence and nature of 'virtual communities'. Rheingold stated that if he were able to re-write his Virtual Communities, he would have chosen the less contentious term of 'online social networks' (Rheingold 2000). Wellman and Giulia argued that virtual communities are computer supported social networks (CSSNs) that provide 'companionship, social support, information, and a sense of belonging' and reminded us that people bring their 'gender, stage in life cycle, cultural milieu, socioeconomic status, and offline connections to their online relationships' (Wellman \& Giulia I997). Wellman later stated that computer networks are inarguably social networks, 'loosely bounded and sparsely knit' which help to increase people's social capital (Wellman 200I: 203I).

This chapter presents the Baby Kingdom (www.baby-kingdom.com) as a strong example of a Chinese language women's virtual community based in Hong Kong. This ethnographic description of the Baby Kingdom asks: How does the Baby Kingdom operate? What makes it a successful virtual community? What do women do in it? The answer is multifold: Hong Kong women use the Baby Kingdom's gendered space to engage in discussion ('gossip') to acquire information, forge social bonds, and engage in what Mary Douglas calls 'the normative debate', which creates, maintains, and challenges social norms wherever people gather together (Douglas 1992). Pregnant women and mothers in Hong Kong have begun to use the Baby Kingdom as a springboard to exercise their power in the household and in the broader community. It is also a place where women continue to create, transmit, and re- 
shape their expressive culture, that is made up of the domestic arts and domestic rituals in Hong Kong (Yip 1997).

The Baby Kingdom acts as a sort of 'electronic park bench' where women meet, gossip, exchange information and stories, plan later meetings, swap or sell goods, and even plan for political action. Using the Web has become part of their everyday life (Haythornthwaite 200I) in which they negotiate their pregnancies, births, and motherhood. As part of their everyday lives, they use it to empower themselves, but sometimes at the expense of others.

\section{Methodology}

I used ethnographic observation for this study, regularly visiting the Baby Kingdom for a period of about two years (2002-2004), mostly 'lurking' (reading). Privacy was not a major concern, because it was a completely public website (no registration required) and all the posters used pseudonyms. I made an announcement of my presence, gave some background on myself and my research interests and received a polite welcome.

I made no face-to-face contact with the women using this forum. Some argue that the online environment allows people to make false representations of their selves. Some of the writing on identities in cyberspace has made much of the fact that one can 'play' with one's identity, in terms of gender, ethnicity, and sexual orientation (Tsang 2000; Danet I998; Nakamura 2000). However, there seems to be little of this type of play in evidence in the Baby Kingdom. It appears that the selves presented in this online environment are grounded in a social reality outside of the Web-group, in agreement with Wynn and Katz's analysis (Wynn \& Katz I997). As Goffman has also pointed out, in 'real life' people constantly shape their presentation of self to fit their ideals and their social circumstances (Goffman I959). Thus, the online personas of virtual community participants are not necessarily less truthful than the selves they may present in their homes, workplaces, or in public. Furthermore, since the women whose postings I read and observed often made plans to meet one another, met, and later discussed and posted pictures of their gatherings, I believe that the women posting on this site were as 'truthful' about writing their lives as people who meet and discuss their lives with each other through other means. 


\section{Technical Issues \& History of Internet Usage in Hong Kong}

In 1993 there was only one licensed commercial Internet provider in Hong Kong. By I995 there were eight providers, and the Office of Telecommunications shut down the seven that were unlicensed (Chong I995). However, the licensing situation was sorted out and by the first quarter of 2004 there were I97 Internet service providers in Hong Kong, providing service to a registered I,071,299 dial-up users and I,249,7I4 registered broadband users, reaching about 43.5 per cent of the population (Key Telecommunication Statistics 2004). In 200I, it was reported that use of the Internet by women in Hong Kong was one of the highest in Asia, and that they made up 45 per cent of Hong Kong's Internet user population (Taiwan Women are the Leading Online Mothers of Asia 200I). Later estimates repeated the 45 per cent figure (Steyn \& Chan 2003). While there is still a small 'gender gap' in Internet usage in Hong Kong, it may be closing, as happened in the USA, where the large gender gap of the mid I990s has disappeared (Ono \& Zavodny 2003).

From the early I990s through the early 2000s, the Internet and Web have been overwhelmingly English-language based. As noted by Bell, 'Most online communities beyond the scale of the national are usually run in English' (Bell 200I: ro9). Language is an important consideration when we look at the online social networks of Chinese women.

Communicating in Chinese on the Internet has never been easy. In addition to the two standard varieties of written Chinese (complex characters, or fantizi, used in Taiwan and Hong Kong; and jiantizi, the simplified characters used in Mainland China and Singapore), there were formerly three different mutually-incompatible standards of characters and character sets: Big5, GB, and CNS. Furthermore, there was a separate version of Windows for Chinese. If one did not have Chinese Windows installed on her PC, or did not have a Chinese software interface like TwinBridge or RichWin installed, then reading and writing Chinese was impossible. By the late I990s a uniform standard character set called 'Unicode' began to be widely adopted, which could write and display both complex and simplified Chinese characters. By 2000, Web browsers such as Internet Explorer, Netscape, and Mozilla enabled one to view Chinese and other non-European fonts without installing additional software.

This is an example of what Bell called the 'material stories' of cyberspace (Bell 200I). Online social relations networks are situated in physical and technical spheres, and the issues of character compatibility and different character sets are likely to have contributed to the relatively late emergence of the Chinese language online community in comparison to English. 


\section{Parenting Sites on the Internet and Web - History and Practice}

Rheingold uses the example of the 'Parenting Conference' at The Well, which he frequented starting in the mid I980s, as one of his primary examples of 'virtual community' (Rheingold 2000). There were other active online parenting sites at the time, and there are even more now. The most universal (in the early to mid I990s) was on the Usenet: misc.kids. Misc.kids has been active since I986 (or earlier - the oldest post available in the archive of Usenet groups maintained by Google as 'Google Groups' is dated I4 October I986). During the next ten years it grew to include misc.kids.pregnancy and misc.kids.breastfeeding. In I996, after numerous 'troll' ${ }^{\mathrm{I}}$ incursions, a misc.kids.moderated was created and still operates alongside misc.kids.

In the late I990s, when the Web became more popular, commercial parenting sites like Parentsoup.com and iVillage.com were created and became active. They were based mostly in the USA and catered to mostly white, Anglophone, middle-class members. These sites are commercial in nature. Similar to magazines, they attempt to make money through selling advertising space to companies that want to sell goods and services to parents (mostly mothers). Sociologists and anthropologists have paid little attention to these groups. Instead they have mostly been of interest to the business press (Frederick I998; Feliciano 200I; Miller 2003).

One of the few exceptions is Koerber, who wrote about 'feminist mothering' and 'alternative parenting' Web rings and sites (Koerber 200I). She considered them to be examples of political resistance of a post-modern kind. If one broadens her analysis, the 'mainstream' parenting sites are no less political. To take a leaf from Douglas's work, discussions on all parenting sites are an important part of the 'normative debate' (Douglas I992) which occurs whenever people gather. When women post their questions or share their experiences they may be asking for knowledge about what the status quo is; working to maintain it; or questioning it, and by that questioning, challenging it. This activity is constant on the Baby Kingdom.

Mothering sites can be considered cousins of women's service magazines $^{2}$ for 'parenting' usually means 'mothering'. The overwhelming consumers of parenting magazines are women, as are those who frequent the parenting sites on the Web. These websites share several features and functions with women's magazines: interactivity, the opportunity for vicarious pleasure, and the opportunity to learn about new products and services (Walker I998). The Baby Kingdom also shares the same commercial base. The site owner delivers an audience to advertisers. 
McCracken showed the importance of vicarious pleasure (what she called 'voyeurism') in her study of women's magazines in the USA in the I980s (McCracken I993). Such pleasures are also available on parenting sites where women read about each other's lives: the good, the bad, and the indifferent. Just as women's magazines have been cited as the place where meanings of sexuality were produced and contested in Taiwan in the I990s (Yang 2004), so can one argue that The Baby Kingdom is a place where motherhood is socially produced, maintained, and re-configured in Hong Kong.

Interactivity among members is conducted on the Baby Kingdom, where the women pose questions and provide answers, descriptions, and announcements about their lives. Whereas in the traditional women's magazine, this interactivity was relegated to letters to the editor, question and answer advice columns, and true-life stories (Walker I998), on the message boards, the interaction is constant. One can pose a question and receive answers, if not instantly, than usually within a day. Rather than interacting with the editors of the magazine, women on message boards interact with each other. Members interact with one another on a level of equality, with specialist advice sought out only occasionally. This displacement of 'expert' advice by peer advice can be seen as a feature of hyper-modernity (Giddens I990) if considered in comparison to the usage in women's service magazines. However, as Wellman and Giulia point out, 'Before life on the Net, people did not always go to experts, be they mechanics for their cars, doctors for their bodies, or therapists for their psyches' (Wellman \& Giulia I997: 7). People often ask friends and neighbours for advice and help before turning to professional experts. This shows that while sharing features of magazines, mothering Web boards also share features of communities of friends and neighbours in a geographic space.

Readers take vicarious joy in the happy messages posted on the Web. Reading about other posters' sorrows and difficulties may excite their empathy, sympathy, or schadenfreude. Reading what other people write allows one a window on their world as women and mothers-tobe. Mothers choose to write and report to give pleasure to others something to read and respond to. Writing gives women pleasure as well. They write to vent their emotions (positive or negative). Writing advice helps to legitimate their experiences; authors often receive positive feedback from their fellow readers who thank them for sharing their advice or experiences and tell them how useful it was. This sort of psychic stroking is one of the incentives frequent posters receive to continue their activities, and is part of the economy of this sort of online environment (Kollock I999).

Reading and writing on the Web has economic value for some site managers. It has been pointed out that 'chat' or discussion is the cheap- 
est form of content a site provider can have, because the users make the content themselves (Brown I999; Margonelli I999). One can view this in two ways. Seen through one lens women's labour of writing and responding to others is being used (exploited) by the manager of a site, or the capitalist system in general, to generate profit. The more regular visits to the site, the more advertising space can be sold, and at higher prices. Seen through another lens, one could say that women make use of the space provided by the capitalist system for their own ends. The evidence in the Baby Kingdom at the present leans towards the latter analysis: women use the site for their own ends.

\section{The Baby Kingdom - Introduction}

At present, there are three main parenting websites in the Chinese language in Hong Kong. The biggest of them is www.baby-kingdom.com, founded in 2002. It is administered by Rainer Sip, as revealed by a 'WhoIs' Internet registration search (WhoIS Information for the BabyKingdom, 2004). It is the largest and most active of the mothering sites in Hong Kong. It consists mainly of posted discussions and advertisements. It is a successful business, as well as a successful community: since 2004, its annual profits have increased 50 per cent (Sun 2007).

Can one consider a commercial site like Hong Kong's www.babykingdom.com to be a community? Sardar argues against the existence of online communities, stating that it is too easy to drop out of online relationships and that there is little commitment and responsibility.

'Communities are shaped by a sense of belonging to a place, a geographical location, by shared values, by common struggles, by tradition and history of a location - not by joining a group of people with shared interests' (Sardar 2000: 743).

However, the emergence of online communities cannot be dismissed as lightly as Sardar has stated, despite the fact that members might come and go. The Baby Kingdom qualifies as a community by virtue of its specificity in language, culture, and place. It differs from a physically-located community by the fact that most of the interactions between people do not occur face to face, but through the medium of words and images on a computer screen. Furthermore, as Wellman and Giulia have pointed out, communities do not have to be fixed in one geographic area, but may exist as social networks flung over wide areas but drawn together by technologies such as the telephone, the automobile, the airplane - and now, the Internet (Wellman \& Giulia I997). 
The Baby Kingdom is open to the public to view, but to join in the discussions one must register by submitting a name and an email address. The Baby Kingdom then contacts the applicant and gives a password. With the password, members can start to post their own questions, answers, and observations and also use 'private mail' to other members through the board.

As mentioned above, although some of the scholarship on identities in cyberspace has discussed issues of deception and 'play' (Tsang 2000; Danet 1998; Nakamura 2000), there appears to be no such deception or 'play' in the Baby Kingdom. This might be attributable to the fact that such a specialized website often only attracts its target group. This is in contrast to dating websites, where people might make use of alternative identities.

Women use the Baby Kingdom for a variety of purposes. It has been suggested that the two main uses of the Internet by people in everyday life are information seeking and inter-personal communication through email (Singh 200I) - in other words, instrumental and social (Bakardjieva 2003) uses - and this is true of the Baby Kingdom. Women's desire to learn about products and services is a strong driver of interactivity on the site. Queries abound about where to obtain certain goods. Women seek opinions about the efficacy of goods or solicit opinions about services, from hospitals that a woman may give birth in, to the merits of different kindergartens and primary schools. User-created content is beginning to be supplemented by Baby Kingdom-provided articles and an online store, but it is still a small part of the site. Registration is free; the website is maintained through revenue received from advertisements as the prices below from 2004 show.

\section{Description of the Baby Kingdom Boards (Forums)}

Some of the Baby Kingdom's features are common to other online boards. Much of the early literature on the Web was based on MUDs and Usenet (Turkle 1995; Kendall 2002; Danet 1998; Baym I998; McLaughlin, Osborne \& Smith 1995). Recently there have been more studies of 'discussion boards' or 'message boards' (Ridings \& Gefen 2004; Ley 2007). The observations made here will hopefully add to the literature on what makes for successful online communities.

In the Baby Kingdom, the timing of communication is asynchronous. The participants do not communicate in 'real time'. Instead, the women will post a comment or question in the forum, which will then be answered or ignored. This provides time for the respondents to compose their replies. People who are slower to think or write can communicate at their own pace, giving them more control over their 
answers, which can be encouraging to shy women. In this way, the communication is rather similar to that of discussion groups on the Usenet. However, the Baby Kingdom's board environment also allows editing after posting, making it even more relaxing, since one can fix typos, or even change meaning or delete one's own writing at will.

Within the Baby Kingdom there are several sub-boards. These boards create smaller communities of interest within the larger community. Thus women can deepen their relations in a smaller group, but at the same time have a broader community to explore as her interests or circumstances change. The sub-communities help to facilitate both the broadening and the deepening of the posters' social networks, increasing their network capital.

The Baby Kingdom attracts Chinese reading and speaking women from within Hong Kong (with minor participation from elsewhere in the world). It is an explicitly Hong Kong-based board; its headline in the banner is 'Hong Kong's Biggest Internet Discussion Group about One's Children' (quangang zuida de wangshang qinzi shequn - 全港最大 的网上亲子社群).

The presence of a large number of Hong Kong Cantonese-speaking women on this Hong Kong-based board has resulted in the common use of Cantonese-style written Chinese. Examples of common expressions include 'Ngo Dou Hai' (我都系) and 'Yau Mou' (有有) to express 'me too' and 'is there' respectively. Such usage may foster more of a 'Hong Kong' identity. Although one can observe women writing in more standard Putonghua, sometimes displaying simplified characters; it is overwhelmingly a Hong Kong site.

Some women write in English at the Baby Kingdom, occasionally apologizing for it, explaining that they do not know how to input Chinese characters, or that they lack Chinese software at home or in the office. They will usually receive replies in Chinese, which they answer in English. It is not uncommon for writers to intersperse the use of Chinese with some English words, for example: “我踏入第7 week la, 预产期系IO月I7日 (I have entered the seventh month, delivery date will be $I 7^{\text {th }}$ October), 系第一胎, 而加 always feel sleepy'(this is my first pregnancy, now I always feel sleepy). This matches the common way that many Hong Kong people speak, using a 'mixed code'. A similar phenomenon has been noted on Taiwanese college discussion boards (Su 2003). Such linguistic use works to foster a stronger local identity on the Baby Kingdom. For the women who post from outside Hong Kong (mainly Hong Kong women living abroad) it may create a feeling of 'home', which other Chinese language boards, using more standard Putonghua, may not. 


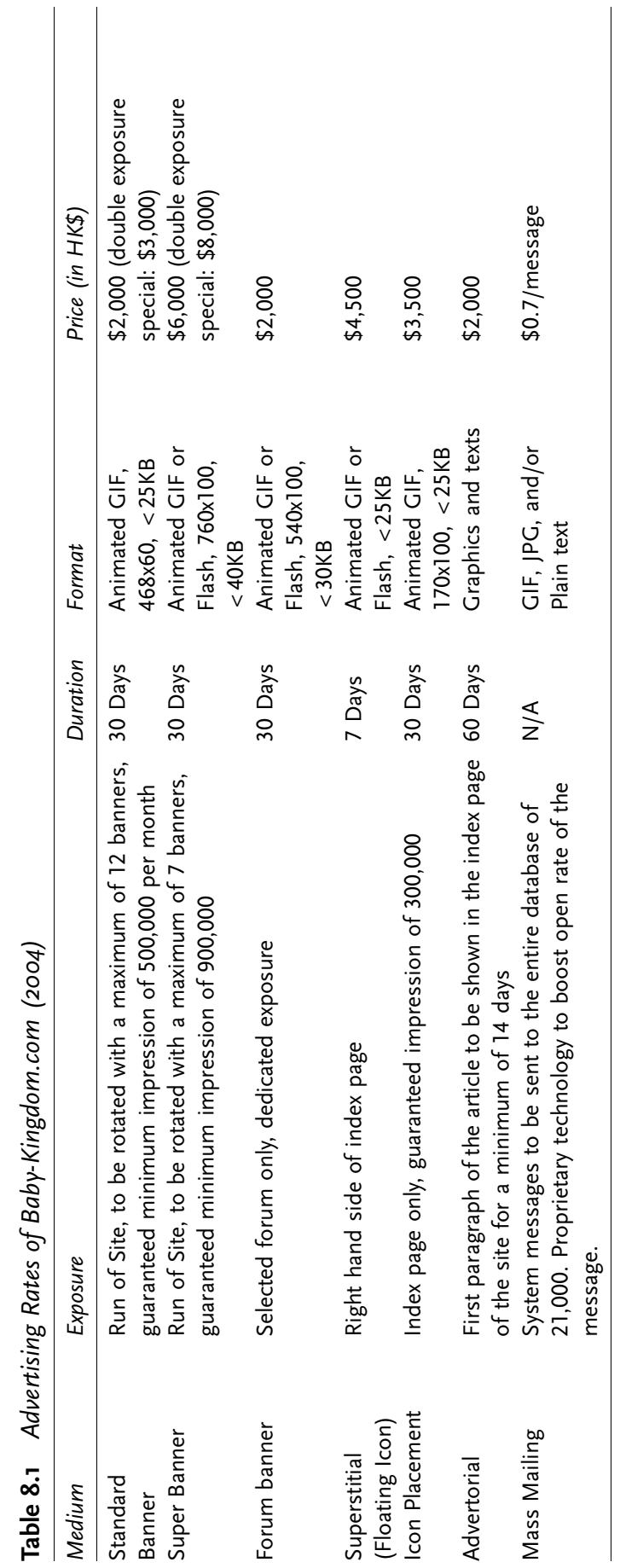




\section{Community Maintenance Tools: Username, Geographical Location, Signature File (sig), Avatar, and Status}

The Baby Kingdom's forum interface has a number of tools for presenting the self: username, geographical location, signature file (sig), avatar, and status on the board. Some Baby Kingdom members make use of all the options; others will only use a few. This presentation of self creates more trust and therefore more commitment among the virtual community members, as has been noted by Ridings and Gefen (2004).

Table 8.2 List of Sub-communities on Baby-Kingdom.com

\begin{tabular}{|c|c|c|}
\hline Name & Description & Examples \\
\hline The Kingdom & $\begin{array}{l}\text { General area for information and } \\
\text { discussion }\end{array}$ & Open Topic Area \& Publisher's Garden \\
\hline Women Talk & $\begin{array}{l}\text { General discussions about beauty, } \\
\text { fashion; and also for arranging } \\
\text { meetings (online } \& \text { in person) }\end{array}$ & $\begin{array}{l}\text { Beauty } \\
\text { Mothers' meeting } \\
\text { Fashion }\end{array}$ \\
\hline Mom's World & $\begin{array}{l}\text { Subdivided for discussions about } \\
\text { being a mother }\end{array}$ & $\begin{array}{l}\text { Before and after the birth } \\
\text { Breastfeeding } \\
\text { Working mothers }\end{array}$ \\
\hline Parenting & $\begin{array}{l}\text { Subdivided for issues about } \\
\text { children: health, nutrition, etc. }\end{array}$ & $\begin{array}{l}\text { Child health } \\
\text { Child nutrition } \\
\text { Children's goods }\end{array}$ \\
\hline Relationship & $\begin{array}{l}\text { Subdivided for discussions of } \\
\text { relationships }\end{array}$ & $\begin{array}{l}\text { Husband \& wife relationship } \\
\text { Healthy talk about sex } \\
\text { Christian households* }\end{array}$ \\
\hline Education & $\begin{array}{l}\text { Subdivided for discussions of all } \\
\text { aspects of education }\end{array}$ & $\begin{array}{l}\text { Kindergarten chat } \\
\text { Extracurricular activities } \\
\text { Primary school chat } \\
\text { Adult education }\end{array}$ \\
\hline Sharing & $\begin{array}{l}\text { General discussions \& } \\
\text { announcement \& goods exchange }\end{array}$ & $\begin{array}{l}\text { Good books } \\
\text { Used goods }\end{array}$ \\
\hline Others & Miscellaneous discussions & $\begin{array}{l}\text { Fathers' area } \\
\text { Travel } \\
\text { Pets }\end{array}$ \\
\hline
\end{tabular}

* The government's annual report, Hong Kong (2003), estimates that the Christian population in Hong Kong is about 540,000 (mostly Roman Catholic and Protestant), making up about 8 per cent of the population. Thus it may seem odd that there is a special section on the mothering board. It could be that some women want to discuss their relationship with God or their churches, or how their Christianity influences their personal relations and that this makes it a convenient location for it. It could also be that women who are Christian and wish to testify to their faith, ask for prayers, or find people to pray for needed a place where they could do so, without having to argue with non-believers, or have non-believers feel in danger of being evangelized, when all the non-believers wanted (for instance) is a some discipline tips for toddlers. It would take a more in-depth study to find the historical reasons for this section. 
The username is an important part of the posters' presentation of self. This has also been noted in other language environments (Stommel 2007) and other computer mediated communication media (Heisler \& Crabill 2006). Usernames are sometimes derived from common English names, like 'Christywai'; others are more colorful ones, such as 'LeBlue', 'cottontail','ec822'. Still others are partially or completely in Chinese: 'Maymay's Ma' (maymay - 妈), 'Little Lucky's Mama' (Xiaoji Mama - 小吉妈妈) or 'Little New's Mama' (Xiaoxin Mama - 小新妈 妈). Since these are names that the women have chosen for themselves, they must be some sort of personally meaningful self identification. Many use the self-identity of 'mother' as part of their name, which provides a degree of anonymity while at the same time proclaiming 'who she is' on the forum.

The Baby Kingdom's software allows for women to note their geographic location. This is another tool women can use to create their online identities, although not all the posters on the Baby Kingdom avail themselves of this option. The varied locations (such as 'Hang Hau', 'Ma On Shan', 'Wan Chai' 'Chai Wan', and 'Tai Po') reflect that the women using the Baby Kingdom come from different parts of Hong Kong, and judging from the locations named, it is possible to argue that not only high status women but also middle and working class women have access to the Internet on a frequent and regular basis. It helps create trust, to see that women are writing from known neighbourhoods.

Further, by noting the geographical location, this cyberspace also offers women from the same physical location opportunities to meet up in real life. For example, women may post questions like 'Any Tuen Mun area mommies want to get together?' or 'Mamas working in North Point, let's get together'. Part of what makes the Baby Kingdom a successful (highly-trafficked) site is the way it is rooted in a specific locale. Location does matter in this cyberspace - for searching out new companions, or for information-gathering. The posters on the Baby Kingdom use it as vehicle to meet like-minded others in Hong Kong. In addition, the Baby Kingdom also organizes formal activities like group barbeques and parties where members can meet. Sub-communities, like 'Year 2000' mothers, also plan get-togethers, working out catering arrangements, location, etc. As mentioned above, these subcommunities, some of which meet in real life, deepen bonds among the Baby Kingdom users.

Another way in which women identify themselves is through their signature file (sig file, or 'sig'). A sig file is a recurrent phrase or phrase-and-graphic combination that appends each message posted. Sig files have a long history on the Usenet and in Email, where netiquette demanded that they be small, 4 or 5 lines at most (Zen and the 
Art of the Internet - Usenet News I993; Shea 2004). This norm developed from the desire to conserve bandwidth, to keep servers from crashing, and to allow faster message download for list members with slower connections. However, the social norm to conserve bandwidth is completely dispensed within the Baby Kingdom. Users often use sig files with more than one photo and very large font. The sigs can then combine with the user-name to create a memorable identity.

The software at the Baby Kingdom, like the software on many message boards, allows the user to customize her identity with a graphic, commonly called an avatar. This offers the reader another visual clue for the author's persona. Sometimes the graphic is a cartoon character or cartoon-like graphic such as Hello Kitty or pictures that appear to have come from Japanese comics (manga). Others are cartoon-like graphics, such as combinations of hearts and smiley faces.

The embrace of cute cartoon graphics as identifiers may be an example of what Chan has seen as the incorporation of Japanese culture into Hong Kong popular culture (Chan 2000). Others choose to use an image of a baby or child, likely their own.

The ones who use babies' or children's pictures are deriving part of their identities from their status as mothers. It may also be that since pregnancy and motherhood are a large part of what they write about, they want to show (or show off) what they write about. These baby pictures are also very cute. Cartoon or photo, cuteness is the governing aesthetic in women's posts on the Baby Kingdom. Whether or not their babies or their lives actually live up to the cheerful cute images of their avatars, this is the way they want to be seen. They want to be seen this way, either because it is the way they wish their life really was, or because they see it as the socially acceptable way to manifest their selves. It also helps to create trust. By allowing people to see their children, the posters are opening themselves up. At the same time, presenting a friendly and cute image to the world may work to keep discussions on the board amiable. It is harder to get into online arguments with someone whose avatar is so cute.

Members are accorded different status (honours) according to the number of posts contributed. From 2002 to late 2004, there were five levels, in ascending order of rank: New Member (新加入会员), Fresh Flower Member (鲜花级会员), Pearl Member (珍珠级会员), Platinum Member (白金级会员), and Diamond Member (钻石级会员). Since then a new hierarchy has been developed, perhaps to adjust to the fact that many people had attained 'diamond' membership and new levels to distinguish heavy posters had to be devised. Now there are ten levels, in ascending order they are: Newly Added Citizen (新加入国民); Fresh Flower Citizen (鲜花级国民); Crystal Citizen (水晶级国民); Jade Citizen (翡翠级国民); Coral Citizen (珊瑚级国民); Amber Citizen (玛 
瑙级国民); Diamond Citizen (金钻级国民) Kingdom Elder/Chief (王国 长老); and Administrator (网站管理).

Such ranking identifies older members, accords their posts weight, and gives them high status. The respect given to 'older' posters in Usenet groups has been noted previously (McLaughlin, Osborne, \& Smith I995). On the Baby Kingdom, this hierarchy is codified. While the Baby Kingdom is not alone in using this sort of 'status marking', it is an unusually elaborate hierarchy.

This gives rise to the question: why does the Baby Kingdom (and other message boards) have this framework to identify the 'heavies'? As Kollock has pointed out, frequent and useful posting enhances one's reputation in online groups (Kollock 1999). The hierarchic identifiers in the posters' personas allow their reputation to be immediately visible. The hierarchic marking is also a tool for community maintenance. As Mary Douglas points out:

'The community, any community, exists because it constitutes a separate claim on the purses and time and energy of its members. There is no community unless its members concede its right to fund itself by levies upon themselves. For their part, the dues they pay are an investment and they exact corresponding rights.' (Douglas I996: II7)

The posts that the women contribute to the message board are the levies. In the Baby Kingdom, the members do not spend actual money to maintain their 'community space', but a great deal of energy is expended in reading and replying. The hierarchic symbols are incentives and rewards for greater community involvement. Douglas also points out that 'showing up' is an important part of the work to maintain a community. It creates solidarity and allows informal-census taking to be made. Who is here and who is not, who is a member, and how much have they given of their time and energy? (Douglas 1996). The status markers immediately declare how often they have shown up and how much they have contributed. Other methods of awarding social status via hierarchy have been studied (Stewart 2005; Studer 2007), but the purpose - to reward contributors for community participation and maintenance - is the same.

This trend towards increasing social presence through graphics and other heavy bandwidth uses was popular in the mid I990s (Wellman et al. I996) and appears to have become even more popular as more people gain access to broadband and as commercial servers become more robust in memory and speed.

Taken together, the user-names, geographic locations, signature files, avatars, and the status markers create a more personalized experience 
for the Baby Kingdom readers and posters. They relieve anonymity by providing a way for the readers to 'get a handle' on the poster in the facelessness of an online environment. These identifiers give the authors more freedom of expression. They also make it easier for the Baby Kingdom posters to build their social connections and friendships, as has been seen as desirable for users in other studies (Ridings \& Gefen 2004). These methods of increasing social presence allow deeper networking and help to make the Baby Kingdom a successful virtual community.

\section{Posting as Gossip - Interpersonal Communication \& Information Seeking}

Virtual communities provide more than just information - they also provide '... knowledge, wisdom, a place to thrash things out and come to new solutions. This outcome is more than just information, but also more than just community spirit and chit chat' (Ellis, Oldridge \& Vasconcelos 2004: I53). In this case, Ellis, Oldridge and Vasconcelos see that more is going on than mere 'chit chat', but by using the word they show a discomfort with this type of discourse. Other scholars, however, have come to look at chit chat or gossip as an important form of interpersonal communication and information seeking.

Ayim (I994) sees gossip as a useful tool in information seeking, especially powerful among marginalized and oppressed groups. This may be why, in so many patriarchal cultures from Ancient Greece to the Han Dynasty (as represented by Lessons for Women by Ban Zhao), women's gossip is disparaged or discouraged. In rural Taiwan in the I96os Margery Wolf showed that gossip is a double-edged sword. Women can gain some social control by deploying gossip, but it is also a tool through which social norms can be enforced (Wolf i972).

An example of Baby Kingdom posters using gossip as a method of social control can be seen in the numerous posts on how to find Indonesian maids who will work for below the legal minimum wage; threads on how to stop maids from using the telephone in their place of employment or eating fruit and cakes in the house. In early 2007 there were press reports that a thread appeared on the Baby Kingdom entitled 'Come in if you want to blacklist a maid' that had over Ioo names, photos, and passport numbers of maids who had been accused of being lazy, dishonest or abusive. It was taken down after over I5, 000 views and was reported to the Privacy Commission (China South Scene 2007).

Ben Ze'ev (I994) writes to vindicate 'gossip' as discourse. It strengthens interpersonal bonds, creates group bonds, and allows one to gain 
information about other people's lives that may shed light on one's own situation. Therefore, if women talk about their pregnancies, they will often cite their own experiences and the experiences of others they know, which is a form of gossip. When women compare notes on home remedies, opinions about the effectiveness of various doctors and their 'bedside manners', and different treatments and medical equipment used in pregnancy and birth - all prominent parts of the discussion on the Baby Kingdom - they engage in what Suls and Goodkin call medical gossip (Suls \& Goodkin I994).

Seeking information about clinics, hospitals, and specific doctors is an important part of the Baby Kingdom. In the Baby Kingdom's 'Before and After the Birth' section, women constantly post questions such as 'Is St. Theresa's Hospital Good or Bad?' or 'What's the difference between public or private hospitals?' or make requests for information like 'Could someone introduce me to a really good doctor at Baptist Hospital?' Some replies give only names and contact information, others include quite extensive details of price, competence, and personal and emotional qualities of the doctors concerned. Here is an example of a poster at the Baby Kingdom providing extremely detailed information and seeking advice: engaging in medical gossip.

'The total charge is around 22,000. I forgot the exact amount but it is not more than this figure. Dr. [X] charged me only 6500 for delivery and regular checking (twice a day, 4 days). 2000 goes to the baby checking, the doctor is also a very famous doctor... I heard some mama said that joining package is more expensive than not joining, so I am just wondering if I should join this time. But my husband said it is better to join for secure reason as at least we can have a budget. But doctor [X] charge a very reasonable price because the first doctor I approached is not him, she is a very famous doctor (one of mama has introduced at below) but she is not very nice to me. I felt she is very commercial and not very sincere and reliable, she charge me almost double of what $\mathrm{Dr}[\mathrm{X}]$ charge me. In fact, no body introduced Dr. [X] to me. I went to [Hospital A] because I had flu when I was pregnant, so I chose Dr $[\mathrm{X}]$ to check flu, not for baby checking. But he was very helpful, he not only gave me the advice of flu but also pregnancy problem. He freely check my baby heart beat. So when I met doctor [X], I changed my mind at once. I think a doctor can make you feel save [sic], reliable is very important...'(cowcowmama 2004)

The medical gossip on this site creates a 'normative debate' about the qualities of a good physician and what the relationship between a wo- 
man and the medical institution she interacts with should be like. It also allows some women to 'get back' or resist by relating their less positive experiences.

\section{The Baby Kingdom as Gendered Space}

Although the Web, especially as it began to be studied in the early to mid i990s, was considered mostly a 'boy's' place (and Sardar described the 'boy' in question as an adolescent white boy (Sardar 2000)), there were already active women's Internet groups, such as the soap operas groups described by Baym (I998). The Baby Kingdom is another example of women's space. Although men can also enter and converse, they rarely do so (there is a father's forum but it has low traffic). The fact that this is a safe Hong Kong women's space is one of the reasons why the Baby Kingdom is such a successful virtual community. Here women are free to discuss issues of importance to them, in a way that is comfortable for them.

In present-day Hong Kong one can see evidence of gendered physical space. For example: playgrounds, areas near markets, and places where children get dropped off or picked up from school are common places where women meet to pass the time of day. Although no formal studies in Hong Kong have yet been published on such phenomena, there has been one on women living in public housing in Singapore (Phua \& Yeoh I998). James Farrer has also noted similar use of small public spaces for meeting and gossip in a housing estate in Shanghai (Farrer 2002).

Phua and Yeoh (I998) describe some physical spaces as 'unfocused sites'. These are informal places where women tend to gather and where they negotiate patriarchal expectations and requirements by coping with or challenging the prescribed notions of gender. I suggest that the Baby Kingdom is similar to such 'unfocused sites', constituting a 'third place' (Oldenburg I997), aside from home and work (the first and second 'places'). It is a bounded space, where the women may feel safe from the presence of men. It can be seen as a $2 \mathrm{I}^{\text {st }}$ century successor to the girl's houses of early $20^{\text {th }}$ century Guangdong (Watson I994; Stockard i989; Yip I997).

In the physically gendered spaces of playgrounds, etc., women can speak with each other and observe other children and their interactions and thus come to see what appears to be 'normal' and what may be odd. Women give and receive advice (solicited or gratuitous) on how to raise children. The places where this happens are also the ones where women can discuss their family relations, do a little boasting, be reassured that their problems are 'normal' (which can be comforting or re- 
pressive), find ideas or solutions to them, and alleviate boredom or loneliness. It is in these 'unfocused sites', as Phua and Yeoh (I998: 322) point out, where women 'increase their store of knowledge and... "compare notes" about "appropriate" gender roles and relations and (re)evaluate their understandings of their own identities against the yardsticks provided by other women's accounts'. As such they are vitally important places, where 'the hegemony' of one's culture may be reinforced or challenged.

Phua and Yeoh (2002) point out both here and in more recent work the importance of the telephone in the lives of many women as a source of 'chit-chat', so that telephone use can also be considered an unfocused site. Similarly, Singh (200I) found that farm women in Australia used the Internet more than their husbands, but when they did so it became no longer 'technology', but rather just a tool, like the telephone. Singh points out that, like the telephone, Internet communication originally was used for terse, businesslike conversation, but that women have turned it into a social medium. One can extrapolate from the frequent and long telephone conversations that women engage in, to the 'meeting' and 'chatting' on message boards. Online forum discussion on a gendered space like the Baby Kingdom is coming to have the same ubiquity and importance as the telephone in women's everyday lives.

For mothers working outside their homes, or first-time pregnant women working outside the home, there is no time to 'hang out' physically and see who stops by and chats. Part of the allure of the Baby Kingdom is that one can go and 'hang out' (or one's words can), so that relationships can be built and information, opinions, and experiences can be shared. For women who work solely at home, as either housewives or home-workers, the message board provides an opportunity to meet and connect with women outside their immediate geographic location.

It cannot be ignored that the boards in the Baby Kingdom are not just women's space, but specifically mothers' space. Discussion of 'DH' or laogong (老公 - literally 'old man', a slang term for husband) is common. I have yet to see mention of lesbian partners and very few women identify themselves as single mothers ${ }^{4}$. The underlying assumption is that being a mother is an important part of their identities. One could say that, by their very existence, such online forums valorise motherhood. 


\section{Baby Kingdom as a Space for Public Action}

When I first began to study the Baby Kingdom, the question of its potential as a space for public action arose. In early 2003, the medical threat of the SARS virus and its affect on hospital services and women who were giving birth in March 2003 was a topic for discussion. But SARS postings never got past the stage of venting fears and writing about empathy and reassurance. It was not until late 2006 that the first overt political action by women who met and organized via the Baby Kingdom came about.

Women posting on the Baby Kingdom shared unhappiness about crowded maternity wards in public hospitals, and a forum poster in October 2006 suggested that they start a campaign. They wrote a letter to legislators, one of whom, Leung Yiu-chung (a Legislative Council member known for representing the 'grass roots') responded to it. Leung helped the Baby Kingdom members plan a public protest which attracted 40 pregnant Hong Kong women on ig November 2006 (Goh 2006; Moy 2007). The target of these protests were 'Mainland mothers', who came to Hong Kong on tourist or two-way visas and made use of the public hospital maternity wards, leading to over-crowding. This protest, combined with information from a Hospital Authority audit, worked to have the Hospital Authority, the Security Bureau, and the Immigration Department create new rules to only allow women from the mainland who were over seven months pregnant to enter Hong Kong if they could show that they had paid a deposit on a hospital bed for delivery. This new entry of pregnant women into the public sphere in Hong Kong (Li 2007) may be seen as a positive development for Hong Kong women's empowerment, but it appears to be at the expense of others, in this case, women from Mainland China. It is an example of a community organizing to protect itself against what it considers outsiders.

\section{Baby Kingdom as a Space for Hong Kong Women's Expressive Culture}

In parts of the Pearl River Delta, including the New Territories, girls used to gather in special houses where they learned songs and traditions from older girls and women (Watson 1994; Stockard 1989; Yip 1997). There they learned, maintained, changed, and passed on in their turn an important part of women's expressive culture, their domestic arts and rituals. Since the I940s, such houses have disappeared, and many of the arts, such as the marriage or death lamentations, are no longer passed on or practised. However, the Baby Kingdom now of- 
fers a new online space where women can maintain, modify and pass on cultural traditions, such as that of the post-natal confinement period.

For example, in a discussion thread about bathing after the birth ${ }^{5}$, a woman asked when one could start to wash. She received different replies recommending that first bathing should occur two days after the birth; five days after the birth; or she could bathe her body three days after the birth and wash her hair five days after the birth. She also received advice on using ginger water. She could then accept or reject any of these varieties of tradition.

Members discuss and give advice about other traditional practices. For example, in one thread, a woman requested advice about drinking a tonic soup her mother-in-law had made for her, called fuzhu tangshui (腐竹糖水?). Most of the replies stated that it was too 'cold' for a pregnant woman to drink, at least until very late pregnancy. One advised checking with a traditional Chinese medicine (TCM) doctor; another stated that she already drank this tonic and other cold soups and teas under the supervision of her TCM doctor. In this example we see childbearing women in Hong Kong using the Baby Kingdom to increase their knowledge and understanding of 'tradition' and to double-check, or in some cases to challenge, the older generation's understanding of folk medicine. Using this highly modern technology and space, Hong Kong women negotiate and perhaps change traditional practices by questioning, sharing experiences, and advising; they create norms and expectations. The Baby Kingdom is thus a new venue for women's expressive culture.

\section{Conclusion}

The Baby Kingdom is an example of Chinese women's online communities in the early $2 \mathrm{I}^{\text {st }}$ century. Through semi-bounded membership, as well as linguistic and visual clues, a sense of solidarity is formed. This is abetted by hierarchic markers that give the incentive of higher status for greater community participation. The group fosters communication among women in their community online and facilitates meeting in real life. In this way, it works to broaden and deepen women's social networks, increasing their network capital. It is a new venue, half-way between an informal 'unfocused site' and a more formal social grouping, like the old 'girl's houses'. It is a space that facilitates gossip, important for information sharing on practical and ritual issues, for personal interaction, and now a place to organize public action. It can be seen as a 'Community of Practice', a paradigm that some sociologists 
have used in describing work groups (Ellis, Oldridge \& Vasconcelos 2004) - in this case, the work is mothering.

The Baby Kingdom is run as a business that makes money through advertisers, or in the broadcast idiom, 'sponsors'. Women who meet here are in a sense 'sold' as a target group to the advertisers by the site owners. Yet at the same time, they make it their own space and use it to further their own ends. Through reading, posting, and meeting on this website, Hong Kong women make use of this highly modern global technical system to transmit and re-shape a modern localized culture of pregnancy, birth, and motherhood.

It is a new venue for community, a supplement to other ways of meeting and relating in real life. As such, it can be a source of empowerment, as women learn and share information, ideas, and experiences. Yet it is also a place where oppressive norms and practices are perpetuated (such as exercising unreasonable power over foreign domestic helpers, or working to keep women without Hong Kong ID cards from giving birth in public hospitals). Like many new technologies, the use of the Internet is a double-edged sword; how women in Hong Kong choose to wield it through means of the Baby Kingdom may make it a boon for the members, but sometimes a bane for 'outsiders'.

\section{Notes}

I. A 'troll' is someone who comes to a discussion list, Web board, or blog for the sole purpose of causing arguments or disrupting the discussion. The term originates from fishing, where 'trolling' is moving along in a boat with the fishing line out, waiting for a bite. For the Internet troll, provocative comments are the bait. The popularity of the name may be because it is a homonym for spiteful supernatural creatures who live underground or otherwise out of the sun.

2. Service magazines are publications like Good Housekeeping, Redbook, Parents, Working Mother, etc. They usually contain information about health, housekeeping tips, childrearing, recipes and new household products, as well as stories.

3. Except in a series of postings in spring 2004 where a pregnant woman reported that her husband moved back to his mother's home and maintained a girlfriend, leading the pregnant woman to think she would soon be a single mother.

4. In Chinese culture, the month after the birth, called zuo yuezi, is a special time of rest and recuperation, when the new mother is enjoined from exertion and engaging in activities seen as 'cold' in the humeral system, such a bathing or washing hair. See (Holroyd and Fung I997; Pillsbury 1982; Wong I998; Martin 1994) for discussion of this practice.

\section{References}

Advertising Rates - Baby-Kingdom.Com 2004. www.baby-kingdom.com 2004 [Retrieved 8 September 2004]. Available from http://corp.baby-kingdom.com/rates.html 
Ayim, M. (I994), 'Knowledge through the grapevine: gossip as inquiry', in A. Ben-Ze-ev \& R.F. Goodman (eds.), Good gossip, 85-99. Lawrence, Kansas: University of Kansas Press.

Bakardjieva, M. (2003), 'Virtual togetherness: an everyday-life perspective', Media, Culture, and Society 25 (3): 29I-3I3.

Barwell, G. \& K. Bowles (2000), 'Border crossings: the Internet and the dislocations of citizenship’, in B.M. Kennedy (ed.), The cybercultures reader, 702-7II. London: Routledge.

Baym, N.K. (I998), 'The emergence of on-line community', in S.G. Jones (ed.), Cybersociety 2.0: revisiting computer mediated communication and community, 35-68. Thousand Oaks, Calif.: Sage.

Bell, D. (200I), 'Community and cyberculture', in An introduction to cybercultures, 92-II2. London: Routledge.

- (200I), 'Storying cyberspace I: material and symbolic stories', in An introduction to cybercultures, 6-29. London: Routledge.

Ben-Ze'ev, A. (I994), 'The vindication of gossip', in A. Ben-Ze'ev \& R.F. Goodman (eds.), Good gossip, II-24. Lawrence, Kansas: University Press of Kansas.

Boneva, B., R. Kraut \& D. Frohlich (200I), 'Using e-mail for personal relationships the difference gender makes', American Behavioral Scientist 45 (3): 530-549.

Brown, J. (I999), 'Must AOL pay “community leaders”?', Salon, I6 April I999.

Chan, A.H.N. (2000), 'Consumption, popular culture, and cultural identity: Japan in post-colonial Hong Kong'. Studies in Popular Culture 23 (I): 35-55.

China South Scene.2007. Financial Times Information. Acc-nno: A2007033I4A-I445-GNW. Retrieved from Lexis-Nexis database I6 April 2007.

Chong, L. (I995), 'HK Internet providers protest raid'. UPI Wire, 6 March I995. Retrieved from Lexis-Nexis Database I5 September 2004.

cowcowmama (2004), Can anyone introduce me to a really 'good' doctor?, I7 March 2004 [Retrieved 27 March 2004]. Available from http://www.baby-kingdom.com/modules/newbb/ viewtopic.php?mode=viewtopic\&topic_id=II8457\&forum=79\&start=I80\&viewmode=flat \&order $=0$

Danet, B. (I998), 'Text as mask: gender, play and performance on the Internet', in S.G Jones (ed.), Cybersociety 2.0: revisiting computer mediated communication and community, I29-I58. Thousand Oaks, Calif.: Sage.

Douglas, M. (1992), 'The normative debate and the origins of culture', in Risk and blame, I25-I48. London: Routledge.

- (1992), 'Risk and danger', in Risk and blame, 38-54. London: Routledge.

- (I996), 'The consumer's revolt', in Thought styles, Io6-I25. London: Sage.

Ellis, D., R. Oldridge \& A. Vasconcelos (2004), 'Community and virtual community', Annual review of information science and technology 38: I45-I86.

Farrer, J. (2002), ' "Idle talk”: neighborhood gossip as a medium of social communication in Reform Era Shanghai', in D. Wank (ed.), Social connections in China: institutions, culture and the changing nature of Guanxi, I97-220. Cambridge: Cambridge University Press.

Feliciano, K. (200I), 'Bringing up baby'. Adweek 42 (2): 26-28.

Frederick, H. \& H. Vogel (I998), 'But can the Internet change diapers', Publishers Weekly 245 (23): 34 .

Giddens, A. (I990), The consequences of modernity. Stanford, Calif.: Stanford University Press.

Goffman, E. (I959), The presentation of the self in everyday life. New York: Doubleday.

Goh, L. (2006), 'Mother-to-be turns rights activist', South China Morning Post, 5 December 2006 , p. I.

- (2007), 'Mainland births in Hong Kong still rising: I7pc more couples cross border for births despite curbs, fee rise', South China Morning Post, 8 November 2007, p. I.

Haythornthwaite, C. (200I), 'The Internet in everyday life', American Behavioral Scientist 45 (3): $363-382$. 
Heisler, J.M. \& S.L. Crabill (2006), "Who are "stinkybug" and "Packerfan4"? Email pseudonyms and participants' perceptions of demography, productivity, and personality', Journal of Computer-Mediated Communication I2 (I), II4-I35.

Holroyd, E., K. Lai \& K. Fung (I997), 'Doing the month: an exploration of postpartum practices in Chinese women', Health Care for Women International I8 (3): 30I-3I3.

Inayatullah, S. \& I. Milojevic (1999), 'Exclusion and communication in the Information Era: from silences to global conversations', in W. Harcourt (ed.), Women@Internet: creating new cultures in cyberspace, 76-88. London: Zed Books.

Kendall, L. (2002), Hanging out in the virtual pub: masculinities and relationships online. Berkeley: University of California Press.

Key Telecommunication Statistics 2004. Hong Kong Office of the Telecommunications Authority, 8 April 2004 [Retrieved 9 May 2004]. Available from http://www.ofta.gov.hk/ frameset/facts_index_eng.html.

Kinsella, S. (I995), 'Cuties in Japan', in B. Morean (ed.), Women, media, and consumption in Japan, 220-254. Honolulu: University of Hawai'i Press.

Koerber, A. (200I), 'Postmodernism, resistance, and cyberspace: making rhetorical spaces for feminist mothers on the Web', Women's Studies in Communication 24 (2): 218-240.

Kollock, P. (1999), 'The economies of online cooperation: gifts and public goods in cyberspace', in M.A. Smith \& P. Kollock (ed.), Communities in cyberspace, 220-242. London: Routledge.

Ley, B. (2007), 'Vive les roses!: the architecture of commitment in an online pregnancy and mothering group', Journal of Computer-Mediated Communication I2 (4): I388-1408.

Li, S. (2007), From 'private' to 'public': pregnant women redefine the boundary of the public sphere in Hong Kong. [Unpublished Conference Paper, presented at 'Dynamics of Transformation in East Asia' held at the University of Edinburgh, 24-26 October 2007].

Margonelli, L. (I999), 'Inside AOL "cyber-sweatshop": how a fortune was built and classaction lawsuit was born on the fingers of tens of thousands of unpaid volunteers', Wired 7 (Iо).

Martin, D. (1994), Pregnancy and childbirth among the Chinese of Hong Kong. PhD Dissertation, Oxford University.

McCracken, E. (I993), Decoding women's magazines: from Mademoiselle to Ms. New York: St. Martin's Press.

McLaughlin, M., K. Osborne \& C. Smith (I995), 'Standard of conduct on usenet', in S.G. Jones (ed.), Cybersociety: computer-mediated communication and community, 90-III. Thousand Oaks, Calif.: Sage.

McVeigh, B.J. (2000), Wearing ideology: state, schooling and self-presentation in Japan. Oxford: Berg.

Miller, M. (2003), 'Building the village', The Deal.com, I December 2003, p. I. Retrieved from Lexis-Nexis database I5 September 2004.

Moy, P. (2007), 'Live \& clicking: concerned citizens are finding the Internet can be a potent agent for social and political change', South China Morning Post, 30 January 2007, p. 5.

Nakamura, L. (2000), 'Race in/for cyberspace: identity tourism and racial passing on the Internet', in B.M. Kennedy (ed.), The Cybercultures reader, 712-720. London: Routledge.

Oldenburg, R. (1997), The great good place: cafes, coffee shops, community centers, beauty parlors, general stores bars, hangouts and how they get you through the day. New York: Marlowe \& Company.

Ono, H. \& M. Zavodny (2003), 'Gender and the Internet', Social Science Quarterly 84 (I): IIII2I.

Phua, L. \& B.S.A. Yeoh (I998), 'Everyday negotiations: women's spaces and the public housing landscape in Singapore', Australian Geographer 29 (3): 309-326.

- (2002), 'Nine months: women's agency and the pregnant body in Singapore', in S. Huang (ed.), Gender politics in the Asia-Pacific Region, I7-40. London: Routledge. 
Pillsbury, B.L.K. (I982), “Doing the month”: confinement and convalescence of Chinese women after childbirth', in M. Kay (ed.), Anthropology of human birth. Philadelphia: F.A. Davis.

Rheingold, H. (2000), The virtual community: homesteading on the electronic frontier. Rev. ed. Cambridge, Massachusetts: The MIT Press.

Ridings, C.M. \& D. Gefen (2004) 'Virtual community attraction: why people hang out online', Journal of Computer-Mediated Communication Io (I), ০০-০o. doi:Io.IIII/j.Io836IoI.2003.tbo0357.x [Retrieved in November 2007]

Ritter, J. (I998), 'Internet groups forges mother of all bonds: moms link up with e-mail', Chicago Sun-Times, 27 September I998, p. I5.

Sardar, Z. (2000) 'Alt.Civilizations.FAQ: Cyberspace as the darker side of the West', in B.M. Kennedy (ed.), The Cybercultures Reader, 732-752. London: Routledge.

Shea, V. (2004), Signature files [Webpage], 5 January 2004 [Retrieved I5 October 2004]. Available from http://www.albion.com/netiquette/book/0963702513p62.html.

Singh, S. (200I), 'Gender and the use of the Internet at home', New Media a Society 3 (4): 395-4I5.

Stewart, D. (2005), 'Social status in an open source community', American Sociological Review, 70 (5): 823-842.

Steyn, P. \& E. Chan (2004), Over half a million Hong Kong people visited an Internet banking site in January 2003 (27 February 2003). Nielsen Net Ratings 2003 [cited I9 September 2004]. Available from http://www.nielsen-netratings.com/pr/pr_030227_hk.pdf.

Stockard, J.E. (I989), Daughters of the canton delta: marriage patterns and economic strategies in South China, 1860-1930. Stanford, Calif.: Stanford University Press.

Stommel, W. (2007), 'Mein nick bin ich! Nicknames in a German forum on eating disorders', Journal of Computer-Mediated Communication, 13(I), article 8. http://jcmc.indiana. edu/volı3/issuer/stommel.html [Retrieved II Nov 2007]

Studer, M. (2007), 'Community structure, individual participation and the social construction of merit', IFIP - International Federation for Information Processing 234: I6I-I72.

Su, H.Y. (2003), 'The multi-lingual and multi-orthographic Taiwan-based Intrenet: creative uses of writing systems on college affiliated BBSs', Journal of Computer-Mediated Communication 9 (I), o-o. doi:Io.IIII/j.I083-6Iог.2003.tboo357.x [Retrieved II November 2007]

Suls, J.M, \& R.F. Goodkin (I994), 'Medical gossip and rumor: their role in the lay referral system', in A. Ben-Ze’ev \& R.F. Goodman (eds.), Good gossip, I69-I79. Lawrence, Kan. : University Press of Kansas, cr994.

Sun, C. (2007), 'Lucrative spin-off over child prodigies', South China Morning Post, ig August 2007, p. 4 .

'Taiwan women are the leading online mothers of Asia' (200I), Deutsche Presse-Agentur, 22 May 200I. Retrieved from Lexis-Nexis database I5 September 2004.

Tsang, D. (2000), 'Notes on queer “n”Asian virtual sex', in B.M. Kennedy (ed.), The Cybercultures Reader, 432-438. London: Routleldge.

Turkle, S. (1995), Life on the screen: identity in the age of the Internet. New York: Simon \& Schuster.

Walker, N.A. (I998), 'Introduction: women's magazines and women's roles', in N.A. Walker (ed.), Women's magazines: 1940-1960, gender roles and the popular press. Boston, Mass.: Bedford/St. Martin's.

Watson, R.S. (I994), 'Girls' houses and working women: expressive culture in the Pearl River Delta, I900-4I', in M. Jaschok \& S. Miers (eds.), Women \& Chinese patriarchy: submission, servitude and escape, 25-44. Hong Kong: Hong Kong University Press.

Wellman, B. (200I), 'Computer networks as social networks', Science 293 (5537): 2031-2039.

Wellman, B. \& M. Giulia (2005), Net surfers don't ride alone: virtual communities as communities [Retrieved I7 February 2005]. Available from http://www.chass.utoronto.ca/ wellman/publications/netsurfers/netsurfers.pdf. 
Wellman, B., J. Salaff, D. Dimitova, L.Garton, M. Guila, \& C. Haythornthwaite (I996), 'Computer networks as social networks: collaborative work, telework, and virtual community', Annual Review of Sociology 22: 213-238.

[Who is information for the Baby-Kingdom] 2004. SamSpadeOrg 2004 [Retrieved I4 October 2004]. Available from http://www.samspade.org/t/lookat?a=www.baby-kingdom.com.

Wolf, M. (1972), Women and the family in rural Taiwan. Stanford, Calif.: Stanford University Press.

Wong, L.L. (1998), Tso Yüeh-Tzu : the post-natal ritual of Han Chinese women in Taiwan, PhD Dissertation, Oxford.

Wynn, E. \& J.E. Katz (I997), 'Hyperbole over cyberspace: self-presentation and social boundaries in Internet homepages and discourse', Information Society I3 (4): 297-327.

Yang, I.F.C. (2004), 'International women's magazines and the production of sexuality in Taiwan', Journal of Popular Culture 37 (3): 505-530.

Yip, H.M. (1997), 'Women and cultural tradition in Hong Kong', in F.M. Cheung (ed.), Engendering Hong Kong society, 307-340. Hong Kong: The Chinese University Press.

Zen and the art of the Internet - usenet news 2004. [Web page]. Computer Science Department at the University of Indiana, 3I July I993 [Retrieved I5 October 2004]. Available from http://www.cs.indiana.edu/docproject/zen/zen-I.o_6.html. 


\section{PART II}

LOVE, SEX AND MARRIAGE 



\title{
9 Sapphic Shadows
}

\section{Sworn Sisterhoods and Cyber Lesbian Communities in Hong Kong}

\author{
SIM Amy
}

\section{Introduction: Background}

Rich's (I980) conception of 'compulsory heterosexuality' to explain the existence of female homosexuality as resistance to heterosexuality has been criticized for its ignorance of the range of female sexuality and the inability to imagine women's same-sex desires as anything but resistance to heterosexuality (Blackwood \& Wieringa I999). However, Rich's central thesis remains unchallenged that many societies are characterized by systems of compulsory heterosexuality, symptomatic of patriarchy.

Rich's (I980) continuity approach located all women on a lesbian continuum with respect to their practices that resist compulsory heterosexuality and dependence on men, defining lesbianism cross-culturally and trans-historically as forms of 'women-loving women' (Radicalesbians I973; Cook I977; Sahli I979; Faderman I981). Discontinuous approaches focusing on lesbianism as geographically rooted and historically developed do not recognize commonalities in universal structures of male domination and reject notions of lesbianism as resistance to patriarchy. Like postmodern feminism, discontinuous approaches are concerned with the divisions among lesbians on issues of race, ethnicity, class, etc. (Ferguson I990). This chapter examines some of these concerns among Chinese women to find support for Rich's (ig80) thesis.

The political agendas of lesbians and feminists in Europe and North America have not always been coterminous. ${ }^{\mathrm{I}}$ The connection between female homosexuality and feminism came about in the development of lesbian feminist theory during the I970s, where 'feminism is the complaint, lesbianism the solution' (Johnston I973), and where 'feminism is the theory, lesbianism the practice' (Ti-Grace Atkinson cited in Echols I989: 238). Political lesbianism was strongly advocated as revolutionary action - e.g. Radicalesbians (I973: 240) proclaimed that 'a lesbian is the rage of all women condensed to the point of explosion', 
advocating lesbianism as a significant form of resistance to patriarchy and identifying lesbians as, first and foremost, feminist. ${ }^{2}$

Political lesbianism in the West has been influential in shaping the aspirations of young lesbians in Hong Kong as they access feminist/ lesbian theories through institutes of higher learning. This chapter employs a dialectical historical approach in examining two diachronic groups in the interlocution of local socio-cultural dynamics in Southern China, and of historical developments in urban modernity. Sworn sisterhoods emerged in the mid nineteenth century in Guangdong Province while its modern-day counterparts are represented by self-identified lesbians in Hong Kong. Their lives are characterized by common cultural traditions and historical opportunities for economic and personal autonomy. No research exists so far that rationalizes what appears to be two distinct groups of homosocially oriented women, rooted in common threads of culture, history and geography.

While comparison and juxtaposition may be odious to some (Steinmetz 2004), they are useful for providing insights into the socio-political culture from which such sub-cultures emerge. This chapter serves to document the existence and emergence of Hong Kong's lesbian community, and provides a commentary of persistent patriarchy in modern Hong Kong. ${ }^{3}$

'The economic development of Hong Kong has reinforced the traditional role of women. It has also created escalating conflicts in women towards their role and status in society. This awareness has assisted in the promotion of a feminist consciousness and has moved women to identify and lay claim for their rights as citizens deserving of equal status with men.' (The Hong Kong Women's Coalition on Equal Opportunities I996)

Homosexuality was not unknown in ancient China, although most existing literature on this subject pertains to homosexuality amongst men of a higher social class. The definition of female homosexuality is taken at its broadest here as: '[W]omen who love women, who choose women to nurture and support and to create a living environment in which to work creatively and independently, are lesbians' (Cook I977 cited in Rupp I990: 398).

Relations of love between women have always existed on a continuum between intimate friendship and physical love; and, despite attempts to camouflage or deny them, these relations are important for those involved in homosocial modernity. ${ }^{4}$ Where theories of kinship and family tend to emphasize women's roles as reproducers and mothers, Chinese sisterhoods and modern lesbian communities epito- 
mize a view of women's lives that includes a range of social relations not confined to social and biological reproduction.

Some have argued that the label 'lesbian' is not applicable to nonwestern sexual relationships between women because of its Euro-American content. It is a moot point whether Chinese sisters could possibly have been 'lesbian' or 'same-sex oriented' or even 'homosexul', given that these terms are Euro-American in origin and did not exist in their language. Precluding the requisite equivalent lexicon to be 'lesbian', the use of identical, parallel or corresponding Chinese terms included an awareness among Chinese lesbians that theirs was a choice that did not conform to categories of normative sexual behaviour.

In locating the institutionalization of the modern lesbian culture within broader notions of civil society in Hong Kong, I employ Fine's (2004) definition of civil society as one made up of 'tiny publics' of overlapping and interacting small groups and networks. Thus, the research for this chapter was based on examining nodes of such interaction within lesbian communities and the generalized ideology and rhetoric defining its relations, 'tied together not through any central point but rather, through intersecting sets of personal relationships and other intergroup linkages' (Gerlack \& Hine I970: 55 ).

Research conducted with sixteen women who catalyzed, used and in some cases abandoned public websites that cater to lesbians in Hong Kong shows how cyberspace has deepened networks that connect them. In addition, the formations and identifications within this community will be examined to reveal aspects of differentiation amongst individuals in their use of cyberspace, ideologies and perspectives of personal/political empowerment.

This chapter concludes with the gains that a combination of patriarchy and capitalistic developments have garnered for modern lesbians over the last three decades. Capitalism has led to the historical separation of kinship and economic organization in ways that have created opportunities for women. Wage earning makes it possible for unmarried women to live independently of kin, and to make choices that take the place of heterosexual marriage. Political activism related to alternative sexualities is a function of women's personal and economic empowerment. And it is this commitment to the political process that promises to change the status quo by embedding and institutionalizing new ways of being for homosexual women.

The next section briefly describes the emergence of the anti-marriage movement in the nineteenth century, in Southern China. 


\section{The Making of the Sohei Community}

Chinese women's historical options were severely circumscribed by gender considerations. As temporary sojourners in their fathers' homes, partially integrated into their marital homes, women were excluded by rules of patriliny from the ownership of land and businesses, and from access to education and secure employment (Wolf 1972: 3237; Watson 1991). While marriage was not the only destiny for Chinese women, other options were not attractive (Hershatter I99I). Women were expendable, despite their contributions as farmers, silk producers, domestic servants and factory workers (Gates I989: 8I4). Among the communist guerrillas of the I930s and I940s, women's lives were no better. Guerrilla leaders promised male recruits wives and by doing so contradicted promises to empower women (Ocko I99I).

The Pearl River Delta in Guangdong had become one of China's major silk-producing regions by 1925 employing more than two million people in sericulture and silk reeling (Howard \& Buswell I925: I5-25). Most of these were women and childlessness favoured the employment of single women (Stockard I989: I48-I49). When the silk industry declined after 1930, large numbers of women became unemployed (So I986: 37). Many became domestics, mail-order brides, day labourers, and indentured workers who migrated to Hong Kong and parts of Southeast Asia (Chiang I994).

During the expansion of Guangdong's sericulture, women workers had the economic wherewithal to refuse to marry altogether (Topley I975). Although there is some debate as to what constitutes 'marriage resistance' (Watson I994: 34-35), silk work was the highest paid among all occupations (So 1986: I26), leading to a radicalization of traditional forms of marriages, making it possible for women to buy themselves out of marriage and sexual contact with men (Stockard I989; Topley

I975). Women affected by these developments were to form the first of the sworn sisterhoods, whose members survived the economic and political turmoil in pre-communist China to seek work elsewhere.

Pre-conditions for the historical emergence of anti-marital bias among young women existed in the cultural and economic conditions that were pervasive in Southern China (Stockard I989). Sworn sisterhoods of spinsters were well-integrated into the traditional social milieu of that time. The spinster life-style was also, for many women and their natal families, a livelihood strategy, as profitably deployed spinster daughters were a reliable source of indefinite remittances to their families.

Different explanations have been offered for the rise of marriage resistance, but it is clear that economic independence had a profound effect on delta women who, given economic independence, challenged 
not their employers but a structure of male authority embedded in the patriarchal family (Eng I986: I27-I29; I990: I43-I45, I55; So I986: I3II34; Topley I975: 74). ${ }^{5}$ Chinese women who joined sisterhoods rejected a life dependent on and obligated to husbands and fathers. They were not inspired so much by oppression stemming from heterosexuality as by patriarchy and its attendant rules of patriliny, which excluded women in terms of social value and relevance. It was the oppression of women through the differential valuation of differently-sexed bodies in a system in which masculinity and masculine desire were constructed as socially valuable, while women's identity and sexuality were categorically limited, confined and made functional (Blackwood r999: 55).

Spinsters could acquire status through a special ritual (Sankar i978; Stockard, I989), despite Chinese prejudices related to unwed daughters. These ceremonies were accompanied by costly dinner-parties, where spinsters were treated as adults and shown respect.

\section{Some Principles of Association among Sworn Sisterhoods}

When delta women left their rural homes and migrated to urban Hong Kong and Southeast Asia, they brought with them certain institutions, beliefs and patterns of behaviour. As migrants, they were aided in the difficult transition from industrial worker to domestic servant by transforming their rural sisterhoods into part-guild, part-family associations. Sisterhoods changed over time motivated by the needs of migrant, and rather than falling victim to the 'destructive effect' of urbanity and modernity, sisterhoods prospered (Sankar I984: 5I-52).

These associations ranged from loose networks to sworn sisterhoods, some of which involved ritualistic worship while others were informal and tacit; ranging from casual friendships to committed lesbian 'marriages'. Functionally, they substituted for the biological family in China and provided an instant network of information and solidarity for women working, often, in very difficult working conditions. For illiterate immigrant women, what counted were free board and lodging, safety and an honorable occupation.

'This category of traditional amahs...who arrived in Hong Kong without families, in search of security and stability...chose domestic service for its quasi-familial qualities. In return for a life of devoted service they anticipated the respect and consideration accorded to the aged in traditional China. However, with the changing economic and social conditions in Hong Kong today, this expectation is more and more frequently disappointed'. (Sankar, I978: I46) 
As such, sisterhoods reduced the women's dependence on employers especially during retirement, when most did not have the option of returning to China. They set up 'vegetarian halls' ${ }^{6}$, which became focal points for their wellbeing and security, and they were concerned with the prosperity and image of the sisterhoods. They identified with one another as spinster sisters, migrant women, workers and family. They were concerned for one another's welfare, often providing loans and training, checking out prospective employers, and negotiating terms of employment for younger women. They offered the protection of modern trade unions and provided opportunities for joint investments. Committed sisterhoods formed in Hong Kong usually had some previous ties, e.g. to the same village, or to a common friend, or as relatives or biological sisters. They took care of their own in life - and even in death, buying memorial tablets for those who had died - strengthening the sisterhoods and providing a refuge for early women migrants (Sankar I978).

\section{TBs \& TBGs in Hong Kong}

Recent research on female homosexuality in Hong Kong has focused primarily on the modern context, e.g. the emergence of 'deviant sexual behaviour' among teenage school girls (Tong 200I), lesbian masculinities and bodily performances (Chou 2000; Kam 2003), and the negotiation of the 'TB' (tomboy) identity in Hong Kong (Lai 2004). ${ }^{7}$ This chapter locates these perspectives within the regional and historical continuity of Chinese women's homosociality.

Homosexuality is not a criminal offence in Hong Kong and lesbian sex is generally not regarded as sex at all. The female homosexual is tolerated but deemed socially undesirable, given the patriarchal context within which a lesbian's sexuality makes her irrelevant to procreation and male sexual access. Almost all the respondents reported that they encountered hostility from members of their immediate families towards their sexual orientation or their partners. For example, Sandy, 26 , reported that her mother was cold to her partner when the latter came for dinner at their home, while she was warm and hospitable towards Sandy's sister's boyfriend. When Sandy confronted her mother after the incident, the latter made a concerted effort to change her attitude, and relations between Sandy's mother and her partner have been 'getting better and better'. In several cases, relations with their families had been strained even before the introduction of their partners, but for others, the introduction of a same sex partner was the cause for conflict. 
'I did not care about what they (her family) thought about my sexuality. In fact, I did not communicate with them much. The family relationship is superficial, diplomatic and I did not even trust them to share any thing, including my sexual orientation. They got to know of my sexual orientation when I was with my first girlfriend and also [because of] my short hair. My father told nearly all my relatives about that and then made a final judgment that I was lesbian for sure. I noticed that most of my relatives gossiped about my sexuality behind my back.' (Cindy, 40)

In Winnie's case, she was from a girls' school and though she thought it 'very natural' to have relationships with women whom she regarded as her 'boyfriends'. She said,

'If I have a TB boyfriend again, I won't bring her back home definitely. Both my family and my TB partner's family knew about us. I visited her family but her family discriminated [against] me as well. Although they did not do anything explicit to discriminate me, I still have a feeling that they gossip behind my back.'

In a rare contrast, Jean's family accepted her sexual orientation despite their misgivings. She said, 'I guess [that] my family knew [about] my sexual orientation. They may not like it but they cannot control this and finally let me go.'

For masculine women, in this predominantly Chinese society where males are valued, the usurpation of maleness by masculine women has resulted in a sense of threat and unease, which has not prevented the entrenchment of such behaviour among these women. The usurpation of mores related to men's dress and demeanor refer to the culturally defined social codes that men depend on to reproduce masculinity in culturally appropriate ways (Beynon 2002:2). Hence, the development of the lesbian community, subject to notions of the conventional binary gender system, bifurcates into 'tomboys', known commonly as TBs, and their girlfriends, TBGs. In Hong Kong, the term 'lesbian' is not generally perceived as negative, nor is it tainted by its Western historical association with mental illness.

The word 'tomboy' abbreviated to 'TB' has been in use in Hong Kong's girls schools since the I960s. TBs are caricaturized as having short hair, flat chests with a penchant for cross-dressing (Lai 2004). By the I990s, 'TB' had come to represent a category of identity associated with patterns of behaviour, dress and desire. In North American roleplaying terms, 'TB' is equivalent to 'butch' and 'TBG' to 'femme'; 
which has sometimes been conflated with 'dominant/active' and 'submissive/passive', mirroring the heterosexist model. ${ }^{8}$

The TB identity is largely independent and requires no signifier, in contrast to TBG, which requires a 'TB' to become that 'TB's G' or girlfriend, thus contrasting with Halberstam's (I998: I28) analysis of butch identity in the United States as being 'femme dependent'. Bodily performances are not, however, an indication of bedroom roles, where, according to Lai (2004), a high degree of fluidity exists, unaffected by public performances of sexual identity. Other self-identified categories apart from 'TB' and 'TBG' in Hong Kong are 'Queer', 'Pure', 'Lesbian' and 'Bisexual'. Those who chose the label 'queer' aimed at being more inclusive and progressive, and to account for sexualities excluded by hegemonic discourses - namely, bisexuality, transgenderism, transvestitism and sado-masochism. 'Pure' seems to have originated from Taiwan and refers to those who do not see themselves as 'TB' or 'TBG', who could be attracted to either TB or TBGs, who avoid role playing (Chou 2000:225) and who come closest to the contemporary Western conceptions of gender androgyny. There is no automatic conflation, however, of the 'pure' label with modes of dress or behaviour, so that one might find a self-identified 'pure' who might be highly feminized or masculinized.

A minority refused to classify their sexuality while others have sought to create their own vague catchall labels, such as 'Not straight enough' which reflect a discomfort with existing categories of lesbian sexuality and a desire to erase differences in identity constructions based on sexual preference. The range in diversity I encountered in the field is testament that there are limits to feelings of unity, 'sameness', and 'community' in the impetus to improvise or resist. These disjunctures create 'free space' where individuality and uniqueness is constituted in discourses of negation (Zita I990: 329). In a study of 27 women identified as TB, Lai (2004) found that nineteen were self-identified as TBs, five identified with being lesbian, two with 'pure' and one bisexual.

From the late nineteenth century, ideas of an 'essential' self identity based on sexual identity in sexology gave rise to the conception of distinctive homosexual identity. Not reducible to homosexual sexual practices (Ellis I895; Freud I963; Krafft-Ebing I886 cited in Ferguson, I990: 75) it facilitated the development of group identity and a self-conscious subculture (Foucault 1978, cited in Ferguson I990). However, claiming one identity is not a precondition for the unity of self but at times a precondition for self preservation, for like other labeled realities that capture a part of the complex whole, a lesbian identity once claimed diffuses into differences once its locations are made real and lived. The concept of 'women-identified women' came into being later, 
to expunge the pathological implications of lesbianism formulated by earlier sexologists (Ferguson I98I).

In the United States, many lesbians felt pressured into cutting their hair short upon 'coming out', and dress and behaviour were highly valued for aligning authenticity, membership and solidarity at the height of feminist and gay movements in the I970s (Zipkin I999). In Hong Kong, these forms of identification remain important for lesbian communities and TBs and their short hair, flat chests and masculine dress have become an icon of lesbian identity (Sim 2004).

Feminine lesbians are perceived as less 'deviant' and more capable of reversion to mainstream sexual normalcy. By this reasoning, homosexuality inheres less well in feminine than masculine lesbians and the latter are perceived to be more essentially lesbian and thus, politically valuable in representing the lesbian community. On the other hand, the 'pure' label has captured the imagination of those who avoid collision with social opinion where 'standing out' is met by different forms of harassment. One of these is through name-calling. In the local slang, 'gay-por' is a derogatory term applied to lesbians with negative connotations of being old, sexless or suggesting something of a sexual pervert. One respondent said that, 'being called gay-por is the worst thing that I have experienced'.

After homosexuality was decriminalized in Hong Kong, nine major gay and lesbian groups were formed in the early I990s. Within the Ten Per Cent Club for gays and lesbians, the lesbian sub-group broke away in I993, when lesbian concerns were marginalized by gay men's interests. In the following year, a lesbian group called 'XX Ś uJeuih' was formed, and with it the first lesbian pub, Smart S. Three lesbian pubs followed - Oasis, Virus and Chatroom. The social interactions within these pubs encouraged the reproduction of dominant regimes of self-presentation and performance amongst TBs and TBGs (Lai 2004). Communal institutionalization deepened with the development of websites providing information, communication and companionship.

Online resources fell into two broad categories. In the first category were lesbian service groups, including Proud of Lesbos, Queer Sisters and F-Union (Lai 2004). ${ }^{9}$ Their websites provided public access and constituted one of the major cornerstones of lesbian community. Most participants were in their 20 s or 30 , with few over 40 and none above 50 , with a ratio of TBs to TBGs of about 4 to I, corresponding to the profile in lesbian pubs. Activities were organized and advertised on these sites, such as workshops on the politics of gender and sexuality, reading groups and games. The second category comprised personal websites whose owners controlled entry and interaction. Both categories featured message boards as well as instant chatrooms, providing 
information on topical issues. ICQ or instant messaging is a popular mode enabling 'chat' with strangers and between known persons. This chapter will, however, explore interactions in the cyber sites of the public kind.

Because of the non-visual, non-confrontational presentation of self in cyberspace, introductions to one another on these public sites are truncated by text boxes that toggle between 'TB' or 'TBG', expediting the 'getting to know you' process. There is less inhibition in these exchanges that cut to the quick in locating each other on the lesbian homosocial landscape.

\section{The Lesbian Community Online}

Popular early websites that served Hong Kong's lesbian community were Queer Sisters, Blur-F, and To-Get-Her. Queer Sisters' message boards, introduced in I997, began as a forum for theoretical discussions of lesbian identity and gay politics, and aspired to be more inclusive welcoming participation from other sexual minorities. As the composition of its leadership changed, its political aspects were replaced by the social agendas of latter committees. Narrow academic interests lost out to populist demands in the context of the public sphere. With some disappointment, one founding member noted that the political objectives of this site were replaced by a social space for 'chitchat'. Proud of Lesbos, another academically inspired site survived some months before succumbing to the same fate.

On the public websites, messages are usually moderated and posted in Chinese (Cantonese), but other discernible axes of differentiation on these sites are age and class background of members. The highest usage is found among those in their upper teens to mid-twenties. Tong, in her (200I) research among I5-year-old lesbian schoolgirls, found no perceptible use of Internet facilities for purposes of communication. Their main means of communication were limited to hanging out in basketball courts and intense letter writing. These kept their participants in contact on a day-to-day basis, and acts as channels of identity referents that provided cultural signification for geographically and socially isolated groups.

The difference between two modes of communication, letter writing and cyberspace interactions, which fulfill similar social needs, lies in the relatively democratic nature of cyberspace access to communities aligned by similar interests and values. The use of cyberspace enlarges these communities of sentiment through impersonalized, institutionalized access, and message boards are but letters at large. Whereas termination of letter writing is taken to mean the end of social interac- 
tions, withdrawal from Web communication does not amount to the severing of ties in the same way. For example, older lesbians may still visit infrequently to check on developments in the lesbian community even as they prefer 'face-to-face' meetings through their personal networks, which provide the opportunity for real-life socialization.

This distinction between the age sets can be understood in terms of the financial resources available to support different patterns of socialization. Younger women remain financially dependent and subject to parental restrictions on mobility and leisure. Class is a trickier issue in Hong Kong, where most of the largely Chinese population are either from Mainland China, or have been born to parents of immigrant stock. In short, with few exceptions, the majority emerged from very poor backgrounds. It is a recent phenomenon that increasing education and affluence have contributed to the emergence of a middle class; hence, the self-selections by respondents reveal no systematic understanding of class.

One founding member of Queer Sisters, with postgraduate tertiary qualifications, is not alone in identifying those who use cyberspace to meet potential partners as coming from a lower 'working class'. Her observation is that Web access is cheap and the use of it to meet others reflects a limitation of wider social networks that comes with the increased social capital of an upwardly mobile social class, where social capital is symbolically codified in relations in social life. ${ }^{\text {IO }}$ The maintenance of a rich social life in Hong Kong is a function of the ability to afford socializing activities. Other lesbians confirmed that the ownership of computers in Hong Kong is highly affordable and would not pose a problem for most families. Yet another respondent who expressed disdain at the inanity of 'meaningless chitchat' online attributes this to differences in age rather than class.

In the formation of lesbian communities in Hong Kong, cyberspace allows the forging and strengthening of collective sentiments - the semi-formal, semi-public alignment of values - which in turn have the effect of attracting and coalescing like-minded individuals into coherent nodes of social relations, resulting in the percolation of a self-conscious group identity. Sites may become defunct without threatening the existence of an institutionalized presence of multiple networks and the viability of a larger community. For those who use them, these virtual spaces are as real to their users as physical rooms and buildings where people meet face to face. There is an expectation of at least some trust and commitment, founded on mutual needs for identification and validation. Interacting with unknown others on cyber sites, users stress the importance of 'feeling safe' and 'protected' in meeting others online, which suggests that lesbians have some grounds for feeling unsafe at other undefined sites. According to Martin \& Mohanty (I986: 
I9I-2I2), in the lesbian's journey into difference she seeks out 'boundaries of protection', non-lesbian space is, hence, undefined space, that poses existential threats. This need for the protection of one's symbolic community resonates with the functions that sworn sisterhoods had provided earlier generations of women.

In online exchanges, it is common to be asked quite early if one is a TB or TBG. The answer then determines how the user responds, because if both parties were alike - say, both are TBs - the relationship becomes one of 'brothers'- i.e., being sexually inaccessible to the other. If the identification is one of opposites, there exists the tension that the other could be a potential lover (Lai 2004). Despite these tensions, the perception is one of safety and non-threat, as users are amongst 'our own people' fostering relationships of fictive kinship. For others, cyberspace provides adventure and escape to more cosmopolitan settings. One respondent in cyber-dialogue with overseas lesbians, mainly expatriate Taiwanese who have returned to Taiwan, said that she found it 'refreshing' because, 'luckily, there are no people from Hong Kong there (sic)'.

Typically, online romances are preceded by 'chatting' on message boards until one party decides that it is safe to reveal her email address. Here again, several respondents with tertiary qualifications view the phenomenon of online love as a working-class phenomenon. This may not be accurate, because in the course of this research I came to know of seven online relationships and they were all between women with some form of tertiary education. One researcher of the lesbian scene in Hong Kong informed me that she did not know any working-class lesbians, that those she knew were all middle class in terms of education and/or occupation. Just as white, middle-class lesbians presumed to represent the lesbian community in social science writing in the United States during the I970s and I980s (Newton 2000b), a disturbing impression is that this is reflected in the documentations of Hong Kong lesbians as being mostly tertiary-educated and middle-class. The same respondent attributed this to the fact that 'Hong Kong has so many universities that it is hard to find lesbians who have not gone to one of these'. Tong's research (200I) into lesbian relationships in a girls' school in Hong Kong attended by students of middle and working class backgrounds clearly contradicts such conjectures and testifies to the existence of unrepresented segments of the lesbian community.

The proliferation of the lesbian public space in the I990s was a response to earlier isolation of the underground homosexual community and symptomatic of the lesbian community's ability to encroach on and colonize newly-available social spaces. At the same time, there remains a wariness and distrust of public institutions and organs of government control. When the Women's Coalition organized a fundraiser, 
it informed its members through email of the date and time but did not reveal the venue of the proposed party. It was shortly before the event that a flurry of telephone calls and texted messages?' were made to those who had registered, informing them of where the party would be held. About 60-70 women showed up. While this level of security may verge on paranoia to those unfamiliar with the 'underlife' (Goffman I96I), none of the women who attended raised an eyebrow at the modus operandi. The organizers explained that it was aimed at protecting the privacy of the social event and its attendees from the press and official attention.

\section{Different Contexts and Common Resistance?}

So are the sworn sisterhoods of the $20^{\text {th }}$ century and the lesbian community in Hong Kong completely distinct phenomena that provide no common ground for theoretical analysis or synthesis? Offering a contrarian view, this section examines some of these differences and suggests that the two groups are on parallel trajectories with considerable historical, cultural, geographical and ideological resonance.

Sworn sisters arrived in Hong Kong as refugees fleeing a sunset industry and political turmoil. Their intentions were to remit wages home to support their families and to make a living through waged labour. Their lack of skills and education led them to undertake menial work as lowly paid domestics. In contrast, almost without exception, lesbians who were born or had grown up in Hong Kong had rights of access to education, health and protection under Hong Kong's law. The difference in material conditions and available opportunities account for the contrasts between them. Among the latter, the expectation of economic independence had become an entitlement. In addition, Hong Kong's legal-political framework ensured that contemporary lesbians enjoy a level of security that an earlier generation of unmarried women could not possibly have envisioned. They formulate their expectations, negotiate situations, and make decisions independently within a modern framework of market relations, governed by legal protocol.

However, despite material advancement, independence and autonomy there is a downside. Modern Hong Kong lesbians are generally perceived as deviant, westernized and committed to an individualism that challenges social stability - traditionally provisioned through marriage, family and child bearing - and filial piety. In contrast to sworn sisterhoods, whose members were appreciated for their dedication to their families' economic wellbeing, Hong Kong's lesbians are perceived as individualistic, selfish and anomalous. They are seen as failed adults, women and pathological beings (Kam 2003: 69). Their financial sus- 
tainability does not necessarily translate into support for their natal families' wellbeing; they do not reproduce, and are sexually irrelevant to the reproduction of the male order in ways that earlier spinsters had not been. The threat that looms is the fragmentation of womanhood as a conduit for the social and biological reproduction of 'Men'.

Hence, female homoeroticism will continue to attract the hostility that sworn sisterhoods, with fewer legal rights, had managed to avoid. Even among earlier sisterhoods, the notion of women's homosexual interest in each other was downplayed because, when not deployed in the relation to male sexuality, female sexuality has historically been regarded as anti-social and deviant. It was a matter of existential concern that the image of their organizations and the ways they were perceived were in keeping with social mores that protected them from ostracism. Communal referents became sources through which they engendered and validated their personal identities. By emphasizing other aspects of their relationships, such as social obligations and religious duties, sisterhoods created social capital as defense strategies. Despite their apparent social acceptability, sisterhoods were formed as guilds to increase their economic and physical safety.

The social capital of modern lesbian women in Hong Kong cannot protect them completely from hostility because, unlike sisterhoods that repressed representations of sisters as sexed bodies, the modern Hong Kong lesbian makes no bones about her attraction towards women with whom they perceive the potential for romantic and sexual involvement. There is less compulsion to 'hide' their sexual orientation, which they attribute, ironically, not to patriarchy, but to their perceptions of women's superior physical beauty, emotional complexity and sexual desirability. (Resistance to patriarchy is not consanguineous with lesbian desires and vice versa.) On the other hand, most modern lesbians remain 'in the closet' in their professional lives. The private staking out of safe space for extending homosocial relations shows the same underlying need for security - from men and homophobes - and remains paramount to both groups of homosocially-oriented women.

One young woman said that in visiting lesbian sites, she felt that she was with her own people who had similar values and who were empathetic. 'I feel so safe' and 'At least we know that people will not disturb us' are common responses when discussing lesbian cyberspace relations. While they are more savvy in many ways, lesbians today do not feel any safer than sworn sisters half a century ago. 'Some men were really nasty. They deliberately picked on you. They were not young guys, they're grown men. They just harassed you when you walked by ... they'd come up to you and say something nasty,' recounted a masculine woman in Hong Kong (Kam 2003: 80). 
In Kam's (2003) study, nearly half her respondents possessed postgraduate tertiary education while more than half of Lai's (2004: 32) respondents had tertiary education. ${ }^{\text {II }}$ With the emergence of a new breed of 'political lesbians', in North America there has been a tendency to self-refer as 'the community', excluding non-feminist lesbians and those not ideologically defined and where public lesbian identity is primarily white and disproportionately well educated. ${ }^{\mathrm{I} 2}$ There are serious shortcomings in calling lesbian-feminist groups under study 'the lesbian community', as it constitutes a grave error and serves as a caveat for the use of the 'lesbian community' here. Likewise, in Hong Kong, it is more accurate to refer to this group of mainly Chinese, well-educated lesbians, who have spearheaded the capture of public imagination and space, as 'a lesbian feminist group'. Same sex relationships in two studies on Filipina and Indonesian migrant women in Hong Kong (Constable 2000; Sim 2004) implicates research as a first step in fostering 'mutual awareness and a spirit of respect' between different groups as 'Scholars of the gay satellite subculture have a responsibility to hold up a mirror that reflects the true diversity of lesbian life' (Newton, 200ob: I62). ${ }^{\mathrm{I}}$

Gay men and lesbians in Hong Kong have begun working together to address social inequalities. In one case, a lesbian couple contrived a 'marriage' with a male homosexual couple in order to apply for public housing reserved for married heterosexuals. In order to challenge the heterosexual privilege of subsidized public housing, they 'exchanged' partners and the two 'heterosexual' couples were married simultaneously at the Registry of Marriages, releasing statements of their intentions to apply for two public apartments as heterosexual couples and to live in them in homosocial partnerships.

In cross-cultural relations, the development of a common lexicon signals recognition across different cultures. In one encounter between lesbians from Hong Kong and Japan, interest revolved around establishing the Hong Kong-Japanese equivalents for terms like TB, TBG and Pure, and placing them on an online lesbian dictionary. In the lexical referents, the Japanese equivalents of TB, TBG and Pure were found to be tachi, neko and riba. TB, which is tachi in Japanese, is derived from its verb-stem tatsu, meaning 'to stand'; neko corresponds to TBG, meaning 'cat'; while riba is imported, abbreviated from the English word 'reversible' and meaning Pure.

Common trends were also found in cross-dressing by Hong Kong's Chinese and Japanese lesbians. Young girls cross-dress to effect a transformation in 'social rank' (Kam 2003: 58), but some counter that physical and psychological changes at puberty have as much to do with this phenomenon. Instead of the rank and privilege attendant to maleness, the transformed becomes an object of social ostracism, an out- 
cast, suggesting that the latter explanation may hold more credence in explaining why young women deliberately de-genderize their bodies at puberty. However, those who behave like men are perceived as 'pathological beings' (Kam 2003: 64), and if this is true, cross-dressers can never get it right, being either too 'male' or not being 'male' enough. This perhaps explains the move away by 'lipstick lesbians' - who are resolutely apolitical and upwardly mobile - towards androgyny and assimilation, a move encapsulated by American television's Ellen. This holds true for post-lesbian feminists, who reject the associations of lesbian feminism as downwardly mobile and politically alienated from centres of power (Newton 2000b: I62). ${ }^{\mathrm{I}}$

For 20-year-old Nic, adopted as a child, her appearance is 'totally a man style (sic)' and she prefers that 'people treat me like roo per cent man'. Her desire to pass as a man came to her head when she was excluded from the patriarchal arrangements surrounding the funeral rituals of her father. She said, 'I have not thought about a sex-change. Now I really want to do that operation so that I can attend my father's funeral and be his real son, to help carry his coffin. It is really important to me to accompany my father on his last journey.' In this case, Nic's cross-dressing and presentation of self as male did not prevent her failure to enter the world of male privilege and significance. In contrast, the success of her 'contrived maleness' became the source of her failure when she passed too well. On visits to her partner's home, 'her family did not know my sexuality. They treat me like a man. I really want them to know my real identity but I am afraid that if they know, it would ruin the relationship. I have experienced this before when my ex-girlfriend's parents found out, they hated me'.

Discrimination based on sexual orientation is not illegal in Hong Kong. Like elsewhere, gays and lesbians in Hong Kong cannot marry or access the security provided for in heterosexual unions. While lesbians, like the sworn sisters before them, resist heterosexual marriage and normative heterosexuality, one difference emerging from today's lesbians and their earlier sisters is their desire to marry. One community leader said, 'Of course, I want to marry. I have always thought that it is a beautiful thing to do'. Not only do these women want to marry each other, they want to do so publicly with the blessing of their families. In the light of the Great Gay Marriage Debate in the United States and elsewhere, this contestation involves intense debates about what a society holds dear.

The struggle for lesbians' rights to exist has been critical for the emergence of a collective identity. Hong Kong lesbians today are active participants in the politicization of gay and lesbian rights, without apology or the defensiveness of earlier generations. Instead there is a sense of claiming what is perceived to be rightfully theirs, the entitle- 
ment to equal rights with heterosexuals, which historically, has never ever existed anywhere.

The communities that have provided support for both sworn sisterhoods and modern lesbians in Hong Kong are vastly different. Sisterhoods were tightly knit, most originating from the same natal villages in China, and were substitute families providing a range of life-support services without which immigrant women could not have survived. Modern lesbians, in contrast, are loosely connected to networks and 'communities of sentiment' that serve predominantly socio-political functions of value and identity alignment, and that challenge discrimination and exclusion. In their strategies for space and identity, and in their political agendas, they are consolidating the silent ground traversed by earlier generations who, too, defied the patriarchal order in their love of women.

\section{Conclusion}

Given the disparities between sworn sisterhoods and modern lesbians in Hong Kong, the continuities between these two disparate groups show that the major themes of patriarchy and its attendant oppression and undervaluation of women remain as valid today as they did half a century ago. However, this research affirms discontinuous approaches to lesbianism because whether or not one agrees that there are sufficient commonalities in structures of male domination across space and time and across cultural differences, and whether one agrees or not with the use of 'feminist' for women who resist patriarchal structures, the concept of being in exclusively female same-sex relationships, whether one terms these lesbian or not, stems from historically discontinuous conditions of capitalist development.

In Southern China in the nineteenth century, women's mobility out of their homes into various states of independence from kin arose from the historical separation of kinship and familial economic inter-dependence. Wage earning remains a common factor between these women, and their modern counterparts in Hong Kong, allowing them to live with other women as life partners in place of heterosexual marriage. At the same time, this does not rule out continuous approaches that individual lesbian 'women-loving women' relationships existed before their identification based on objective economic conditions, which made them real alternatives to heterosexual unions.

Furthermore, socio-economic developments through education and the development of work related rights and opportunities have helped modern lesbians gain a presence that is impossible to ignore. They are politically astute in forming political alliances, strategizing to push the 
limits of government policy and public opinion. They are vocal and unapologetic, questioning the norms and roles of society, and they insist on being heard. They are engaged in redefining notions of 'womanhood' to include those who choose to love women, and they are actively shaping a legacy of lesbianism as a historically distinctive identity for those who will come after them.

By examining the connections between sworn sisterhoods and modern Hong Kong lesbians, this chapter emphasizes local interactions and small groups as cause, context, and consequence of civic engagement. They are nodes for framing and motivating, encouraging individuals to partake in public discourse, and providing impetus in the development of civil society constituted by robust 'tiny publics' of overlapping and interacting groups and networks. Civic engagement engenders the expansion of communities of sentiment and shows how civil society can be transformed and thickened even in the absence of formal and institutionalized associations. Hence, not only does the development of lesbian space pose a challenge for compulsory heterosexuality, but it is influential in changing the perception of gays and lesbians as individual deviants to an understanding that they constitute an oppressed social minority. This shift is socially significant for aligning individual and sectoral interests, and providing the basis on which to build a coherent gay liberation movement, like those that have taken place in other parts of the world.

\section{Notes}

I. See, for examples, Careaga-Pérez, 2003; Jiménez, 2003; Newton, 2000a.

2. The underlying premise is that it is men who have power in relationships with women and that is the cause of heterosexual oppression, and that doing away with the requisite masculinity and femininity required in heterosexuality would result in a residual egalitarian sexuality - i.e. open, honest, caring, and non-oppressive. This is why lesbianism is assumed to be intrinsically more egalitarian than heterosexuality. However, this is not always the case. For more, see Newton, 2000c.

3. Isolated work on the identity of young tomboys and the constructions of butch women in Hong Kong has been undertaken in postgraduate theses at a Master's degree level by Tong (200I), Kam (2003) and Lai (2004).

4. For those who have written about deep celibate friendships between women, see, for examples, Smith-Rosenberg, I975 ; and Faderman I981, I983. As for the role of romantic love in homosocial modernity, see Ong, I99I.

5. Topley, 1975: 74, wrote of the Pearl River Delta as a haven for semi-secret sects, which stressed sexual equality and placed a high value on chastity, during the same period.

6. These are residential establishments of varying sizes and memberships where followers of a religion can live and concentrate on purifying their souls. The sisterhoods were able to manipulate the vegetarian halls to serve their own purposes while adhering and adapting to the specific restraints and demands of these halls. For an extended discussion of 'chai t'ang' or vegetarian halls, see Sankar (I), I978: 203-2I0. 
7. Studies accessible to the author are published in English.

8. For the complexities in differentiating erotic identities, roles and acts, see Newton, $2000 \mathrm{c}$.

9. Most of these are in Chinese. Some other sites which have become popular include BlurF [http://www.blur-f.com/], and a bilingual Taiwanese site, To-Get-Her < http://www.toget-her.org>.

Io See, Savage and Kanazawa (2004) for a fuller discussion of why social life is 'capital'.

II. Both Kam's and Lai's research were conducted at about the same time in Hong Kong from 2002-3. Neither had intentionally chosen to over-represent women with tertiary education. If there is indeed a charge for such over-representation, this could be attributed to their own social positions, a fault which both tried to remedy with snowballing and random selection techniques.

I2. See, for examples, Hidalgo \& Hidalgo-Christensen, I976; Blumstein \& Schwartz, I983. For exceptions, see Lisagor, I980; and Davis, Kennedy \& Michelson, I98I, cited in Newton, $2000 \mathrm{~b}$.

I3. Humphreys (I979: I40) proposed the use of 'satellite culture' instead of 'subculture' because 'there are a number of well-defined subcultures operating within the gay world... that includes lesbian feminists, gay academics, suburban couples, street hustlers, drag queens and gay bikers'.

I4. Lesbian-feminism's raison d'être was political change; it was anti-capitalist, rejected established social order, and was downwardly mobile (Newton 2000b:I62).

\section{References}

Aguilar, M.I. (1999), 'Localized kin and globalized friends: religious modernity and the "educated self" in East Africa', in S. Bell \& S. Coleman (eds.), The anthropology of friendship, I69-184. Oxford \& New York: Berg.

Beynon, J. (2002), Masculinities and culture. Buckingham: Open University.

Blackwood, E. \& S.E. Wieringa (I999), 'Sapphic shadows: challenging the silence in the study of sexuality', in E. Blackwood \& S. Wieringa (eds.), Female desires: same-sex relations and transgender practices across cultures, 39-66. New York: Columbia University.

Blumstein, P. \& P. Schwartz (1983), American couples: money, work, sex. New York: William Morrow.

Boswell, J. (1989), 'Revolutions, universals, and sexual categories', in M.B. Duberman, M. Vicinus \& G. Chauncey, Jr. (eds.), Hidden from history: reclaiming the gay and lesbian past, I7-36. London: Meridian.

Careaga-Pérez, G. (2003) 'Sexualities, the challenge of the feminist movement: analysis of the Beijing +5 Process', in Sexual orientation in women's struggle. Brussels \& Mexico: El Closet de Sor Juana, WS \& ILGA.

Chiang, C. (I994), 'Female migrants in Singapore: towards a strategy of pragmatism and coping', in M. Jaschok \& S. Miers (eds.), Women \& Chinese patriarchy: submission, servitude and escape, 238-263. London: Zed Books.

Chou, W.S. (2000), Tongzhi: the politics of same-sex eroticism in Chinese societies. New York: Haworth.

Constable, N. (2000), 'Dolls, t-birds, and ideal workers: the negotiation of Filipino identity in Hong Kong', in K. Adams \& S. Dickey (eds.), Home and hegemony: domestic service and identity politics in South and Southeast Asia, 22I-248. Ann Arbor: University of Michigan.

Cook, B.W. (I977), 'Female support networks and political activism', Chrysalis 3: 43-6I.

Davis, M., E. Kennedy \& A. Michelson (I98I), 'Buffalo lesbian bars: I930-I960', paper read at Berkshire Conference on Women's History, Vassar College.

Eberhard, W. (1968), The local cultures of South and East China. Leiden: EJ Brill. 
Echols, A. (1989), Daring to be bad: radical feminism in America 1967-1975. Minneapolis: Minnesota.

Ellis, H. (I895) 'Sexual inversion in women', Alienist and Neurologist I6: I4I-58.

Eng, Y.Y. (I986), Economic imperialism in China: silk production and exports, 1861-1932. Berkeley: University of California Press.

Faderman, L. (I98I), Surpassing the love of men. London: Junction.

- (1983), Scotch verdict. New York: Quill.

Ferguson, A (I990), 'Is there a lesbian culture?', in J. Allen (ed.), Lesbian philosophies and cultures. New York: State University of New York Press.

Fine, G.A. (2004), 'Tiny publics: small groups and civil society', Sociological Theory 22 (3): $34 \mathrm{I}-356$.

Foucault, M. (I978), The history of sexuality, v.I. New York: Pantheon.

Freud, S. (1963), 'The psychogenesis of a case of homosexuality in a woman', in P. Rieff (ed.), Freud: sexuality and the psychology of love, I33-I59. New York: Collier Books.

Gates, H. (1989), 'The commoditization of Chinese women', Signs I4 (4): 799-832.

Gerlach, L.P. \& V.H. Hine (I970), People, power, change: movements of social transformation. Indianapolis: Bobbs-Merrill.

Goffman, E. (I96I), Asylums: essays on the social situation of mental patients and other inmates. New York: Doubleday \& Company, Inc.

Grahn, J. (I984), Another mother tongue: gay words, gay worlds. Boston: Beacon.

Halberstam, J. (I998), Female masculinity. Durham \& London: Duke University Press.

Hershatter, G. (I99I), 'Prostitution and the market in women in early twentieth-century Shanghai', in R.S. Watson \& P.B. Ebrey (eds.), Marriage and inequality in Chinese society, 256-285. Berkeley: University of California.

Hidalgo, H. \& E. Hidalgo-Christensen (1976), 'The Puerto Rican lesbian and the Puerto Rican community', Journal of Homosexuality 2 (winter): Io9-2I.

Howard, C.W. \& K.P. Buswell (I925), A study of the silk industry of South China. Ling Nan Agricultural College, Agricultural Bulletin No. I2. Hong Kong: The Commercial Press.

Humphreys, L. (I979), 'Exodus and identity: the emerging gay culture', in M.P. Levine (ed.), Gay men: the sociology of male homosexuality, I34-I47. New York: Harper \& Row.

Jiménez, P. \& G. Careaga-Pérez (2003), 'Lesbians in Beijing' in Sexual Orientation in Women's Struggle. Brussels \& Mexico: El Closet de Sor Juana, WS \& ILGA.

Johnston, J. (I973), Lesbian nation. New York: Simon \& Schuster/Touchstone.

Kam, Y.L. (2003), Negotiating gender: masculine women in Hong Kong. A Master of Philosophy thesis. Hong Kong: Chinese University of Hong Kong.

Krafft-Ebing, R. (I886), Psychopathia sexualis.Trans. S.K. Franklin. New York: Bell.

Lai, F. (2004), Identity and body construction among tomboys in Hong Kong. A Master of Philosophy thesis. Hong Kong: Chinese University of Hong Kong.

Lisagor, N.L. (1980), Lesbian identity in the subculture of women's bars. Ann Arbor, MI: University Microfilms International.

Lockard, D. (I986), 'The lesbian community: an anthropological approach', in E. Blackwood (ed.), Anthropology and homosexual behaviour, 83-96. New York: Haworth.

Ma, E. (I999), Culture, politics and television in Hong Kong. New York: Routledge.

Martin, B. \& C.T. Mohanty (I986), 'Feminist politics: what's home got to do with it?', in T. Lauretis (ed.), Feminist studies/Critical studies, I9I-2I2. Bloomington, Indiana: Indiana University.

Newton, E. (2000a), 'Excerpt from womenfriends (with Shirley Walton; I976)', in Magaret Mead made me gay, I42-I54. Durham \& London: Duke University.

- (2000b), 'Will the real lesbian community please stand up?' in Magaret Mead made me gay, I55-I66. Durham \& London: Duke University. 
- (2000c), 'The misunderstanding: towards a more precise sexual vocabulary (with Shirley Walton; 1976)', in Magaret Mead made me gay, I67-I75. Durham \& London: Duke University.

Ocko, J.K. (I99I), 'Women, property, and law in the People's Republic of China', in R.S. Watson \& P.B. Ebrey (eds.), Marriage and inequality in Chinese society. Berkeley: University of California.

Ong, S. (199I), Because this is about love: a portrait of gay and lesbian marriage, a videorecording. New York: Filmakers Library.

Putnam, R. (I995), 'Tuning in, tuning out: the strange disappearance of social capital in America', PS: Political Science and Politics 28: 664-683.

Radicalesbians (I973), 'The woman-identified woman', in A. Koedt, E. Levine \& A. Rapone (eds.), Radical feminism, 240-245. New York: Quadrangle.

Rich, A. (I980), 'Compulsory heterosexuality and lesbian existence', Signs 5 (4): 63I-660.

Rupp, L.J. (I990) 'Imagine my surprise": women's relationships in mid-twentieth century America', in M.B. Duberman, M. Vicinus \& G. Chauncey, Jr. (eds.), Hidden from history: reclaiming the gay and lesbian past, 395-4IO. London: Meridian.

Sahli, N. (I979), 'Smashing: women's relationships before the fall', Chrysalis 8: 17-28.

Sankar, A.P. (1978), The evolution of the sisterhood in traditional Chinese society: from village girls' houses to chai t'angs in Hong Kong. Doctor in Philosophy dissertation, University of Michigan.

— (I984), 'Spinster sisterhoods', in M. Sheridan \& J.W. Salaff (eds.), Lives: Chinese working women, 5I-70. Bloomington: Indiana University Press.

Savage, J. \& S. Kanazawa (2004), 'Social capital and the human psyche: why is social life “capital”?', Sociological Theory 22 (3): 504-524.

Schlesinger, Jr., A. (I980), 'Interesting women', The New York Times Book Review. I7 February I980.

Sim, A. (2004), 'Sexuality in migration: the case of Indonesian domestic workers in Hong Kong', paper presented at the Asian Studies Conference, I9-20 June 2004, Tokyo, Japan.

Smith-Rosenberg, C. (1975), 'The female world of love and ritual: relations between women in nineteenth century America', Signs I: 2-29.

So, A.Y. (1986), The South China silk district: local Historical transformation and World-System Theory. Albany: State University of New York Press.

Steinmetz, G. (2004), 'Odious comparisons: incommensurability, the case study, and "small n's" in Sociology', Sociological Theory 22 (3): 37I-400.

Stockard, J.E. (1989), Daughters of the Canton Delta: marriage patterns and economic strategies in South China, 1860-1930. Hong Kong: Hong Kong University Press.

Stolte, J., G.A. Fine \& K. Cook (200I), 'Sociological miniaturism: seeing the big through the small in social psychology', Annual Review of Sociology 27: 387-413.

The Hong Kong Women's Coalition on Equal Opportunities (1996), 'NGO report on women in Hong Kong', Report prepared by Sue Romaniuk, United Church of Canada, Hong Kong Women Christian Council. Updated for the Second East Asian Women's Forum, 2224 August 1996.

Tong, K.M. (200I), Being a tomboy: an ethnographic research of young schoolgirls in Hong Kong. A Masters in Philosophy thesis. Hong Kong: The University of Hong Kong.

Topley, M. (1975), 'Marriage resistance in rural Kwantung', in M. Wolf \& R. Witke (eds.), Women in Chinese society, 67-88. Stanford, California: Stanford University Press.

Watson, R. (I99I), 'Wives, concubines, and maids: servitude and kinship in the Hong Kong region, I900-1940', in R.S. Watson \& P.B. Ebrey (eds.), Marriage and Inequality in Chinese Society, 23I-255. Berkeley: University of California.

Wolf, M. (I972), Women and the family in rural Taiwan. Stanford: Stanford University Press.

Yang, Y.Q. (I999), Nu-shu: a hidden language of women in China. A documentary. Vancouver, B.C.: East-West Film Enterprise, Ltd. 
Zipkin, D. (1999) 'The myth of the short-haired lesbian', in J. Cogan \& J.M. Erickson (eds.), Lesbians, levis and lipstick: the meaning of beauty in our lives, 9I-IOI. New York: Haworth.

Zita, J.N. (I990), 'Lesbian body journeys: desire making difference', in J. Allen (ed.), Lesbian philosophies and cultures, 327-346. New York: State University of New York Press. 


\title{
10 Sex \& Life Politics Formed Through the Internet
}

\section{Online Q Offline Dating Experiences of Young Women in Shanghai}

\author{
PEI Yuxin a HO Sik Ying
}

\section{Introduction}

By using the sexual life of young women in Shanghai, China, this study endeavours to understand the rapid changing sexual and social culture of the city. It will focus on young women's sexual encounters in cyberspace and with offline dating, and provide us with useful information about their sex lives and how, as women, they deal with a fastchanging, modern city in the digital age of the $2 \mathrm{I}^{\text {st }}$ century. We will see how women create new virtual networks for themselves and more importantly, how they transform these virtual networks into so-called 'real' social networks, and how they use these networks to achieve their personal goals. By exploring how women improve their lives through the Internet, we also examine how they use 'underground activities' to create new social spaces and opportunities for themselves. Also explored is how young women justify these activities as morally correct while practicing multiple sexual relationships via the Internet and in their offline lives.

\section{Internet Sexual Behaviour}

Researchers have studied various aspects of cybersexual activity. These scholars (Cooper 2004; Cooper, Mansson, Daneback, Tikkanen, \& Ross 2003; Cooper, Mcloughlin, \& Campbell 2000; Cooper, Morahan-martin, Mathy, \& Maheu 2002; Cooper, Putnam, Planchon, \& Boies I999; Cooper, Scherer, \& Mathy 200I) were concerned about Internet sexuality and attempted to generalize about the character of Internet users. Cooper collected evidence of the sexual addiction of certain internet users to describe and discuss online sexual compulsivity (Cooper et al. 2000) and other therapists have described the treatment of people ob- 
sessed with online sexual activity (Cooper et al. I999; Schneider 2003). Cyber sex is also viewed as 'high-risk sex' because of the high probability of 'sexual adventurers' tracking their sexual contacts in 'real life' (Toomey \& Rothenberg 2000). Other researchers are interested in gender differences in cybersex behaviour. Women have been reported to engage in more 'social' forms of cybersex behaviour, such as using chat rooms and emailing, while men were reported to engage in more visual, isolating activities, such as viewing or exchanging pornography online (Cooper et al. 2000; Ferree 2003). In addition, women's online sexual behaviour was found to mirror their offline behaviour, in that they preferred relationally-oriented activities (Ferree 2003). Social support formed on the basis of a group of people who engage in regular computer-mediated communication with one another for an extended period of time served as a key psychological reinforcement for computer-based interaction (Young I997).

Doring (2000) identified three cybersex perspectives: The victimization perspective which interprets cybersex as a male heterosexual practice through which women can only experience online harassment, virtual rape and cyber prostitution without resistance because 'the net is a part of the computer culture and therefore traditionally a male domain' (Doring 2000: 868). The victimization perspective sees women as objects and victims, and thus fails to acknowledge the existence of (hetero) sexual (online) activities that are mutually consensual and enjoyable. The liberalization perspective demonstrates how cybersex gives a woman autonomy to find sexual pleasure. Cybersexual interactions helps 'undermine the heterosexist social order and the accompanying sexual suppression by making more sex, better sex, and different sex available to women at will' (Doring 2000: 870). The liberalization model exaggerates women's control and choice in heterosexual (online) interactions and thus fails to acknowledge the existence of a structural power imbalance between the genders in society including the cyber world.

The sexual empowerment perspective acknowledges power discourse as an essential sexual online and offline issue:

'The empowerment model reveals the many contradictory sexual realities women experience. Discourses are begun (not just in academic circles) in which supposedly irrefutable statements about the female sexuality or about what women "as women" want or do not want are questioned, and we are continuously forced to take the specific social context of individual sexual scenarios, including their subjective meanings, into account.' (Doring 2000: 87I) 
Doring claims that the empowerment perspective has seldom been applied to cybersex in the feminist sex discourse. She regards sexual empowerment as a process that takes place on both an intellectual level and an experiential one, a process by which women learn to make sexual interactions (especially those with men) at once safe and satisfying. In order to do so, Doring thinks it is necessary for women to draw boundaries, to articulate needs and, on the basis of these terms, come to a mutual agreement about the course of the interaction. However, mutual agreement is not necessarily a given, 'since the structural gender hierarchy is often revealed in the asymmetrical power balance in personal relationships and the phallic-centered sexual norms' (Doring 2000: 873). In fact, many women have had violent and abusive sexual experiences online. Thus, Doring suggests that 'an intellectual understanding of how these experiences were influenced by the gender hierarchy' instead of just attributing them to 'personal failure or bad luck' is necessary (Doring 2000: 873). From a feminist viewpoint, sexual empowerment is both an individual learning process as well as a political emancipation process directed towards 'developing a positive attitude towards female (and male) sexualities' (Doring 2000: 873). To achieve emancipation, an open theoretical and practical exploration of the conception of sex should be taken into account, as well as what self-determined sexuality is like for women of various ages, religions, ethics, social classes or lifestyles.

From the sexual empowerment perspective, Doring analyzes women's online negotiating strategies and how they explore their desires via cybersex. However, as she admits, her analysis is confined within the narrow concept of 'cybersex', and fails to disclose how these women use the strategies they got from cybersex to organize their offline lives. We will attempt to fill these lacunae by exploring how a small number of Chinese women use what they have learnt online to improve their offline lives.

The Shanghai women interviewed in this case study mostly engaged in interactive activities, including e-mailing, chatting, performing in front of a Web camera in virtual locations, as well as browsing male profiles online. These activities were usually targeted at the opposite sex.

\section{Cybersex in the Context of Contemporary China}

The mass media in China often uses the term wanglian (net love) to explore issues around cybersex. A Taiwanese writer wrote an online novel entitled The First Intimate Touch under his net name $\mathrm{Pi} \mathrm{Zi} \mathrm{Cai}$ in I999. It is regarded as the first online Chinese novel, and the first no- 
vel about wanglian (C.B. Zhou 2000). Following the popularity of the novel, newspapers and journals on computer and Internet technologies, began to promote wanglian as a fast track to 'romantic', 'special' and 'advanced' love as well as a means to promote the use of Internet (L.M. Wang 2002; Xiao 2000; C.B. Zhou 2000). However, this discourse on wanglian changed rapidly with the boom of Internet users and the emergence of cyberlove practioners in late 2000 in China. Cyberlove came to be seen as 'short', 'instant', 'deviant', 'traumatic' and 'virtual' (Chen \& Zhao 200I; Duo 200I; F.M. Liu 200I; Shui 200I; X. S. Wang 200I; Zhang 200I), something which couldn't exist in 'real' life and was prone to cause tragedies and crime (Ji 200I; Yu 2002; Zhi 200I; J.F. Zhou \& Chen 200I). In short, wanglian was meaningless because it was destined to be a 'failure' when 'lovers' finally met offline in 'real' life.

Psychological and/or psychiatric problems also began to be associated with wanglian, especially among Internet users whom were becoming addicted to it (Dong 200I; Q. Li 2003; Yang \& Lan 200I). Dealing with youth 'deviant' cyberlove behaviour also became a hot topic (Tan 2003; X. Wang 2003). Another focus was on the various crimes that cyberlove led to, such as fraud, extortion, blackmail, violence, kidnapping and murder (Bian 2002; Hai 2002; Han \& Yuan 2002; Y. Li 2003; Shi 2002; D.Y. Wang 2002; T.Y. Wang \& Li 2002).

Despite the decidedly negative light with which it is seen by academia, wanglian has become a popular way of dating in China. Dating in the same city is one of the biggest and most popular dating websites in China. In addition to this website, there are numerous others offering chat rooms and instant messaging, all doing their best to serve the ever-increasing number of wanglian practitioners.

With the boom in Internet users and the update in technology more complicated sexual issues have arisen. People can now use voice chat systems and webcams to 'have sex' online or to expand their online sexual relationships into offline encounters. These developments have worried some critics in the media and in academia who have argued that cybersex is simply 'pornographic' and devoid of 'emotional communication' (Tang 2005; Xue 2003; Zheng 2005). However, some researchers (for example Ren 2005) also began to consider the 'democracy' and 'equality' of online sexual interactions and the positive experiences of people who 'found themselves' through cybersex by playing with multiple identities (Ren 2005: IO).

Therefore, the growing popularity of cyberlove in contemporary China is viewed with a mixture of suspicion and alarm by most academics on one side, and with acceptance and pleasure by its users on the other. For the former, it is an ethical and moral problem that needs to 
be addressed (Q. Liu 2004; Zhao 2004). Many have tried to 'persuade' cyberlove practioners to go back to their 'real' lives.

What attracted these practioners to the Internet in the first place? What keeps them using these new technologies? The answers lie in how a woman practices online flirting and offline dating, how they judge themselves in these situations, and what is their pay off from the interaction between their so called 'virtual' and 'real' lives.

\section{Theoretical Framework: 'Deviant' Sex and Life Politics}

This chapter will use the sexual empowerment perspective to look at women's sexuality, to understand more about their everyday life and their need for survival, identity, social resources, as well as the social context that constitutes their sexuality. In most of the studies already mentioned, women's cyber flirting and offline dating are regarded as 'deviant' sexual behaviour which could have negative consequences in their 'real' lives. To explore how women portray their sexuality through the Internet and what they gain from it, we turn to Gidden's useful concept of life politics. Life politics is 'about how we should live in a world where everything that used to be natural (or traditional) now has in some sense to be chosen, or decided about'(Giddens I994: 90-9I). It is about lifestyle and life decisions and hence, those decisions that concern the development of self-identity (Giddens I992: I97; Kaspersen 2000: IIO ). We can practice life politics in different spheres of our lives in our modern society, since all conditions of life are incorporated as a part of the reflexive project of the self.

Chinese women's sexuality and their attempt at Internet love is an area of life politics. It is argued that these women are making their gender in their everyday lives by blurring, negotiating or deconstructing the boundary or division between positions, identities and life domains - such as subject and object, private and public, personal and political, social and sexual, consumption and production. The everyday practices of these women with online dating helps gain a deeper understanding and insight into Chinese 'women' and 'sexuality'.

While cyber activities become a part of the everyday life of these women, how do they use them for their life politics? The eight women of our research use cyber contact or cyber flirting as a tool to approach their potential sexual partners, and to change their offline lives, including their sexual lives, as well as their social and economical status. The Internet is the tool which allows them to meet men whom they cannot reach otherwise, or at least not so easily. They are able to formulate multiple strategies from their online experiences since they communicate so often with different men online. They would not have had such 
rich experiences or come up with so many strategies if they had stayed away from the Internet. Their strategies, both online and offline, is the focus in this chapter. The strategies form a kind of life politics, and are used to overcome the practical problems and moral dilemmas that are constricting their lives. The processes, while not always strictly 'sexual', are useful in enhancing their status as modern women. Special attention will be given to women who are marginalized for being non-natives of Shanghai, coming as they do from small cities or rural areas outside the city. For these women, the Internet is an easily accessible tool used to expand their social spaces.

\section{Methodology}

Eight women, who reported to have both offline dating and online flirting experiences, were chosen from the forty informants of our study. Six of the eight mentioned they had had sex with the men whom they got to know on the Internet. Three of the eight mentioned text-based cybersex, phone-based cybersex and video-based sex with their Internet dating partners. Three of the eight used Internet as often as they could to find possible partners, and their significant sexual relationships mostly originated from cybersex.

The eight women are between the ages of 25 and 35. Their marital status, work, education level, income and social class are all diverse. The group includes a nude model from a rural area, a home-maker, a single mother separated from her husband, a divorced woman, a woman living with a steady boyfriend, a PhD student, an editor and a nurse. It is interesting to note that all the eight women are from areas outside Shanghai. We hope the diversity in their background will enrich our understanding of the picture. Data was obtained through indepth face-to-face interviews and online chatting. We did not have structured interview questions for these women about their approaches to cyberlove or cybersex: Instead, we would begin our discussion with a general question: 'have you ever tried wanglian?', especially if they had not mentioned this topic out of their own initiative.

Of the eight women, only the home-maker needed the question to help her disclose her online sexual experiences. The other seven women talked about their cyber sexual encounters naturally when they talked about their sexual experiences generally. Many of them had actually met their lovers, boyfriends or friends through the Internet. During their story telling, we did pay attention to how they 'searched' or 'met' their friends who later became their sexual partners and what they gained from their Internet experiences. We interviewed these women only once, but some interviewees became our friends and they in- 
vited us to have tea or go shopping with them when we stayed in Shanghai. We are still in communication with some of them by online instant messaging. Most of these current messages are centered around the new developments in their sexual relationships. We have their permission to use their messages for this study.

\section{Cyberspace as a 'Virtual' Space}

Both Western and Chinese literature prefers to use the binary 'virtual / real' or 'virtuality/reality' to distinguish between online life as a 'virtual life' and offline life as 'real life' (Chen \& Zhao 200I; Duo 200I; F.M. Liu 200I; Shui 200I; X.S. Wang 200I; Zhang 200I). The eight women interviewed also used $x u$ ni/xian shi (virtual/real) to refer to their online and offline lives. From their accounts, we can understand how they see the distinction between what is virtual and what is real. For most of them, the Internet is a new thing which they have not learnt from their parents or schools, but from friends, people in the net bars or the computer market. They spontaneously take the new terms such as $\mathrm{xu}$ ni/xian shi to describe 'cyberspace' and 'real life' to express themselves when they communicate with other Internet users. However, while using this terminology to describe and express themselves, they do not just follow the conventional meanings of the new terms; they give their own personal meaning too. Rose's example is a case in point.

For Rose, a 33 year old woman who has been separated from her husband for one year and lives with her 5 years old son, 'virtuality' (xu ni) means that 'you can't depend on it very much'. Before her husband's affair and subsequent separation, Rose had never indulged in sexual contacts with other men. To take revenge against her husband's betrayal and to prove that she could still charm men, Rose started to chat with male strangers online. This led to sexual contact. Among the thirteen partners who had had sex with Rose in the past year, three of them have been what she considered 'relatively long and serious relationships' which lasted from one to three months. Two of the three even proposed marriage, and one took her to find houses with the view of living together. To Rose, this meant the men were serious about their relationships with her. However, Rose felt very disappointed with the Internet, because she had not met her 'true love' - a man who loves her as much as she loves him. She has met men with 'good qualifications' - meaning a man has high social status, money or a promising economic future. For example, she met a millionaire who had his own company and another man who was 33 years old and with a master's degree from overseas. Neither however seemed to have much in- 
terest in a single mother who was not 'really young'. Rose was angry with these men:

'Cyberspace is virtual. Some men are too naïve to understand that it is not real life. They find it so easy to meet girls via the Internet, that they think they are popular in real life too. They always dream that they can find a perfect woman soon. They are very selective and unrealistic, all in all, they are just naïve. Don't they know that cyberspace is different from real life? There is no perfect woman in the world!' (Rose, 33)

Despite Rose's complaints against these men's naïvity and the virtuality of the Internet, she has not given up her online search for the 'perfect man' or her 'true love'. She tries to improve her search techniques and has purchased a digital camera because she believes that 'if you have a picture on your profile, you could get much more feedback.' She changes her name and pictures, depending on the different websites she uses. This is how Rose analyzes the markets offered by different websites:

'The one dating website on Sina.com attracts local men. Usually they are young and don't like divorced woman, I seldom go to the website. Shanghai night is very popular but most people want to find 'one night stands' there. The one on MSN usually attracts men who want to practice their English, they are not very serious. ICQ is the most effective one to find Westerners. I don't know why, most of my netfriends were from there, maybe because the netname I used there was very attractive. My name there is Zhen ai cai mei li (Beautiful when in true love).' (Rose, 33)

Rose believes that by using such a name she can be identified as a woman more easily since men will not use such a poetic name.

'I find the word "beautiful" useful to attract men online, because men will dream that you are a beautiful woman. Actually, I find myself very attracted to some men, especially when I wear pink. So I don't think it is a lie for me to call myself by that name.' (Rose, 33)

From Rose's account, cyberspace is a place to meet strangers which is not beyond her reach at all. She knows the characteristics of different websites and the types of men who approach these websites. She also knows how to deal with the formalities of these websites by disclosing her gender and nurturing men's fantasies. She adds that she would 


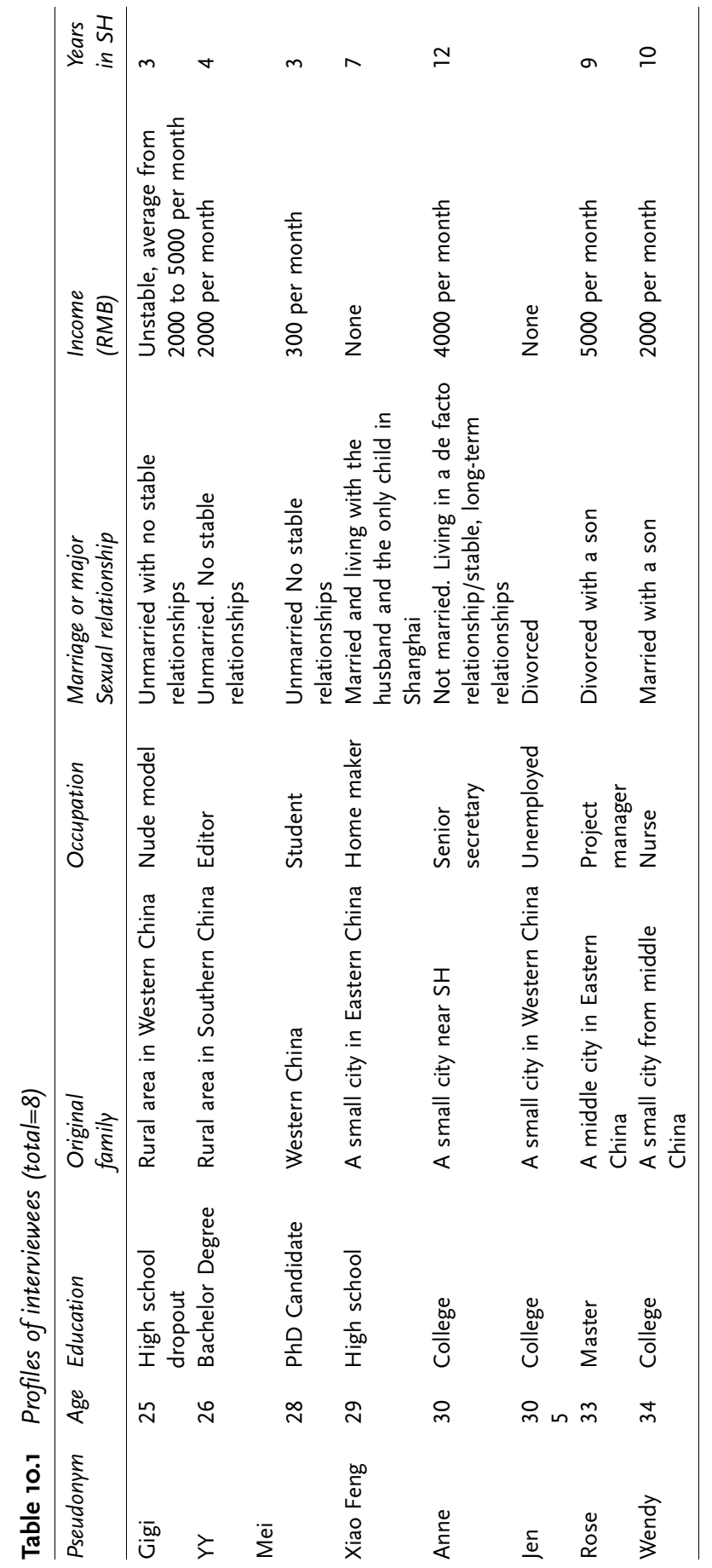


never mention her child before they meet. 'Men will lose interest in you if you have a kid, however, they may change their attitudes after they have known you.' This is another of Rose's strategies to attract male net friends and future partners.

Rose likes to use $x u$ ni to complain about her partners' unrealistic and impractical attitudes with regard to the criteria these men use to find their 'perfect woman' online, even after repeated failures. Rose, however, never mentions that she, just like the men whom she complains about, is not practical or realistic either. She too wants to find the 'perfect' partner there. While she uses 'virtual' to describe cyberspace and the things that she has gained from it, such as the channels to approach the kind of men whom she would never have met if not for the Internet, she is also aware of the fact that 'the Internet is a useful tool, but it is not everything, you can't depend on it too much'.

$X u n i$, the official translation of the English term 'virtual/virtuality' to describe cyberspace is made up of two Chinese characters which refer to something 'invented', 'imagined' and 'difficult to grasp or handle'. The media and popular literature use the term to describe and discourage cybersex and netlove. But in Rose and her peers' dictionary, cyberspace is not just 'invented' and 'imagined'; one can actually use it to gain life experiences. $X u n i$ is a powerful word for them to criticize the men who fantasize about women too much and as an expression for which alerts them to the problems of depending too much on the Internet.

\section{Cyberspace as Real Life}

Going online has become an addiction for the interviewees as they claim they go online almost everyday; at home, at work wherever and whenever they have time. For most of them, cyberspace has already become part of their 'real life', especially as an expression for their 'unconventional' sexual relationships.

Anne, a 30 year old woman from a small city near Shanghai, now a senior secretary in a foreign investment company, likes to stay long hours at work. This is because her office provides access to the Internet, and she keeps in touch with her college lover online. After living with a stable boyfriend for three years, she has fallen in love with a college student who is ro years younger. They met online after Anne needed help with her computer skills. Her 'virtual love' majored in computer studies. They use QQ, a popular instant messaging software in China. After several months chatting online, they decided to meet. At that time Anne's relationship with her former boyfriend was in crisis. She had 'no more passion' for him. The college student impressed 
her with his good looks and manner, constantly talking about his life at the university. 'He is just that kind of handsome Shanghai male student, tall, fashionable and gentle,' Anne said. At the office, Anne always chatted with him online because this was the safest way. Her boyfriend could not rush to her office and would not be able to get her chat history records from the company's computer. He always thought she was busy at work. It is regarded as 'normal' in foreign investment companies for employees to work extra hours. People even think it's prestigious because only profitable companies need their staff to work extra hours, without receiving extra money for it. 'I am glad to be seen as hard working', Anne said. Her 'overtime' has surprisingly landed her a promotion from junior secretary to senior secretary.

Friends cannot understand Anne's love affair:

'They say: Anne, how you can fall in love with someone who is Io years younger than you? And so what? I often answered back. I am not thinking about marrying him. I really like him, I feel really happy with him; sometimes I think that life would have no meaning without him.' (Anne, 30)

For Anne, chatting online with her lover is part of her 'real life' instead of belonging to the 'virtual' sphere. The college student is 'real', the happiness Anne gets from chatting is 'real', and therefore the Internet becomes the tool Anne uses to find her happiness without disturbing her relationship with her boyfriend.

\section{Cybersex as an Empowerment Experience}

All eight women who experienced online chatting and offline dating thought the experiences were empowering rather than victimizing.

Xiao Feng, a full-time home-maker, thinks that the 'Internet is a game, if you know the rules of the game, you can earn a lot.' After nine years of marriage, Xiao Feng was not satisfied with her husband's sexual performance. Every time her husband asked for sex, Xiao Feng felt it was a burden. Her husband was also not happy about their sex life. He always complained about Xiao Feng's 'sexual coldness', her 'need to be asked', and her inadequacies in 'pleasing' a man. Xiao Feng thus tried to 'save' her marriage by consulting her net friends about her sexual 'problems' especially when she did not know how to discuss these things with her friends 'in real life'. When her husband went to work and her daughter was in kindergarten, she started her online sexual exploration. She wanted to know more about the male sexual psychology, their sexual desires and frequency of intercourse requests, the length 
of intercourse, and their requests for oral sex. So firstly, she chose some male netfriends. Usually she would ask them: 'How many times do you make love every week?' or 'Is it you or your wife who asks for sex?' But instead of answering these questions, most male netfriends would boast about their 'sexual prowess', and many asked Xiao Feng for a date, attesting she would be 'satisfied.' That was not what Xiao Feng wanted. She would close the chat window immediately if she was 'sick' of what these men said. Instead of making friends with these men, Xiao Feng bonded with some women who had had similar experiences. Some women advised her to treat her husband 'better' in bed and some advised her to go out to look for a job, so that she could be more attractive to her man. Whatever the advice, these women became her good friends online. However, Xiao Feng has never tried to ask about their identities.

'Once you know a friend in real life, you will not feel so free and frank. You will have some taboos. For example, you will feel pressure to disclose yourself as a real person, and you will feel a kind of competition between you and your friend.' (Xiao Feng, 29)

So Xiao Feng has never tried to meet a netfriend in 'real' life if their conversations were all about sex. But she has met a lot of netfriends with whom she has become friends in her 'real' life.

'These friends of mine all live in the same community. We have a community website and we have gotten to know each other though this forum. Sometimes we have a gathering, such as drinking tea together or having dinner. My husband never attends such activities. But he doesn't disapprove of them either. That's quite good. You know, he disapproves of everything else that I do. I can get a lot from my net community friends, for example, where you can get cheaper gas and which school is the best.' (Xiao Feng, 29)

For Xiao Feng, the Internet and her netfriends have empowered her. While chatting with women about her sexual issues online, she felt less anxious about her 'problem'. She has found an outlet and found other women who have had similar problems to hers. Xiao Feng has tried to use the suggestions from her netfriends, such as 'giving him oral sex as praise for his good behaviour outside the bedroom' or 'pretending to have an orgasm'.

Before going online, Xiao Feng felt like a 'failure', a home-maker who could not please her husband sexually. After chatting about sexual 
issues with men and women online, she has new strategies to use with her husband, but most importantly, she has received the support from her netfriends which helped her resist her husband's criticisms. The Internet thus becomes a powerful tool which equipped Xiao Feng with the skills to become a more independent woman.

\section{Cybersex as a Lifestyle Politics}

As already stated, the eight women interviewed are migrants to Shanghai. They believe that this large city will contribute to their dreams of a better life, whether emotionally, financially and/or physically.

Gigi, a 25 years old woman from a rural area, now a nude model for photographers and artists in Shanghai, thinks that she may never have come to Shanghai and become a 'successful' model without the Internet.

'At that time, I was eager to know more about Shanghai. I chatted online with a guy in Shanghai on and off for more than a month. At last, he said, 'Come to Shanghai. You can live at my place.' (Gigi, 25)

Back then, Gigi was a high school drop-out and waitress. With the help of her netfriend who soon become her boyfriend, Gigi got access to her dream city of Shanghai which is perhaps a dream city for all rural girls in their late teens and early 20s. By chatting with netfriends, Gigi found a job as a nude model for photographers and artists. She likes this job because she is in touch with 'high-level people', something she could never have done were she still an ordinary waitress. The modeling job has given her greater working opportunities and perks such as expensive dinners, airplane travel and exhibitions. Her first Shanghai net friend/ boyfriend has left her, but she does not feel regretful. 'He would have left me someday anyway. How can a Shanghai man marry a rural girl?'

With China's urbanization in recent years, migrants from other areas to the large cities find it very hard to survive. Recently, Shanghai has issued a regulation which only welcomes migrants who have more than a Bachelor degree or other special skills (Shanghai People Government Order 2002). Only people with these relevant qualifications can be issued a 'Certificate of Shanghai citizenship'. The others, the majority of migrants, find life very hard. Only those with strong abilities or social resources survive.

Gigi is not disappointed with her situations: 'Shanghai is a city of legends, a city for adventurers. You can be what you want in Shanghai.' She has found potential friends and lovers online and has taken a lot 
from these men. Apart from the material support, Gigi emphasized the 'social skills' and 'technical skills' that she has learnt from these men, such as how to make herself up like a 'proper woman', how to receive a phone call like a 'local' woman, how to converse when at a party, how to use professional cameras, how to appreciate a work of art and how to organize a website. Gigi is proud of her Internet savvy because 'most models even don't have their own email addresses.' Gigi even thought of developing a new business online: charging netfriends to see her masturbate through her Web portal. However, the plan did not materialize because 'no one wanted to pay as they could get the same thing free at other websites.' Gigi does occasionally let some netfriends see her masturbate through her webcam without charging: 'It feels like a performance, I feel excited when I hear their breaths. Maybe they fake an orgasm, but I don't care. That makes me happy.' For Gigi, a rural girl with limited exposure to urban culture, these skills were part of her 'education' process in Shanghai.

Gigi has had experienced some horrendous experiences through her Internet 'courtships', such as being forced to perform oral sex on an old man while another watched. She has also experienced some sexually transmitted diseases and has had six abortions. Strangely, she does not think that they were necessarily very bad experiences. 'No one wanted that, but it happened. I am more careful now. However, all these things can happen to women even without the Internet'.

Many of the eight women have become more skillful and effective in dealing with their sexual relationships and in using the new technologies. They have turned the very idea of courtship upside down by challenging the conventional notions of men being active and women being passive. They have taken the initiative to find new possibilities in their social and sexual relationships, thus becoming happier and more independent and developing a greater sense of control as well as a stronger network of social connections and support.

\section{Cybersex as a Transforming Process}

For most women who have had experiences with cybersex, their concepts of 'sex', 'love' and 'marriage' have been transformed. For them, having sex with netfriends is acceptable and their concept of what is 'true love' or 'happiness' is placed side by side with 'sexual pleasure'. For these women, their interpretation of 'true love', which means 'a man who loves me and I love him too' has changed. Marriage may still be their practical pursuit, though most of them don't believe they will have a 'perfect marriage'. Marriage may fulfill some of their emotional and physical needs, but not all. 
Most of the women interviewed said that when they were young, they believed 'sex was the ultimate expression of love, you could only have sex with your husband or future husband whom you really loved, and you could not have sex with other men once you were married. A perfect marriage was the perfect combination of love and sex. However, this notion has changed because society has also changed. What women treasured in the past such as 'virginity, loyalty and pure love' was not being valued as much by society today. Women cannot be assured of happiness through their 'virginity and loyalty' especially if their husbands or sexual partners do not do the same. 'Happiness' and 'passion' are now more important for these women and they are prepared to get them in unconventional ways.

Wendy, a 34-year-old married woman with multiple net lovers, felt herself very 'pure' when she was in her early 20 s and not married. Now, her opinion is different.

'When I was young, I thought you can only love and make love with one man in your whole life, that's pure love. Now I recognize that love is just like cakes; different cakes have different tastes. You can't have only one taste in your life, that's not a rich life, is it?' (Wendy, 34)

Jen, an unemployed 30-year-old divorcee, compared her attitude to sex before and after marriage:

'Before I was married and divorced, I couldn't imagine how women could have sex with a stranger. Now that I have a lot experience, I know men always want to have sex on a first date. When they make such suggestions and I don't like them, I will not let them walk me home.' (Jen, 30)

From their presentations, we can see the transformation of sex, love and marriage in these women's practices with cybersex. 'Love, sex and marriage' was once a package as was 'virginity and loyalty' to a future husband. Now, however, the women interviewed do not see these qualities as essentials. Virginity before marriage and loyalty in the marriage is not their primary focus anymore. Instead, 'happiness' and 'passion' are emphasized in their sexual lives. They stress they want a rich life that is more fulfilling. They focus more on sexual pleasure or happiness for their own sake.

For the interviewed women, these changes do not come easily. They face moral dilemmas, ethical struggles and emotional confusion. Their new choices are seen as a kind of resistance to 'proper' womanhood, motherhood and 'normal' femininities (Foucault 1978; Ho 200I; Ho \& 
Tsang \& Ho, 2007; Wong, Cheng \& Pei, 2005). They do appreciate the Internet as a new social space which allows the exchange of new ideas and facilitate the formation of a new culture that celebrates women's choices and sisterhood. They feel that the Internet has provided them with new ideological resources to change their lives, especially the possibilities of finding new sexual partners and developing new friendships that can offer useful, practical and emotional support.

\section{Conclusion}

Women who engage in cybersex do so for a variety of reasons, but mainly what they expect to get out of it is money, work opportunities, possible boyfriends or husbands or new life experiences. Many of them felt that they had learnt a lot, by their engagement in cybersex, especially about how to approach and choose possible sexual partners. They all wanted to impress the researcher with their new qualifications; their competence and intelligence in handling relationships with men.

It is worth noting that most women emphasized the way the Internet could function like a filter in their interactions with men. Because all cybersex users have to put up a profile, women can filter out the most promising looking men and use this information to judge whether their communication should continue or if their online relationship should develop into offline dating. They believe that by engaging in cybersex they have learnt how to make better judgements about men. They have also gained experience in coping with the difficult problems these online interactions sometimes bring up, which has been useful to their self-development.

It is also worth noting that the women in this study are all marginal and under-privileged. As migrants, they have little social resources to draw on, especially in terms of their social relationships in Shanghai. However, armed with the strategies they have learnt from the Internet, especially from their multiple sexual experiences, they have taken advantages of virtual communities and relationships and made good use of a powerful and low-cost resource for developing 'real' communities and 'real' relationships.

To take the road less travelled means to open oneself up to possibilities. These women have challenged the conventional norms. By forming their own cultural and social groups of Internet friends and sisters, they can share their experiences and support one another both online and offline. By doing so, they are both increasing and carving out new spaces for themselves and for one another. In this context, therefore, we argue that they are in fact engaging in new forms of life politics. 
Gidden's concept of life politics is useful for understanding women's everyday life in terms of a sexual empowerment model. However, he adopted a macro approach, and said little about how individuals can influence society. Our study indicates the need to supplement Gidden's concept by providing concrete examples and atypical stories of how women actually live their lives and change the world around them via their Internet interactions.

This study highlights the central importance of women's subjectivity and sheds light on how women struggle to survive in a big city by making use of sex and whatever limited resources they have. They use their sexual relationships and experiences for personal growth and social positioning. Sex via the Internet is not just about sex. It is also their politics.

\section{References}

Bian, J.B. (2002), 'Nusheng "wanglian" pian chihe (Female students use "cyberlove" to cheat)', Chinese Youth and Technology 6: 42.

Chen, L. \& F. Zhao (200I), 'Wanglian, cong wuzhong zou chu lai de meili (Cyberlove: Beauty in the mist)', Law Q Life I: 78-80.

Cooper, A. (2004), 'Online sexual activity in the new millennium', Contemporary Sexuality 38 (3): I-7.

-, S.A. Mansson, K. Daneback, R. Tikkanen \& M. Ross (2003), 'Predicting the future of Internet sex: online sexual activities in Sweden', Sexual and Relationship Therapy I8 (3): 27729 I.

-, I.P. Mcloughlin \& K.M. Campbell (2000), 'Sexuality in cyberspace: update for the 2Ist Century', Cyberpsychology \& Behaviour 3 (4): 521-536.

-, M.J. Morahan, R.M. Mathy \& M. Maheu (2002), 'Toward an incresed understanding of user demographics in online sexual activities', Journal of Sex \& Marital Therapy 28: I05I29.

-, D.E. Putnam, L.A. Planchon \& S.C. Boies (1999), 'Online sexual compulsivity: getting tangled in the net', Sexual Addiction a Compulsivity 6: 79-I04.

-, C. Scherer \& R.M. Mathy (200I), 'Overcoming methodological concerns in the inverstigation of online sexual activities', Cyberpsychology ar Behaviour 4 (4): 437-447.

Dong, F. (200I), 'Wanglian xinli tanmi (The exploration of cyberlove psychology)', China Healthcare Q Nutrition II: 20-2I.

Doring, N. (2000), 'Feminist views of cybersex: victimization, liberation and empowerment', Cyberpsychology a Behaviour 3 (5): 863-884.

Duo, D. (200I), 'Wanglian shi yizhong hen xuan de dongxi (Cyberlove is very profound)', Today Nurse 7: 4I-42.

Foucault, M. (I978), The history of sexuality (Vol. I: An introduction). New York: Pantheon (Original work published 1976).

Giddens, A. (1992), The transformation of intimacy: sexuality, love and eroticism in modern societies. Cambridge: Polity Press.

- (1994). Beyond left and right: the future of radical politics. Cambridge, UK: Polity Press.

Hai, N.C. (2002), 'Doushi wanglian rede huo (All the disaster caused by cyberlove)', Issues on Juvenile Crimes and Delinquency 6: 53-55. 
Han, Q. \& D. Yuan (2002), 'Wanglian yinfa de qiaozha an (The extorting case triggered by Cyberlove)', Issues on Juvenile Crimes and Delinquency 4: 55-56.

Ho, P.S.Y. (200I), 'Breaking down or breaking though: an alternative way to understand depression among women in Hong Kong', The Journal for Ethnic and Cultural Diversity in Social Work ro (3): 89-106.

- (2006), 'The (charmed) circle game: reflections on sexual hierarchy through multiple sexual relationships', Sexualities 9 (5): 547.

-, \& A.K.T. Tsang (2005), 'Beyond the vagina-clitoris debate: from naming the sex organ to the reclaiming of the body', Women's Studies International Forum 28: 528-523.

—, \& A.K.T. Tsang (2007), 'Lost in translation: sex \& sexuality in elite discourse and everyday language', Sexualities io (5): 623-644.

-, D.H.W. Wong, S.L. Cheng \& Y.X. Pei (2005), 'The real deal or no big deal - Chinese women in Hong Kong and the orgasmic experience', Issues in Contemporary Culture and Aesthetics, I: I77-I87.

Ji, X. (200I), 'Wanglian bei hou de zuier (The crimes behind cyberlove)', Dangfeng Tongxun 2: 43 .

Kaspersen, L.B. (2000), Anthony Giddens: an introduction to a social theorist. Oxford, UK; Malden, MA: Blackwell Publishers.

Li, Q. (2003), 'Wanglian dui ren xinli yingxiang de yanjiu zongshu (The study of cyberlove's e impact on one's psychology)', Chinese Youth Studies I2: 42-45.

Li, Y. (2003), 'Wangluo jiaowang yu wanglian xianjing (The traps of online communication and cyberlove)', Xueshu Luntan r: I27-I29.

Liu, F.M. (200I), 'Wanglian, xiang shuo "ai ni" bu rongyi (Cyberlove: it's not easy to say "I love you")', Health II: I9-20.

Liu, Q. (2004), 'Shilun Wanglian jiqi dui gongmin daode de fumian ying xiang (Cyberlove and its negative effect on civil morality)', Journal of Zhongzhou University i: 75-77.

Ren, W. (2005), 'Cong wangluo xinai kan weicheng nian ren xing jiaoyu de jinpuoxing (Emergency of education for the sexual moral of minors viewed from Internet sexual love)', Zhonguo Qinnian Zhengzhi Xueyuan Xuebao 2: 8-I4.

Schneider, J.P. (2003), 'The impact of compulsive cybersex behaviours on the family', Sexual and Relationship Therapy I8 (3): 329-354.

Shi, W.X. (2002), 'Wanglian pianju (Cheating in the name of Cyberlove)', Procuratorial View 02: $54-57$.

Shui, Y. (200I), 'Dalao Wanglian (Getting out of cyberlove)', Chinese Times I: I5.

Tan, J.Y. (2003), 'Daxuesheng wanglian de xinli fenxi ji duice (The analysis and countermeasures of university students' cyberlove)', Jingjishi 6: 108-I09.

Tang, Q. (2005). Guanzhu wangluo xuni xingai yanjiu (On cybersex research). The Chinese Journal of Human Sexuality, 14(6), 3I-32.

Toomey, K.E. \& R.B. Rothenberg (2000), 'Sex and cyberspace-virtual networks leading to high risk sex', The Journal of the American Medical Association 284 (4): 485-487.

Wang, D.Y. (2002), 'Xuni wanglian, cuanchu zhengshi selang (From virtual love to real sex perpetrator)', Public Security Monthly 4: 32-35.

Wang, L.M. (2002), 'Wanglian, yidao du te de fengjing xian (Cyber love: a special scene)', Computer Knowledge and Technology 6: 70.

Wang, T.Y. \& Z.S. Li (2002), 'Wanglian xuean (The murder case of cyberlove)', Zhongguo Baoan 8: 24-25.

Wang, X. (2003), 'Shengmeyang de haizi rongyi wanglian (Which kind of children fall easily into cyberlove?)', Jiating Keji 2: II.

Wang, X.S. (200I), 'Wanglian, yuexian yueshen yue miwang (Cyberlove: Being trapped and lost in quick sand)', Chinese Health 200I (6): I9-2I.

Xiao, L. (2000), 'Wanglian wei sheng me ge wai mei (Why Cyber love is so beautiful?)', China Computer and Network I8: II. 
Xue, Y. (2003), 'Wangluo xingai de youhuo (The tempt of cybersex)', Baike Zhishi 3: 47-49.

Yang, G.H. \& J.S. Lan (200I), 'Wanglian zhi jingsheng fenxi (The psychoanalysis of cyberlove)', Society 4: I4-I6.

Young, K.S. (I997), Internet addiction: what makes computer-mediated communication habit forming? Paper presented at the $105^{\text {th }}$ Annual Convention of the American Psychological Association Chicago.

Zhang, T.K. (200I), 'Wanglian de "jian guan si" yu ganjue de jiaxiang ("Dying once exposed": the false image of emotion and cyberlove)', Modern Communication 9: I8-I9.

Zhao, Q.J. (2004), 'Wanglian de lunli helixin fenxi (The ethical analysis of cyberlove)', Social Sciences in $\mathrm{Hu}$ Bei I: I22-123.

Zheng, Y. (2005), 'Wangluo xinai jiqi lunli wenti (Network sextual affection and its ethics problem)', The Chinese Journal of Human Sexuality I4 (I2): I4-I7.

Zhi, R.Y. (200I), 'Youren de wanglian xianjing duoduo (The temptations and traps of cyberlove)', Life Q Health II: 50.

Zhou, C.B. (2000), 'Wanglian, ai bing lang man zhe (Cyber love, romantic love)', Computer Technology 9: 39 .

Zhou, J.F., \& Y. Chen (200I), 'Xiongsha, yuanyu yichang langman de wanglian jiqing (A murder from a romantic but abnormal cyberlove)', Public Security Monthly 5: 52. 



\title{
11 On Sale in Express Package
}

\section{Chinese Female Bodies as Commodities in Cyberspace}

\author{
LEUNG Maggi W.H.
}

\section{$1 \quad$ Introduction}

'I have a close friend who is Asian-crazy. He's got Asian pussy fever so bad that he can apparently only get it up for a pretty Thai or Korean girl, and wouldn't give Pamela Anderson a second look. Used to be I didn't quite understand it, but now I'm in Hong Kong and watching all these pretty girls walking around in the hot evenings wearing these high heel fuck-me shoes, and earlier today, I was walking behind this Hong Kong girl who just got back from the tennis courts, her legs all sweaty and I could see through her shorts to this perfect ass... well, I have the condition now too... as well as an erection. Man, all I wanted to do is fuck her silly. Here's a picture of her ...'

Welcome to Hong Kong! The above quote is taken from the Guide to Adult Travel in Hong Kong, found easily - free-of-charge, warning-free, and question-free - on the Web (http://hongkong.worldsexarchives. com/, retrieved I5 November 2007). The excerpt is part of the author's - JustJoe's - prelude to the 'real' guide. In this virtual tour guide's perception, Hong Kong is a sexual city. Subjects of erotic fantasy are just everywhere. In the main body of his guide, he provides detailed information on the where, what, how, how much ... - practically all one wants to know about sex and the city.

This sharing of sex tour experiences is only one of the many diverse Internet usages that relate to the trading of female bodies and their images online. New communication and information technologies have brought about a global revolution in the access to, and exchange of, information on practically all branches of the economy. The sex industry has been eager and effective in adopting every new IT technology to enhance their business. ${ }^{\text {I }}$ With the advancement of the Internet technologies and the aid of the expanding coverage and power of the cyber network, women and children are being traded, both in physical 
and virtual forms, more quickly and over longer distances than ever before. Women, men and children's bodies can now be marketed in prostitution or related activities with new means, including online strip performances, sex shows and commercial voyeurism. While consumers are able to purchase pornographic services and excitement in anonymity, individuals being watched and sold are, on the contrary, being exposed and exploited more and more publicly, practically at all times and in all places with telephone connections.

This chapter charts the reach of Internet pornography, online prostitution and other forms of female-trading (e.g., mail-order brides) with emphasis on the situation of Chinese women in the national context and global market. In the following, I shall provide a survey of the diverse ways in which women are displayed, packaged, bought and sold in the cyber world. An examination of a selection of online prostitution websites, mail-order bride Internet catalogues and chat rooms will provide insights into the sexist and racist nature of the global sex industry. In the latter part of the chapter, I shall bring forth how cyberspace can also be used by women to market their sex services and by individuals and civil groups to criticize the spread of sex trade. Governmental and non-governmental efforts (both international and, in particular, within China) to patrol, control and curtail exploitation and abuse of women and children in cyberspace will also be discussed.

\section{Cyberspace as Gendered and Embodied Space}

To state that cyberspace has changed our world might be somewhat exaggerating. To date only ig per cent of the world's population has access to the Internet, with disparate access percentage in different world regions - ranging from 70 per cent in North America to only 5 per cent in Africa (Internet World Stats 2007). Nevertheless, among those whose life has been affected by these new information technologies, the power of the Internet and cyberspace can be and has been dramatic. In his influential work The rise of the network society, Manuel Castells (1996) offers an analysis focusing on the impact of the Internet. He considers the new technology - as an integration of print, oral and audiovisual modalities into one system - to be as powerful as the alphabet, which can create new forms of identity and inequality, redistributing power and establishing new forms of social organization. Di Maggio et al. (200I) consider the Internet as a particular intriguing technological change that humans have experienced in history for its high level of malleability. The Internet can be, at the same time, a means of real-time communication like a telephone, a space for information storage like a library, a forum for discussions and a mass med- 
ium for broadcasting information in a sizable and geographical dispersed user population. These multiple purposes and changeful nature of the Internet call for more critical thinking about its reach, usage patterns and impact.

Social scientists have analyzed the impact of the new technology from a variety of perspectives. Analysts of the Internet technology, either enthusiasts or sceptics, have provided well-founded examples on the power of cyberspace and the Internet. While the former group advocates the capacity of the new technology in reducing inequality by lowering the cost of information; the latter group believes that the benefits of the hi-tech information technology would be reaped by the already privileged, thus widening the power gap that already exists. A few edited volumes have been dedicated to the study of women and the cyberspace, paying attention to issues ranging from access, the gendered nature of cyber communication, to the impact of the Internet on community building and empowerment (Cherny \& Weise I996; Harcourt I999; Hawthorne \& Klein I999; Spender I995). One of the major themes concerns the patterns of inequalities known as the gender 'digital divide', often compounded with other lines of bias such as class, wealth, race, ethnicity and geographical location (Bimber 2000; Castells 200I; Compaine 200I; Noris 200I; Warf 200I). In addition to studying how access and usage of the Internet is gendered in a quantitative sense, research has also illustrated other aspects of the gendered nature of the digital world. Boneva and Kraut (2002), Ebo (I998), Evard (I996), Kolko (I999), Kramarae and Kramer (I995), Lessig (I999), Nakamura (I995), Silver (2000), Spender (I995), and Sussman and Tyson (2000) among others, have investigated the gender, sexual and racial dynamics in online interactions. These studies conclude generally that cyberspace is male-dominated, and that gender differentiation and power displays in communication are apparent as in other modes of exchange. Some studies have focused on the phenomenon of cybersex (Döring 2000; Waskul 2006). Döring (2000) argues that existing analyses either adopt the victimization or liberation perspective both considered to be inadequate - and advocates the empowerment perspective that 'acknowledges power discourse as an essential sexual issue online and off'. McLaren (2007) presents an intriguing and unique case of Web marriage in China. By engaging in Web marriage, participants build a cyber partnership and often a family with another 'player' and can but do not necessarily engage in Web sex.

Avatars are also interesting subjects to analyze and the extent to which real-world gender and racial dynamics are transferred to, negotiated, reinforced or rejected in cyberspace. Kolko's (I999) study on rhetorical aspects of avatars within multi-user graphical virtual realities reveals that the bodies are far from disappearing in cyberspace as per- 
ceived by some; rather, virtual bodies (both text-based and graphical ones) roaming cyberspace are mostly embodiments of real world identities, recreating patterns of gender and racial prejudice and discrimination. Nakamura (200I) concludes from her observation of the radicalized and gendered bodies in LambdaMOO, a popular chat space:

'Performances of Asian female personae in LambdaMOO are doubly repressive because they enact a variety of identity tourism which cuts across the axes of gender and race, linking them in a powerful mix which brings together virtual sex, Orientalist stereotyping, and performance. A listing of some of the names and descriptions chosen by players who masquerade as "Asian" "females" at LambdaMOO include: AsianDoll, Miss_Saigon, Bisexual_Asian_Guest, Michelle_Chang, Geisha_Guest, and MaidenTaiwan. They describe themselves as, for example, a "mystical Oriental beauty, drawn from the pages of a Nagel calendar", or, in the case of the Geisha_Guest, a character owned by a white American man living in Japan: “... a petite Japanese girl in her twenties. She has devoted her entire life to the perfecting the tea ceremony and mastering the art of lovemaking. She is multi-orgasmic. She is wearing a pastel kimono, 3 under-kimonos in pink and white. She is not wearing panties, and that would not be appropriate for a geisha. She has spent her entire life in the pursuit of erotic experiences."' (Nakamura, 200I: 23I)

Nakamura's analysis reminds readers that cyberspace is per se far from being a space for alternative ideas or a 'third space' for other visions of power organization. While she emphasizes primarily on race, her insight is also relevant in an analysis of the gender stereotyping loaded in the above log. Drawing upon my survey in sections of cyberspace that concerns the commodification of Chinese women, this chapter intends to underline the strong connections between the 'cyber' and the 'real' in our world, debunking an often unquestioned idea that the cyberspace is an alternative space where non-reality can take place. The cyberspace is after all a human-made product, a construct that has its root in the power structure of our 'real' world, and a forum where real human relationships are played out. As Damer (I997) aptly observes in his analysis of the virtual world:

'One of the reasons I and many other people refer to this new medium as virtual worlds and not virtual reality is that the worlds we visit are virtual (they exist nowhere else but cyberspace and in our minds) but we go there to meet and interact with real people. There is nothing virtual about the reality of your interac- 
tions and relationships with other people in these spaces.' (Damer, I997: 12)

By drawing the connection between the 'real' and the 'virtual' worlds, I do not intend however to undermine the imaginative power of cyberspace. As I illustrate in the following, the Internet not only reproduces the power structure of the real world, it has also allowed and encouraged the desires and imagination of some individuals and (virtual or imagined) communities going wild, which consequently exacerbates the power imbalance in 'real' world along gender, ethnic and class divides.

The reproduction and arguably reinforcement of male-dominance in the digital world is particularly apparent when the use of the cyberspace in the objectification and commodification of women's bodies is concerned. Donna Hughes (I999a, I999b, 2000a, 2000b, 2003) has written extensively on the topic, especially focusing on online prostitution, as part of her general scholarship and activism in addressing violence against women and children in the age of intensified globalization. Using a social psychological perspective, Fisher and Barak (200I) offer an analysis of the causes and impact of experiences with Internet sexually explicit materials.

\section{United Colour of Eroticism in a Time-space Compressed World}

Globalization, as signified by an increased connectivity among societies and their elements, and the explosive evolution of transport and communication technologies that facilitate international cultural and economic exchange, has revolutionalized the sex industry. While sexual exploitation and the trafficking of women and children have existed since time memorial, new technologies have escalated the trade in both virtual and physical forms. In addition to the speeding up of the commercial transactions, globalizing forces have also introduced qualitative changes in these processes. In his analysis of the impact of globalization in recent eras, geographer David Harvey (I993) has brought forth the concept of 'time space compression', as characterized by an erosion of place into space, creating, often, a postmodern condition of 'universal placelessness'. He observes:

'Spaces of very different worlds seem to collapse upon each other, much as the world's commodities are assembled in the supermarket and all manner of sub-cultures get juxtaposed in the contemporary city. Disruptive spatiality triumphs over the 
coherence of perspective and narrative in postmodern fiction, in exactly the same way that imported beers coexist with local brews, local employment collapses under the weight of foreign competition, and all the divergent spaces of the world are assembled nightly as a collage of images upon the television screen.' (Harvey, I993: 32)

Indeed, in exactly the same way as other consumer products, women of different skin colours, ethnicities, ages, sizes, body shapes, personalities and 'styles of performance' are displayed in catalogues, also on Internet pages, in the time-space compressed world. Whether consumers are seeking virtual pleasure or real-life excitement, they are offered a choice - of 'Noble Savages' and 'Sable Queens' of Africa, 'Tahitian Beauties' or 'Oriental Temptresses' - comparable to the wide range of foods and drinks available on an international buffet table. As a matter of fact, as Kemadoo (I996: 76) aptly concludes, the 'sex industries today depend upon the eroticization of the ethnic and cultural "other"'. Fuelled by the explosion of global exchange of people, products and images, consumers seeking sexual pleasure can opt to 'go ethnic' to satisfy their globalized fantasies. Just as we would say 'Let's have Chinese tonight!' for dinner, the sex industries run wild in the borderless capitalist sex market. The World Sex Archives page claims that its members are 'seasoned travelers who have been around the world experiencing the finest pussy on the planet" (http://www.worldsexarchives.com/ demo/, retrieved 28 November 2007).

The at-the-fingertip availability of women of a cultural diversity is now commonplace also in physical form, especially in cosmopolitan cities worldwide. On his sex tour of Hong Kong, JustJoe came into contact with 'poor Chinese women', 'Filipino maids', 'Thai girls', 'China girl' and 'Hong Kong girl'. He shares his 'scientifically-proven' philosophy about having sexual contact with women of different cultural backgrounds with the Web readers (http://hongkong.worldsexarchives.com/, retrieved 28 November 2007):

'But what's the reason that we globetrot all over the world, and find women of other cultures (especially Asian) so delicious to fuck and compelling and addictive? Well, there might be a clue in something called a genetic diversification strategy.... Maybe we're driven by (it) to foreign countries to fuck their women, not only because it's fun, but also because we're fulfilling some drive that much deeper. So maybe we're not driven by only what's in our jeans, but what's in our genes.' (JustJoe, 2007) 
In addition to cultural diversity, women of differing body features, personalities and levels of sophistication are made available. In advertizing its escort and massage service in Hong Kong, the Executive Services agent writes (http://www.hongkong-nightlife.com/, retrieved 28 November 2007):

'... short or tall, slim or plump, Chinese or perhaps another Asian nationality or Western, someone quiet or a conversationalist, someone suave enough to accompany you to a top class restaurant or a business function yet laugh with you at a joke etc. It's your call.'

In the progressively globalized economy, women are increasingly perceived as commodities, like world music or ethnic cuisines, to be ordered and consumed anywhere and anytime. Marketing strategies anchor on sexist and racist stereotypes. 'Non-Western' women are often considered to be more satisfying compared to their 'Western' counterparts (http://www.worldsexarchives.com/demo/, retrieved I4 October 2004):

'But there are many places in the world where women will treat you like a king for a minor fraction of what your Western girlfriend costs. Any woman living outside of the Western world knows that if she treats her man poorly he will walk down the street and have her replaced in less than I5 minutes. Accordingly, when you tell your non-Western girlfriend to start sucking she knows she better do a real good job! This website is about finding those types of women.'

Women of diverse qualities are made increasingly available in and via the cyber network. In this realm of business, international women's bodies and sexual satisfaction are removed from human relationships, commitments and morality, and converted into gross consumables. In the following, a closer look at the different forms of trading methods in women and children's bodies in the globalized, time-space compressed world economy will be provided.

\section{Sexual Enjoyment at Your Fingertips}

In the last few decades, the global sex industry has adopted aggressively the increasingly affordable air transport and telecommunication technologies to remove spatial barriers, expand businesses and increase profit. The sector is among the top five groups buying state-of-the-art 
computer equipment (The Guardian I998, cited in Hughes 2000). Sex industry businesses were, for instance, the first to buy and use expensive $\mathrm{T}_{3}$ phone lines that transmit compressed, high-resolution images (Chicago Sun Times 1997, cited in Hughes 2000). In a time-space compressed world, speedy transportation methods and telecommunication technologies like the Internet have worked to accelerate the pace of economic process and made the world a smaller place by connecting disparate markets together into a world market with global producers and global consumers. The Internet technology and high-speed transmissions allow a diversification of modes in delivering information, news and entertainment, including e-mail, forums online, file transfer protocol (ftp), the World Wide Web, chatrooms, newsgroups, peer-to-peer (P2P) file sharing, video conferencing and WebTV. Some prostitution websites are more or less electronic versions of yellow pages or advertising tabloids used conventionally by the sex industry. In other cases, there has been more creativity involved. The rapid rise in the speed, capacity (e.g. bandwidth), wired and wireless coverage of the communication and information technologies and their increasing affordability enable prostitution and related activities (such as online strip shows, sex performances, and commercial voyeurism) to be marketed and sold at light-speed, reaching far to practically any phone jack or mobile phone with $3 \mathrm{G}$ technology.

The first Web-based prostitution business, A Personal Touch Services, from Seattle, Washington, USA, appeared in I994, the very same year that Netscape initiated the World Wide Web (Hughes 2003). Popular pornographic publications rapidly moved to the Web. Playboy managed to make its first e-appearance already in I994, and was specially designed to appeal to a younger and wealthier audience. Ever since then such e-sex businesses have mushroomed in cyberspace, enabling Internet users easily to buy, sell and exchange millions of images and videos of the sexual exploitation of, predominantly, women and children. Research institute TopTenREVIEWS reports that there are 4.2 million (I2 per cent of total websites) pornographic websites - a boom from approximately 88,000 in 2000 (Websense 2004) - hosting 420 million pages. About 25 per cent of total search engine requests (i.e. daily 68 million), 35 per cent of all downloads (i.e. monthly I.5 billion) and 8 per cent of all emails (i.e. daily 2.5 billion) are pornographic in nature. Internet pornographic sales reach US\$4.9 billion (Ropelato 2007).

This rapid increase in pornographic sites viewers is not only demand-driven. To a large extent, it is also a result of the increasingly aggressive tactics pornography companies have adopted to capture and keep clients, from hacking into existing mainstream sites to stopping surfers from leaving their sites. These include methods such as pur- 
chasing expired domain names for innocent-sounding websites and use them to redirect Web surfers unknowingly to their own X-rated sites and 'mousetrapping', which redirects surfers automatically to another website when they attempt to leave a pornographic site.

While pornography has saturated the Web for years, online prostitution has only soared in the last decade, according to law enforcement and Internet authorities. With high resolution and high-speed transmission, as well as new gadgets like webcams, pornographic site users can interact with service providers in a real-time manner. Immediately after the availability of live videoconferencing in 1995, pimps adopted this new technology for online prostitution through live person-to-person video and audio transmission. By late 1995, live strip performances and sex shows were delivered to buyers over the Internet via this means (Rose 1997, cited in Hughes 2003). With either the keyboard or telephone, consumers could communicate with the performers in the pornographic show across distance and make requests for what they wanted them to do. ${ }^{2}$ In 2002, all large sex industry subscription websites included live video chat, live strip and sex shows.

While varying in technical details, this plethora of technological developments has engendered a new spatiality in the operation of the sex industries. Sexual predators and pimps consume and deal, exploit and harm women and children quickly and anonymously, and even in the privacy of their homes and at work, rather than requiring them to expose themselves in pornographic stores or theatres, while images and descriptions of the service providers are being displayed and discussed more and more publicly.

Virtual sex might give an impression that the women would be better protected from abuse due to the physical distance between users and service providers. In fact, researchers have revealed that abuse in the cyber sex space is common. In an e-mail a sex worker writes, '... it's pretty bad working at [an] adult [web]site... the abuse is way beyond what goes on at strip clubs...' (Hughes 2003: II5). While technically a sex worker can click away their clients when interactions are abusive and unpleasant, it is seldom performed because of the need to earn and the control of supervisors (Döring 2000). The Internet also enables abuse to take place without the victims' knowing. Some women may not realize that their photographs and videos (sometimes taken without the women's knowledge or consent) are posted and sold on pornographic websites. Descriptions and discussions about their appearance, bodies and 'performance' in the world wide forum, which by the way is dominated by male users, intensify humiliation and trauma involved in the sex business, which has always been marked by immense power difference between consumers and service providers. These hundreds of publicly accessible chatrooms and websites provide 
a space for pornographic consumers to normalize and legitimize their abusive hobby, and reinforce their attitudes with their peers, creating a support community. Hughes (2003) expresses her worry that the accessibility of such material would lead men and boys to search for increasingly violent and extreme pornography, and travel to places where they can exploit and abuse women and children without likelihood of arrest. In a similar vein, the United Nations Children's Fund has also underlined their concern that, 'Digital technology, with its obvious attractions for children, often facilitates recruitment of kids into these practices. It can also be seen as a safer form of prostitution' (The Manila Times 2005).

Detailed information about the development of Web sex trade on China mainland is not easy to find. Nevertheless, journalistic reports and governmental officials have brought forth the observable growth in both the sex industry and Internet use. Prostitution has been on a rise in China in recent years, as a result of the macro restructuring of the economy (BBC News 2000; Lin 2004). The World Health Organization estimates that 6 million Mainland Chinese woman engage in sex work (Lin 2004). As Internet usage increases at rocket-speed in China, it is not surprising to find that online prostitution is also making a surge (Li 2004). In June 2007, China had I62 million Internet users, representing a penetration rate of 12.3 per cent (Xinhua 2007a). As in 2007 , more than 70 percent of these Internet users were under 30 years old, and 58.3 per cent of them were male. ${ }^{3}$ The two largest age groups for users were eighteen to 24 , with 35.2 per cent, and 25 to 30 , with I9.7 per cent. According to official statistics from June 2007, 46 per cent of the Web users younger than eighteen admitted to have visited pornographic sites. The Ministry of Public Security further claims that 80 per cent of the juvenile delinquents have been negatively influenced by violence and pornography on the Internet (Shanghai Daily 2007). A survey conducted in Hong Kong also illustrates the prevalence of pornographic sites among teenagers. Among 786 who participated in the survey, 35 per cent of them indicated a habit of browsing pornographic websites and 30 per cent of them admitted that they had attempted to follow the behaviour shown in these materials (Hong Kong Daily News 2007).

The rapid rise in Internet use has also accompanied an increase in online pornographic content, together with other 'harmful' elements as perceived by the Chinese authority including gambling, violence and information that could 'endanger state security, leak state secrets, overthrow the government and spoil unity', 'damage state honour and interests, include national hatred, discrimination', 'violate state religion policies and promote cults', 'spread rumours, [and] disturb the social order'. The authority reports that most of the pornographic Web 
materials accessed by Mainland Chinese users are loaded onto small websites, chatrooms, point-to-point websites and Internet content providers targeting mobile phones, and that more than 90 per cent of obscene movies and images come from overseas websites (Zhuang 2007). A New York Times journalist found these two Chinese sites after a quick search (Barboza 2006):

A pornographic website asks people to pay \$2 a month to download sex videos and chat with other online customers in the nude.

A website advertises the sale of gamma hydroxybutyrate, a drug that acts as a relaxant and is thought to reduce inhibitions. Sometimes called a 'date rape' drug, it is sold on the Web in China with instructions about how to use it to assault women.

In November 2006 the police cracked the largest pornographic website in China. Operated using overseas-based servers, the website contained 9 million pornographic images and articles and had more than 600,000 registered users within one year after operation. The operation first caught the attention of the authority when an Internet surfer was redirected to the homepage while trying to access a site run by a local hospital in Taiyuan. The creator was sentenced to life imprisonment (Li 2006; Li 2007). In a campaign against Web crime launched in April 2007, ten responsible authorities closed down 4,800 pornographic sites or channels and deleted 90,000 pieces of pornographic information. The police also received I,I70 cases involving online pornography for investigation and solved 244 of them, and detained more than 270 individuals (Zhuang 2007). In August 2007, the authority identified, in one week, 348 domestic websites that posted and distributed pornographic novels and pictures and eight of them (e.g. 5I7z.com, xs4.xggirl.com, book.maobob.com) were ordered to shut down permanently (Liu 2007). A similar 'successful' operation was also found and shut down in Taiwan in 2006 . Within one year the website was able to attract Io8,000 members, generating handsome revenue of Io million Taiwan dollars (Chen 2006).

The most common usage of the Internet in 'real life' sex trade is in advertizing. In April 2007, the Hong Kong police succeeded in cracking down a triad-controlled operation that had been selling sex service offered by undocumented Mainland Chinese women who could be earning as little as HK\$9o per transaction, advertized through the Internet (Nil 2004; Sing Tao Daily 2007). Hosting an Internet directory (e.g. sexi4I, Besti6I, sextvb etc.) proves to be a lucrative business. According to the Hong Kong police estimation, such Web directory generates a monthly-revenue ranging from half to one million Hong Kong 
dollars, by charging sex workers up to $\mathrm{HK} \$ 4,000$ for an advertisement (The Sun 2007) - due to intensified competition, the average monthly advertisement has dropped to about HK\$500 to HK\$I,ooo (Apple Daily 2007).

In addition to their function in marketing sex-related services, computer technologies are also used by pimps to conduct surveillance of their business operations. Pimps install webcams in different 'branches' of their businesses to transmit live images for monitoring women and police crackdowns from remote locations. These 'branches' could be anything from a room in a brothel to practically any location with an Internet connection. In 2004, the Hong Kong Police arrested the operators of a 'pornographic kingdom' of over 20 brothels in different parts of the city, which were monitored and watched in Tsim Sha Tsui District using webcams (Mingpao 2004). According to some sex workers, the surveillance of them at work deepens the humiliating nature of their work. Not only are the women being watched when the transactions take place: video-taping also allows the storage, editing and processing of the images for advertisement purpose or sales.

\section{Sun, Surf, Sand and Sex}

Aided by the increasingly affordability of international travel, sex tourism has also flourished in the last few decades. Exotic women in luring natural landscapes (sun and fun on paradise islands) have become easily-found commodities on the Internet. Web advertisements for prostitution tourism were first found in I995. Calling himself PIMPS ' $R$ ' US, Munn from New York City, offered four-day-and-three-night trips to a 'wonderful setting' which includes 'many female prostitutes' in the Dominican Republic and Nevada, USA (Hughes 2003). Globalization of the service followed quickly. Sex tours to Asia, Europe and South America can be found in abundance, offering 'Tropical Paradise Vacations' for 'single men'. ${ }^{4}$ Common destinations for sex tourists include Brazil, Thailand, Cambodia, Costa Rica, Cuba, Russia, Hungary and the Czech Republic. As China becomes more connected with the global economy and general tourism in the country gains popularity among international tourists, sex tourism has also expanded (Li 2002). A quick search on the Desterhorn homepage (http://www.dexterhorn. com/country/asia/china.htm\#overview, retrieved 28 November 2007) shows that Hainan, Beijing, Guangzhou, Hong Kong and Macau are considered hotspots for sex hunters. As sex tourism constitutes the major source of the government revenue of Hainan Province, the local government has implemented a number of policies to boost the industry, including condoning prostitution and gambling. There have also 
been anecdotes that the police in Sanya take part in the sex industry by 'rounding up girls and tak(ing) them out to the big yachts filled with Hong Kong tourists out in the harbour' (posted by 'karenb' on the Chinadaily forum on I7 October 03). ${ }^{5}$ Due to the proliferation of the tourism industry, women from different parts of China have made their way to Hainan, which has gained the reputation as the "paradise for sexcursion'. The Dextorhorn tourist guide writes with enthusiasm:

'Men go to Hainan for the following reasons: A variety of girls with the lowest price in China. No harassment by cops. [sic] or inspectors. Lodgings are cheap; how about a 3-4 star hotel for \$20-\$40. Fresh air, un-polluted seashores and delicious seafood...What are you waiting for?'

As downward competition for wages is commonly observed in manufacturing industries in the Third World, sex tourists are also enjoying cheaper and cheaper service as they survey around the world. The tourist guide reports further the competitive advantage of Chinese sex workers, drawing upon his international sex travel experiences:

'Another specialty is the local sauna bath. You pick up the girls in the lounge and go to the room with a big air curtain. The girls do the massage with their boobs exclusively. You may have tried this in Thailand, but in China, it's a different story. The price for a boob massage is \$I2. If you wanna have sex afterwards it will cost another \$I2 for the girl and no extra tips.'

The enticing descriptions serve to persuade viewers to click on one of the hyperlinks and book a tour any time, from anywhere. Just by clicking a few icons, with a credit card in the hand, interested sex tourists can arrange everything from air ticket to hotel, food and sex, and at a 'good price' before they leave their computer desk.

\section{Brides per E-mail Order}

While arguably of a different nature than that of online prostitution, the business of mail-order brides can be considered as a blatant form of trade in women's bodies. Feminists generally consider the business as a form of women trafficking, through which men from wealthier countries can obtain women from impoverished places. On the other hand, some argue that the arrangement can offer women an avenue for a better and more secured life elsewhere. 
The mail-order bride business is by no means a new business. Chinese women, for example, have been bought and sold in an organized manner - as brides, maids and prostitutes - ever since the mid nineteenth century following the Opium War (Jaschock \& Miers I994; Kani I990; Tong I994). Internet technology, however, enables the agencies to update their catalogues with multi-media stimulations quickly and easily. Just by typing in the keywords 'Chinese' and 'brides' or 'Chinese' and 'women', one finds pages of hyperlinks to dating services and marriage agencies (e.g. China Bride, Chinese Kisses, Chinese Brides, Chnlove.com). Those interested can browse the catalogue, establish contact with the women advertized or subscribe to e-mail newsletters to receive update profiles regularly. Some services claim that they update their selection of women twice weekly.

Just as the prostitution business, arguably even more so, the mail-order bride terrain is highly ethnicized. International agencies are specialized in providing wives from different geographical regions. Introduction services promise to hunt 'loving and devoted' women who are 'traditional', 'submissive and docile', 'faithful', 'value home and family', 'please rather than compete' and, very importantly, are 'feminine rather (than) feminist'. Women from all ethnic and racial backgrounds are flattened into mere stereotypes. 'Non-western' women, especially Asian women, are generally considered superior to 'Western' (i.e. North American and West European) ones as wives. On the NoMarriage.com webpage, the webmaster provides an analysis explaining why 'Chinese women make much better wives than American women’ (http://www. nomarriage.com/x/chinesebride.html, retrieved 27 November 2007):

'An American woman has several fundamental problems that will never go away and that will get much worse a few years after she is married:

I. Her inherent anti-male bias and pre-occupation with fairness that was drilled into her at high school, college, and through the media. Her constant confrontations and trying to prove herself and to make a point;

2. Her self-centeredness, her ridiculously high expectations, her sense of entitlement, her high-maintenance, superficial, and stuck up attitude, her snootiness and her sense of superiority. This "princess" syndrome means that she will always think that she is better than you, and that she deserves and she is entitled to whatever she wants from you;

3. Her general mental instability and psychological disorders;

4. Her using sex as a weapon and reward to get things.

Chinese women generally don't have any of these problems. Marrying an American woman simply does not make sense. 
The ONLY reason men stay with American women is because they did not have enough exposure to Chinese women. Any man who spent a few months in Asia will not even look at American women again.'

In addition to ethnicity, women's age, height, weight, and bust, waist and hip measurements, religion, education level, occupation and hobbies are typically listed alongside their photos on the Web. Intriguing is the value placed on Web-virginity. On the China Bride webpage, one finds a link to 'Chinese FIRST TIME Gallery (Be her first!)' where men find women who are available for the first time (http://www.chinabride.com/gen/cwomen.html, retrieved 27 November 2007):

'These Chinese ladies have joined within the past 60 days and have not had their addresses sold yet (as of this date). So if you don't like competition from other men, order addresses of these ladies [sic] right away. Then you will be the first to get all of her attention. Once her address is sold for the 'First Time' she will be removed from this page. In addition to these ladies there are a total of over 3,000 for you to choose from.'

The involvement of women from different ethnic and geographical backgrounds is closely related to the political-economic conditions of their mother countries. Traffickers, pimps and mail-order bride agencies have tapped into the Eastern European market in the last decade and have taken advantage of the political turmoil, economic crisis, poverty and high unemployment in the region after the collapse of the Soviet Union. Another source of a large number of mail-order brides is the Philippines, where a lot of women (and men as well) are eager to find a way out of their country to escape from the hopeless economic situation.

The rise in Chinese women's presence in the mail-order bride world, and other forms of trafficking, is directly related to the intensification of the Chinese relationship with the global political economy (Xin 2004). In fact, China has become one of the major sources of international trafficking victims, alongside Burma, Laos and Cambodia (US Embassy, Japan 2003). Official figures showed that the police freed more than 42,000 kidnapped women and children in China in 200I and 2002. Many of the victims are believed to have been sold into marriage or prostitution, either domestically or internationally (McCurry \& Allison 2004). As overseas travelling is increasingly feasible for Chinese citizens and as the socio-economic inequality in the country worsens, it is not far-fetched to expect that the trafficking of Chinese women will exacerbate. 
The way in which women are presented in the mail-order catalogues represents only the beginning of the abuse experienced in these women's lives. Citing examples of wife abuse, Anderson (I993) underlines the problem of the conditional residency status commonly given to foreign spouses in many countries, as it sometimes serves as license for mistreatment in the private sphere of the household. The growing problem of mail-order bride abuse attracted attention when a man murdered his Russian wife in Seattle in 2000 . Common and serious cases of abuse have also been reported among foreign women - predominantly Chinese, Vietnamese and Filipinas - who have married rural South Korean men in recent years. Most of these are arranged to marry men much older than they are by marriage brokers (claim-to-be) of international religious groups. These brides are expected to serve as wives and workers on farms. In addition, these foreign wives are expected to care for the parents-in-law and bear children for the men. Poverty and violence has been widely reported (Chung 2005). Cases in which the marriage fails, the women can hardly find help, as domestic abuse is considered a private problem. Even if they manage to escape their marriages, they would have no rights to their children under South Korean legislation (Personal communication with personnel of a migrant service NGO in Manila, January 2005).

\section{$7 \quad$ Cyberspace $=$ Evil?}

Legitimately, activists and scholars have emphasized the exploitative and abusive nature of Web pornography, online prostitution and, to a lesser extent, mail-order bride businesses. One ought not, however, repeat the obsolete stereotypes that women are submissive, helpless, long-suffering and passive victims of family interests. To different degrees, women of different historical periods have been aware and have tried to resist suppression.

Before looking at how women challenge and at least attempt to change patriarchal subordination in the cyber age, it is necessary to examine cyberspace as a space of opportunity for sex workers to make a, possibly, better living. Some sex workers have moved to use the Internet, rather than the traditional street corner, to advertize their services. They post pictures and descriptions of themselves, describe the kinds of sexual activities they will perform and post rates and even contact numbers and e-mail addresses. 'It's convenient, accessible and discreet,' said a semi-retired prostitute and sex-workers' rights activist in San Francisco. '[Online prostitution is] getting bigger and bigger as the Internet gets bigger.' (Bahari 2004) Sex workers' usage of the Internet in advertizing their business has also been reported in Hong Kong 
since Internet became popular in 2000 (The Sun 2007). ${ }^{6}$ By the same token, some women perceive opportunities - such as working as domestic workers, entertainers or even sex workers overseas (BBC News 200I; Jiudan 200I $)^{7}$, or being mail-order brides - as ways out of their unsatisfying situations at home (Constable 2003).

Turning to the other side of the issue, individuals and communities opposed to the sex industry have also made use of cyberspace to disseminate information, communicate and organize efforts - though they have not been as aggressive as the global sex industry in making use of the technological revolution. The episode of a two-day orgy held by 400 tourists from Tokyo with 500 Chinese prostitutes on the eve of the anniversary of the Imperial Army's invasion of Manchuria (in I93I) provides an interesting case in point. The uncovering of the story ignited an inflammatory debate on the Internet. A million people signed an online petition urging the Chinese government not to offer a contract to a Japanese rail company to build the Shanghai-to-Beijing highspeed rail link. Heated debates were found on the Web, where chatroom participants exchanged reactions about the 'Japanese devils' wanting to celebrate their country's wartime behaviour' and that 'The Japanese are animals. They deliberately selected the date to humiliate the Chinese people,' claiming that the tourists had attempted to raise their national flag at the hotel (Watts 2003). While this example represents a rather sensational reaction to a one-off event, a number of (mainly women's) networks have been formed to work to challenge the trafficking of women, making use of cyberspace on a more regular basis. The Coalition Against Trafficking in Women, for example, has made use of the net to promote discussion and strategies for achieving the coalition's aims. More general networks working for improvements in labour rights, such as the China Labour Bulletin, have also been active in cyberspace.

\section{Strategies against E-sex}

As the technological revolution pushes forward at full speed in the Internet-based sex industry, strategies of various forms have been carried out to counteract the problem:

\subsection{Techno-fix}

The most commonly-adopted approach to patrolling and stopping the usage of the Internet to promote the sex trade is the installation of filters and other scanning software. It is well known that the Chinese government screens e-mail, censors online chatrooms and blocks access to for- 
eign websites that are considered subversive. Critics have dubbed the filtering mechanisms imposed by the Chinese authority as the 'Great Firewall of China'. Among the I,০oo plus taboo terms are 'sex', 'prostitution', 'democracy', 'human rights', 'oppose corruption', 'Taiwan independence' and the name of the president 'Hu Jintao'. An analysis of the list estimated that I5 per cent of the forbidden terms are sexual while the rest are politically sensitive expressions (Hutzler 2004).

Techno-fix strategies have also been adopted by private companies, as surfing pornographic websites has become a problem at workplace all over the world. Web filtering software is available for IT managers to block access to questionable Internet categories, such as pornography, adult, and tasteless material. Similar screens are also available for home computer users to prevent children from accessing problematic websites. While these tactics can be installed relatively easily, there exists a dilemma between freedom of expression and the control of 'unethical' information in the media. Arguably, such control devices can be implemented without great problems in China where freedom of expression has always been restrained.

\subsection{Regulatory-fix}

Internet is the most unregulated communication network in today's world, presenting immense challenges to national and international regulation and enforcement. Legislation controlling the usage of the Internet is still very immature in the global community. Nevertheless, many governments have set up regulations and conducted crackdown campaigns against unlawful activities conducted via the Internet. Since I994, the Chinese government has issued a series of regulations to restrict the 'proper' monitor usage of the Internet and tens of thousands of Internet police are dedicated to the responsibility of enforcing their provisions. The Chinese authority has also set up a website (http://net. china.cn, 'China Internet Illegal Information Reporting Centre') for Internet users to file complaints about particular websites in 2004. Internet providers, websites and related organizations are being urged to sign a 'self-discipline' agreement (Chan 2004). Since April 2007, one female and one male 'virtual' police officer 'monitors' the cyberspace on motorcycles, in a car or on foot, at the bottom of users' computer screens every 30 minutes. These icons offer easy links for computer users to report illegal activities and 'harmful' information to the police (Wu 2007). Within three weeks of operation, the police had received more than I3,000 reports from Internet users, about one-third of which were about pornographic websites (Xinhua 2007b).

Effective legislation is difficult. A recent report commissioned by the United Nations Children's Fund 'Child Pornography in the Philippines' 
also underlines the concern that new technology such as the Internet has taken pornography to a new level that is much more difficult to detect (The Manila Times 2005), especially because the Web transcends national borders. While child pornography has attracted much legislative attention and is banned in an increasingly number of countries, usage of the Web for adult trafficking or mail-order brides for sexual exploitation has been less challenged, or controlled less effectively (Council of Europe 2003). The Filipino government, for example, has officially prohibited the operation of sex tours and mail-order bride agencies since I990. Due to the footloose nature of Web-based business, however, the legislation has been ineffective. A mail-order bride pimp had no qualms in announcing that he would simply move his computer to the USA and have his Filipina wife make contact and recruit women and adolescent girls in the Philippines. Official data have also shown that the trafficking of women and girls from the Philippines continues to rise despite the enactment of the law by the government (Hughes 2003).

The development of online prostitution cannot be understood in isolation from other socio-cultural and political-economic forces. In China, structural economic transition to market economy, marked by the closing down or down-sizing of state-run businesses, has created a high level of unemployment. Jobless women and even men, especially those from the rural areas, are compelled to enter the sex trade, which is booming in cities like Shanghai, Beijing and Shenzhen (Isis International Manila 2003).

Other policies that have direct impact on the gender subordination in society are also important. The Chinese one-child policy provides a good example. After 25 years of the implementation of the policy, men outnumber women significantly in certain geographic areas. This has created a high demand for brides in these regions. Traffickers meet the demand of the 'excess' men by trafficking women from poorer regions of China or from other countries. Recently, Li, the advisor to China's Political Consultative Conference on population issues, highlighted the negative impact of the one-child policy on the healthy, harmonious and sustainable growth of the Chinese population. He predicted that the serious gender disproportion would also trigger crimes and social problems such as the abduction of women and prostitution (McCurry \& Allison 2004). This disturbing warning illustrates the interrelatedness of seemingly unrelated socio-economic and political processes in the development of the trade of female bodies. As a matter of fact, all legislation that relates to gender relations and workers' benefits would affect the sustainability and development of this industry, both within national borders and internationally. 


\subsection{Mentality-fix}

Previous efforts in controlling sexual exploitation and gender discrimination with technological or legislative methods (e.g. the cases of the Filipino state effort in curtailing trafficking of women or the Chinese effort in controlling abortion of female foetuses) have shown ineffectiveness. Only fundamental changes in the mindset of the global society can eliminate the trade in female bodies, either using the Internet or conventional means. This kind of social change demands a reappraisal of practically all spheres of society, backed by a fundamental correction of old-fashioned gender-biased thinking and domination. Political changes needed range from the guarantee of equal rights to education and health care to girls, to fair access to dignifying employment and reasonable compensation and respect for biological and social reproductive work. ${ }^{8}$

\section{Conclusion}

There is no age.

No age

There are no infirmities

There are only minds

Only minds

Utopia?

No

The Internet

Where minds, doors, and lives open up

Is this a great time or what?

The above transcript originates from 'Anthem', the eye-catching MCI television advertisement from the mid-I990s in the US. The short television clip offers a simple path to a utopic future. With this advertisement clip in mind, I began my investigation into the proclaimed 'racelessness' and 'genderlessness' of cyberspace, specifically looking at the nature and role of the portion cyberspace in which women's bodies are being created, manipulated, commodified and abused. My observations echo what Wajcman (I99I) emphasizes in her critique on the nature of technology, namely technology is created and ideologically shaped by gender (and class, race etc.) power difference and interests, and serve consequently to reinforce existing structure of power and authority.

New technologies have provided the sex industry new means of exploiting, marketing, and delivering women and children as commodities to buyers in the globalized economy. Internet technologies allow 
the entrance and expansion of lucrative pornographic businesses with relatively little investment. As women and children are being displayed, discussed and traded more and more in all time-space, consumers of such services can satisfy their wild-running globalized sexual fantasies anonymously in the comfort and security of their home. The Coalition Against Trafficking in Women (I998) considers that 'many of the practices of trafficking and prostitution on the Internet are characterized by domination, control, and violence so extreme as to constitute slavery, serious violation of human rights, and forms of sex discrimination'. This provides a good illustration that there is nothing intrinsically liberating about the Internet revolution. The cyberspace is highly gendered and works to deepen many exploitative relationships that have always existed in the non-cyber world. It would be fair to conclude that the IT revolution in the sex industry has mostly exacerbated the gender power difference in the sector. As the technology of cyberspace, like any other technology, can be used for good and evil, oppression or resistance, I argue that it is more productive to contextualize its utilization, both proper and improper, in our society, taking into account the underlying forces which work interactively to divide social and economic opportunities among individuals and social groups.

More importantly, we should focus on the macro conditions that shape the commodification of women's and children's bodies. In the contemporary era of globalization, one witnesses more and more women being pushed away from their traditional formal employment and placed into unorganized and informal sectors of industry. Many of these displaced women find themselves in situations where selling their bodies - locally or in other parts of the country, or the world - appears to be the one of the better economic solutions available. In the Philippines and Thailand, many sex workers come from extreme poverty to work in foreign-owned bars that cater to foreign military men and tourists. As its economy opens up, China has also witnessed a share of this problem. Do you recall JustJoe from the beginning quote? He writes with thankfulness, 'for [the sex] hobbyists, the torrential influx of poor Chinese women into the prostitution workforce [in Hong Kong] has increased the likelihood of finding good sexual services at reasonable prices.' One could argue that the proliferation of the sex industry in China is one of the social costs of the rapid economic growth of recent years. Illustrations of the impact of the Internet technologies on male domination, exploitation and abuse of women and children in sex-related industries in this chapter suggest that the problem is likely to worsen in China, when income inequality exacerbates, and the acceptance of gender bias and female body trading are left unchallenged. 


\section{Notes}

I. Borrowing Hughes' (2000a) definition, the sex industry here is defined as the collection of legal and illegal, single and multi-party operations that profit from the selling of women and children through trafficking, organized prostitution and/or pornography. Although there is sexual exploitation of men in mainly gay pornography and prostitution, this chapter will focus exclusively on the sexual exploitation of women.

2. In I999, live video chat for online prostitution attracted much world attention when an American man announced that he was opening a live 'rape camp' online (www.rapecamp.com). Customers could pay for and watch acts of rape and torture perpetrated against Asian women in Phnom Penh (Hughes 2003).

3. There has been a rapid feminization of Internet usage since the popularization of the technology in China as women accounted for only I2.3 per cent of all users in 1997 (Bu 2003: 5).

4. While sex tourists are mostly male customers, female customers also travel to locations like Bali, Indonesia to seek sexual pleasure with young men and sometimes boys.

5. The problem of corruption is not only found in sex-tourist spots. Cooperation between police and the sex industry is commonly found all over China (Lin 2004).

6. The level of economic exploitation, especially of those who have entered Hong Kong illegally or as tourists, should however not be underestimated, as discussed previously in the chapter.

7. The publication of Jiudan's (200I) novel Wuyan about the stories of Chinese-born students going to Singapore to make money by becoming prostitutes, hostesses or mistresses caused much controversy in the Singaporean Chinese community.

8. In China, more than 220 million people are illiterate or literate at a socially dysfunctional level. Among them, more than half are women in rural areas. Chinese officials reported that in I989, among seven million children who dropped out of school, 80 per cent were girls in rural areas (Xin 2004).

\section{References}

Anderson, M. (I993), 'A license to abuse: the impact of conditional status on female immigrants', The Yale Law Journal Io2 (6): I40I-I430.

Apple Daily (2007), 'Seqingwang yueru guanggaofei shushiwan', I2 April. Aıo.

Bahari, S. (2004), 'Online prostitution a problem on the Web', Centre Daily. 24 August. www.centredaily.com/mld/centredaily/9480735.htm.

Barboza, D. (2006), 'The wild web of China: sex and drugs, not reform', New York Times, 8 March.

BBC News (2000), 'China concerned about rise in prostitution' 29 February. news.bbc.co.uk/ I/hi/world/asia-pacific/6607I9.stm.

BBC News (200I), 'Chinese prostitute book sparks outrage’ 6 August. news.bbc.co.uk/2/hi/ entertainment/I475842.stm.

Bimber, B. (2000), 'Measuring the gender gap on the Internet', Social Science Quarterly 8I (3): $868-876$.

Boneva, B. \& R. Kraut (2002), 'Email, gender, and personal relationships', in B. Wellman \& C. Haythornthwaite (eds.), The Internet in everyday life, 372-403. Malde: Blackwell.

$\mathrm{Bu}, \mathrm{W}$. (2003), 'Study of gender gaps in Internet in China', paper presented at the China and the Internet Conference, Los Angeles. US, 30-31 May 2003.

Castells, M. (I996), The rise of the network society. Cambridge, MA: Blackwell Publishers. 
- (200I), The Internet galaxy: reflections on the Internet, business, and society. Oxford \& New York: Oxford University Press.

Chan, J. (2004), 'China cracks down on Internet cafes and "cyber dissidents"'. 30 June. www.wsws.org/articles/2004/jun2004/chin-j30.shtml.

Chen, J. (2006), 'Seqingwang zhange yinian laiqianwanyuan', United Daily News. 6 October.

Cherny, L. \& E.R. Weise (eds) (1996), Wired women: gender and new realities in cyberspace. Seattle: Seal Press.

Chicago Sun Times (I997) 'X-rated sites pace online industry', 24 June.

Chung, A.J. (2005), 'Respect for cultural diversity key to understanding', The Korean Times. 26 October.

Coalition Against Trafficking in Women (CATW) (1998), 'Misuse of the Internet for the purpose of sexual exploitation: submission to: United Nations Working Group on Contemporary Forms of Slavery'. action.web.ca/home/catw/readingroom.shtml?x=I6286\&AA_EX_Session $=\mathrm{f}_{403} \mathrm{C}_{6}$ 9793bd535e $7 \mathrm{~b}_{34}$ efdab77faf64.

Compaine, B. (ed.) (200I), The digital divide: facing a crisis or creating a myth? Cambridge, Mass.: MIT Press.

Constable, N. (2003), Romance on a global stage: pen pals, virtual ethnography, and 'mail-order' marriages. Berkeley: University of California Press.

Council of Europe (2003), 'Report by group of specialists on the impact of the use of new information technologies on trafficking in human beings for the purpose of sexual exploitation'. Strasbourg: Council of Europe.

Damer, B. (1997), Exploring and building virtual worlds on the Internet. Berkeley: Peachpit Press.

Di Maggio, P., E. Hargittai, W.R. Neuman \& J. Robinson (200I), 'Social implications of the Internet', Annual Review Sociology 27: 307-36.

Döring, N. (2000), 'Feminist views of cybersex: victimization, liberation, and empowerment', CyberPsychology and Behavior 3 (5): 863-884.

Ebo, B. (ed.) (1998), Cyberghetto or cybertopia?: race, class, and gender on the Internet. Westport: Praeger.

Evard, M. (1996), ' “So please stop, thank you': Girls online', in L. Cherny \& E.R. Weise (eds), Wired women: gender and new realities in cyberspace, I88-204. Seattle: Seal Press.

Fisher, W.A. \& A. Barak (200I), 'Internet pornography: a social psychological perspective on Internet sexuality', Journal of Sex Research 38 (4): 312-323.

The Guardian (1998), 'Surfing for sex'. I4 May.

Harcourt, W. (ed.) (I999), Women@internet: creating new cultures in cyberspace. London: Zed Books.

Harvey, D. (1993), The condition of postmodernity: an enquiry into the origins of cultural change. Oxford: Blackwell.

Hawthorne, S. \& R. Klein (eds) (I999), Cyberfeminism: connectivity, critique and creativity. North Melbourne: Spinifex.

Hong Kong Daily News (2007), '35\% zhongxuesheng chenruo seqingwang', I5 July. Aor.

Hughes, D. (I999a), 'The Internet and the global prostitution industry', in S. Hawthorne \& R. Klein (eds), Cyberfeminism: connectivity, critique and creativity, I57-I84. North Melbourne: Spinifex.

- (I999b), 'Pimps and predators on the Internet: globalizing the sexual exploitation of women and children'. Report published by The Coalition Against Trafficking in Women.

- (2000a), 'The Internet and sex industries: partners in global sexual exploitation', IEEE Technology and Society Magazine Spring: 35-42.

- (2000b), "Welcome to the Rape Camp": sexual exploitation and the Internet in Cambodia', Journal of Sexual Aggression 6 (I-2): 29-5I.

— (2003), 'Prostitution online', Journal of Trauma Practice 2 (3/4): II5-I32. 
Hutzler, C. (2004), 'China finds new ways to restrict access to the Internet', The Wall Street Journal, I September. Cited in 'The great firewall of China' http://www.bookofjoe.com/ 2004/09/the_great_firew.html.

Internet World Stats (2007), Internet usage statistics: the Internet big picture - world Internet users and population. www.internetworldstats.com/stats.htm.

Isis International Manila (2003), "Prostitution on the rise in China" Newsletter. January, number 4. www.isiswomen.org/pub/we/archive/msgooiıo.html.

Jaschock, M. \& S. Miers (eds) (I994), Women and Chinese patriarchy: submission, servitude and escape. Hong Kong: Hong Kong University Press.

Jiudan (200I), Wuya. Singapore: Ling zi chuan mei si ren you xian gong si.

Kani, H. (I990), Zhu hua - bei fan mai hai wai de fu nü. Zhengzhou: Henan ren min chu ban she.

Kemadoo, K. (1996), 'Prostitution, marginality, and empowerment: Caribbean women in the sex trade', Beyond Law 5: 69-84.

Kolko, B. (I999), 'Representing bodies in virtual space: the rhetoric of avatar design', The Information Society I5: I77-I86.

Kramarae, C. \& J. Kramer (1995), 'Legal snarls for women in cyberspace', Internet Research: Electronic Networking Applications and Policy 5 (2): 14-24.

Lessig, L. (I999), Code and other laws of cyberspace. New York: Basic Books.

Li, R. (2006), 'Porn webmasters on trial in Shanxi', South China Morning Post. I September. EDT7.

Li, F. (2007), 'Gambling and porn targeted', China Daily Hong Kong Edition. I4 April. Por.

Li, W. (2004), 'QQ sees "cute" biz growth in China', Business Weekly, I3 January. www.chinadaily.com.cn/en/doc/2004-0I/r3/content_29942r.htm.

Li, Y. (2002), 'The impact of tourism in China on local communities', Asian Studies Review $26(4): 47 \mathrm{I}-486$.

Lin, Y. (2004), 'Sex trade dominates debate on Chinese women' Report for Radio Free Asia. II April. bric.rfaweb.org:8080/english/news/social/2005/04/II/china_prostitution/.

Liu, W. (2007), 'Close watch on pornographic websites', China Daily Hong Kong Edition. I4 April. Po3.

The Manila Times (2005), "Study: RP prostitution is $4^{\text {th }}$ largest source of GNP". 6 April. www.manilatimes.net/national/2005/apr/06/yehey/top_stories/20050406top7.html.

McLaren, A. (2007), 'Online intimacy in a Chinese setting', Asian Studies Review 3I (4): 409422 .

McCurry, J. \& R. Alison (2004), '40m bachelors and no women ... the birth of a new problem for China', The Guardian. 9 March.

Mingpao (2004), 'Yanhou luowang jie liangnian zhuan 2600 wan: lirun touzi wuye xihieqian'. 7 October.

Nakamura, L. (200I), 'Race in/for cyberspace: identity tourism and racial passing on the Internet', in D. Trend (ed.), Reading digital culture, 226-235. Malden, Mass. \& Oxford: Blackwell Publishers.

Nil (2004), 'Jiwangwang yuezhuan Liushiwan', Next Magazine. 25 November.

Norris, P. (200I), Digital divide: civic engagement, information poverty, and the Internet worldwide. Cambridge: Cambridge University Press.

Ropelato, J. (2007), Internet pornography statistics. http://internet-filter-review.toptenreviews.com/internet-pornography-statistics.html\#anchor4.

Rose, F. (1997), 'Sex sells: young, ambitious seth warshavsky is the Bob Guccione of the I990s', Wired 5. I7 December.

Shanghai Daily (2007), 'Grubby fumbles give way to porn paradise'. 2 June.

Silver, D. (2000), 'Margins in the wires: looking for race, gender, and sexuality in the Blacksburg Electronic Village', in B. Kolko, L. Nakamura \& G. Rodman (eds), Race in Cpberspace, I33-I5O. London: Routledge. 
Sing Tao Daily (2007), “Shukezhi” fangsao dangju banü liangmafu heibang zujiudian maiyin “yitiaolong”'. I2 April. A22.

Spender, D. (I995), Nattering on the net: women, power, and cyberspace. North Melbourne: Spinifex Press.

The Sun (2007), 'Zhaojiwang guanggao meiyue jingchang baiwan', II June. Ai3.

Sussman, N.M. \& D.H. Tyson (2000), 'Sex and power: gender differences in computermediated interactions', Computers in Human Behaviour I6 (3): 38I-394.

Tong, B. (I994), Unsubmissive women: Chinese prostitutes in nineteenth-century San Francisco. Norman and London: University of Oklahoma Press.

US Embassy, Japan (2003), 'State Dept. links sex tourism, human trafficking in Thailand' japan.usembassy.gov/e/p/tp-200306I7a6.html.

Wajcman, J. (I99I), Feminism confronts technology. University Park: Pennsylvania State University Press.

Warf, B. (200I), 'Segueways into cyberspace: multiple geographies of the digital divide', Environment and Planning B: Planning and Design 28 (1): 3-19.

Waskul, D. (2006), 'Internet sex: the seductive "freedom to"', in S. Seidman, N. Fischer \& C. Meeks (eds), Introducing the new sexuality studies, 262-270. London: Routledge.

Watts, J. (2003), 'Japanese “orgy” claims spark outrage in China', The Guardian. 29 September.

Websense (2004), 'Websense research shows online pornography sites continue strong growth, increasing by over I.5 million since 2000 , as Internet porn vendors pioneer new technology', 5 April. www.websense.com/company/news/pr/Display.php?Release= 040405588

Wu, V. (2007), 'Purge of online criticism ahead of party congress', South China Morning Post. I September. EDT 6.

Xin, R. (2004), 'Violence against women under China's economic modernization: resurgence of women trafficking in China', Australia Institute of Criminology. 2I6.239.4I.IO4/ search?q=cache:FXOs8kphuY8J:www.aic.gov.au/publications/proceedings/27/ren.pdf+chiina+prostitution+problems+government+crackdown\&hl=en\&ie=UTF.

Xinhua (2007a), 'China has I62 mln Internet users', People's Daily Online, I9 July. http:// english.peopledaily.com.cn/9000I/9078I/62I9100.html.

- (2007b), 'Population rallies in war against Internet porn', Shanghai Daily, 4 May.

Zhuang, P. (2007), 'Crackdown aims to wipe out porn databases', South China Morning Post. 28 May. EDT4. 



\title{
12 Boundary-Crossing through Cyberspace
}

\author{
Chinese Women and Transnational Marriages Since 1994
}

\author{
LIU Lihui \& LIU Hong
}

\section{Introduction}

Since 1978 a large number of Chinese women have emigrated from the People's Republic of China (PRC) through transnational marriages, and this phenomenon has attracted enormous media attention in China. Those Chinese women who tie the knot with foreigners have often been portrayed as seekers of financial gain, while other motivations for expatriation have been overlooked. Moreover, stories of misery in host countries have often been underlined, leaving the real situation of most female emigrants unnoticed. By over-estimating women's motives of financial gain through transnational marriage, existing studies seem to have failed to look at women's own strategies and understandings of their marriages.

This chapter puts this conventional wisdom into contestation by studying women's strategies in the process of negotiating new circumstances. It is informed by the new wave of theoretical perspective on transnationalism, which is defined as 'the processes by which immigrants form and sustain multi-stranded social relations that link together their societies of origin and settlement. We call these processes transnationalism to emphasize that many immigrants today build social fields that cross geographic, cultural, and political borders' (Basch, Schiller \& Blanc-Szanton I994: 6; Bryceson \& Vuorela, 2002). As a new field of study concerned with 'a growing number of persons who live dual lives: speaking two languages, having homes in two countries, and making a living through continuous regular contact across national borders' (Portes, Guarnizo \& Landolt I999: 2I7), the transnationalism approach has gained wide scholarly attention over the last decade. Some recent studies have critically applied this approach in research on the Chinese press (the special issue on 'Transnationalism and the Chinese press', China Review, vol. 4, no. I, 2004), Chinese religion, and overseas Chinese nationalism (the special issue on 'Modern Chinese religious transnationalism', European Journal of East Asian Studies, vol. 2, no. 2, 2003; Liu 2006). Nevertheless, while there are some 
studies on changing family patterns within the framework of Chinese cosmopolitanism (e.g., Chan I997; Constable 2003), little attention has been paid to the patterns of transnational marriage forged through the Internet and their role in the making of 'Transnational Chinese' communities (Liu 2002).

This chapter is divided into two parts. The first focuses on the period before the emergence of large-scale transnational marriages, examining multiple reasons for transnational marriage and means contributing to it. Concerning reasons, two sets of factors are considered: the local and global contexts, and the motivations of both Chinese women and their foreign partners. With respect to the means of forging the transnational marriage, the role of cyberspace will be discussed. The second part investigates women's lives after their transnational marriages, challenging the conventional argument that Asian women entering transnational marriages are dependent wives forever.

It is necessary to provide a working definition of 'transnational marriage', which is often used interchangeably with 'international marriage'. Some argue that it involves couples from both different and same backgrounds who participate in international migration (Sinke I995), while Jane Khatib-Chanidi, Rosanna Hill and Renee Paton (I998) conceptualize it as 'cross-cultural, i.e. the women's husbands were born and brought up in different countries from their own'. This chapter defines transnational marriage as 'marriage between a PRC national and a foreign person (including those former PRC citizens who hold foreign passports now and the ethnic Chinese living abroad)', paying particular heed to marriages between Chinese women from the PRC and foreign men. Because of the lack of official statistics involving Chinese transnational marriages, this chapter relies on a wide range of reports published in the newspapers and relevant websites as well as on the authors' interviews with women who entered into transnational marriages through the facilitation of cyberspace. While these data cannot provide us with accurate statistics and demographical details, they are useful for an understanding of the general patterns and characteristics of transnational marriages under discussion.

\section{Chinese Transnational Marriages since 1994: A General Background}

As a result of China's opening-up and subsequent trend of international migration since the early I980s, transnational marriage has surged. About 90 per cent of the marriages are between Chinese women and foreign men. According to a survey conducted by the Shanghai Civil Affairs Bureau and East China Normal University, 38 per cent 
of interviewers in Shanghai admitted that they knew a friend who had been married to a foreigner; the figure for Beijing was 29.4 per cent, and 22.9 per cent for Guangzhou (Beijing Qingnian Bao, ro December 2003). The increase of transnational marriages has been significantly facilitated by the introduction of the Internet in I994.

It should be pointed out that the growing number of transnational marriages is an integral component of the rapidly growing number of new Chinese migrants who have left China (semi-)permanently since the end of the I970s, when China started its reform policies. By the end of 2003, the number of Chinese emigrants from the PRC (excluding Hong Kong, Macao, and Taiwan) is estimated to be more than three million (Liu 2005a). The emigration of Chinese women through transnational marriages occupies a greater proportion of the overall figures for overseas Chinese emigration than ever. It not only remarkably changes the demography of Chinese overseas, but also shows great influence in China. Although there are limited inquiries into other categories of emigration from China since 1978, such as for studying abroad (Cheng 2003), there is even less research on Chinese women involved in transnational marriages and how they can be compared with other types of new migrants.

Elsewhere, Hong Liu (2005a) has categorized new migrants into four types: students-turned-migrants, professionals, chain migrants (those joining their families and relatives who are foreign citizens or permanent residents of foreign countries) and undocumented immigrants. Women entering transnational marriages fall generally into the category of chain migrants, but they are different from traditional chain migrants, who as a rule went overseas to join their relatives connected by kinship, blood ties, or pre-existing marriage.

The so-called 'leaving-country-fever' (chuguo re) since the I980s has continued steadily, although recent years have witnessed a growing returning trend. The formal introduction of the Internet into China in I994 further facilitated this trend. By 2004, the number of the Internet users in China had increased to 87 million (www.chinapop. gov.cn, retrieved 22 July 2004). The online gender gap continues to narrow down rapidly. According to 'Statistical survey report on the Internet development in China' conducted by the China Internet Network Information Center in June 2007, China has had $\mathrm{I}_{2}$ million Internet users, second only to the US (2II million), and the proportion of female Internet users reached 45.I per cent (http://english.peopledaily. com.cn/9000I/9078I/90877/622070I.html, retrieved 22 October 2007). With the help of this technology, more and more women entered into transnational marriages during the last decade.

There is a great degree of diversity in the region of destinations for Chinese women who enter into transnational marriage. In Shanghai, 
40 countries and regions (including Hong Kong, Macao and Taiwan) were on the list of destinations by I999 (Xinhua News Agency, I7 June 2003). As for the main destination countries, before the I990s, the United States, Canada and Australia were the top receiving countries; however, Japan has become the most popular destination country in recent years. Since I99I, the number of transnational marriages between Chinese and Japanese increased at a speed of 40 per cent each year; since I996, China has ranked first on the sending lists. For example, in 2002, there were 10,762 Chinese (9,884 females) marrying Japanese (Huasheng Bao, 7 March 2002).

Although Chinese women involved in transnational marriages may have different backgrounds, they can be generally divided into three types: women with good educations and/or some social status, divorced or widowed women, and less-educated women. The first category includes the earliest group who has entered into transnational marriages during the recent period. Examples include famous actresses such as Wu Junmei and Shi Ke; popular singers such as Su Xiaoming and Wei Wei; musicians such as Zheng Su; sports stars such as He Zhili, Jiao Zhimin and Zhu Chen; and famous writers such as Yan Geling and Zhang Xinxin. As celebrities, they have had more choices for transnational marriage (San 2002). Well-educated women have also been part of this tide. For instance, in Shanghai, from I996 to 2002, 23.8 per cent of brides who married foreigners held at least a diploma, which is higher than the average level of local women aged between 20 and 49 (II.8 per cent) (www.sina.com.cn, retrieved 9 December 2003). In Nanjing, most of the local women marrying foreigners were actresses, physicians, and individuals with undergraduate or postgraduate degrees (Shenghuo Shibao, 29 August 2000).

The second group is made up of divorced or widowed women who may or may not have good educations. Some statistics show this trend: in Guangxi, I8.or per cent of local women entering transnational marriages were re-marrying, compared with the average of 3.37 per cent for the overall number of Mainland marriages. This is more evident in big cities. For example, in Shanghai, 40 per cent of local women marrying foreigners between 1996 and 2002 were remarrying (www.sina.com. cn, retrieved 9 December 2003).

Low-educated women fall into the third category of this tide of transnational marriage. According to a report (Zhongwen Daobao, II September 2003), many Chinese women marrying Japanese were laid-off workers before marriage. In Nantong (Jiangsu province), between 2000 and 2002, 80 per cent of involved women came from rural areas and had low-paying jobs before marriage (Yangzi Wanbao, I7 January 2002). 
With respect to the total number of transnational marriages since I994, there is no exact data available, but statistics from the media and the Chinese government give us some clues. In this chapter, 'mixed' marriage is divided into three categories: mixed marriage between PRC citizens and residents of Hong Kong, Macao and Taiwan; transnational marriage between PRC citizens and citizens of foreign countries; and mixed marriage between PRC citizens and permanent residents of foreign countries who hold Chinese passports. During the last two decades, especially in recent years, there has been rapid growth in the number of mixed marriages. In I982, official sources show that there were I4,I93 Chinese citizens involved in mixed marriages; the figure for I988 grew to more than 20,000; it was 23,762 in 1990 and 50,773 for I997; and since 2001 there have been more than 70,000 cases each year (Huanqiu Shibao, 26 September 2003; www.mca.gov.cn, retrieved 9 May 2004). Based upon various sources, our estimation is that the number of mixed marriages from 1994 to 2005 is at least 500,000 .

Among these mixed marriages, what is the proportion of transnational marriage? Ratios differ in different places. In Shanghai, there were more than 21,000 registered mixed marriages between I996 and 2002. Among the local women's foreign partners, Japanese were ranked first (39.6 per cent), followed by overseas Chinese (those living abroad who hold Chinese passports) and those from Hong Kong, Macao or Taiwan (38 per cent). People from the United States accounted for 6.3 per cent, Australians for 5.4 per cent and Europeans for 3.9 per cent. In other words, 62 per cent of mixed cases are transnational marriages (China Daily, 9 June 2003; www.sina.com.cn, retrieved 9 December 2003). This ratio may be higher than that for many other places. For instance, it was about 50 per cent in Guizhou Province in 2003 (Guiyan Wanbao, I9 October 2003); during the first half year of 2003, transnational marriages only accounted for 28.48 per cent of the overall mixed marriages in Shanxi Province ( $D a$ Jiyuan, 23 October 2003). In Hainan Province, this ratio was no more than 20 per cent in 2003 (Haikou Wanbao, 27 September 2003). It is widely held that Chinese women are involved in 90 per cent of the mixed marriages. Among such mixed marriages, we estimate that about 30 per cent are transnational. This is to say, during the last decade, at least I50,000 Chinese women have married foreigners.

It should be noted that due to differences in levels of development, different places have exhibited different patterns of transnational marriage. For example, more laid-offs in Heilongjiang Province may choose transnational marriage than those in Beijing; the number of transnational marriages in Shanghai is much larger than that of Ningxia Province. Moreover, even the same place may differ at different per- 
iods. For instance, in the well-known Qiaoxiang (hometowns of the Chinese overseas) - Chaozhou and Shantou - the number of mixed marriages (transnational marriages included) decreased to I35 in 200I, compared with 679 ten years earlier. In 2002, there were even fewer (no more than 30) (www.xinhuanet.com, retrieved 22 June 2002).

Among the minimum 150,000 transnational marriages of women since 1994, we cannot know the exact number of marriages which involved the use of cyberspace. However, it is possible to identify the characteristics of boundary-crossing through cyberspace during the last decades.

\section{Characteristics of Transnational Marriages Involving Cyberspace}

Transnational marriage through cyberspace mainly includes two types, marriage from Internet dating (contacts by Internet for the purpose of finding potential marriage partners) and marriage facilitated by international marriage agencies. A carefully examination of transnational marriages involving in the cyberspace reveals striking signs. The first characteristic of this flow is that those engaging in the Internet date tend to be well-educated. According to a survey of female Internet users conducted by www.sinoi.com (March 2000), 90 per cent were well-educated, having at least a diploma or above. Another survey conducted by Hong Kong-based Internet measurement specialist Iamasia (Interactive Audience Measurement Asia) in 200 also shows the same pattern of female Internet users. Most of the female Internet users were well-educated: 30 per cent had a bachelor degree, and 49 per cent were white-collar women (www.ccidnet.com, retrieved I5 May 200I). Women had different reasons from men in their net-surfing. Their main activities were sending emails, chatting, and searching for healthcare information and entertainment news. By contrast, males' interest was more focused on sports news and technological issues. Chatting was the sole purpose for 70 per cent of female respondents in Beijing (Interfax China IT \& Telecom Report, I3 April 200I; Beijing Wanbao, 9 March 200I).

The second characteristic is that sometimes a marriage can be decided before new couples see each other in actual life. For example, in an interview in Singapore, Sha Ying, a woman from Xian, told us such a story. In 1999 she made acquaintance with a local man in Singapore who sought her assistance to find a beautiful girlfriend. She introduced a close friend, Wang Ying, a woman in Kunming, to him. Then the Singaporean contacted Wang Ying by Internet. After "chatting" in cyberspace for half a year, they decided to get married. Dong 
Haiyan, a widowed woman from the same city, met an American in cyberspace in April 2003. The marriage was decided in one month, and the wedding ceremony was held within six months (Chutian Dushi Bao, I6 October 2003). In such cases, although the lovers exchanged photos through cyberspace, they never saw each other in person before tying the knot. This situation has not been rare in recent years. It seems that the lack of face-to-face communication before marriage will not be an obstacle to marriage.

The third characteristic is that women living in cities (including women from rural areas working in cities) are the main participants in transnational marriages facilitated by cyberspace. Before 1994, Chinese women in big cities such as Guangzhou, Shanghai and Beijing were the participants in this tide, but in recent years women from smaller cities, especially from cities of northeastern China, have been becoming part of this tide (Zhongwen Daobao, II September 2003). For instance, the number of transnational marriages in Heilongjiang has been rising rapidly in recent years: between 2000 and 2003, the number reached 4,586. Among them, about 2,000 were between Chinese and Japanese or Koreans (Heilongjiang Ribao, I5 February 2003). There is no doubt that women living in cities occupy a predominant proportion of those engaging in transnational marriage. A variety of factors are responsible for this situation, such as educational level and economic ability, etc. One of the key elements, however, is related to the fact that women living in cities can get information more easily than those living in rural areas. After all, the Internet is widely used in the cities of China now. It was reported that 58.2 per cent of Internet users lived in small cities - more than those in middle-sized cities $(53.3$ per cent) but fewer than those in big cities (70.7 per cent). Nearly 60 per cent of Internet users are below 24 years of age (Zhongguo Qingnian Bao, September I8, 2003).

It is true that some women got married with foreigners just for the purpose of financial gain instead of love. However, this situation is changing gradually. This is evidenced by the following trends. The first is that differences in age, income and educational levels of couples are getting smaller and smaller. In Shanghai, all the women registering for marriage in June 2002 had at least a bachelor's degree, good professional background and foreign language capacity, and 75 per cent of the couples matched each other in age, education degree and language proficiency (www.xinhuanet.com, retrieved I9 October 2002). In addition, people's perceptions of transnational marriage are changing. In the past, to marry a foreigner was fashionable in some places. Now, in a survey by the Shanghai Civil Affairs Bureau, 43.5 per cent of respondents believe that Chinese youth are not taking economic factors as main considerations when marrying to a foreigner (Beijing Qingnian 
Bao, Io December 2003). Furthermore, more and more transnational couples prefer living in China instead of settling down abroad, which was once the popular trend for transnational marriages (Xinhua News Agency, 20 June 2003). These factors, combined with rapid growth in the proportion of transnational marriages which involve Chinese men and foreign wives (from 8.5 per cent to II.3 per cent between I990 and 200I), reflect not only the changes taking place in both China and the outside world, but also the shifting perceptions of transnational marriage.

\section{Causes for Transnational Marriage}

What are the reasons for the emergence of the 'leave-the-country fever' (chuguo re) through transnational marriage? To answer this question, we have to investigate four factors: (I) changing political, economic and other environments in China; (2) changing political, economic factors of the destination nations; (3) the specific motivations for Chinese women; and (4) motivations for involved foreign men.

\subsection{The Local Perspective: Changes in China}

Just as the flow of international migration itself, transnational marriage involving cyberspace has been influenced by the political, economic and social changes in China since i978. First, the Chinese government changed the policy which had limited mobility and international migration. Since the People's Republic of China was founded in I949, the Chinese government had undertaken strict measures to limit emigration. As a result, large-scale international migration almost ceased. It was not until I978, the first year of 'reform and opening-up', that China became a region of movement and migration became 'truly global' (Massey et al. I998; Liu 2002, 2006). Secondly, with the development of the Chinese economy, a great deal of foreign capital has flooded into China, with more and more foreign employees being sent to work there, and this has given rise to more opportunities for understanding between natives and foreigners.

Thirdly, the growth of transnational marriage is a side-product of China's continuous opening-up to the outside world. The Chinese have become more open to new things. In a joint study by the Shanghai Civil Affairs Bureau and East China Normal University, 36.8 per cent of the interviewees in Beijing, Shanghai and Guangzhou were willing to marry foreigners (Beijing Qingnian Bao, ro December 2003). People's attitudes towards transnational marriage have become more tolerant than in the past. For example, General Claire Lee Chennault (I893- 
I958), not uncommonly, had to spend two years to persuade the family of Chen Xiangmei (later known as Anna Chennault) to agree to their marriage in the ig40s. Now, however, Chinese women have the decision-making power over their own marriages and transnational marriages can be decided upon in a very short time. Consequently, transnational marriage has increased sharply, especially since the beginning of the ig9os.

\subsection{A Global perspective: Host Countries}

The rapid growth of transnational marriage during the last decade is also closely related to political, economic and social changes in the receiving countries. Certain political factors may lead to the increase in transnational marriage. After the 1989 Tiananmen Incident, a large number of students and scholars settled down abroad. Many who emigrated in I989 and I990 have returned to seek spouses in subsequent years. For example, I8 per cent of the mixed marriages (including transnational marriages) registered in Shanghai in August, September and October I995, are in this category. 'Those back from Australia took up the majority', said Li Xuezhen, Director of the Shanghai Marriage Administration Department under the municipal Bureau of Civil Affairs (Shanghai Star, I7 November I995).

Secondly, policies in some developed countries designed to attract skilled and/or unskilled workers have also contributed to the growing proportion of transnational marriages. As their economies have developed, industrialized countries have faced a growing demand for various types of labor (skilled or unskilled) from less-developed countries. From the I970s onwards, western workforce policies have sought the cultural capital of educated middle-class women and men. In the I990s, state policies further attracted economic capital and the restrictive immigration policies were swept away, allowing the entry of people with a wide variety of origins, cultures and races (Salaff I997; Liu $2005 \mathrm{~b})$. Chinese women were very popular among the singles who have expatriated from China during the last two decades and are foreign citizens now. Chinese women could settle down in developed countries on a large scale. Whether they entered the labor market or not after marriage, they benefited from the changing policies of the host countries.

\subsection{Why Marry a Foreigner?}

It is widely held that Asian women marry men from developed countries purely for economic reasons. However, when we investigate the motivations of involved women, we find there a variety of elements be- 
yond economic considerations. In the case of China, we find that women choose transnational marriage for multiple reasons, some of which are not directly related to financial gain: I) Because people enjoy the freedom of travelling overseas (e.g., some famous celebrities are richer than their husbands); 2) Some women hope to study overseas (they support themselves with scholarships); and 3) Some business women choose transnational marriage for possible career advancement. ${ }^{\mathrm{I}}$

One of the main motivations for entering into a transnational marriage is to enjoy a greater degree of freedom in travelling overseas. In China, although controls over overseas travel have been relaxed since the I980s, the procedures for going abroad are still complicated and strict. In February 2002 it was declared that 'Chinese citizens going abroad are no longer required to submit a foreign invitation together with their applications, nor do they need to obtain prior approval' (Liu 2002), but before that it was not easy for people to travel overseas. Although some women choose transnational marriage as a tool to go abroad and lead a rich life in destination countries, some well-known singers or actors are exceptions. They marry a foreigner, but work in China. The fact is that they are richer than their husbands and they like the feeling of travelling freely between countries. Ning Jing, a famous movie star in China, was satisfied with her transnational marriage: 'I have two families. One is in the Untied States, the other is in China. I need to travel between the two countries...I like the feeling [travelling between countries]' (Shanghai Hotline, 2I February 2005).

Secondly, transnational marriage affords opportunity to study overseas. Since 1978, more and more Chinese study abroad. Many students in China regard those going abroad as role models. It is widely held that if students apply for scholarships in the host countries, it is easier to get than if they apply in China. 'At that time, I knew I could not fulfill my dream by myself. So I asked my friends to introduce me to some single Chinese who are already in the States', said Wang Yanxia ( 38 years old) in an interview. 'Yes, he was not my ideal type, but at least I could go to America and my dream might come true.' Finally, she went to the United States and received a scholarship from a famous university. In this case, transnational marriage is a tool to enter the United States for education. This couple kept their money separately, she supported herself.

Thirdly, possible career advancement is also a motivation for rich Chinese women to tie the knot with a foreigner. Tomoko Nakamatsu (2003) has noted that some Chinese women with university degrees marry transnationally for this reason. We find that some rich women who own their own business in China also fall into this category. For example, Kuang Changqing ( 36 years old) who has multi-million yuan property in Chengdu, Sichuan, married an African American who is a 
clerk in the United States. They made acquaintance with each other through the Internet in May 2003, and decided on marriage in less than three months. 'I do not want to be a housewife', she said. 'I will expand my business to New York and London' (Tianfu Zaobao, 4 August 2003).

\subsection{Why Marry a Chinese Woman - Foreigners' Perspectives}

Transnational marriage is linked with social desires, as more and more local women in developed countries are refusing the ideology of domesticity. As Thanh-Dam Truong (I996) has noted, those males involving in transnational marriages are often divorced, windowed with dependents, or sometimes disabled and low-paid workers are in the majority. While 84 per cent of the foreign counterparts in transnational marriages in Nanjing were workers, most of the local women involved had at least a diploma (Zhejiang Xuekan, no. 5, 2000). Some foreigners were unemployed and living on welfare. In other words, many foreign men have difficulties in finding local partners in their countries.

In a documentary entitled 'Chinatown' by the Phoenix TV, Zhang Yali, a woman from Beijing, got married to a widowed American who is twenty years older than her. After marriage, her husband treated her like a maid. When she talked about her transnational marriage facilitated by the Internet, she could not conceal her disappointment: 'There is no love and no happiness in this marriage.' Another bride, Lin Ying from Shenyang, was very upset during her married life. For her American husband, who had been unemployed for many years, there was no love. She advised other women who hope to marry an American, 'If not for our children, please do not choose an international marriage; Life is too hard here.'

Japan is the most popular destination for Chinese brides. Women from cities in China, especially Shanghai, have entered this country in large scales in recent years. Most of them settle down in rural Japan. Some are expected to do farm work and take care of the family members of their partners. To those women from cities in China who have not done farm work before, it is very hard to get used to the rural life in Japan. Huang Ling's story is very typical of some Chinese brides in Japan. She came from Shanghai. Ten years ago, when the car she took finally stopped at a house in a small and poor village, she saw her husbands' family members: an old hunchbacked couple and a disabled brother. At that moment, her dream was broken (Huanqiu Shibao, I6 January 2004). 


\section{The Formation of Transnational Marriage}

\subsection{Conventional Means}

As Nicola Piper and Mina Roces (2003) have noted, women are often portrayed as 'victims' of socioeconomic structures. 'There are typically stronger economic and social constraints on women than men...entering into marriage may offer them a better chance of economic security than remaining single' (Piper \& Roces 2003: IO). When investigating those Chinese women who emigrate from China through marriage, we find that the traditional meaning of 'victims' is not suitable for them. Different from their mothers and grandmothers whose marriages were normally arranged by parents, they can control their fates and have the right to choose a spouse themselves. They actively use three main means to enter into transnational marriages.

The most popular way for new couples to get to know each other is through matchmaking. Transnational marriage involves a high degree of commercialized matchmaking, such as mail-order-bride services (Thanh-Dam Truong I996; Constable 2003). Since I978, a large number of women have married overseas with the assistance of matchmakers. With the rapid growth of demand, more and more agencies enter the transnational marriage market. In east Kyoto, there are about ten agencies whose female customers are all from northeast China. Some agencies overseas are owned by Chinese and their numbers have increased. There were at least 36 agencies advertising in the Chinese newspapers (Huasheng Bao, 7 March 2002). For marriages between Japanese and Chinese, Chinese agents usually receive RMBio,००० (about US\$I,200). Other brokers charge men in Japan 2.4 million yen (about US\$2I,800) each for arranging marriages with Chinese women (Asian Political News, 26 August I996). Furthermore, private agencies are also involved in the market. Among the 2,000 marriages between Chinese from Heilongjiang Province and Japanese or Koreans from 2000 to 2002 , about one-fourth of all marriages are arranged by private agencies (Heilongjiang Ribao, I5 February 2003). Most private agents had relatives in Japan or Korea, and some agents were former brides themselves. These intermediary agents (legal and illegal), create a large market for marriages between these countries. Transnational marriage is a lucrative business.

Introduction by friends or relatives is the second way to find potential transnational marriage partners. Since 1978, more and more foreigners have gone to China for tourism or businesses, but only a small minority of Chinese can reach them. Chinese translators or colleagues may introduce their female friends or relatives to these foreigners. New migrants overseas may also introduce Chinese women to local singles. From all kinds of statistics, we can deduce that making ac- 
quaintances through friends or relatives, together with matchmaking, account for the majority of transnational marriages in China.

\subsection{Internet as a Social Network}

Getting to know each other without a mediator is another major way for Chinese women to find transnational marriage partners. Potential couples may meet each other during trips, or as classmates or colleagues. However, transnational marriages involving Internet dating are increasing significantly in recent years. As mentioned, this is a byproduct of the rapid growth of Internet users in the PRC. By June 2007, China's Internet penetration rate in the urban areas had reached 2I.6 per cent (http://english.peopledaily.com.cn/9000I/9078I/90877/ 622070I.html, retrieved 2I November 2002). The fast increase in the number of China's netizens leads to more and more Internet dating. Although 6I.82 per cent of Internet users admitted that they have been involved in Internet dating (chat with somebody through the Internet for the purpose for marriage) (http://news.enorth.com.cn, retrieved 2I November 2002), only o.I per cent finally tied the knot (Xinkuai Bao, 27 October 2002), and even fewer got married with foreigners through cyberspace. Nevertheless, due to the size of China's population, the number of female Internet users involved in transnational Internet dating might be quite considerable.

It has been reported that during the last decade, decisions to marry a foreigner are mainly made by Chinese women themselves (San 2002). They use the above-mentioned three means to enter transnational marriage. They are not passive but active in choosing their foreign spouses and deciding to control their fate by themselves. They show great courage in being responsible for their own behavior. In this sense, they are not victims.

The future trend, in terms of these three ways of arranging transnational marriage, can be deduced. With fast economic and social progress in the foreseeable future, women will become more independent. The rates of the first and second methods for finding transnational marriage partners may decrease. In addition, with more Chinese studying or working abroad and more foreigners coming to China, the proportion of those who get to know each other without a mediator will increase. 


\section{Cyberspace: A Gendered Space for Masculine Authority or Feminist Liberation?}

Over the last decade, new modes of communication such as ComputerMediated Communication (CMC) and video-conferencing via satellite have become widely used by international agencies. Cyberspace is likely to play an increasingly important role in facilitating both domestic and transitional marriages. After all, the three major paths to transnational marriage largely rely on the Internet now. For example, matchmaker-brokers provide a dating service that allows foreign men to pick their brides on television. Chinese women may keep in touch through translation software provided by brokers until they tie the knot, and new couples who make acquaintance through friends or relatives may contact each other through the Internet. Those engaged in transnational dating depend heavily on cyberspace. What are the effects of this profound and rapidly-developing technology on women's lives? Are women objects or subjects in this postmodern world? What is the tension between women's body-related selves and cyberspace? What are the constraints it has on women?

In order to clarify these issues, we would like to explore theories about cyberspace first. It is widely held that identity is not connected to bodies or physical attributes - that identity can be multiple and malleable. For example, according to Koo Chiew Tee (I999: I2), IRC (Internet Room Chatting) is a stage, 'with front and back stage behavior difference'. On the front stage, the Internet provides new opportunities for the presentation of self. This is a free world, without restrictions of age, race, religion, class, etc. Chatters tend to be friendly and enthusiastic, and have good manners. They conceal the parts of themselves which may be frustrating 'in real life' and try to express the best of them. They feel free to use endearing terms, like 'honey', 'darling', etc, and flirting can be carried out easily. However, backstage in IRC, in private chats, or in email exchange, and without embarrassing eye contact or other uncomfortable reactions, people are likely to divulge their personal details. It seems that this new flexible space contains fragmented, multiple subjectivities. It provides women space and opportunities to escape fixed conceptions of the self and of power relations in patriarchal society. But is this true? Are 'fluid' selves less subject to cultural hegemonies and regulated cultural norms than 'solid' ones?

In feminist perspective, the answer is 'No'. At first, on the front stage, race, age, sex and other body-related identities are affected by those in 'real life'. As Lisa Nakamura's research on cross-racial impersonation in an online community has shown, 'when users are free to choose their own race, all were assumed to be white. And many of those who adopted nonwhite personae turned out to be white male 
users masquerading as exotic samurai and horny geishas' (Nakamura 2002: 325). In other words, racism, sexism and other body-related identity characteristics appear in cyberspace.

Since almost all lovers chat or exchange emails in private spaces, how about the situation backstage? In our interview through the Internet, Li Wei, from Liaoning Province, told us her story. In 1997, she was laid off from a big factory in Shenyang. In 1998, suffering from the bankruptcy of her own business, she was tired of her situation and wanted to leave town through transnational marriage. Talking about their communication before wedding, she said:

'I used translation software provided by an agency and chatted with him everyday. In his letter, he expressed that I should be a good wife and mother and would not need to take a job. I was not sure about that. But I promised that I would be the kind of woman he likes.'

However, after marriage, she ignored her husband's wish and found a job. In this case, masculine rules in reality were introduced into cyberspace. It seems that on the back stage, body-related identities are also not as fluid as much as cyber-theory would like us to see them.

As Mary Flanagan and Austin Booth (2002) have pointed out, in ideal domestic and office arrangements, both women and computers, taken together as units, serve as mechanical brides of men. However, in terms of marriage facilitated through cyberspace, the female body should not be seen as a mere extension of a computer. The Internet as a gendered space not only promotes masculine authority but also represents feminist liberation.

Some involved women also use it as a space to liberate themselves. In a documentary by the Phoenix TV, Zhang Yali, a divorced woman, used the Internet to chat with an American. In reality, she was shy and conservative, like many Chinese women in their forties. In cyberspace, she was brave, active and enthusiastic, like a modern and young woman. She talked about everything freely. The American respected all of her thoughts. Finally, they tied the knot in America.

There are both oppression and oppositional maneuvers in this space. Chinese women, as objects and subjects, negotiate the Internet and actively treat it as social capital. The advantage of the Internet is obvious: it speeds up the decision for marriage. However, the tension between utopian world of cyberspace and the real world may impose threats on married life.

In the case mentioned above, in cyberspace, Zhang Yali's boyfriend was very considerate. He supported all her decisions such as searching for a job after marriage. They communicated well through the Internet. 
She was very happy to find such a satisfactory partner. However, on the day after her arrival, her husband told her: 'You can begin your job.' She was surprised to know that her job was to look after her husband, a retired engineer. From then on, a strict and fussy boss in actual life took the place of the considerate lover in cyberspace. In this case, the cyberspace serves as a tool not only to liberate her but also to conceal the American's real thoughts and provide her with an illusion. Because of the tension of a utopian world and a real world she was disappointed at her situation since the beginning of the marriage.

\section{Living with Transnational Marriage: A "Dependent" Wife or an Independent Woman?}

Tomoko Nakamatsu (2003) notes that some scholars tend to regard Asian women entering into transnational marriage as dependent 'outsiders' forever in the host countries. This argument is challenged when we carefully examine the situation of the involved Chinese women. Although many Chinese women lack preparation for a hard life abroad, they show the courage to be independent women.

In the first place, Chinese women attempt to acquire financial independence by entering the labor market. According to Tao Chunfang (I993), in the I990s the proportion of employed women in China was 80-90 per cent. Most of the involved women had jobs prior to their emigration. From the survey we conducted in Singapore in April 2005, 93 per cent of Chinese women who got married to a Singaporean worked in China before migration. Jobs can bring not only economic power, but also a social life. It is not easy to abandon this source of self-confidence after marriage. In the same survey, 78 per cent of Chinese brides in Singapore had a regular or irregular job. Although most of the involved Chinese women are supposed to be housewives, they have strong desires to find jobs to support themselves. In our interviews, 96 per cent of the interviewers in Singapore had a job or wanted to find a job after marriage. There are, however, at least two main obstacles to this goal. One is language. As Nakamatsu (2003: I88) has suggested, at the beginning of transnational marriage, 'communication difficulties were felt most acutely'. This problem not only influences the relationship between new couples, but also is an obstacle to Chinese woman's mergence into host societies. They always try all means to learn the appropriate foreign language, such as going to language schools, learning from TV or from their family members. In an interview, Lin Lin, a bride from Wuhan city, told us that she practiced English with her Singaporean husband every day. She also grabbed all chances to chat in English with her Indian neighbours. When she 
could speak fluently in English, she finally landed a job as a social worker after sending out 589 resumes.

In comparison with Lin Lin, some women are less fortunate. For them, seeking economic independence is particularly hard, as the biggest obstacle in the way of their careers is their husbands. In such cases, they have to suffer a lot. In a case reported by www.chinanews. com.cn (retrieved 9 August 200I), Meng Siyi, a woman from Shanghai, got married to an American 23 years older than her in 1997 through an agency. They had a peaceful life at the beginning of their marital life, but quarrels began when she wanted to find a job. During the subsequent years, she was forbidden to go out of their house, make new friends, drive, or work; punishments such as being driven out of their house, being put into prison and having law suits filed against her were all imposed. 'What he wants is an Oriental wife who can be controlled like a servant', she said.

Secondly, although some women become the citizens of the countries they reside in, their cultural orientation is still towards China. As first generation migrants born in China, they are receptive to Chinese culture and remain keenly interested in China's development (Liu 2005 b). We can see their cultural orientation from their children's education. According to a survey conducted by Zhongwen Daobao, in Japan, 87.5 per cent of married Japanese-Chinese couples with families hope their children will learn both Japanese and Chinese cultures; 93 per cent of such families say that their children will learn Chinese; and 79 per cent believe that their children are 'international children'. This survey shows that most such families wanted their children to know Chinese culture (Huasheng Bao, Io February 2003). Furthermore, since many Chinese women still maintain close family and social connections with their homeland, some of them work in China and fly between China and host countries, such as actors Wei Wei, Luo Qi and Ning Jing. Some open their own business, building bridges between China and receiving countries.

In social relationships, as outsiders and strangers, the involved Chinese women suffer from discrimination. Sometimes this comes from the extended family. One strategy women employ in the process of negotiating their roles is to prove themselves. Ma Xiaoli (Life and Lover, December 2002) married an American man in I992. After marriage, she had to face her in-laws' prejudice against Chinese. After a quarrel with her mother-in-law, she established her own business with all her money. Selling tissue paper was really hard for her; she failed and even had the idea of giving up. But when her mother-in-law arrogantly offered to take over her company, she refused and decided to try again. This time, she solved the problems and improved the company's sale plan. In I997, her company reportedly contributed to one-fifth of tissue 
paper sales in Washington and she subsequently gained her in-law's respect.

Finally, with respect to their political identity, some brides refuse to change nationalities although they live abroad. In our interview, You Yi said that:

'Yes, it is really inconvenient to hold a PRC passport but live here (in Singapore). My husband ever tried to persuade me to change nationality since only I need to apply for a visa when our family travels abroad. But because I am very proud of my nationality, I can overcome any difficulties.'

They have political allegiances to China rather than to the countries where they reside. Those women who become local citizens still support China's major political objectives, such as national unification, and contest with the forces that are hostile to China (Liu 2005b). Although few Chinese women who tied the knot with foreigners during the last decade could not play personal roles, as Anna Chennault did, in political areas in host countries, they have tried to show their strength in a few recent cases. In our interview, Li Shenyan, who got married to an American through Internet dating in I998, admitted that she took part in the protest against the U.S. bombing of the Chinese Embassy in Belgrade in I999. It happened in New York on I5 May I999. 'One of my friends asked me to go. My husband could not understand this. But I told him, I should go, because I am a Chinese.'

In short, in economic, cultural, social and political areas, many involved Chinese women show their own characters and have their own voices, which may be different from those of their partners. They behave as independent women rather than as dependent wives.

\section{Concluding Remarks}

The preceding discussions on the patterns and characteristics of the Chinese women involved in transnational marriages and by way of cyberspace lead to three preliminary observations.

In the first place, Chinese women enter transnational marriages for different reasons, but this does not necessarily mean that their marriages are without love. It is not true that all the involved women marry for money. As to life after marrying transnationally, although most of the involved Chinese women are expected to be housewives, they strive to be independent women rather than dependent wives. They are eager to seek and maintain financial independence and have their own voices in cultural, social, and political areas after the transnational marriage. 
Secondly, the Internet as a gendered space not only represents masculine authority but can also be a site for feminist liberation. There is both oppression and oppositional maneuvering here. Chinese women actively use the Internet as a means of accumulating social capital to facilitate their marriage. However, this technology creates some problems: for one thing, the cyberspace tends to give people illusions and hides unpleasant physiognomic features in actual life.

Finally, the patterns and characteristics of Chinese women in transnational marriages, especially those who have traversed cyberspace, should be understood within the broader framework of modern Chinese transnationalism which has been significantly facilitated by the advance of global capitalism and its accompanying trend of flexible citizenship (Ong 1999). The existing studies on Chinese transnationalism have paid inadequate attention to new transnational families formed through the union of Chinese women and foreign men. These nevertheless constitute an integral component of Chinese transnationalism at the turn of the $2 \mathrm{I}^{\mathrm{st}}$ century, as many of these women still maintain some forms of regular contact with their relatives in China. Although these contacts may be different from those of transnational businesspeople, the perspectives and practices of females in transnational marriages can be fruitfully incorporated into a closer understanding of the inner working and characteristics of modern Chinese transnationalism at a time of globalization.

\section{Note}

I. According to a report about transnational marriages in Shenzhen in 2004, eight reasons were being listed for Chinese women marrying foreign men, only two of them were directly related to financial considerations and they were placed on the bottom of priority list. See 'Why Chinese women seek foreign husbands', Shenzhen Daily, I April 2004.

\section{References}

Asian Political News (I996), 'Shanghai Weekly warns women against marrying Japanese'. 26 August.

Basch, L.G., N.G. Schillier \& C. Blanc-Szanton (1994), Nations unbound: transnational projects, post-colonial predicaments, and de-terrirorialized nation-states. Langhorne, PA: Gordon and Breach.

Beijing Qingnian Bao (2003), 'Sanfen zhiyi weihun beifangzhe yuanyi zhao laowai [One-third of the single responders wish to marry a foreigner]'. Io December.

Beijing Wanbao (200I), 'Qicheng nv wangmin shangwang zhi liaotian [Chatting is the sole purpose for 70 per cent of female Internet users in Beijing]'. 9 March.

Bryceson, D. \& U. Vuorela (2002), The transnational family: new European frontiers and global networks. New York: Berg. 
Ccidnet.com (200I), 'Zhongguo nv wangmin zhenzheng chengqi banbian tian [Chinese women account for almost half of the overall Internet users in China]'. I5 May.

Chan, K.B. (1997), 'A family affair: migration, dispersal, and the emergent identity of the Chinese cosmopolitan', Diaspora 6 (2): I95-2I4.

Cheng, X. (2003), Dangdai zhongguo liuxuesheng yanjiu [A study of Chinese students overseas in the Contemporary Era]. Hong Kong: Hong Kong Press for Social Sciences.

China Daily (2003), 'Overseas marriages up seven times'. 9 June.

China News Online (200I), 'Shanghainv jia Meiguo zaoyu monan, zhong tongbao shen yuanshou dingli xiangzhu [A Shanghai woman marrying to the Untied States has met with frustrations, many Chines Overseas are trying their best to help her]'. 9 August. http:// www.chinanews.com.cn.

Chinapop (2004), 'Tongji ziliao: Zhongguo wangminshu yida 87,000,000, rengju shiji dier [Statistics: the Internet users in China hit 87 Million, ranked second in the world]'. 22 July. http://www.chinapop. gov.cn.

Chutian Dushi Bao (2003), 'Wangluo zaojiu yiguo qingyuan, Wuhan xinniang qianshou hanguo xinlang [A Chinese bride from Wuhan got married to a Korean through Internet dating]'. I6 October.

Constable, N. (2003), Romance on a global stage: pen pals, virtual ethnography, and 'mail order' marriages. Berkeley: University of California Press.

Da Jiyuan (2003), 'Shanxi shewai hunyin riqu zengduo, gangaotai hunyin chaoguo qicheng [Mixed marriages are increasing rapidly, 70 per cent is between a Chinese and a person from Hong Kong, Macao and Taiwan]'. 23 October.

Flanagan, M. \& A. Booth (eds.) (2002), Reload: rethinking women and cyberculture. Cambridge: MIT Press.

Guiyan Wanbao (2003), 'Guizhou shewai hunyin you liang tedian [Two characteristics of the mixed marriages in Guizhou]'. I9 October.

Haikou Wanbao (2003), 'Hainan shewai hunyin qicheng waijia nvhai xuan Taiwan lang [In Hainan, 70 per cent of women involving in mixed marriage got married to a Taiwanese]'. 27 September.

He Jinye (1993), 'Geren wenjuan diaocha zhong de zhongguo funv diwei [The status of Chinese women as shown in the survey]', in Zhongguo funu yu fazhan: diwei, jiankang he jiyu [Chinese women and development: status, health And employment]. Zhengzhou: Henan People's Press.

Heilongjiang Ribao (2003), 'Yong kuaguo hunyin gaibian shengcun zhiliang, kuaguo hunyin rang ai kaobian zhan [Choosing transnational marriages for upgrading the living standards, women get married to a foreigner not for love]'. I5 February.

Huanqiu Shibao (2004), 'Tiantangmeng suile, yuanjia riben de Zhongguo guniang [Dream broken: Chinese women who got married to a Japanese]'. I6 January.

Huanqiu Shibao (2003), 'Shewai hunyin chuxian xin bianhua, zhenai chengwei zhu xuanlv [New changes appeared: true love became the main reason for mixed marriage]'. 26 September.

Huasheng Bao (2003), 'Riben guoji hunyin jizeng, zhongri tonghun bili jushou [International marriages in Japan increased rapidly, marriages between a Japanese and a Chinese ranked first]'. Io February.

Interfax China ITQ Telecom Report (200I), 'A closed look at China's female netizens'. I3 April.

Khatib-Chahidi, J., R. Hill \& R. Paton (I998), 'Chance, choice and circumstance: a study of women in cross-cultural marriages', in R. Breger \& R. Hill (eds.), Cross-cultural marriage: identity and choice: 49-66, New York: Berg.

Koo, C.T. (I999), Exploring Internet relay chat (IRC): presentation of self in a cyber sub-culture. Singapore: Department of Sociology, National University of Singapore.

Life and Lover (December 2002), 'Aodui yanggongpo: wode dixian shi baiwan meijin [Telling my foreign in-law proudly: I will earn at least one million dollars]'. 
Liu, H. (2002), 'Kuaguo huaren: shizheng fenxi yu lilun sikao [Transnational Chinese: empirical analyses and theoretical formulations]', Ershiyi Shiji [21 ${ }^{\text {st }}$ Century] June: I08-I2I.

- (2005a), 'Explaining the dynamics and patterns of Chinese migration since 1980: a historical and demographical perspective', Journal of Oriental Studies 39 (I): 92-I10.

- (2005b), 'New migrants and the revival of Overseas Chinese nationalism', Journal of Contemporary China I4 (43): 29I-3I6.

- (2006), 'Introduction: toward a multi-dimensional exploration of the Chinese Overseas', in H. Liu (ed.), The Chinese Overseas, vol. I, I-30. London and New York: Routledge.

Liu, X.C. (I99I), 'Beijing, Guangzhou, Hong Kong nvxing renkou jiuye bijiao yanjiu [A study of the employment of females in Beijing, Guangzhou, and Hong Kong]', Zhongguo Renkou Kexue [Population Science of China], no. 3.

Massey, D. et al. (1998), World and motion: understanding international migration at the end of the Millennium. New York: Clarendon Press.

Nakamura, L. (2002), 'After/images of identity: gender, technology, and identity politics', in M. Flanagan \& A. Booth (eds.), Reload: rethinking women + cyberculture, 32I-33I. Cambridge: MIT Press.

Nakamatsu, T. (2003), 'International marriage through introduction agencies: social and legal realities of "Asian” wives of Japanese men', in N.Piper \& Mina Roces (eds.), Wife or worker? Asian women migration, I88. Lanham: Rowman \& Littlefield.

Nationwide News (2002), 'Lover crosses all borders'. 28 October.

Ong, A.H. (1999), Flexible citizenship: the cultural logics of transnationality. Durham: Duke University Press.

Online China News (2002), 'Sichuan shangwang qingnian diaocha jieguo, yiban shoufangzhe bu xiangxin wanglian [Half of the young Internet users in Sichuan Province do not trust Internet dating]'. 2I November. http://news.enorth.com.cn.

Piper, N. \& M. Roces (2003), 'Introduction: marriage and migration in an age of globalization', in N.Piper \& Mina Roces (eds.), Wife or worker? Asian women migration, 9-II. Lanham: Rowman \& Littlefield.

Portes, A., L.E. Guarnizo \& P. Landolt (I999), 'The study of transnationalism: pitfalls and promise of an emergent research field', Ethnic and Racial Studies 22 (2): 217-37.

Salaff, J. (1997), 'The gendered social organization of migration as work', Asian and Pacific Migration Journal 6 (3-4): 295-316.

San, M. (2002), 'Xianhua wanqing yilai de zhongwai tonghun chaoliu [The tide of international marriages since the late Qing Dynasty]', Shuwu [World of Books] 9: 72-76.

Shanghai Hotline (2005), 'Ning jing sheji de baobei anle wo [Ning Jing's peaceful families]'. 2I February.

Shanghai Star (1995), 'Foreign-related marriages surge'. I7 November.

Shenzhen Daily (2004), 'Why Chinese women seek foreign husbands'. I April.

Shenghuo Shibao (2000), 'Shewai hunyin pinxian budengshi [The problems in the mixed marriages in Nanjing]'. 29 August.

Shijie Huaren Mingren Lu [Famous Overseas Chinese in the World] (February 2002), 'Kaichuang ziji de tiankong [Creating her own career]'.

Sina.com.cn (2003), 'Shewai hunyin ershinian da pandian [A study of international marriages during the last two decades]'. 9 December.

Sinke, S.M. (I995), 'International marriage market: theoretical and historical perspectives', in D. Hoerder \& J. Nagler (eds.), People in transit: German migrations in comparative perspective, 1820-1930, 227-248. Cambridge: Cambridge University Press.

Sinoi.com (March 2000), 'Sinoi "sanba nvxing wangshang guangjie da tiyan" huodong diaocha baogao [Report on women's shopping experience through the Internet during the March 8 Festival]'. 
Thanh-Dam, T. (1996), 'Gender, international migration and social reproduction: implications for theory, policy, research and networking', Asian and Pacific Migration Journal 5 (I): 27-52.

Tianfu Zaobao (2003), 'Wanglian cucheng kuaguo hunlian, Chengdu fujie zuotian jiagei meiguo heiren [Internet dating leads to transnational marriage: a rich woman from Chengdu married an American yesterday]'. 4 August.

http://Tom.com (2003), 'Wusun gongzhu he tade beichou ge [Princess Wusun and her sorrowful song]'. I June.

Wenhui Bao (2004), 'Zhu Chen anjia zai Doha, yu zhangfu xieshou wei zhongguodui zhuwei [Zhu Chen settled down in Doha, she took her husband to the court to support Chinese team]'. 4 March.

Xinhua News Agency (2002a), "Chaoshan guniang buzai rezhong waijia, shewai hunyin riqu lengluo [Local women in Chaozhou and Shantou do not want to emigrate from Mainland through marriage, mixed marriages are deducing]'. 22 June.

- (2002b), 'Zhongguoren kaishi lixing miandui shewai hunyin, gengiia kanzhong duifang renpin [Chinese begin to hold more rational attitudes toward international marriages, more focusing on characters of their foreign partners]'. I9 October.

- (2003a), 'Wider range of foreigners marry Shanghai natives'. I7 June.

- (2003b), 'Love knows no nationality in Shanghai'. 20 June.

Xinkuai Bao (2002), 'Diaocha xianshi wanglian chenggongzhe zhiyou qianfeng zhiyi” [Survey shows that only o.I per cent of the Internet users got married through Internet dating]'. 27 October.

Yangzi Wanbao (2002), 'Jiangsu Nantong kuaguo hunyin zhong jia laowaizhe, you bacheng shi dagongmei [In Nantong, Jiangsu Province, 80 per cent of the local women involved in international marriage came from rural areas]'. I7 January.

Zhejiang Xuekan (2000 Issue 5), 'Shewai hunyin pinxian budengshi [Chinese women and their foreign partners do not match each other in many aspects].

Zhongguo Funv Bao (2003), 'Zhongde hunyin shi tiantang haishi xianjing? [Is transnational marriage between a German and a Chinese a paradise or a hell?]. Io February.

Zhongguo Qingnian Bao (2003), 'Shekeyuan baogao: xianshi wangminshu zhan zong renkou I/4 [According to the Chinese Academy of Social Science: one-fourth of the population in China is Internet users]'. I8 September.

Zhongwen Daobao (2003), "Rechao cong nan yongxiang bei, zhongri hunyin mianlin duohun duoli guaiquan [Tide from the South to the North, more marriages and more divorces between a Chinese and a Japanese]'. II September. 


\section{Contributors}

CAPLAN Victoria, librarian at the Hong Kong University of Science and Technology

lbcaplan@ust.hk

GAO, Chong, Lecturer, Department of Sociology, Hong Kong Shue Yan University cgao@hksyu.edu

GREVE, Arent, Professor, Department of Strategy and Management, The Norwegian School of Economics and Business Administration, Bergen, Norway

arent.greve@nhh.no

HO, Kiu-chor, Lecturer, School of Professional and Continuous Education, University of Hong Kong

Hokiuchor@hotmail.com

HO, Petula Sik-ying, Associate Professor, Department of Social Work and Social Administration, University of Hong Kong psyho@hkucc.hku.hk

JOHNSON Helen, Senior Lecturer, Department of Anthropology, University of Queensland, Australia

h.johnson@mailbox.uq.edu.au

KUAH-PEARCE, Khun Eng, Associate Professor and Head, Department of Sociology; Honorary Academic Director, Centre for Anthropological Research, University of Hong Kong

kekuah@hkucc.hku.hk

LEUNG, Maggi W.H., Assistant Professor, Department of Geography, The University of Hong Kong

mwhleung@hku.hk 
LIU, Hong, Professor and Director, Centre for Chinese Studies, University of Manchester; Changjiang Scholar, School of Asian Pacific Studies, Sun Yat-sen University hong.liu@manchester.ac.uk

LIU, Lihui, Teacher at National University of Singapore High School, Singapore

liu_lihui@highsch.nus.edu.sg

LIU, Ting, PhD Candidate, Department of Political and Social Change, Research School of Pacific and Asian Studies, Australian National University, Canberra

Tina.Liu@anu.edu.au

PEI, Yuxin, Assistant Professor, Department of Sociological and Social Work, University Sun Yat-sen peiyuxin@hotmail.com

SALAFF, Janet, Professor emeritus, Department of Sociology, University of Toronto salaff@chass.utoronto.ca

SIM, Amy, Research Fellow, Southeast Asia Research Centre, City University of Hong Kong amysim@cityu.edu.hk

TANG, Wesley Siu-hang, Instructor, School of Creative Media, City University of Hong Kong wesley@speechlessness.com 


\section{Index}

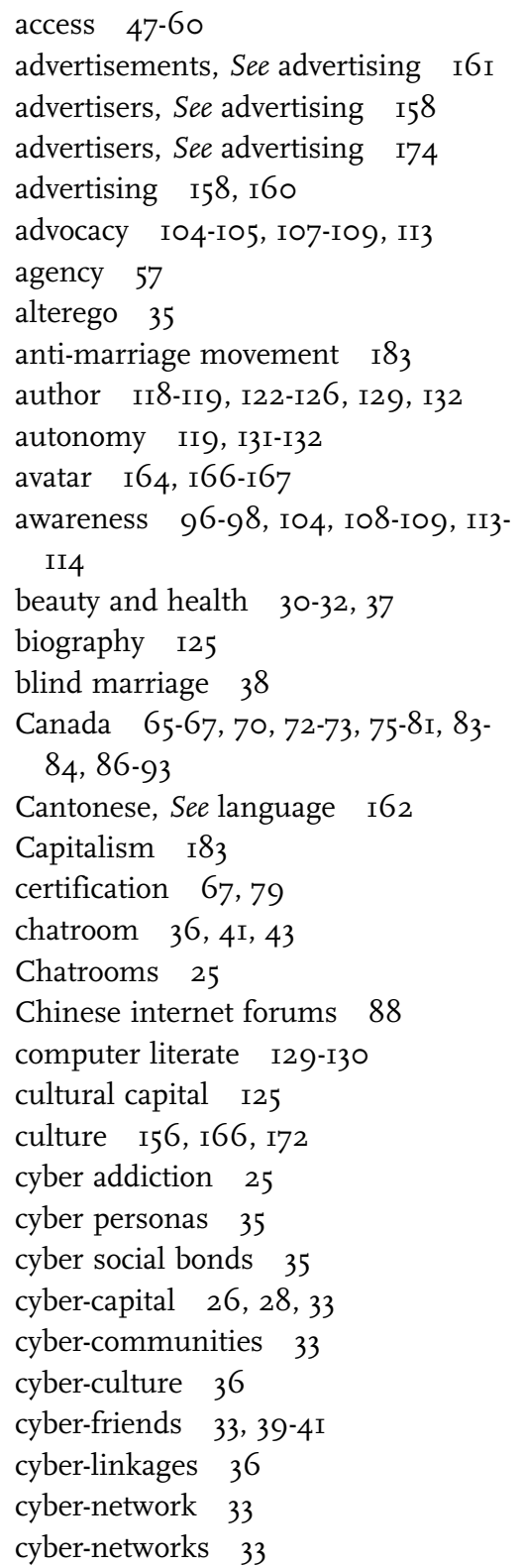

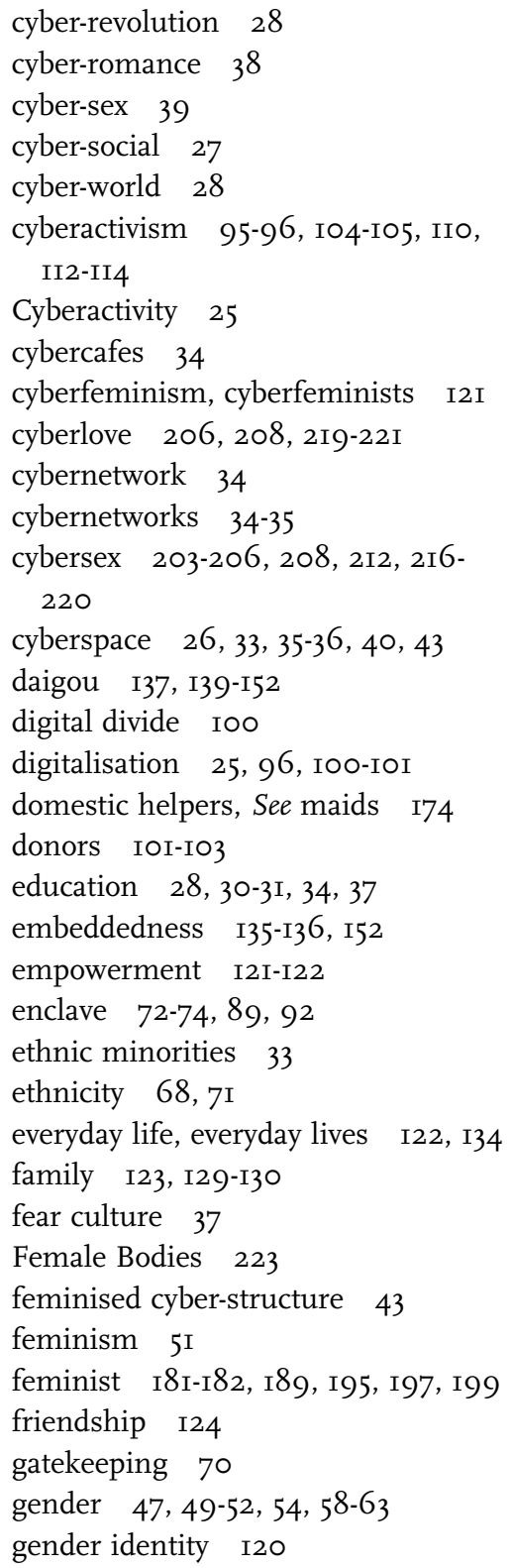


gender stratification $69-70$

girlhood I32

global migration 33

globalisation 25

gossip I55, I68-I70, I73

Guangdong Province $\mathrm{I} 82$

guestbook I25

heterosexuality I8I, I85, I96, I98, $20 \mathrm{I}$

homepage II8-II9, I22-I23

homosexuality I8I-I82, I86, I89, 200

Hong Kong II7-II8, I22, I26-I27, I29-I3O, I32-I34, I8I-2OI

hyperlink I24-I25

ICQ accounts 4I

identity 54, I56, I62, I65-166

immigrant $65-69,72-74,77,85,89$ 92, I85, I9I, I97

instant messenger $\quad$ I27

institutional discrimination 67

interactive communication 33,35

interactive websites 25

international education $66,84,87$

internet 48-49, 5I-52, 54-58, 6I-63, 65-67, 70-7I, 73-78, 84-89, 9I-92

Internet pornography $224,245-246$

labour market $66,68,74,76,78$, 89

language $\mathrm{I} 57, \mathrm{I} 62$

Lesbian I8I, I88, I99-202

maids $\mathrm{I} 68$

mail-order bride $224,235-238,24 \mathrm{I}$

mail-order brides 224, 237, 239, 24I

mainland mothers I72

marriage I83-I84, I93, I95-I97, 201

matchmaking agency 38

men-women relationship I28-I30

mixed code, See language $\mathrm{I}_{2}$

MM I44-I45, I52

mobile phones 38

mobilisation I04, IO9-IIO, II2

motherhood I56, I59, I66, I7I, I74

narrative I2O-I2I, I23, I2 6 netfriends $38,40-4 \mathrm{I}, 43$

netizen I36, I38, I43, I5I-I52

netizens $25,27,30,33-37,40$

Ning Jing 258, 265

normative debate $155,158,169$

off-screen I22-I24, I3O-I3I

on-screen I22-I24, I3O-I3I

online $73-77,84-9 \mathrm{I}$

online diary II7, I26-I27, I33-I34

online prostitution $224,227,23 \mathrm{I}-$

232, 235, 238, 24I, 244

online shopping I36-I38, I45-I47,

I5O-I5I

Organisation Io9

organising 96, 99-IOI, II2-II4

patriarchy 43, I8I-I83, I85, I94, I97,

I99

performative discourse $\quad$ I27

personal blogs 25

personal network II7

personal website II7-I32

political action $\quad$ I72

pornography 23I

pregnancy I69, I73-I74

professions 67-70, 75

real life II9, I2I, I23, I30-I3I

resistance II8, I2I, I3O

screening $\quad 66,68,76-77,87$

self-identities II8, I22-I23, I30

self-image 124, I26, I32

self-representation II8-I22, I26, I30

selfhood II8, I32

sericulture $\mathrm{I} 84$

sex tourism 234, 247

sexual empowerment 204-205, 207,

2I9

sexuality $37,39,43$

signals $67-68,70-71,73-74,77,85$,

$89-90$

Sina.com 36

Singapore $47,49-50,53,57-63$

sisterhood I25, I8I, I85, I97

sisterhoods I82, I84-I86, I92-I94,

I97-I98, 201 
sisters I4O, I46-I48, I5I-I52

social capital $65,70-73,76,83-84$, 90

social construction 68,92

social institutions 89

social networks 26, 33, 35, 65, 7I-72, $76,83,85-86,92$, І35-г 36, I42-г43, I48-I5I

Sohei $\quad$ I84

Southern China $182-184$, I97

TBGs I86-I89

TBs I86-I89, I92

techno-guerrilla II8

teenage 186

tiezi I37, I4I, I43

trade unions I86

virtual community $\quad$ I34-I37, I39, I42I43, I46, I48, I5O-I52

virtual netword I23

virtual life I2I virtual network I22, I24

Virtual Space 38,43

virtuality I2I-I22

wanglian 205-206, 208

wangyou I42

Web $2.0 \quad 25,27$

web-friend I24

web-reader I23

web2.0 I32

weblog, blogging, blogger I25

webmaster II7, I22, I3I-I32

womanhood I32

women 47-52, 54-62

women organising 96-97, I00-IOI, I03-106, I08-109, II2-II6

women's movements 95, 97-98

work 53

writing II7, I23, I25-I27, I3I-I32, I34

xu ni 209, 2I2 